\title{
Der persische Typ
}

Staatsbibliothek zu Berlin: ${ }^{1}$ Ms. or. oct. 146: Iran, 16. Jh. (1570-1580?) 9.5×596 cm. Zu diesem Belegstück ist ein Parallelexemplar bekannt, das 2010 bei Sotheby's, London, als lot 20 versteigert wurde. Der Auktionskatalog bringt es mit dem Osmanischen Reich in Verbindung und datiert es ins 16. Jh. ${ }^{2}$ Diese Zuordnungen sind m.E. allerdings nicht gesichert. Eine Entstehung des Berliner Dokuments in Iran bzw. eine Anfertigung durch Hersteller mit einem iranischen Hintergrund scheint wahrscheinlicher. Für diese Kontextualisierung spricht insbesondere, dass es nicht nur Titelbalken mit persischen Überschriften, sondern auch längere Gebete auf Persisch enthält.

Ms. or. oct. 146 ist mit einem Schutzteil aus Leder versehen, das ca. $23.5 \mathrm{~cm}$ lang ist. Am Anfang dieses Schutzteils ist ein grünlicher Stoffbändel zum Verschliessen der Rolle befestigt (Länge: $41 \mathrm{~cm}$; Breite: $1 \mathrm{~cm}$; Авв. 93-94). ${ }^{3}$ Dieses Schutzteil wird seitlich und unten durch ein Wellen-

$1 \mathrm{Zu}$ diesem Dokument und seiner Kontextualisierung vgl. Nünlist, Devotion and protection: Four amuletic scrolls from Safavid Persia 78-101.

Beschreibung in Ahlwardt, Verzeichniss der arabischen Handschriften der Königlichen Bibliothek zu Berlin III, Nr. 3687; Pertsch, Verzeichniss der persischen Handschriften 256, Nr. 209. Abbildungen der gesamten Rolle sind online zugänglich unter http://digital.staatsbibliothek-berlin.de/ werkansicht?PPN=PPN791133532\&PHYSID=PHYS_ooo1\& DMDID=DMDLOG_ooo1 (Stand 3 o Januar 2017).

2 Dieses Parallelexemplar misst $9 \times 310 \mathrm{~cm}$. Es wurde am 5 . Oktober 2010 als lot 10 bei Sotheby's, London, versteigert. Es war nicht möglich, dieses Belegstück am Original zu untersuchen. Auch war davon kein weiteres Abbildungsmaterial zugänglich als die folgenden Aufnahmen: http:// www.sothebys.com/en/auctions/ecatalogue/2010/a-princ ely-collection-treasures-from-the-islamic-world-lio225/lo t.2o.html (Stand 3o. Januar 2017).

3 Auch dieser Bändel ist am Anfang mit einem kurzen Lederstück versehen. band in Goldprägung eingefasst. Auf dem Lederteil lassen sich ausserdem zwei Reihen mit je fünf Gruppen von zusätzlichen Zierpunkten in Goldprägung erkennen. Das erste Drittel dieses Schutzteils stimmt nicht in allen Details mit dem Rest überein (dunklere Farbe des Leders, andere Ausführung des Wellenbands, abweichende Anordnung der Zierpunkte). Diese Unregelmässigkeiten legen nahe, dass das Lederschutzteil zu einem späteren Zeitpunkt repariert worden ist.

Das Schutzteil der Berliner Rolle weisst grosse Ähnlichkeiten mit jenem der Rolle Is 1626 aus der Chester Beatty Library (Dublin) auf. ${ }^{4}$ Eine weitere Gemeinsamkeit zwischen den beiden Exemplaren besteht darin, dass ihr Schriftspiegel auf der gesamten Länge beidseits durch ein goldenes Seitenband eingefasst wird. Die Breite dieser beiden goldenen Seitenbänder beträgt im Fall von Ms. or. oct. 146 ca. $1.3 \mathrm{~cm}$; sie sind nach einem Abstand von ca. $0.9 \mathrm{~cm}$ vom Rollenrand aus gemessen mit zwei feinen schwarzen Linien versehen. Die weitere Gestaltung der beiden Dokumente weicht aber erheblich voneinander ab. So ist das Belegstück aus Dublin auf grünen Stoff aufgezogen worden. Beim Berliner Exemplar fehlt ein solches Gewebe. Ausserdem weicht die Gestaltung im Innern der beiden Dokumente grundlegend voneinander $a b$, wie die weiteren abschnittsweisen Beschreibungen aufzeigen. Ms. or. oct. 146 wird übrigens in einem ledernen Behältnis (Etui) aufbewahrt, in das es nur passt, wenn es äusserst satt aufgerollt wird. ${ }^{5}$

4 Vgl. Kapitel 4.9, bei Anm. 1 und 3-4.

5 Das Belegstück befand sich bei der ersten Untersuchung des Dokuments im Februar 2009 in diesem Etui. Aus konservatorischen Gründen wurde damals darauf verzichtet, es erneut derart satt zusammenzurollen, dass es wieder in dieses Etui gepasst hätte. Dieses Lederetui ist gut erhalten; es könnte allenfalls aus späterer Zeit stammen. Sein Durch-

(C) TOBIAS NÜNLIST, 2020 | DOI:10.1163/9789004429154_007

This is an open access chapter distributed under the terms of the CC BY-NC-ND 4.O license. 
Auf Ms. or. oct. 146 lassen sich die folgenden Abschnitte erkennen, die mit römischen Zahlen numeriert werden:

Abschnitt I (AB B. 95): Am Anfang lässt sich ein Abschnitt von ca. $6 \mathrm{~cm}$ Breite und $56 \mathrm{~cm}$ Länge erkennen. Er wird durch einen schmalen roten Rahmen eingefasst. Innerhalb dieses roten Rahmens verläuft ein Zierstreifen von ca. 1.o cm Breite. Dieser Streifen wird auf der linken und rechten Seite durch Kartuschen von jeweils etwa $4 \mathrm{~cm}$ Länge gegliedert. Der Hintergrund dieser Kartuschen ist jetzt schwarz; sie sind mit einem feinen goldenen Rankenmuster versehen, das mit blauen und roten Blüten (?) und goldenen Blättern versehen ist. Diese Kartuschen werden durch Vierpässe voneinander getrennt.

Ganz am Anfang dieses ersten Abschnitts lässt sich im Mittelstreifen ein Zierfeld erkennen. Es besteht aus einer Basis mit goldenem Hintergrund, auf dem sich ein achsialsymmetrisch angeordnetes pflanzliches Ziermuster erkennen lässt. Aus diesem unteren Teil steigen drei Hasten auf, die ebenso aus pflanzlichen Elementen (Blätter und Blüten) zusammengesetzt sind. Links und rechts je eine halbe Haste. Es folgen vier Zierelemente (a.d.) mit Text; sie werden entlang der Mittelachse durch eine haarfeine Linie miteinander verbunden: 6

a. und c. Es handelt sich um zwei identisch gestaltete Medaillons von ca. $3.8 \mathrm{~cm}$ Durchmesser. Sie werden durch eine goldene Wellenlinie eingefasst und weisen auf einem schwarzen Hintergrund Einträge in goldener Schrift auf. Der Text

messer beträgt ca. $5 \mathrm{~cm}$, die Höhe ca. $13 \mathrm{~cm}$. Am Etui ist eine weinrote Doppelschnur befestigt (Länge ca. $104 \mathrm{~cm}$ ). Sie bildet eine Schlaufe von ca. $5^{2} \mathrm{~cm}$ Länge, sodass man sich das Dokument umhängen konnte. Auf der Klappe des Etuis wurden weisse Stickereien angebracht (weisser Faden; Ranken mit Blättern und Blüten). An die Klappe wurden drei Kordeln angenäht; sie dienen zum Verschliessen des Etuis und lassen sich durch drei Schlaufen stecken. Auf dem Deckel lässt sich ausserdem ein sechsstrahliger Stern erkennen (Streicheisenlinien in Blindprägung).

6 Vgl. dazu die Abb. 1-2 der Rolle (link in Anm. 1). ist horizontal ausgerichtet. b. Zwischen den beiden Medaillons a. und c. befindet sich eine oben und unten spitz zulaufende Kartusche von ca. $6 \mathrm{~cm}$ Länge. Sie weist einen blauen Hintergrund auf und ist mit vertikal ausgerichtetem Text in goldener Schrift versehen. d. Nach einem Abstand von ca. $2.6 \mathrm{~cm}$ folgt das vierte Zierelement mit Text. Es ist einfach ausgeführt, weist einen goldenen Hintergrund und horizontal ausgerichteten Text in silberner Schrift auf.

Diese vier Zierelemente enthalten folgenden Text a. „Muhạmmad rasūl Allāh“; b. „Allāh, Muḥammad, Abū Bakr, 'Umar, 'Uțmān und 'Alī'; c. „Riḍwān Allāh tacālā“ und d. „'alay-him ağma'īn“. In der länglichen Kartusche b. sind die sechs darin enthaltenen Namen ineinander verschlungen angeordnet. Der Buchstaben 'ayn wurde nur einmal notiert und gehört zu 'Umar, 'Uțmān und 'Alī gleichzeitig.' Bei Abū Bakr, 'Umar, 'Uțmān und 'Alī handelt es sich um die vier rechtgeleiteten Kalifen, die die islamische Gemeinschaft nach Muhammads Tod leiteten. Aus den textlichen Einträgen in den Zierelementen a.-d. geht hervor, dass Gott mit ihnen allen und Muhammad zufrieden sein möge.

In Abschnitt I folgen drei weitere Elemente, die ausschliesslich zur Verzierung dienen; eine haarfeine schwarze Linie verbindet sie entlang der Zentralachse:

e. eine längs ausgerichtete mandelförmige Kartusche. Sie wird von einer goldenen Linie eingefasst, weist einen blauen Rand und im Innern einen goldenen Hintergrund auf. Auf dem blauen Rand und dem goldenen Hintergrund ein goldenes Rankenmuster mit vereinzelten roten Blüten. In der Mitte eine weisse Blüte mit rotem Punkt im Zentrum.

7 Auch wenn der Name 'Utmān auf den ersten Blick nicht erkenntlich ist, muss doch auch er in dieser Kartusche enthalten sein. So lassen sich drei Punkte erkennen, die nur zum $\underline{t} \bar{a}$ ' im Namen 'Uțmān gehören können. Alif und nūn im Namen 'Uțān dürften durch die beiden links aufsteigenden goldenen Linien dargestellt werden. 
f. Ein einfaches Zierelement, das aus einer horizontal ausgerichteten, blau und hellblau ausgefüllten Kartusche mit goldenem Rankenmuster besteht.

g. Eine Verzierung mit dunkel- und hellblauem Hintergrund; sie ist erneut mit einem goldenen Rankenmuster und vereinzelten Blüten versehen.

h. Zuletzt folgt in Abschnitt I ein Rechteck mit goldenem Hintergrund. Darauf lässt sich in silberner Schrift der Eintrag „Allāh ḩayrun ḥāfizạa“ erkennen. ${ }^{8}$

Abschnitt II (AB B. 96): Länge insgesamt $95 \mathrm{~cm}$. Er enthält 15 identisch aufgebaute Einzelteile, die jeweils aus einem auf der Spitze stehenden Quadrat bestehen. Sie treten durch die weiteren um sie herum gruppierten Zierelemente optisch nicht deutlich in Erscheinung. Bei diesen zusätzlichen Zierelementen handelt es sich um je vier entlang der Seiten der einzelnen Quadrate angeordnete Kartuschen mit dunkelblauem Hintergrund und Einträgen in goldener Schrift. Auf diesem Hintergrund ausserdem ein goldenes Rankenmuster mit einzelnen roten Zierpunkten. Entlang der Mittelachse, die die auf der Spitze stehenden Vierecke miteinander verbindet, wurden achtlappige Zierelemente angebracht; sie weisen einen goldenen Hintergrund und hellblaue Verzierungen auf. Die Ecken der einzelnen Quadrate entlang des linken und rechten Rands des Mittelstreifens werden durch jeweils halbe derartige Zierelemente mit goldenem Hintergrund markiert. Die verbleibenden Teile um die einzelnen Quadrate herum sind hellblau grundiert.

Diese 15 Quadrate haben im Innern abwechselnd einen hellblauen bzw. goldenen Hintergrund und sind mit einem goldenen Rankenmuster mit zusätzlichen farbigen Zierelementen versehen. Sie enthalten als dominierendes Element im Innern ausserdem fünf Mal die folgende Serie von Zierelementen: a. horizontal ausgerichtete rechteckige schwarze Kartusche mit goldenem Rankenmuster; überdies lässt sich in der Vertikalen oberhalb

8 „Allāh ist der beste Beschützer“ (aus Q 12:64). und unterhalb der Kartusche eine blaue blattförmige Verzierung erkennen; b. eine achtlappige schwarze Verzierung mit goldenem Rankenmuster. c. eine horizontal ausgerichtete rechteckige schwarze Kartusche. Diese Abfolge wiederholt sich in diesem Abschnitt fünf Mal $(5 \times 3$ Elemente). Die Leerräume zwischen den Quadraten entlang der beiden Seitenbänder sind gegen innen golden ausgefüllt und weisen ein florales Rankenmuster auf.

Auf dem dunkelblauen Hintergrund der rechteckigen Kartuschen um diese Quadrate herum Text in goldener Schrift: Es handelt sich um Q 2:285-286 (die beiden Schlussverse von Q 2). ${ }^{9}$ Die Abschrift beginnt in diesem Abschnitt unten links und ist wie folgt zu lesen:

1. Links unten, Quadrate $15^{-14^{-13} \mathrm{~b}}$ (Textrichtung aufsteigend):

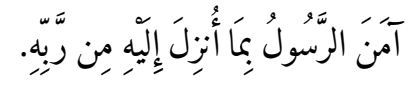

2. Sprung auf die rechte Seite, Quadrate 14-13 (Textrichtung aufsteigend):

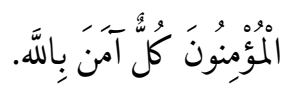

3. Sprung auf die linke Seite, Quadrate $13 a-6 b$ (Textrichtung aufsteigend); hier folgt der Schluss von Q 2:285:

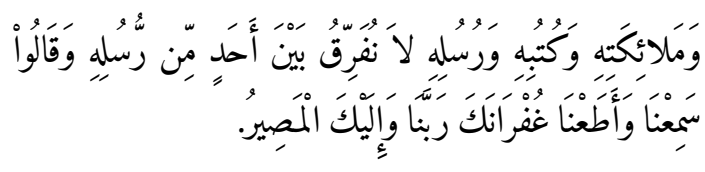

4. In den beiden Kartuschen auf der rechten Seite des untersten Quadrats steht:

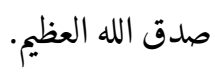

Q 2:286 schliesst sich darauf zuerst auf der linken Seite aufsteigend und danach auf der rechten Seite absteigend an:

9 Vgl. dazu Canaan, Decipherment 129, 131; Padwick, Muslim devotions $116 \mathrm{f}$.; die beiden Verse sind als Hawātim alBaqara bekannt. 
1. Linke Seite, Text aufsteigend, Quadrate 6a-1a:

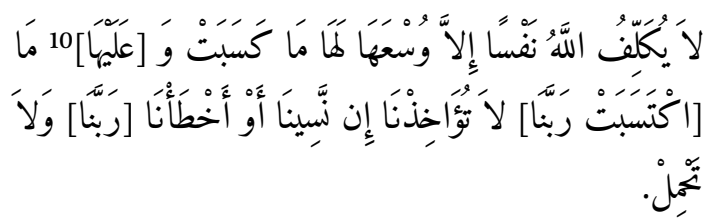

Der Schreiber erreicht hier den Anfang dieses Abschnitts II und wechselt von der linken auf die rechte Seite dieses Abschnitts:

2. Rechte Seite, Text absteigend, Quadrate 1a$12 b: 11$

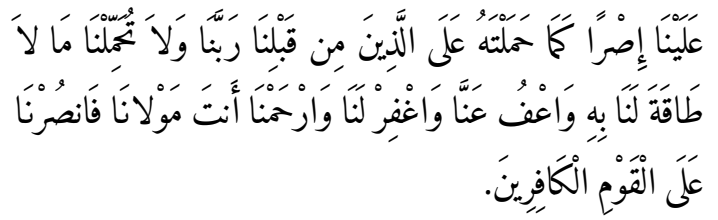

Abschnitt III (ABB. 97): Länge ca. $42 \mathrm{~cm}$; in der Mitte ein rechteckiges Textfeld (b. Länge ca. $20 \mathrm{~cm}$ ). Vor und nach diesem Textfeld: die beiden identisch aufgebauten Teile a.1-3 und c.1-3 (Länge je ca. $11 \mathrm{~cm}$ ). Sie enthalten je zwei horizontal ausgerichtete Textbalken (a.1 und 3 bzw. c.1 und 3) und ein Sechseck (2) dazwischen. Die Gestaltung dieser einzelnen Teile wird zusammen mit ihrem Inhalt beschrieben.

a.1 und a.3: Die beiden Textbalken enthalten in weisser Schrift auf goldenem Hintergrund je eine Anrufung Gottes: "yā fattāḥ“ (a.1) bzw. "yā subhāana“ (a.3). a.2: Zwischen diesen beiden Textbalken befindet sich in einem Quadrat ein Sechseck mit blauem Hintergrund und Text in goldener Schrift. Der Hintergrund des Quadrats ist golden ausgefüllt und mit einem feinen schwarzen Ziermuster versehen. Dieses obere Sechseck enthält in goldener Schrift sechs Mal den Ausdruck al-karim, der zu den Schönen Namen Gottes gehört. Die Oberlängen der Buchstaben aliflām (bestimmter Artikel al), des kāf und der ver-

10 Der Text in eckigen Klammern fehlt auf der Rolle.

11 Ab Quadrat 13 folgt in den seitlichen Kartuschen Text aus Q 2:285. längerte Abschluss des Buchstabens mìm durchmessen das ganze Sechseck. Im Zentrum entsteht durch die sich überschneidenden Linien ein sechsstrahliger Stern.

b. Den Hauptteil dieses Abschnitts nimmt jedoch ein rechteckiges Textfeld ein (Hintergrund mit haarfeinem Rankenmuster), aus dem mehrfach zumeist rote Blätter und Blüten hervorwachsen. Zentrales Element dieses Abschnitts bildet ein Text, der durch zwei komplex ineinander verschachtelte Zeilen gebildet wird. ${ }^{12}$ Der darin enthaltene Text spielt auf das Konzept des tawakkul an, bei dem es sich um eine besonders in der islamischen Mystik befolgte Einstellung des bedingungslosen Vertrauens des Menschen auf Gott handelt. ${ }^{13}$ Der kopierte Satz besteht aus blauen und goldenen Wörtern, Buchstaben und Vokalisationszeichen. In zumeist goldenen Buchstaben steht: „Tawakkaltu bi-mag̈firati l-muhaymani“. Der Kopist setzt die Abschrift in zumeist blauen Buchstaben fort: „Huwa l-gafūr dū r-raḥmati““. ${ }^{14}$ Derselbe Satz in andern Farben auf einem Einzelblatt im Museum für Islamische Kunst in Berlin. ${ }^{15}$

c. Dieser Abschnitt wird durch einen dritten Teil (c.1-3) abgeschlossen, der identisch aufgebaut ist wie Teil a (a.1-3). Der Titelbalken c.1 enthält die Anrufung yā razzāq („o jener, der den Lebensunterhalt verleiht") und spielt auf eine weitere Eigenschaft Gottes an. Der Textbalken c.3 liest Asmā al-husnā (sic); dies dient offensichtlich bereits als Überschrift zu Abschnitt IV. Dazwischen befindet sich mit c.2 ein weiteres Sechseck mit blauem Hintergrund (vgl. a.2, oben). Die Oberlängen der Buchstaben durchmessen auch hier das ganze Sechseck und lassen im Zentrum ein Hexagramm entstehen. Diese Figur enthält die folgenden sechs Ausdrücke,

\footnotetext{
12 Siehe Abb. 6 der Rolle (link in Anm. 1).

13 Zum tawakkul siehe Reinert, Die Lehre vom tawakkul; Lewisohn, Tawakkul, in $E I^{2}$.

14 „Ich vertraute auf die Vergebung des Beschützers. Wahrlich er ist der All-Vergebende, der Mitleidvolle."

15 Vgl. Kühnel, Islamische Schriftkunst 55 (Abb. 57; Auflage 1986).
} 
die ebenso zu den Schönen Namen Gottes zählen: al-Ğāmi', al-Fātiḥ, al-Māni', ar-Rājic, an-Nāfic und al-Wāsic'16

Entlang der Abschnitte I-III weist die Rolle keine seitlichen Textbänder auf. Dies ändert sich mit Abschnitt IV. Ab hier werden die einzelnen Abschnitte der Rolle auf beiden Seiten von einem Textband von ca. $1.2 \mathrm{~cm}$ Breite flankiert; es enthält Text in normal grossem Nash; es handelt sich um Q 48 (Sūrat al-Fath). Der Text verläuft auf der rechten Seite absteigend. In Vers 16 erreicht der Schreiber das Ende der Rolle. Das Textband umfährt die Rolle unten und steigt auf der gegenüberliegenden Seite wieder empor. Der Schreiber erreicht in Vers 29 (Schlussvers) das obere Ende dieses Schriftbands. Ihm fehlt allerdings im breiten Schriftband der Platz, auch die zehn letzten Wörter von Q 48 zu notieren. Er fügt sie deshalb in deutlich kleinerer Schrift auf der linken Seite von Abschnitt III hinzu. ${ }^{17}$ Mit diesem Kniff ist Q 48 in diesen seitlichen Textbändern vollständig kopiert. Die Farben von Schrift und Hintergrund des Textbands mit $\mathrm{Q} 48$ wechseln in den weiteren Abschnitten.

Abschnitt IV: $\mathrm{Zu}$ diesem Abschnitt gehört ein Titelbalken mit der Überschrift Asmā al-husnā (sic). Unter Berücksichtigung des Layouts der Rolle gehört dieser Titelbalken eigentlich noch zu Abschnitt III, inhaltlich handelt es sich aber um die Überschrift des folgenden Abschnitts im Mittelstreifen, der die Schönen Namen Gottes aufzählt. Inklusive Titelbalken beträgt die Länge dieses Abschnitts etwa $27.5 \mathrm{~cm}$. Er wird links und rechts von einem Schriftband mit schwarzem Hintergrund und Text in goldener Schrift flankiert (Abschrift von Anfang bzw. Schluss von Q 48).

16 Al-Ğāmi : „der Vereinigende, der Umfassende“; al-Fātih: „der Öffnende, der Sieg Verleihende“; al-Māni : „der Verhinderer [von Schaden]“; ar-Rāfi: „der Erhöhende“; an$N a \bar{f} i$ : „der Erschaffer von Gutem, der Wohltäter“; al-Wāsic "der Allumfassende“.

17 Es handelt sich um den letzten Teil des Schlussverses von Q 48 (Q 48:29):

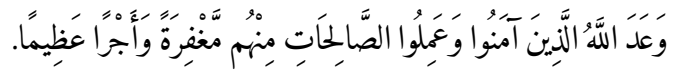

Diese beiden seitlichen Schriftbänder erstrecken sich noch bis in die Mitte des nächsten Abschnitts (v).

Die Schönen Namen Gottes werden in diesem Abschnitt im Mittelstreifen notiert. Er enthält $4 \times 25$ Zellen (Quadrate). Ihr Hintergrund ist abwechselnd golden bzw. blau. Die Zellen mit goldenem Hintergrund enthalten Text (einzelne der Schönen Namen) in schwarzer Schrift. Der Text verläuft in diesen Quadraten diagonal von rechts unten nach links oben. In den Zellen mit blauem Hintergrund wurde der Text in weisser Schrift notiert; er verläuft darin von rechts oben nach links unten. Die oberste Zeile dient als Einleitung und hält fest: Huwa Allāh allad̄i lā ilāha illā huwa; danach werden die Schönen Namen Gottes aufgeführt. Eigentlich umfassen diese Listen der Schönen Namen Gottes 99 Einträge. Dies wird auf den Rollen allerdings nicht immer respektiert. Im vorliegenden Fall stehen dem Schreiber noch 96 Kästchen für das Eintragen einzelner Attribute Gottes zur Verfügung.

Abschnitt v: Dieser Abschnitt ist mit einem Titelbalken versehen, in dem in silberner Schrift steht Ism Muhammad. Danach folgt ein rot eingefasster quadratischer Abschnitt von ca. $4 \mathrm{~cm}$ Seitenlänge, in den ein weiteres, auf der Spitze stehendes Quadrat eingefügt wurde. Es enthält Textelemente in Schachbrett-Kūfì. In Übereinstimmung mit der Überschrift handelt es sich um den Namen Muhammad. Er lässt sich in diesem Quadrat vier Mal erkennen. Das erste mìm des Namens wurde nur einmal geschrieben und befindet sich in der Mitte des Quadrats.

Abschnitt VI (ABB. 98): Die beiden Schriftbänder mit Text aus Q 48 weisen entlang dieses Abschnitts einen hellblauen Hintergrund auf; Surentext in goldener Tinte. Im Mittelstreifen (Länge ca. $23 \mathrm{~cm}$ ) Text in grosser goldener Schrift. Er füllt die gesamte Breite des Mittelstreifens (ca. $4 \mathrm{~cm}$ ) aus und verläuft von unten nach oben. Es handelt sich um den bekannten Schluss von Q 2:137: 


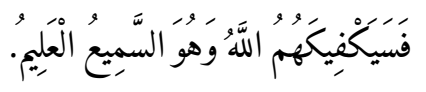

Dieser Schriftzug befindet sich auf einem bläulichgrünen Hintergrund; der Abschnitt wurde mit einem goldenen Rankenmuster mit einzelnen, oft roten, Blüten verziert.

Abschnitt VII (АВ B. 98): Länge ca. $42 \mathrm{~cm}$. Im Titelbalken mit einem bräunlichen Hintergrund steht in bläulich-silbernen Buchstaben Čihil Ismi mubārak („Die vierzig gesegneten Namen“). Auf den seitlichen Schriftbändern wurden die Stellen aus Q 48 zuerst in bläulicher Schrift (auf bräunlichem Hintergrund), danach in goldener Schrift auf schwarzem Hintergrund kopiert. Der Mittelstreifen ist in zwei Spalten aufgeteilt. Jede Spalte enthält 20 quadratische Zellen (zusammen 40 Zellen). Ihr Hintergrund ist abwechselnd golden bzw. blau. In den Zellen mit goldenem Hintergrund wurde der Text in schwarzer Tinte kopiert und verläuft von rechts unten nach links oben. Der Text in den Zellen mit blauem Hintergrund wurde in weisser Schrift kopiert. Er verläuft von rechts oben nach links unten. ${ }^{18}$ In der folgenden Abschrift werden die Zeilen numeriert; bei den Spalten wird zwischen a und b unterschieden:

Dieses Gebet (Čihil Ism-i mubārak) lässt sich in der Fatwāa-Sammlung Suyūṭīs (gest. 1505) mit Abweichungen im Wortlaut und in der Abfolge der Textelemente nachweisen. ${ }^{19}$ Derselbe Gebetstext lässt sich mit deutlich engerer Anlehnung an die zitierte Quelle auch auf Is 1626 aus der Chester Beatty Library (Dublin) belegen. ${ }^{20}$

18 Auf den drei obersten Zeilen verläuft der Text in diesen blauen Feldern von rechts unten nach links oben. Vgl. dazu Ğalāl ad-Dīn as-Suyūțî, al-Hāwwì li-l-Fatāwā 440 f. Bayrūt, Dār al-Fikr li-n-našr wa-ț-ṭibāaa, 1424/2004. Siehe auch: http://library.islamweb.net/newlibrary/displ ay_book.php?flag=1\&paragraphid $=\& b k \_n o=130 \& I D=39$ $7 \& \% 20$ Books (Stand 4. Oktober 2017). Ebenso abgedruckt in Suyūṭī, al-Hāwì li-l-Fatāwā I, 367 f. Bayrūt, Dār al-Kutub al-ilmiyya, 1395/1975.

20 Vgl. dazu Kapitel 4.9 bei und in Anm. 241.

(1b) سبحانك لا إله إلا أنت يا رب كل شيء وراحمه (1a) يا إله الآلهة22 الرفيع جلاله (2a) يا الله المحمود في كل فعاله يا رحمن كل شيء وراحمه يا حي (3a) (يا حي)23 حين لا حي في ديمومته وملكه وبقائه23 (3b) يا قيوم فلا يفوت

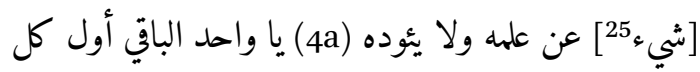

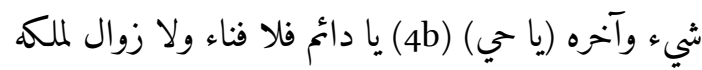
(5a) ياصمد في غير شبه [ولاشيء كثثله يا بار] فلاشيء كفؤه

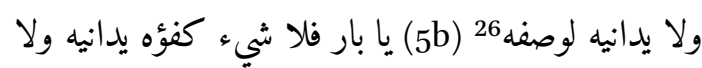
لوصفه (6a) يا كبير أنت الذي لا تهتدي العقول لوصفه يا باري النفوس بلا مثال خلا عن غيره (7a) يا زاكي الطاهر من كل افت 28 بقدسه (7b) يا كبير أنت الذي لا بالا تهتدي العقول لوصفه 29 (8a) يا كافي الموسع لما خلق من عطاء فضله 30 يا حي (8b) يا حنان أنت الذي وسعت كل

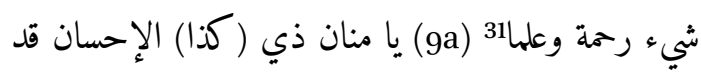
عم كل الخلائق منه (9b) يا نقيا من كل جور لم ميرضه ولم يخالط فعاله (10a) يا ديان العباد [ف][كل يقوم خاضعا لرغبته (11a) يا رحيم كل صريخ ومكروب وغياثه ومعاذه (10b)

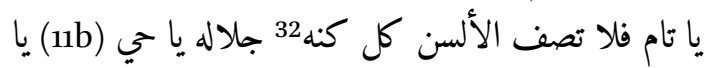
خالق من في السماوات والأرض وكل [إليه] معاده (12a)يا مبدى33 البدائع لم يبغ في إنشائها عونا من خلقه (12b) يا حليم

Die Vorlage liest hier ووارثه.

Hier steht erneut die Anrufung Allāhs als „Gott der Götter“; vgl. dazu Kapitel 4.1, vor Anm. 8o.

Wiederholung auf der Rolle.

Die Vorlage liest hier حين لا حي في ديمومة ملكه وبقائه.

Ausdruck fehlt auf der Rolle.

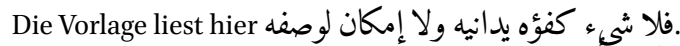

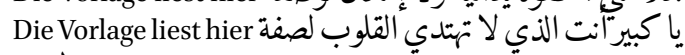
عظمت

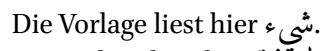

يا كبير أنت الذي لا تهتدي القلوب لصُفة Die Vorlage liest hier عظمت

Auf der Rolle steht hier wahrscheinlich من عطايا لفضله.

Abweichende Textfolge in der Vorlage.

يا تام فلا Ein Ausdruck ist unleserlich; die Vorlage liest hier تصف الألسن كل جلاله ووزه

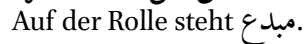


ذي (كذا) الأنات فلا يعادله شيء من خلقه (13a) يا معيد

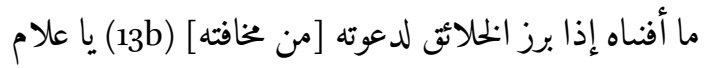

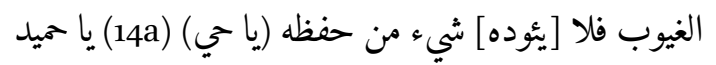
الفعال ذي (كذا) المن على جميع خلقه [بلطفه] (14b) يا قاهر ذي (كذا) البطش الشديد أنت الذي لا يطاق انتقامه (15a) يا قريب المتعالي فوق كل شيء علو ارتفاعه (15b) يا غزيز

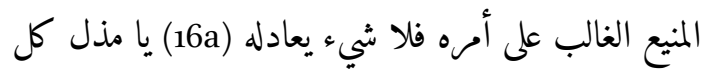
جبار بقهر غزيز سلطانه (يا حي يا قيوم) (16b) يا عالي الشاخخ فوق كل شيء [علوه و] ارتفاعه (يا حي) (17a) يا قدوس الظاهر على 34 كل شيء فلاشيء يعادله [من خلقه] (يا حي)

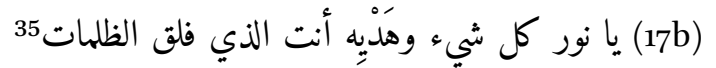

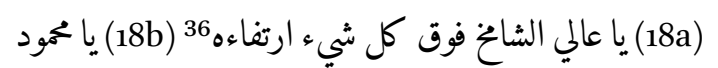
فلا تبلغ الأوهام كل كنه ثنائه ومجده (19a) يا كريم العفو

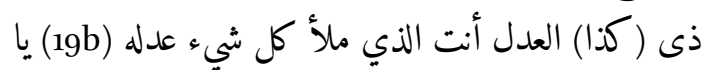
قدوس الظاهر من كل شيء فلا شيء يعادله ${ }^{37}$ (2Oa) يا عظيم ذو (كذا) الثناء الفاخر فلا يذل عزهم38 (2ob) يا بجيب المداني

$$
\text { (كذا) دون كل شيء39 يا غياثي عند كل كربة. }
$$

Abschnitt viII: Ṣad qul huwa Allāh (A B B. 99):40 Auf der Rolle schliesst sich ein Abschnitt (Länge ca. $19.5 \mathrm{~cm}$ ) mit der Überschrift Șad qul huwa Allāh an; diese Überschrift greift den Anfang von Q 112 auf, die mit der Anrufung beginnt: Qul huwa Allāh al-aḥad Allāh aṣ-șamad („Sag [hundert Mal, șad] er ist Gott, der Eine, Gott, der Beständige“). ${ }^{41}$ Das Textband mit der Abschrift von Q 48 auf der linken und rechten Seite weist entlang dieses Abschnitts

34 Auf der Rolle steht من einen blauen Hintergrund auf; der Surentext selbst wurde mit goldener Tinte kopiert.

Der Mittelstreifen ist ca. $4 \mathrm{~cm}$ breit. Darin lässt sich eine aus unterschiedlichen Einzelelementen aufgebaute Figur erkennen. Sie setzt sich u.a. aus acht blau bemalten fünfstrahligen Sternen, dunkelblauen Vielecken ${ }^{42}$ und kleineren grünen Zierelementen ${ }^{43}$ zusammen. ${ }^{44}$ Diese Elemente werden von schmalen Schriftbändern mit Text in $\dot{G} u b \bar{a} r$-Schrift umfahren. Beim kopierten Text handelt es sich um mehrfache Abschriften von Q 112 (Sūrat al-Iḩlāṣ) bzw. von Elementen daraus, auf die die Überschrift des Abschnitts ja auch anspielt. Im oben links beginnenden Schriftband lässt sich der Text nachverfolgen; der Schreiber erreicht nach mehreren Abschriften von Q 112 am Schluss im äussersten Schriftband rechts das untere Ende dieses Abschnitts. Auch bei den weiteren hier kopierten Textstellen handelt es sich um Abschriften von Q 112 bzw. von Teilen davon. Der Schreiber war einfach darum bemüht, die Schriftbänder auszufüllen.

Abschnitt Ix: $\boldsymbol{D a f} \boldsymbol{a f}^{\mathrm{i}} \boldsymbol{i} \boldsymbol{t} \boldsymbol{t} \overline{\boldsymbol{a}} \boldsymbol{u} \overline{\boldsymbol{n}}$ („[Zur] Abwehr der Pest"):45 Dieser Abschnitt (Länge ca. 20 cm) ist mit einem bräunlich-goldenen Titelbalken mit der Überschrift $D a f^{\prime}-i t \underline{t} \bar{a} \bar{u} n$ (in weisser Schrift) versehen. Dieser Abschnitt schützt also gegen die Pest (țāūun). Er wird beidseits von den bekannten Schriftbändern mit der Abschrift von Q 48 flankiert (goldene Tinte auf schwarzem Hintergrund).

Im Mittelstreifen selbst lassen Textelemente in $\dot{G} u b \bar{a} r$-Schrift ein Rankenmuster entstehen, aus dem Blätter hervorspriessen. Im Hintergrund lässt sich zusätzlich ein feines goldenes Rankenmuster erkennen, aus dem goldene Blätter und blaue Blüten (?) herauswachsen. Die Stellen in $\dot{G} u b \bar{a} r$ beste-

42 Häufig handelt es sich um Sechsecke mit unregelmässigen Seitenlängen: auf dem dunkelblauen Hintergrund dieser Figuren lassen sich goldene florale Verzierungen erkennen.

Für ein ähnliches Muster vgl. Meinecke, Mamlukische Architektur I, Tafel 129.d: Fensterrahmen an der Yağ Cami in Adana (9o6/1501).

45 Vgl. Abb. 10 der Rolle (link in Anm. 1). 
hen einerseits aus zwei langgezogenen Ranken, die sich wellenförmig über diesen Abschnitt erstrecken. Diese Ranken werden durch Wiederholungen der Anrufungen Gottes yā rabb(i) gebildet. Die Anrufungen wurden zumeist in absteigender Richtung, in einem kurzen Abschnitt in aufsteigender Richtung, notiert. Aus diesen Ranken spriessen die Blätter hervor, die ebenso durch Stellen in $\dot{G} u b \bar{a} r-$ Schrift gebildet werden. Sie enthalten Anrufungen oder Lobpreisungen Gottes. Es handelt sich u.a. um die Basmala oder die Feststellungen Lā ilāha illā Allāh bzw. illā anta, Subhāna-ka, yā Allāh oder al-'aziz. Diese Stellen bilden keinen fortlaufenden Text, sondern werden lose derart aneinandergefügt, dass sie Blätter bilden.

Abschnitt x: Du'āy-i dawlat („Gebet um Glück“, АВB. 100), begleitet von einem Abschnitt mit der Überschrift Šarh-i $d u^{\prime} \bar{a}\left[{ }^{\prime}\right]: 46$ Dieser Abschnitt umfasst zwei annähernd gleich lange Teile; sie messen zusammen ca. $38.5 \mathrm{~cm}$. Der erste Abschnitt ist in einem bräunlich-goldenen Titelbalken mit der Überschrift Ducāy-i dawlat versehen. Die seitlichen Schriftbänder mit Text aus Q 48 weisen einen bräunlich-goldenen Hintergrund auf; der Text selbst in hellblauer Tinte. Beim anschliessenden Abschnitt handelt es sich um einen Kommentar zu diesem Gebet, wie sich aus der Überschrift (Šarh-i du`ā [’]) ableiten lässt. ${ }^{47}$ Aus der Überschrift zum Gebet (Du'āy-i dawlat) ergibt sich, dass dieser Abschnitt dem Träger der Rolle Glück (dawlat) verheisst.

Der erste Abschnitt mit dem Gebet selbst ist im Mittelstreifen ähnlich aufgebaut wie der Abschnitt IX (Daf'-i țā ūn). Auch hier lassen sich Verzierungen erkennen, die aus Stellen in $\dot{G} u b \bar{a} r-$ Schrift gebildet werden und Ranken und Blätter bilden. Dieser Abschnitt weist einen blauen Hintergrund auf und ist mit einem feinen goldenen Rankenmuster versehen, aus dem goldene Blätter und gelb-goldene und rote Blüten hervorspriessen.

46 Vgl. Abb. 11 der Rolle (link in Anm. 1).

47 Überschrift in goldener Tinte auf schwarzem Hintergrund.
Auch in diesem Abschnitt werden die Stiele dieser pflanzlichen Verzierungen zumeist aus Wiederholungen der Anrufung Gottes mit yā rabb[i] gebildet. In den Blättern lassen sich sodann die Basmala, Wiederholungen der Aussage Lā ilāha illā Allāh, Subhāna-ka oder ar-rahmān ar-rahīm erkennen. Soweit ersichtlich entsteht dabei kein zusammenhängender Text. Auch lässt sich diese Textfolge kaum als Gebet im eigentlichen Sinn bezeichnen.

Danach schliesst sich der Kommentar (Šarh $-i$ $\left.d u^{\prime} \bar{a}\left[{ }^{\prime}\right]\right)$ an. Die seitlichen Schriftbänder mit den Stellen aus Q 48 weisen einen goldenen Hintergrund auf; der Surentext wurde in weisser Schrift kopiert. Der Kommentar selbst wurde in persischer Sprache in schwarzem Nash auf einem grünlichen Hintergrund kopiert; die einzelnen Zeilen werden durch zumeist drei goldene Zierbalken voneinander getrennt. Der Text lautet:

$$
\begin{aligned}
& \text { (1) روايت از حضرت رسالت | كم فرمود كم هر كم اين }
\end{aligned}
$$

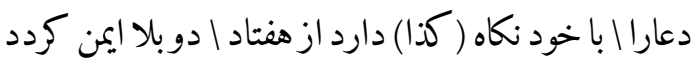

$$
\begin{aligned}
& \text { (كذا) اول | (0) از شر شيطان و جور سلطان | و بلاي }
\end{aligned}
$$

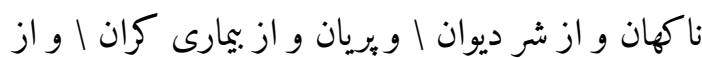

$$
\begin{aligned}
& \text { زبان بدكويان (كذا) و از جشم البدان و اكر (كذا) كسى لهى }
\end{aligned}
$$

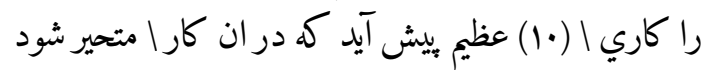

$$
\begin{aligned}
& \text { در شب آدينه دو | ركعت نماز كند و در هر ركعتى (؟) | } \\
& \text { يكبار الحمد و ده بار قل هو الله | احد بخواند و بكويد (كذا) } \\
& \text { المى بحرمت | (ها ) اين دعا كم حاجت من روا كن روا } \\
& \text { شود (كذا) \ا شرح اين دعارا بسيار است. }
\end{aligned}
$$

Wie bereits aufgezeigt enthält dieser Abschnitt kein Gebet stricto sensu. Im Abschnitt mit den Stellen in $\dot{G} u b \bar{a} r$-Schrift wurden vielmehr weit verbreitete Formeln und Anrufungen Gottes derart angeordnet, dass sie ein Rankenmuster mit Blättern bilden. Dass es sich dabei um ein Gebet handelt, geht im wesentlichen aus dem soeben festgehaltenen Kommentar hervor. Er hält fest, dass gemäss dem Propheten jeder vor allen Übeln in Sicherheit 
sei, der dieses Gebet auf sich trage. Der Kommentar zählt ausgewählte dieser Übel auf. Das PseudoGebet soll feien gegen das Übel des Satans (šarr$i$ Šaytāan), die Willkür des Machthabers ( ̌̆awr-i sulțān), plötzliches Unheil (balā-i nāgahān), das Übel durch Dämonen (az šarr-i dīwān wa pariyān), schwere Erkrankung (bìmārī-i girān), üble Nachrede (az zabān-i bad-gūyān) und die Bösen Blicke bzw. die Blicke der Bösen (az čašm-i badān). Der Kommentar macht danach noch knappe Angaben zur Rezitation des Gebets, damit dieses auch nütze.

Dieser Kommentar zum Gebet wurde auf persisch geschrieben. Der Buchstaben $g \bar{a} f$ wurde stets als $k \bar{a} f$ notiert. Dies ist nicht der einzige Abschnitt mit persischem Text auf der vorliegenden Rolle. Zwar wurde Persisch im 16. Jh. auch im Osmanischen Reich gern verwendet. Dennoch dürfte das vorliegende Dokument aufgrund der Verwendung des Persischen in erster Linie mit Iran in Verbindung zu bringen sein. Es lässt sich nämlich feststellen, dass Rollen aus dem 16. Jh. aus dem Osmanischen Reich selbst - gerade solche von durchschnittlicher Qualität wie die vorliegende auch Textelemente in türkischer Sprache enthalten. Dies aber ist vorliegend nicht der Fall.

Abschnitt XI: Daf'-i ğānwarān („Zur Abwehr der Tiere"):48 Länge ca. $19.8 \mathrm{~cm}$; Überschrift in goldener Schrift in schwarzem Titelbalken. Der Text aus Q 48 in den beiden Schriftbändern zur Linken und Rechten in goldener Schrift auf hellblauem Hintergrund.

Im Mittelstreifen erneut eine pflanzliche Verzierung, die aus Stellen in $\dot{G} u b \bar{a} r$-Schrift gebildet wird. Im Hintergrund ein feines goldenes Rankenmuster mit vereinzelten farbigen Blättern und Blüten (rot, blau, grün). Die Stellen in $\dot{G} u b \bar{a} r$ bilden Stiele mit Blättern und Blüten. Die Stiele werden hier erneut zumeist durch Wiederholungen der Anrufung Gottes mit ya $r a b b[i]$ gebildet. Die Blätter und Blüten entstehen durch Wiederholungen der Formeln $L \bar{a}$ ilāha illā Allāh (auffällig häufig), der Basmala, rabb al-ālamin, hayy und qayyūm. Diese Wiederholun-

48 Abb. 12 (link in Anm. 1). gen bilden keinen zusammenhängenden Text. Für den Schreiber stand das Ausfüllen der pflanzlichen Verzierung im Vordergrund.

Die Abschnitte XII-XV ${ }^{49}$ bilden insofern eine Einheit, als sie in vier Abschnitte aufgeteilt eine Abschrift der beiden Schlussverse von Q 68:51-52 enthalten. Diese Abschrift verläuft in der Rollenrichtung vorwärts, wobei der Text die Breite des Mittelstreifens ausfüllt. Die einzelnen Buchstaben dieses grossen Texts in schwarzer Schrift werden aus Stellen in kleinem $\dot{G} u b \bar{r} r$ gebildet. Die Aufteilung von Q 68:51-52 auf die einzelnen Abschnitte erfolgt wie nachstehend aufgeführt: ${ }^{50}$

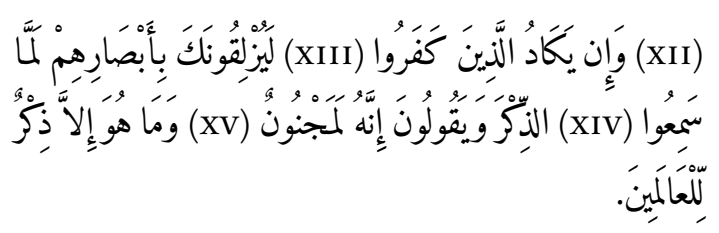

Abschnitt XII: Ǧihat-i čašm-zah̆m („Gegen den Bösen Blick“): Länge (inkl. Überschrift) ca. $19.9 \mathrm{~cm}$. Titelbalken mit silber-gräulichem Hintergrund mit der Überschrift in blauer Tinte. Der Text aus Q 48 in den beiden Seitenbändern links und rechts in goldener Tinte auf schwarzem Hintergrund. Im Mittelstreifen wurde der Hintergrund neutral belassen. Er wurde mit einem feinen goldenen Rankenmuster versehen, das aus vier konzentrisch angeordneten Kreisfiguren besteht. Aus den goldenen Ranken dieser Kreisfiguren wachsen farbige (rot, blau, grün, gelb) Blätter und Blüten hervor.

Die einzelnen Buchstaben des grossen Texts werden durch Wörter in schwarzem $\dot{G} u b a \bar{r}$ gebildet. Diese $\dot{G} u b \bar{r} r$-Stellen enthalten u.a. folgende Aussagen und Begriffe: Basmala, Lāilāha illā Allāh, Subhāana, yā hayy yā qayyūm, ${ }^{51}$ wa-l-hamdu li[A]llāh. Es lassen sich auch Anrufungen Gottes bei einzelnen seiner Schönen Namen feststellen. Letztlich bilden diese Stellen in $\dot{G} u b a \bar{r} r$ selbst aber keinen zusammenhängenden Text.

49 Abb. 12-14 (link in Anm. 1).

50 Q 68:51-52 lässt sich auf Schutzmitteln vielfach nachweisen.

51 In den beiden Punkten von yakādu. 
Abschnitt XIII: Daf'-i bad-gūyān („Für das Abwehren der Verleumder"):52 Länge (inkl. Überschrift) ca. $19.4 \mathrm{~cm}$. Titelbalken mit silber-gräulichem Hintergrund mit der Überschrift in blauer Tinte. Der Text aus Q 48 in den beiden Seitenbändern links und rechts wurde entlang dieses Abschnitts in blauer Tinte auf einem bräunlichgoldenen Hintergrund notiert. Der Mittelstreifen weist einen bläulichen Hintergrund auf. Er wurde mit einem feinen goldenen Rankenmuster versehen, das aus vier einzelnen, konzentrisch angeordneten Kreisfiguren besteht. Aus den goldenen Ranken dieser Kreisfiguren wachsen farbige (rot, blau, grün, gelb) Blätter und Blüten hervor.

Der grosse Text wird auch hier aus Stellen in $\dot{G} u b \bar{r}$ gebildet; sie lassen keinen in sich geschlossenen Text entstehen. Es lassen sich u. a. folgende Elemente erkennen: yā hayyy yā qayyūm ${ }^{53}$, Là ilāha illā Allāh, Subhāana Allāh wa-l-hamdu li-[A]llāh [...] là ilāha illā anta ${ }^{54}$ oder ähnliche Begriffe.

Abschnitt XIV: Du'ā [-i] buzurgwār (Gebet, das man ausspricht, bevor man sich an eine wichtige Person wendet): ${ }^{55}$ Länge ca. $19.8 \mathrm{~cm}$; ähnliche Gestaltung wie Abschnitt XII. Die grossen Buchstaben sind erneut aus Textstellen in kleinem $\dot{G} u b \bar{a} r$ zusammengesetzt. Es lassen sich die bereits bekannten Einzelausdrücke erkennen (vgl. oben zu Abschnitt XIII).

Abschnitt Xv: Daf'-i hasūdān („[Zur] Abwehr der Eifersüchtigen“): ${ }^{56}$ Die beiden Schriftbänder mit den Stellen aus Q 48 weisen einen hellblauen Hintergrund auf; der Surentext in goldener Tinte; vgl. ansonsten die Angaben zum vorangehenden Abschnitt.

Abschnitt XVI: Šarh̆-i Du'á['] („Kommentar zum Gebet“):57 Länge ca. $19.5 \mathrm{~cm}$. Die Stellen aus Q 48 auf den beiden Seitenbändern in hellblauer

52 Vgl. Abb. 13 (link in Anm. 1).

53 In den beiden Punkten des $y \bar{a}^{\prime}$ ganz am Anfang, im Punkt des $z \bar{a} l$.

54 Im oberen Teil des kāf von la-yuzliqūna-ka.

55 Abb. 13 (link in Anm. 1).

56 Abb. 14 (link in Anm. 1).

57 Abb. 14 (link in Anm. 1).
Tinte auf einem bräunlich-goldenen Hintergrund. Der Kommentar selbst wurde im Mittelstreifen in persischer Sprache in schwarzem Nash auf einem grünlichen Hintergrund kopiert; die einzelnen Zeilen werden durch zumeist drei goldene Zierbalken voneinander getrennt. Der Text lautet:

$$
\begin{aligned}
& \text { (1) بسم الله الرحمن الرحيم | روايتست از ابو هريره كه } \\
& \text { حضرت | بيغمبر صعلم وصيت بر تمام صحابه (؟) ا كرد كه } \\
& \text { برشماباد كم اين دعارا (ه) بيوسته (كذا) با خود نكاه (كذاب } \\
& \text { داريد اتا ايمن باشيد از جمله بلاها | و اكز كسى بيش بيش }
\end{aligned}
$$

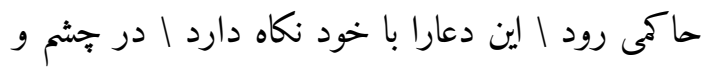

$$
\begin{aligned}
& \text { دل يادشاه عزيز ا و مكرم كردد (كذا) و اكر (•1) كسى } \\
& \text { بجنك يا سفرى بزرك | رود و اين دعا با خود دارد | از تهاز } \\
& \text { زخم شمش[يـ]ـر و تير و نيزه | و تف[ن]]كى و خطا شدن } \\
& \text { از اسب (ها) ايمن كردد (كذا) و اين دعارا شرح بسيار } \\
& \text { است. }
\end{aligned}
$$

Der Schreiber macht in diesem Abschnitt auf verschiedene Wirkungen des Gebets aufmerksam. Dieser Kommentar-Abschnitt dürfte sich zugleich auf mehrere weitere Abschnitte der vorliegenden Rolle beziehen. Gemäss den im persischen Text enthaltenen Angaben gehen die Aussagen auf den Prophetengenossen Abū Hurayra zurück. Demnach habe der Prophet allen seinen Gefährten geraten, dieses Gebet stets auf sich zu tragen. Sie seien dann vor allen Heimsuchungen gefeit. Wer dieses Gebet auf sich trage, wenn er vor einen Machthaber (hākim) trete, erscheine in dessen Augen und Herzen in einem guten Licht. Das Gebet schütze ausserdem jene, die sich in den Krieg oder auf eine lange Reise begäben. Es würde vor Verwundungen durch Schwert, Pfeil, Lanze und Gewehr und vor Stürzen vom Pferd schützen. Auch habe es noch viele weitere Nutzen. ${ }^{58}$

58 Hier als šarḥ bezeichnet. 
Abschnitt XVII: Ğihat-i muhāâraba-i 'askar-i kuffār („Für den Kampf gegen das Heer der Ungläubigen“, Ав В. 101):59 Länge ca. $19.5 \mathrm{~cm}$. Titelbalken mit Überschrift auf einem gräulichen Hintergrund in silberner Schrift. Auf den beiden Seitenbändern entlang dieses Abschnitts sind die Stellen aus Q 48 in goldener Tinte auf schwarzem Hintergrund notiert worden.

Der Hintergrund des Mittelstreifens ist neutral belassen worden. Es lässt sich darin ein feines goldenes Rankenmuster erkennen, das in vier Kreisen angeordnet ist. Aus den Ranken spriessen verschiedentlich goldene Blätter und farbige (rot, blau) Blätter und Blüten hervor. Am oberen und unteren Ende lässt sich eine geschwungene dreiteilige Verzierung erkennen, deren Mittelbogen an die Form eines mihrāo erinnert.

Das zentrale Element in diesem Abschnitt ist aber ein doppelklingiges Schwert, das sich leicht als das Schwert $\underline{D} \bar{u}$ l-faqār identifizieren lässt. ${ }^{60}$ Es wird aus Textstellen in feinem $\dot{G} u b \bar{a} r$ gebildet. Beim kopierten Text handelt es sich um ein Gebet; es lautet wie folgt:

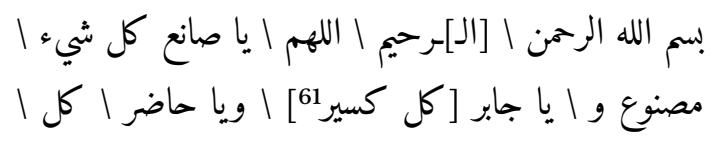

خالان

Hier zweigen links und rechts zwei Querteile ab; der Text ist teilweise zusammen mit jenem im senkrechten Teil zu lesen, damit er Sinn ergibt:

$$
\text { يا62 حاضر كل خلا [ن] \الله لا اله الا الله63. }
$$

Linker Teil unsicher

Fortsetzung im senkrechten Teil:

59 Abb. 15 (link in Anm. 1).

6o Vgl. zum Dū l-faqār-Schwert: Calmard, D̄ū 'l-Faqār, in EIr.

61 Zwei Zeilen sind hier sehr schlecht lesbar.

62 Rechts.

63 Dies undeutlich und versetzt; der Schreiber füllte den Griff aus.

$$
\begin{aligned}
& \text { لا اله الا الله | ويا صاحب (؟) كل | فقير (؟) ويا |شافي | }
\end{aligned}
$$

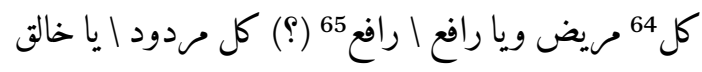

$$
\begin{aligned}
& \text { كل مخلوق ويا حا | ويا حافظ كل محفوظ | ويا فاتح كل } \\
& \text { مفتوح } \\
& \text { ويا غالب | كل | مغلوب | ويا شاهد كل | نجوي ويا | } \\
& \text { كشف ا كل كربة | ومكروب | اجعل لي في ا امري فرجا }
\end{aligned}
$$

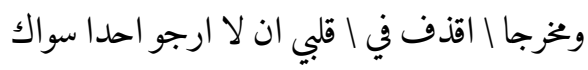

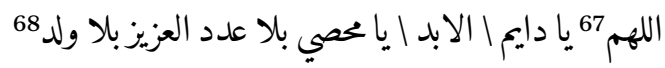

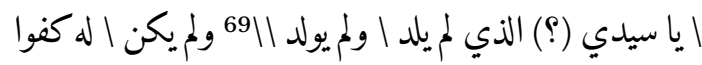

$$
\begin{aligned}
& \text { | احد | ويا ملاذ70 | المتحيرين | ويا جار | المستجيرين | |يا } \\
& \text { |مان | الخائفين }
\end{aligned}
$$

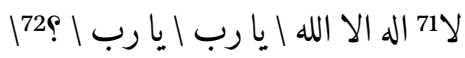

$$
\begin{aligned}
& \text { يا بجيب73 || بحق } 74 \text { ادم صفي الله | [و[نوح نجي الله }
\end{aligned}
$$

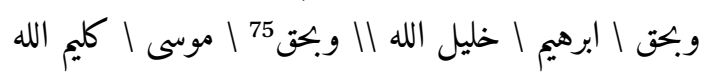

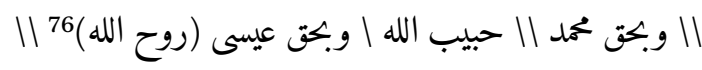

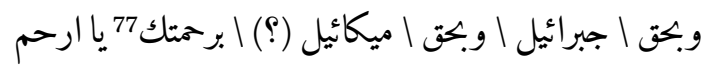

$$
\begin{aligned}
& \text { الراحمين. }
\end{aligned}
$$

Die Entzifferung des im Schwert enthaltenen Texts in $\dot{G} u b \bar{a} r$-Schrift ist zwar verschiedentlich mit

64 Hier beginnt eine kugelförmige Figur.

65 Unklar.

66 Ende der kugelförmigen Figur.

67 Der Schreiber befindet sich jetzt noch drei Zeilen über der Stelle, wo sich die Klinge des Schwerts aufteilt.

68 Ab hier trennen sich die beiden Teile der Klinge; der Text springt vorerst zwischen linkem und rechtem Teil hin und her.

69 Wechsel in den rechten Klingenteil.

70 Auf der Rolle steht hier ein anderer Begriff.

71 Dies im linken Klingenteil.

72 Dieser Ausdruck unleserlich.

73 Dies im rechten Klingenteil.

74 Ab hier im linken Klingenteil.

75 Dies im rechten Klingenteil.

76 Dies nicht mit Sicherheit leserlich.

77

Dies senkrecht absteigend in der Spitze des linken Klingenteils. Im rechten Klingenteil liessen sich 6 oder 7 Wörter am Schluss nicht mit Sicherheit lesen. 
Unsicherheiten verbunden. Es lässt sich allerdings mit Gewissheit festhalten, dass es sich beim kopierten Text um ein Gebet handelt, das allgemeiner bekannt sein muss. Es liess sich einstweilen mit Abweichungen im Internet belegen. ${ }^{78}$ Es dürfte

78 Vgl. https://www.facebook.com/permalink.php?id=396o 96390411733\&story_fbid=5916o3074194396 (Stand 2. Februar 2017, 10. Oktober 2017). Siehe ausserdem: https://ar -ar.facebook.com/permalink.php?story_fbid $=193558507$ 391131\&id=182093435204305 (Stand 10. Oktober 2017); der entscheidende Text lautet hier:

اللّهم يا صانع كل مصنوع، ويا جابر كل كسير، ويا حاضر كل

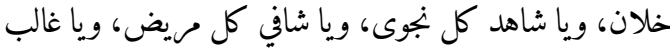
كل مغلوب، ويا طالب كل مطلوب، ويا مؤس كل وحيد، ويا

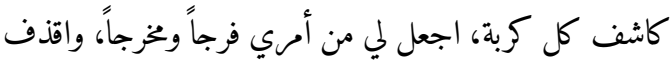
قلبي أن لا أرجو سواك برحمتك يا أرحم الراحمين.

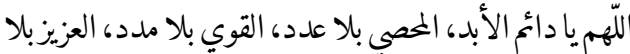

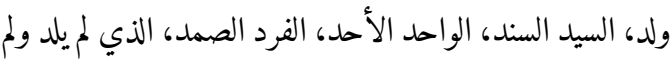

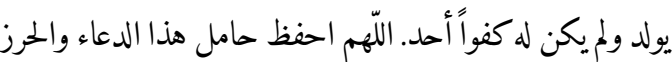

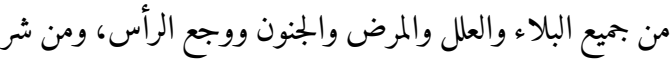

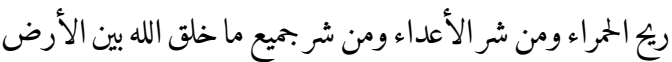
والسماء، بحق خاتم سليمان بن داوود عليه السلام يا رباه يا سيداه

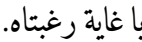

أسألك يا الله يا الله يا رحمان يا رحيم يا غياث المستغيثين يا

كاشف كرب المكروبين يا قاضي الحاجات يا مجيب الدعوات استجب دعائي بحق آدم صفي الله ونوح نجي الله وإبراهيم خليل

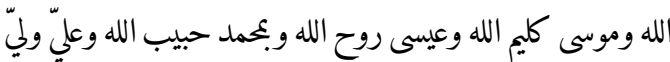

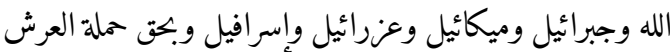

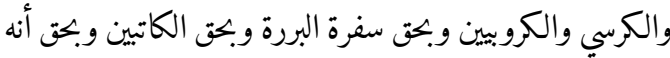
من سليمان وأنه بسم الله الرحمن الرحيم أن لا تعلو علي وآتوني مسلمين. اللّهم يا ولي الولاء ويا كاشف الضر والبلاء، ارفع عن حامل

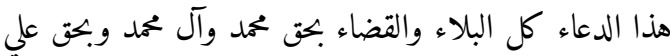

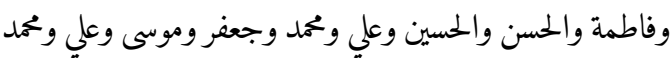
والحسن والمهدي صلوات الله عليهم أجمعين. sich grundsätzlich auch in gedruckten Gebetssammlungen belegen lassen. Es ist bis anhin aber nicht gelungen, dieses Gebet abschliessend $\mathrm{zu}$ identifizieren.

Abschnitt XVIII: Šarh-i Du'ä['] („Kommentar zum Gebet"): ${ }^{79}$ Unterhalb des Abschnitts mit dem Du l-faqār-Schwert schliesst sich ein nächster Kommentarteil an; er bezieht sich wahrscheinlich auf das im Schwert in $\dot{G} u b \bar{a} r$-Schrift kopierte Gebet und weist auf dessen Nutzen hin. Die Länge dieses Abschnitts beträgt ca. $19.4 \mathrm{~cm}$. Die Stellen aus Q 48 sind entlang dieses Abschnitts in hellblauer Schrift auf einem bräunlich-roten Hintergrund kopiert worden. Der Kommentar selbst wurde im Mittelstreifen in persischer Sprache in schwarzem Nash auf einem grünlichen Hintergrund kopiert; die einzelnen Zeilen werden durch zumeist drei goldene Zierbalken voneinander getrennt. Der Text lautet:

$$
\begin{aligned}
& \text { (1) روايتست از حضرت بيغمبر صلعم ا كه هر كم اين دعا }
\end{aligned}
$$

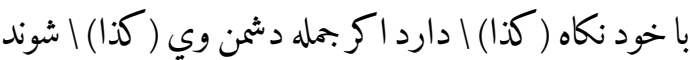

$$
\begin{aligned}
& \text { ضرري بر وي نتواند (ه) رسانيد (؟) و اكر بيماري دارد ال }
\end{aligned}
$$

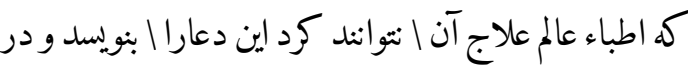

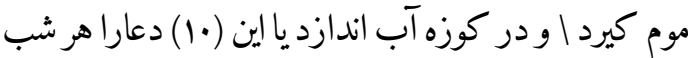

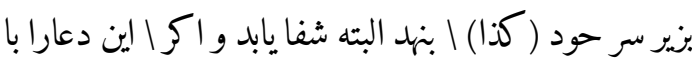

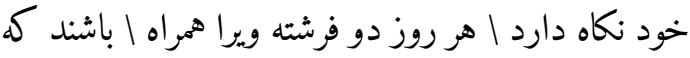

$$
\begin{aligned}
& \text { ويرا از قضاهاي كونا (ها) كون نكه دارد إين دعارا شرح } \\
& \text { سبياراست. }
\end{aligned}
$$

Der soeben transkribierte Begleittext hält fest, dass dieses Gebet, wahrscheinlich jenes im $\underline{D} \bar{u}$ l-faqārSchwert, unterschiedliche Nutzen hat. Gemäss dem Propheten schützt es seinen Träger, selbst wenn alle Menschen zu seinen Feinden würden. Sie könnten ihm keinerlei Schaden zufügen. Wer an einer Krankheit leide, gegen die sämtliche Ärzte auf der Welt kein Mittel wüssten, solle dieses Gebet

79 Abb. 15 (link in Anm. 1). 
aufschreiben, in Wachs einwickeln (?) und es in einen Wasserkrug werfen. Auch könne er es jede Nacht unter seinen Kopf legen, dann werde er bestimmt Heilung finden. Wenn er dieses Gebet auf sich trage, würden ihn jeden Tag zwei Engel begleiten und vor den unterschiedlichsten Schicksalsschlägen bewahren. Dieses Gebet habe vielfachen Nutzen (šarḥ).

Abschnitt XIX: Daf'-i balā-hā („Zur Abwehr der Heimsuchungen“): ${ }^{80}$ Länge ca. $19.6 \mathrm{~cm}$. Die Überschrift in weisser Schrift in einem Titelbalken mit goldenem Hintergrund. Die Stellen aus Q 48 entlang dieses Abschnitts in goldener Tinte auf schwarzem Hintergrund. Der Hintergrund des Mittelstreifens ist neutral belassen worden; darin ein feines goldenes Rankenmuster, aus dem goldene Blätter und farbige (blau, gelb, grün) Blüten hervorspringen. Die zentrale Verzierung in diesem Abschnitt besteht aus vier Figuren, die durch Stellen in $\dot{G} u b \bar{a} r$-Schrift gebildet werden. Sie sind unmittelbar übereinander angeordnet, weisen jeweils zwei Schenkel und darüber ein auf der Spitze stehendes Quadrat auf. Der in diesen Figuren kopierte Text lautet:

Figur 1:

$$
\begin{aligned}
& \text { |.81 . بسم \الله \الرحمن \الرحيم | وعليه توكلت وإليه [...] }
\end{aligned}
$$

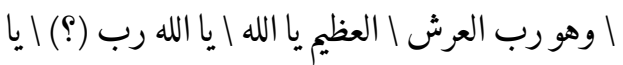

$$
\begin{aligned}
& \text { (?) }
\end{aligned}
$$
قيوم (؟)

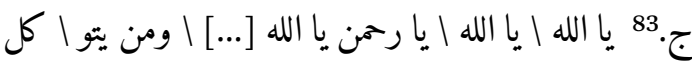

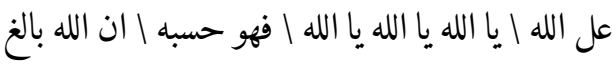

8o Abb. 16 (link in Anm. 1).

81 Quadrat an der Spitze.

82 Rechter Schenkel.

83 Linker Schenkel.

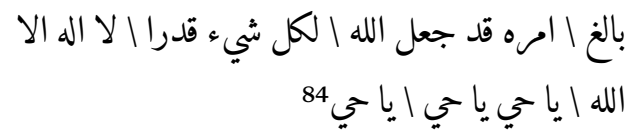

Figur $2: 85$

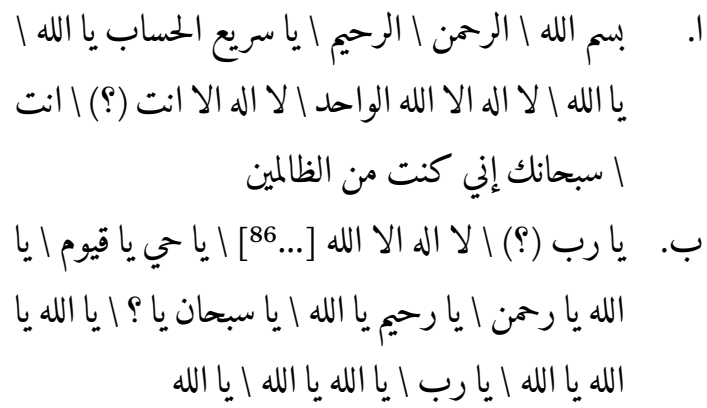

Figuren 3 und 4 weisen einen ähnlichen Inhalt auf, wie die beiden vorangehenden Elemente; er wird hier nicht speziell festgehalten.

Abschnitt Xx: Ğihat-i daf'-i darrandigān („Zur Abwehr der Raubtiere"): ${ }^{87}$ Länge ca. $19.8 \mathrm{~cm}$. Die Überschrift in weisser Schrift in einem Titelbalken mit goldenem Hintergrund. Der Text aus Q 48 auf den beiden Seitenbändern wurde entlang dieses Abschnitts in goldener Tinte auf hellblauem Hintergrund notiert.

Der Hintergrund des Mittelstreifens ist neutral belassen worden. Darauf lässt sich ein feines vierteiliges Rankenmuster erkennen, das konzentrisch angeordnet ist. Aus den Ranken gehen farbige Blätter und Blüten hervor (golden, rot, blau, grün). Im Vordergrund dieses Abschnitts steht aber ein weiteres vierteiliges Zierelement, das durch Stellen in $\dot{G} u b \bar{a} r$-Schrift gebildet wird. Es lässt sich eine von unten aufsteigende Wellenlinie erkennen. Sie wird durch Wiederholungen der Anrufung Gottes mit $y \bar{a}$ rabb(i) gebildet. Entlang dieser Wellenlinie sind

84 Vgl. dazu Q 65:3 (der Anfang dieses Verses fehlt in der beschriebenen Figur):

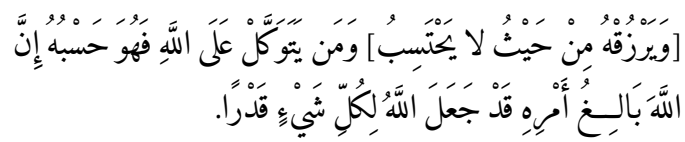

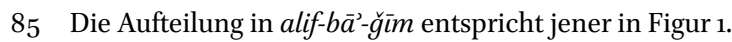

86 Eine kurze Zeile unklar.

87 Abb. 16 (link in Anm. 1). 
zusätzliche Elemente aus Stellen in $\dot{G} u b \bar{a} r$ angeordnet; sie können allenfalls als Blätter und Blüten interpretiert werden. Diese Stellen enthalten u.a. die Basmala, Subhāana-ka, Lā ilāha illā Allāh, yā Allāh yā Allāh, yā rạ̣mān, yā ḥayy.

Abschnitt XXI: Dưāy-i čašm-zahm („Gebet gegen den Bösen Blick“):88 Es folgt darauf der letzte Abschnitt; Länge ca. $15 \mathrm{~cm}$. Der Text aus Q 48 in weisser Tinte auf gold-braunem Hintergrund. Dieses Schriftband umfährt den Mittelstreifen unten und schliesst ihn ab. Im Mittelstreifen selbst wurde das Gebet gegen den Bösen Blick auf arabisch in schwarzem Nash auf einem grünlichen Hintergrund kopiert; die einzelnen Zeilen werden durch zumeist drei goldene Zierbalken voneinander getrennt. Der Text des Gebets lautet:

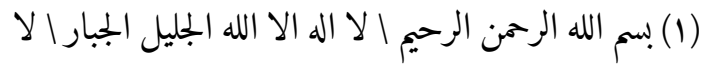

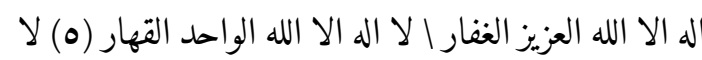

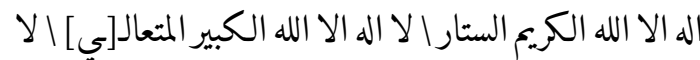

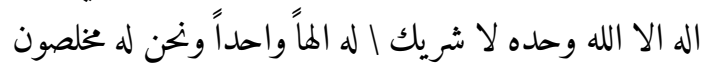

$$
\begin{aligned}
& \text { الا اله الا الله وحده لا شريك | (·1) له الهاً واحداً ونخن له } \\
& \text { عابدون الا اله الا الله محد رسول الله. }
\end{aligned}
$$

Dieses Gebet enthält Anrufungen Gottes bei ausgewählten seiner Schönen Namen und macht auf seine Einheit und Einzigartigkeit aufmerksam. Es hält auch fest, dass Muhammad sein Gesandter sei. Die Gläubigen aber seien ihm ergeben und würden ihn verehren.

Abschnitt XXII (Schluss der Rolle; AB B. 102): ${ }^{89}$ Am Schluss der Rolle folgt ein letzter Abschnitt von ca. $6 \mathrm{~cm}$ Länge. Er enthält direkt unterhalb des Schriftbands mit der Stelle aus Q 48 ein Rechteck und darüber einen Eintrag in schwarzer Schrift, der zu einem späteren Zeitpunkt von einer anderen Hand angebracht worden ist. Darunter befindet sich das Rechteck (Höhe ca. $5.1 \mathrm{~cm}$ ), das einen neutralen Hintergrund aufweist. Es war mutmass-

88 Abb. 17 (link in Anm. 1).

89 Abb. 17 (link in Anm. 1). lich für einen weiteren Texteintrag bestimmt; dieser wurde allerdings nie hinzugefügt.

Von Interesse ist allerdings der handschriftliche Eintrag unmittelbar davor, enthält er doch einen für die Einordnung des Dokuments wichtigen Hinهذه هذه هدية الحقير الداعي ميرزا مخدوم الحسيني الشريني الجرجاني. Ër hält älso fest̂t, dass die vorliegende Rolle ein Geschenk (hidya) des Mīrzā Mahudūm al-Ḥusaynī aš-Šarīfì al-Ǧurğānī an eine nicht genannte Person sei; er war offensichtlich als Beter, allenfalls als Gebetsrufer $(d \bar{a} c \bar{\imath})$ tätig. Dieser Mīrzā Māhdūm dürfte mit grosser Wahrscheinlichkeit identisch sein mit Mīrzā Maḩdūm aš-Šarīfì, der angeblich vom bekannten Gelehrten Šarīf Ğurğānī (13391413) abstammt. Mirzā Mahudūms Stammbaum mütterlicherseits soll auf Ḥusayn, den 3. Imām, zurückgehen. Die weiteren Angaben zu ihm stützen sich auf zwei Artikel von R. Stanfield Johnson und Sh. Golsorkhi. ${ }^{90}$

Mīrzā Mahdūm war ein iranischer Religionsgelehrter, der 995/1587 in Mekka starb. Er war unter den Safawiden ab ca. 975-976/1568-1569 politisch aktiv. Sein Vater hatte bereits unter Tahmāsp I. als Wesir gedient; er ermutigte seinen Sohn dazu, aus der Provinz Fārs in die damalige Hauptstadt Qazwīn zu kommen. Bis zu Šāh Ṭahmāsps Tod im Jahr 984/1576 lehrte und predigte Mīrzā Mahdūm in Qazwīn und weiteren iranischen Städten. Er war wahrscheinlich zum Qā ầ l-quḍāt über Fārs ernannt worden. Als Ismācīl II. - er war zuvor während 18 Jahren in der berüchtigten Festung Qahqaha in Nord-Iran eingesperrt gewesen - 984/1576 an die Macht kam, ernannte er unseren Mīrzā zu seinem șadr, seinem Minister in Religionsangelegenheiten. Er war deshalb der bekannteste Staatsdiener unter Ismāî̀l II.

Es ist bekannt, dass Ṭahmāsp I. und Ismāōll II. in religiösen Fragen ganz unterschiedliche Standpunkte vertraten. Țahmāsp I. hatte massgeblich

9o Stanfield Johnson, Sunni survival; Stanfield Johnson schrieb dazu auch ihre unveröffentlichte Dissertation: Mirza Makhdum Sharifi: a 16th century Sunni Sadr at the Safavid court. Golsorkhi, Ismail II and Mirza Makhdum Sharifi. 
zur Stärkung der Zwölfer-Schia in Iran beigetragen. Obwohl sein Sohn Ismāîl II nur 14 Monate lang regierte, leitete er ernsthafte Schritte zur Rückkehr Irans zur sunna ein. Verschiedene Chronisten erklärten Ismā̄īls Massnahmen mit Mīrzās Einfluss auf ihn. Diese Auffassung wird durch Aussagen Mīrzā Mahudūms gestützt, der in seinen Schriften meinte, dass er als șadr eigentliche jene Person war, die die Politik von Sulțān Ismāōil kontrollierte und er de facto der wahre sultān war.

Nach Ismāīils Tod im Jahr 985/1577 wurde Mīrzā Mahdūm auf Bestreben der Qizilbāš-Amīre wegen seiner Umtriebe als sunnitischer Aufrührer zweimal inhaftiert. Er wurde jedoch durch die Vermittlung hoher Angehöriger aus dem Umfeld des Herrscherhauses wieder freigelassen. $\mathrm{Zu}$ seinen Fürsprechern zählte auch die wohlbekannte ParīHuānum. ${ }^{91}$ Mit Mühe und Not konnte Mīrzā Mahdūm Iran verlassen und liess sich im Osmanischen Reich nieder. Er verfasste jetzt auch mehrere polemische Schriften. Am bekanntesten darunter ist das auf arabisch abgefasste Werk an-Nawāqid libunyān ar-rawāfị (beendet 987/1580). Mīrzā Mahdūm widmete diesen Text dem osmanischen Sultan Murād III.

Schlussfolgerungen: Es sind nicht zuletzt diese soeben aufgezeigten Bezüge der Rolle zu Mīrzā Mahdūm, die die Zuordnung dieses Dokuments in einen iranischen oder zumindest iranisch beeinflussten Kontext nahelegen. Überdies ergibt sich daraus ein Anhaltspunkt für die Entstehungszeit des vorliegenden Dokuments. Mīrzā Mahdūm war 1587 in Mekka verstorben; in Iran hatte er unter dem Safawiden Ismāīl II. um 1577 für kurze Zeit eine wichtige Rolle gespielt. Das vorliegende Dokument dürfte somit um diese Zeit oder allenfalls etwas zuvor entstanden sein. Es wird ausserdem darauf verwiesen, dass dieses Belegstück mehrfach längere Textabschnitte in persischer Sprache aufweist. Die entsprechenden Einträge beschränken sich in diesem Fall nicht auf die Überschriften zu den einzelnen Gebeten. Vielmehr enthält dieses Belegstück ganze Gebete auf Per-

91 Siehe zu ihr Pārsādūst, Parik̄ān Knānom, in EIr. sisch. Auch diese Feststellung legt eine Entstehung des Dokuments in Iran selbst nahe.

Neben den Gebeten tragen zusätzliche Elemente zum Schutzcharakter dieses Belegstücks bei. Es wird hier auf ausgewählte Elemente nochmals besonders aufmerksam gemacht: Beachtung verdient einerseits jene längliche Kartusche, die an Allāh, Muḥammad, Abū Bakr, 'Umar, 'Uțmān und 'Alī appelliert. ${ }^{92}$ Beim Betrachten des Dokuments fällt sodann das zweiklingige Schwert auf, das sich leicht als 'Alīs Schwert D lässt. ${ }^{93}$ Diese gemeinsame Anrufung 'Alīs mit den drei weiteren rechtgeleiteten Kalifen ist durchaus üblich und lässt an und für sich keine Rückschlüsse auf eine Entstehung des Dokuments in einem sunnitischen bzw. schiitischen Kontext zu. Die Abbildung des $\underline{D} \bar{u}$ l-faqār-Schwerts könnte schon eher für einen allenfalls schiitischen Hintergrund dieses Belegstücks sprechen. Es ist allerdings daran zu erinnern, dass die Verehrung 'Alīs im Umfeld der hier bereits mehrfach erwähnten Männerbünde durchaus üblich war und nicht a priori für einen Bezug zur Schia spricht. Ein unmittelbarer Bezug zur Schia dürfte vorliegend auch unwahrscheinlich sein, da Mīrzā Mahudūm explizit sunnitische Standpunkte vertrat und deshalb zum Verlassen seiner Heimat gezwungen war. Die mehrfache Bezugnahme auf 'Alī und die Abbildung seines Schwerts dürften vielmehr auf die Wertschätzung hindeuten, die 'Alī gerade im Umfeld von Männerbünden genoss (Derwischorden, Futuwwa- bzw. AhīBünde). Es ist auch bekannt, dass das bedingungslose Vertrauen auf Gott (tawakkul) in diesen Kontexten eine wichtige Rolle spielte. Auf der vorliegenden Rolle thematisiert eine komplex gestaltete Kartusche dieses Konzept. Dies ist ein zusätzlicher Hinweis, der für eine Zuordnung dieses Dokuments ins Umfeld von mystisch orientierten Gruppierungen spricht.

Zur Schutzwirkung des vorliegenden Dokuments tragen ausserdem die zehn thematisch ausgerichteten Gebete bei, auf die hier der besseren

92 Vgl. die Beschreibung von Abschnitt I (bei Anm. 7).

93 Vgl. Abschnitt XVIII, bei Anm. 59-79. 
Übersichtlichkeit halber nochmals hingewiesen wird (von oben nach unten): ${ }^{94}$ a. Daf'-i țā $\bar{u} n$ („Zur Abwehr der Pest"); ${ }^{95}$ b. Du'āy-i dawlat („Gebet um Glück“), gefolgt von einem Kommentar (šarḥi du'a $\left.\bar{a}^{\prime}\right) ;{ }^{96}$ c. Daf'-i ğānwarān („Zur Abwehr der Tiere“); ${ }^{97}$ d. Ğihat-i čašm-zahm („Zur Abwehr des Bösen Blicks“); ${ }^{98}$ e. Daf'-i bad-gūyān („Zur Abwehr der Verleumder" ${ }^{\prime \prime} ;{ }^{99}$ f. Du'ā ['-i] buzurgwār (Gebet, das formuliert wird, bevor man vor eine Autoritätsperson tritt); ${ }^{100}$ g. Daf'-i hasūdān („Zur Abwehr der Neider“, zusammen mit einem šarh-i $\left.d u^{(} \bar{a}^{\prime}\right) ;{ }^{101} \mathrm{~h}$. Ğihat-i muhāaraba-i 'askar-i kuffār („Für den Krieg gegen das Heer der Ungläubigen“, gefolgt von der Abbildung des $D \bar{u}$ l-faqār-Schwerts und einem Abschnitt Šarh-i du' $\left.\bar{a}^{\prime}\right) ;{ }^{102}$ h. Daf'-i balā-hā („Zur Abwehr der Heimsuchungen“);103 i. Ğihat-i daf'-i darrandigān („Zur Abwehr der wilden Tiere“);104 j. Dưāy-i čašm-zahm („Gebet gegen den Bösen Blick“; die Vorstellung wird auf der Rolle also zwei Mal erwähnt). ${ }^{105}$

94 Zuvor lasse sich auf dieser Rolle u. a. auch die folgenden Abschnitte feststellen: a. Die Schönen Namen Gottes (Abb. 7); b. Muhammads Name in geometrisierendem $K \bar{f} \iota \grave{\imath}$ (Abb. 7), c. Die vierzig gesegneten Namen (Čihil Ism-i mubārak; Abb. 7); d. Șad qul huwa Allāh („Sag hundert Mal; ,Er ist Gott“", Abb. 10).

95 Abb. 10 (link jeweils in Anm. 1).

96 Abb. 11.

97 Abb. 12.

98 Abb. 12.

99 Abb. 13.

100 Abb. 13.

101 Abb. 14

102 Abb. 15.

103 Abb. 16.

104 Abb. 16

105 Abb. 17. 

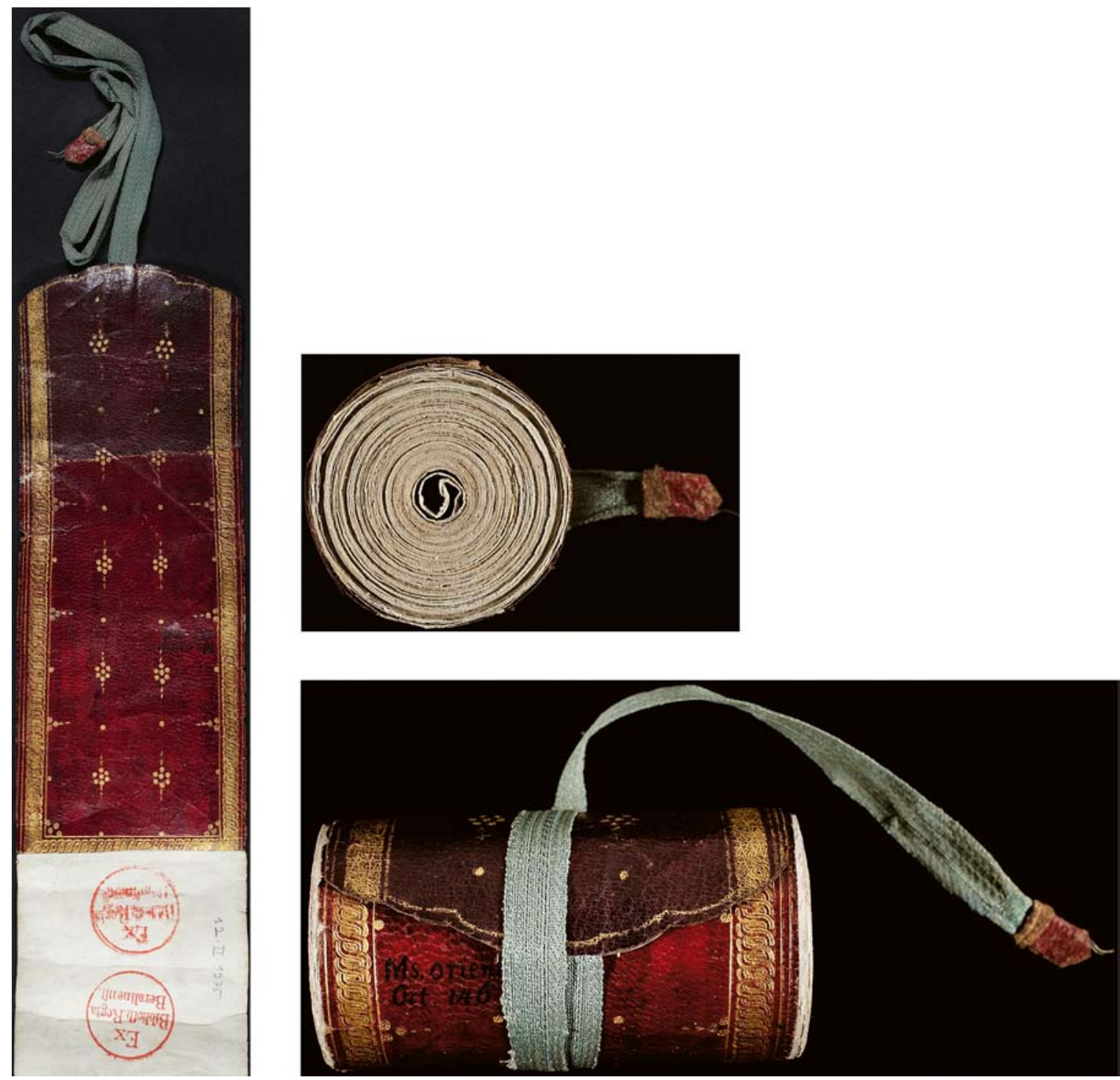

Авв. 93-94 Staatsbibliothek zu Berlin, Ms. or. oct. 146 (vgl. bei Anm. 3-5): Abbildung des Schutzteils aus Leder am Anfang von Ms. or. oct. 146. Dieses Schutzteil muss repariert worden sein, wie sich anhand von Unregelmässigkeiten in den beiden seitlichen Wellenbändern feststellen lässt. АвB. 94 zeigt die verschlossene Rolle.

STAATSBIBLIOTHEK ZU BERLIN-PREUSSISCHER KULTURBESITZ-ORIENTABTEILUNG, MS.

OR. OCT. 146 


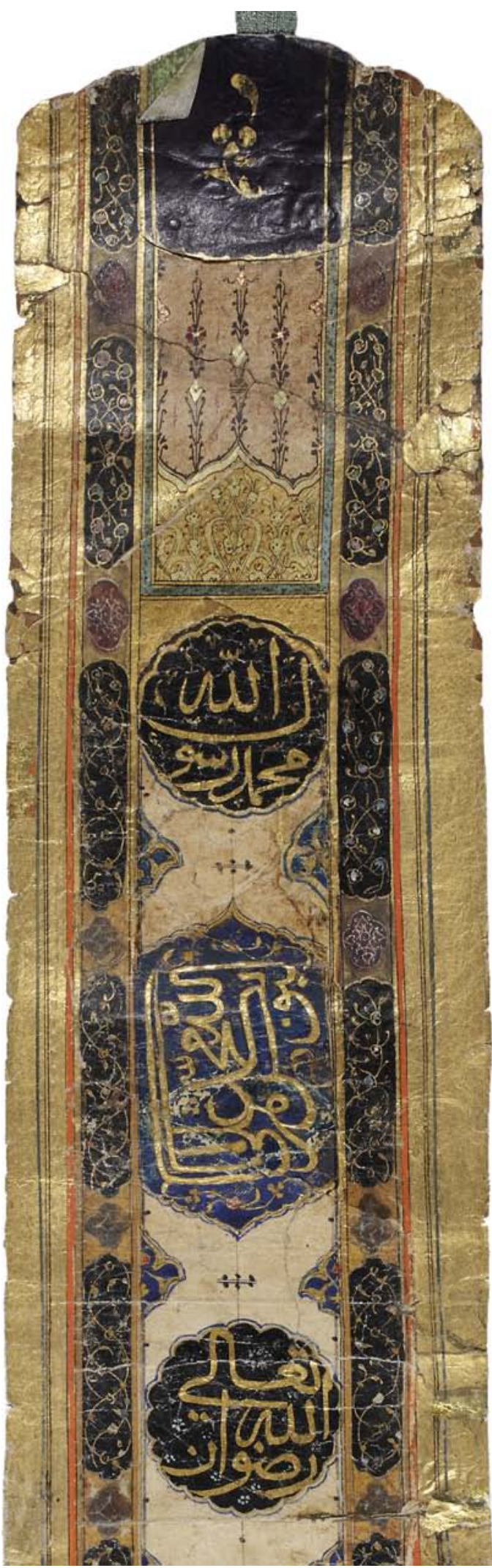

ABB. 95

Staatsbibliothek zu Berlin, Ms. or. oct. 146 (vgl. bei Anm. $5^{-8}$ ): Der Beginn von Abschnitt I der Rolle. Man beachte die breiten Goldbänder zur Linken und zur Rechten. Das Anfangszierfeld ist ähnlich auch von Handschriften in Kodexform bekannt. Die zweite Kartusche mit blauem Hintergrund führt in goldener Schrift die Namen Allāh, Abū Bakr, 'Umar, 'Uțmān, 'Alì auf. STAATSBIBLIOTHEK ZU BERLIN-PREUSSISCHER KULTURBESITZ-ORIENTABTEILUNG, MS. OR. OCT. 146 


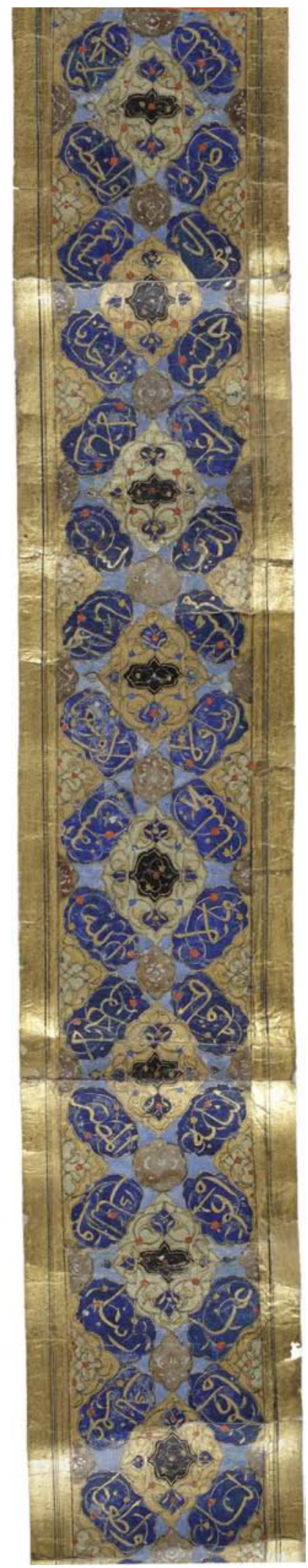

ABB. 96

Staatsbibliothek zu Berlin, Ms. or. oct. 146 (vgl. bei Anm. 8-11): Abschnitt II der Rolle, in dem die beiden Schlussverse von Sure 2 (Q 2:285-286; Hawātim al-Baqara) kopiert worden sind. Q 2:285 beginnt allerdings erst am Schluss dieses Abschnitts (hier nicht gezeigt).

STAATSBIBLIOTHEK ZU BERLIN-PREUSSISCHER KULTURBESITZ-

ORIENTABTEILUNG, MS. OR. OCT. 146 


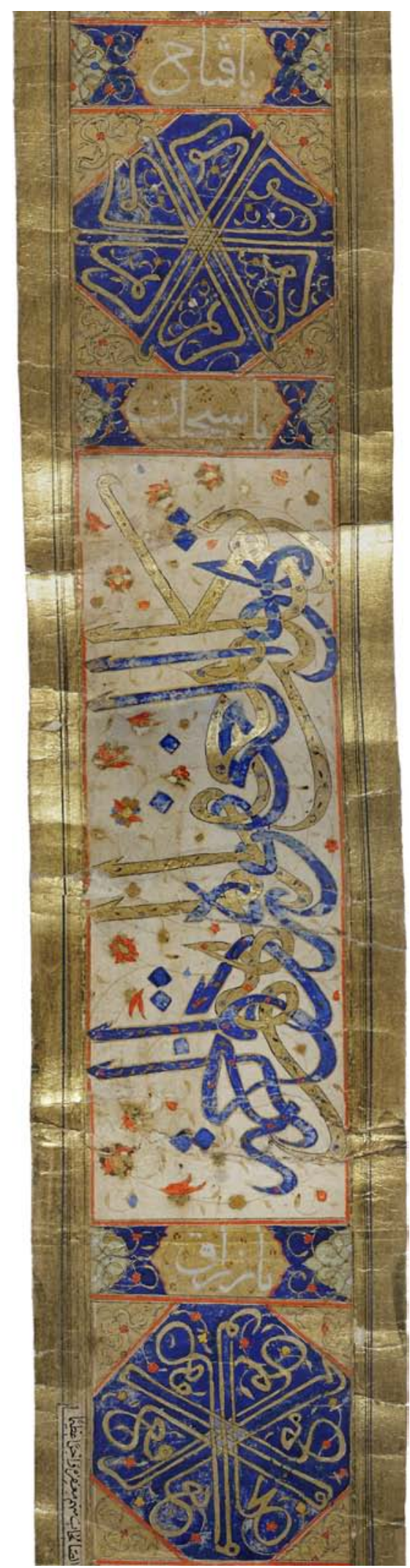

ABB. 97

Staatsbibliothek zu Berlin, Ms. or. oct. 146 (vgl. bei Anm. 11-17): Abschnitt in goldener und blauer Zierschrift; die Ausdrücke sind ineinander verschlungen. Der Schreiber thematisiert hier das bedingungslose Vertrauen in Gott (tawakkul). Der Text lautet: a. (zumeist golden): „Tawakkaltu bi-magifirati lmuhaymani“ und b. (zumeist blau): „Huwa l-gafūr dū r-raḥmati“. STAATSBIBLIOTHEK ZU BERLIN-PREUSSISCHER KULTURBESITZORIENTABTEILUNG, MS. OR. OCT. 146 


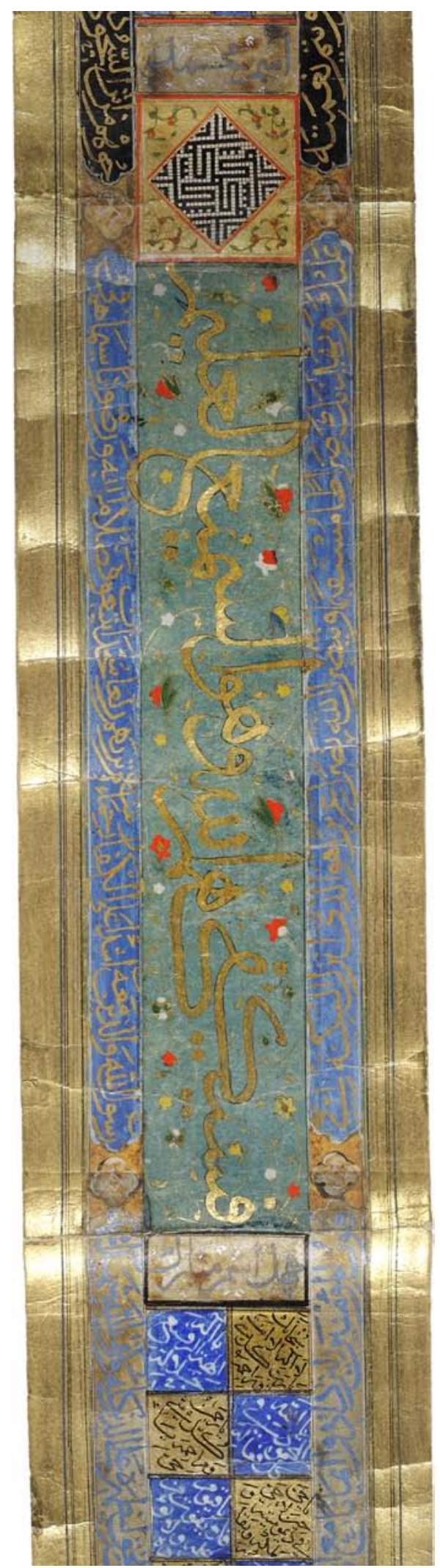

ABB. 98

Staatsbibliothek zu Berlin, Ms. or. oct. 146 (vgl. vor Anm. 18 und bei Anm. 18-39): Im Mittelstreifen steht in goldener Schrift auf hellblauem Hintergrund der Schluss von Q 2:137 („Fa-sa-yakfī-ka-hum Allāh wahuwa s-samı̄' al-'alīm“). Gerade anschliessend beginnt ein Gebet mit der Überschrift Čihil Ism-i mubārak. Die Seitenbänder in Rollenrichtung enthalten eine Abschrift von Q 48.

STAATSBIBLIOTHEK ZU BERLIN-PREUSSISCHER KULTURBESITZORIENTABTEILUNG, MS. OR. OCT. 146 


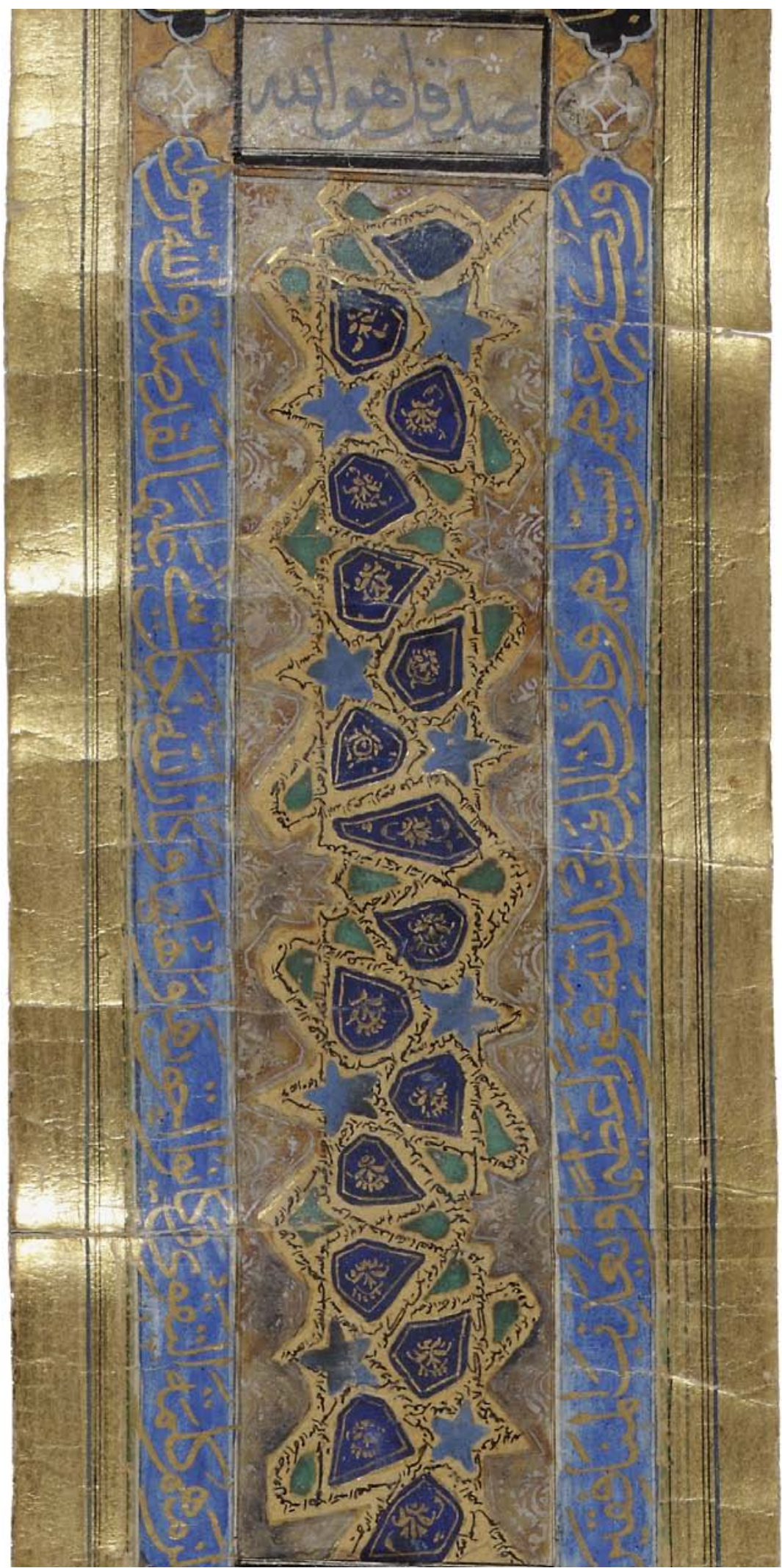

АBB. 99

Staatsbibliothek zu Berlin, Ms. or. oct. 146 (vgl. bei Anm. 4044): Die Überschrift zu diesem Abschnitt VIII lautet Șad qul huwa Allāh („Sag hundert Mal, Er ist Gott"). Die Abschrift in $\dot{G} u b \bar{a} r$ um die Figuren im Mittelstreifen herum besteht aus Teilen von Q 112 (Sūrat al-Ihlāss), die auf derartigen Rollen besonders häufig kopiert wird.

STAATSBIBLIOTHEK ZU BERLIN-PREUSSISCHER KULTURBESITZ-

ORIENTABTEILUNG, MS. OR. OCT. 146 


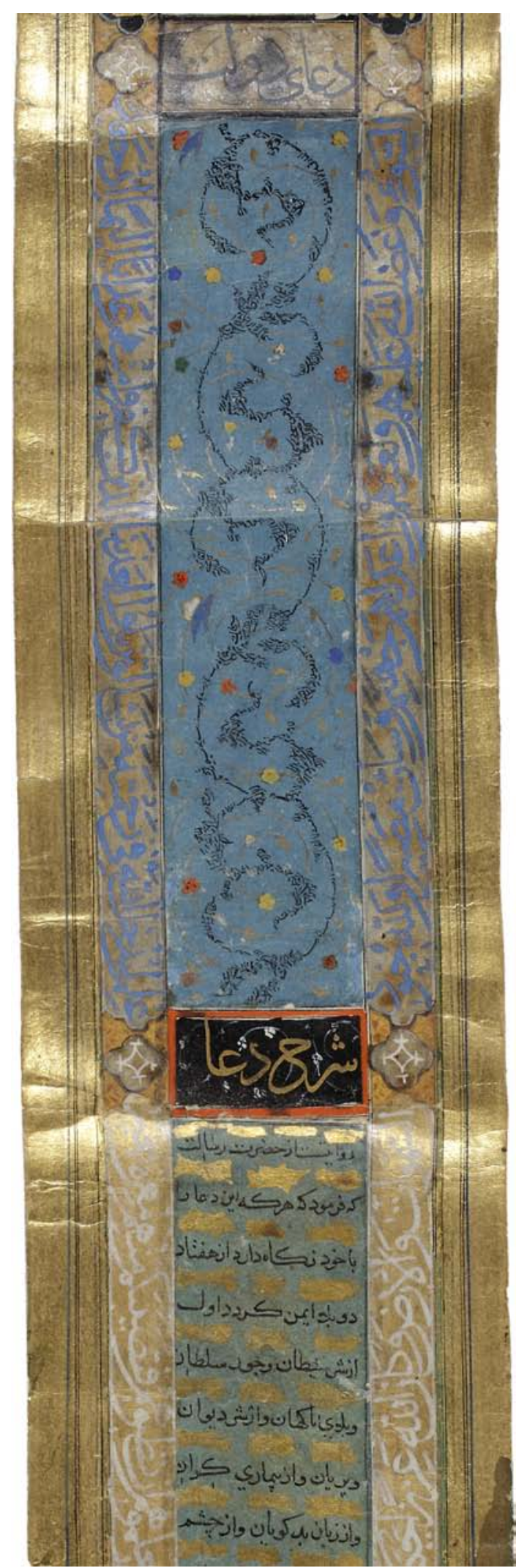

ABB. 100

Staatsbibliothek zu Berlin, Ms. or. oct. 146 (vgl. nach Anm. 46): Abschnitt x mit der Überschrift Du'āy-i dawlat („Gebet um Glück“). Das Rankenmuster wird aus Anrufungen Gottes gebildet (in $\dot{G} u b \bar{a} r$ ). Der anschliessende Abschnitt ( ̌́arḥ-i du'ā) erläutert die Vorzüge dieses „Gebets“.

STAATSBIBLIOTHEK ZU BERLIN-PREUSSISCHER

KULTURBESITZ-ORIENTABTEILUNG, MS. OR. OCT. 146 


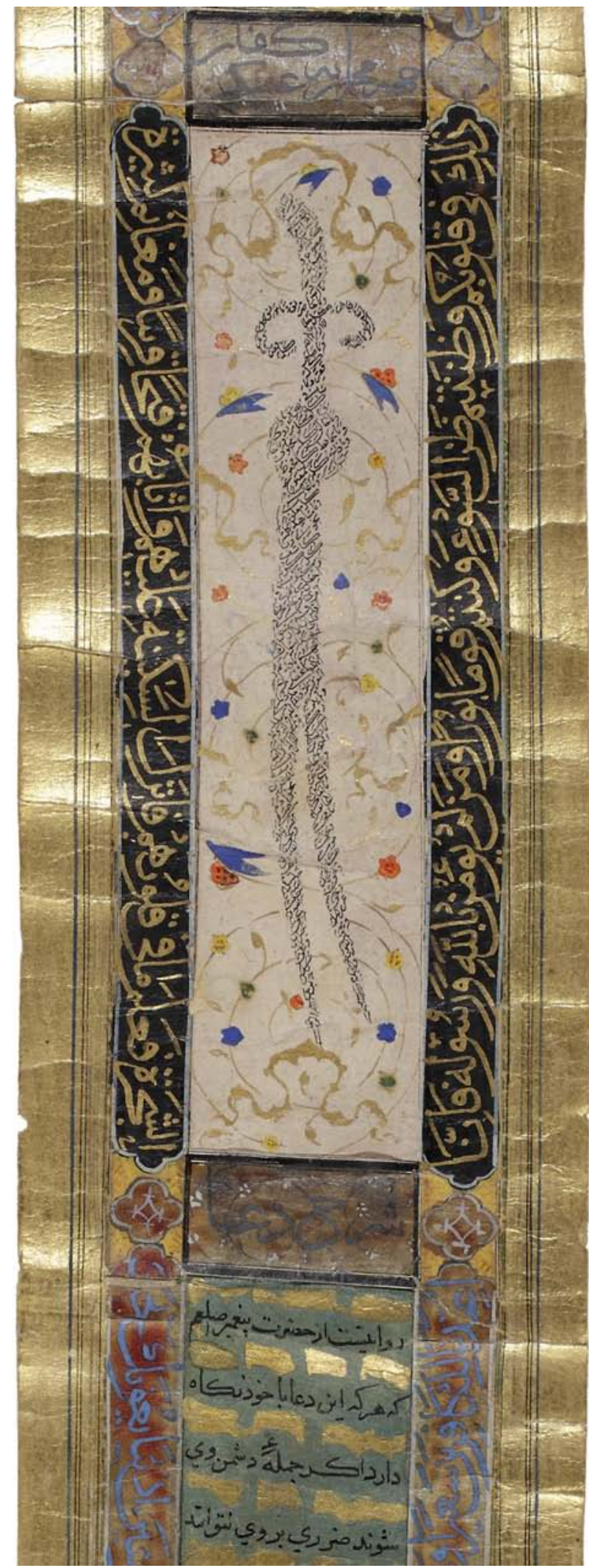

ABB. 101

Staatsbibliothek zu Berlin, Ms. or. oct. 146 (vgl. bei Anm. 59-78): Die Überschrift von Abschnitt XVII lautet Ğihat-i muḥāraba-i 'askar-i kuffār („Für den Kampf gegen das Heer der Ungläubigen“). Darunter folgt eine Abbildung des doppelklingigen $\underline{D} \bar{u}$ l-faqār-Schwerts, das Text in $\dot{G} u b \bar{r} r$ enthält.

STAATSBIBLIOTHEK ZU BERLIN-PREUSSISCHER KULTURBESITZ-ORIENTABTEILUNG, MS. OR. OCT. 146 


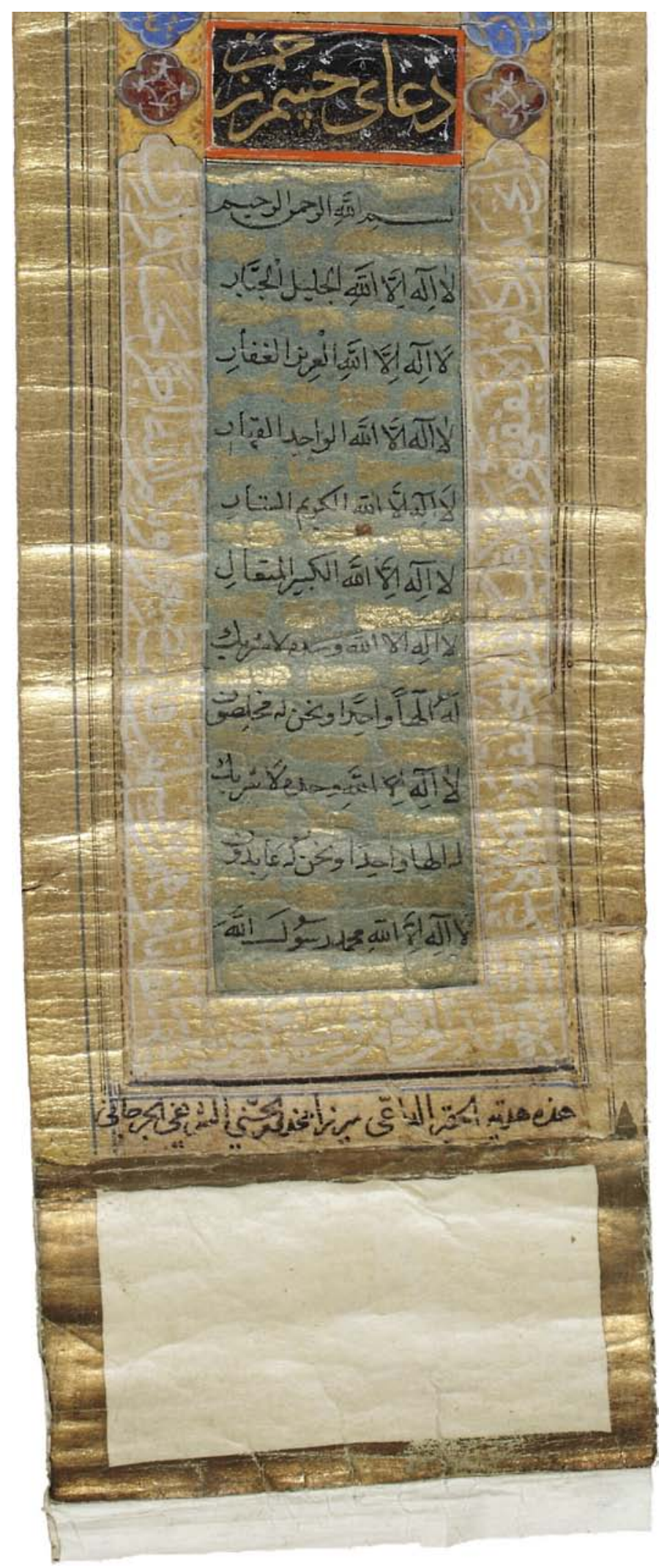

ABB. 102

Staatsbibliothek zu Berlin, Ms. or. oct. 146 (vgl. nach Anm. 89-9o): Der Schluss der Rolle. Aus einem Eintrag in schwarzer Schrift lässt sich ableiten, dass sich das Exemplar früher im Besitz von Mīrzā Maḩdūm al-Ḥusaynī aš-Šarîî̄ alĞưğānī befand. STAATSBIBLIOTHEK ZU BERLINPREUSSISCHER KULTURBESITZORIENTABTEILUNG, MS. OR. OCT. 146 

(Genève), CB 542

Das Dokument ist vollständig erhalten und misst $12.3 \times 969.6 \mathrm{~cm} .^{1}$ Beim Beschreibstoff handelt es sich um feines Papier, das auf dünnen grünen Stoff, wohl Seide, aufgezogen ist. Die Rolle besteht aus 19 zusammengeklebten Papierstreifen. ${ }^{2}$ Am Anfang schützt ein dünnes, dunkelbraunes Stück Leder (Länge $3.7 \mathrm{~cm}$ ) das Dokument gegen aussen. Die Rolle ist auf ein Holzstäbchen (Durchmesser ca. $0.4 \mathrm{~cm}$ ) aufgewickelt. ${ }^{3}$ An den beiden Enden des Stäbchens sind zwei runde schwarze Plättchen (Durchmesser ca. $3 \mathrm{~cm}$ ) derart angebracht, dass eine Spindel entsteht. Das Dokument wird in einer schmucklosen Blechbüchse aufbewahrt. ${ }^{4}$ Vergleichbare Büchsen wurden für Schutzhemden aus dem Osmanischen Reich angefertigt. ${ }^{5}$

1 Der Verfasser behandelt die Rolle св 542 auch in zwei Aufsätzen: Nünlist, Entzauberte Amulettrollen; ders., Devotion and protection: Four amuletic scrolls from Safavid Persia.

Die Fondation M. Bodmer hat dem Verfasser Digitalisate des gesamten Dokuments zur Verfügung gestellt, auf die sich diese Beschreibung stützt.

2 Diese 19 Streifen messen: $1.7 .6 \mathrm{~cm} ; 2.56 .6 \mathrm{~cm} ; 3.57 .0 \mathrm{~cm}$; 4. $57.3 \mathrm{~cm} ; 5.57 .8 \mathrm{~cm} ; 6.57 .8 \mathrm{~cm} ; 7.55 .2 \mathrm{~cm} ; 8.55 .3 \mathrm{~cm} ; 9$. $54.6 \mathrm{~cm} ; 10.55 .5 \mathrm{~cm} ; 11.56 .4 \mathrm{~cm} ; 12.54 .5 \mathrm{~cm} ; 13.49 .8 \mathrm{~cm} ; 14$. $48.5 \mathrm{~cm} ; 15.49 .5 \mathrm{~cm} ; 16.50 .5 \mathrm{~cm} ; 17.51 .2 \mathrm{~cm} ; 18.49 .0 \mathrm{~cm} ; 19$. $45.5 \mathrm{~cm}$. Der Verfasser dankt Florence Darbre, Konservatorin der Fondation M. Bodmer, für diese präzisen Angaben.

3 Nur das Stoffstück ist direkt am Stäbchen festgemacht. Das auf die grüne Seide aufgezogene Papier endet ca. $1.8 \mathrm{~cm}$ davor. Das Übergangsstück besteht nur aus grüner Seide.

4 Diese Büchse besteht aus zwei Teilen. Der Deckel wird über die Büchse selbst gestülpt und verschliesst sie. Die Höhe der Büchse misst $13.9 \mathrm{~cm}$. Der Durchmesser des Deckels beträgt $5.4 \mathrm{~cm}$, jener des Bodens $5.1 \mathrm{~cm}$. Vgl. dazu die Abbildungen der Rolle: Scans 1-3 (fmb-cb-o542_eoo1, fmb-cb-o542_eoO2, fmb-cb-0542_eoo3).

5 Tezcan, Tılsımlı Gömlekler 76 (Kat. Nr. 11), zeigt eine Büchse, die zu einem Schutzhemd aus dem Anfang des 17. Jh. gehört. Rollen von der hier beschriebenen Art wurden grundsätzlich in einem Behältnis (Büchse, Etui etc.) aufbewahrt. Diese Behältnisse fehlen heute allerdings häufig bzw. die Dokumente werden in einem Ersatzbehältnis aufbewahrt. Für solche Behältnisse siehe u.a. Agha Khan Foundation, Inventar AKM 623, 624; Maddison und
$\mathrm{Zu} \mathrm{CB} 542$ ist ein ähnlich gestaltetes Paralleldokument aus der Forschungsbibliothek Gotha bekannt. ${ }^{6}$ Es ist allerdings nur fragmentarisch

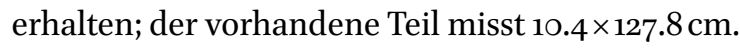
Bei der Herstellung des Belegstücks aus Genf ist ein deutlich höherer künstlerischer und materieller Aufwand betrieben worden. Verschiedene Gestaltungselemente auf diesen beiden Rollen legen eine Entstehung in einem iranischen bzw. iranisch geprägten Umfeld nahe. Die Rolle с в 542 steht exemplarisch für den persischen Typ dieser Art von Dokumenten in Rollenform.

$\mathrm{Zu}$ diesen persischen Stilmerkmalen gehört einerseits ein Quadrat mit der Inschrift al-'azama li- $[A] l l a \bar{h}$ („die Majestät ist Gottes“) in geometrisierendem Kufi (АВв. 103). Auf Св 542 ist dieses Element 16 Mal vorhanden. Auf dem Fragment aus Gotha ist es in ähnlicher Ausführung drei Mal erhalten geblieben. Ähnlich gestaltete Inschriften finden sich auf aus Backstein errichteten Moscheen und andern Baudenkmälern in Iran und Zentralasien. Sie sind u. a. aus der Timuridenzeit bekannt. Dieser Schrifttyp wird als Bannā̄i-Kū oder Máqilì-Küfı bezeichnet. ${ }^{7}$ Derartige Inschriften lassen sich z.B. auf der Moschee Mīr Čāqmāq in Yazd (errichtet 1437) und dem Mausoleum des Qāḍī-zāda Rūmī (um 1425) im Šāh-i Zinda-

Savage-Smith, Science, tools \& magic 142-143. Gemäss einer schriftlichen Auskunft von F. Linder Mathieu (3. April 2009) besitzt das Bernische Historische Museum mehrere Amulettbehältnisse aus dem islamischen Kulturraum; sie seien allerdings alle leer. Zusammen mit seinem ursprünglichen Behältnis erhalten geblieben ist wohl RA 204 aus der Badischen Landesbibliothek, Karlsruhe (vgl. dazu Kapitel 6, Anm. 8 und 231; Авв. 151), und Cod. arab. 2616 aus der Bayerischen Staatsbibliothek, München. Abschliessende Beweise zur Zusammengehörigkeit von Amulettrolle und Behältnis dürften jeweils nur schwer zu erbringen sein.

6 Forschungsbibliothek Gotha, Ms. orient. A. 1372; vgl. dazu Nebes, Orientalische Buchkunst 174-175 (mit Abb.; Beschreibung von T. Seidensticker). Siehe auch Pertsch, Die orientalischen Handschriften III, 33 (Nr. 1372).

7 Siehe dazu Yūsufì, Calligraphy, in EIr (unter Kufic-ma'qeli or banna'i style, mit Abb. 43-45); O'Kane, Timurid architecture $67-68$. 
Komplex in Samarkand nachweisen. ${ }^{8}$ Ähnliche Verzierungen sind auch von der Masğid-i Ğāmic in Aštarǧān bei Ișfahān bekannt. ${ }^{9}$ Ein gutes Beispiel dafür ist überdies der Grabturm für Šayh Șafī uddīn im Șafawiyya-Schrein in Ardabil. ${ }^{10}$

Anderseits lässt sich auf den beiden Dokumenten aus Genf und Gotha ein feingliedriges, spiralförmiges florales Rankenmuster erkennen, das sich in modifizierter Form in iranischen Kontexten auch anderweitig belegen lässt. Es bildet auf Св 542 den Hintergrund von 29 rechteckigen Kartuschen mit Textstellen (vgl. AB B. 105-106). ${ }^{11}$ Eine zusätzliche dreissigste Kartusche am Rollenanfang wurde abweichend gestaltet (vgl. АВB. 104). ${ }^{12}$ Auf dem Fragment aus Gotha sind noch vier derartige Kartuschen erhalten. Auf св 542 sind diese Ranken und die an ihren Spitzen vereinzelt hervorspringenden lanzettenförmigen Blätter mit goldener Tinte ausgeführt worden (vgl. ABВ. 105-106). Dieses Grundmuster ist auf allen 29 Kartuschen vorhanden. Auf jeder zweiten Kartusche lockern aus den Ranken herauswachsende kleine mehrlippige Blüten in den Farben Rot, Grün, Hellblau und vereinzelt Braun diesen Hintergrund auf. ${ }^{13}$ Sie betonen die Leichtigkeit des Rankenmusters und tragen zu seiner Eleganz bei. Auf der jeweils anschliessenden Kartusche sind Blüten nur spär-

8 Degeorge und Porter, L'art de la céramique 110 (mit Abb. von der Moschee Mīr Čāqmāq) und 117 (Mausoleum des Qāḍīzāda Rūmī). Für zusätzliche Abbildungen der Moschee Mīr Čāqmāq und ihrer Bannā’’-Inschriften siehe https://archnet.org/sites/1692/media_contents/925 (Stand 15. Oktober 2017). Siehe ausserdem Lentz und Lowry, Timur and the princely vision $34^{-37}$ (mit Fig. 5-7): Timurs Masǧid-i Ğāmic in Samarkand (ca. 1398-1405).

9 Vgl. dazu auch die Ausführungen zu Is 1626 (Chester Beatty Library), Kapitel 4.9 (bei Anm. 99). Beachte https://archnet.org/sites/1597 mit Abb. unter https:// archnet.org/sites/1597/media_contents/480 (Stand 27. Juli 2017).

10 Siehe Kapitel 4.9 (Anm. 97)

11 Siehe zu diesen Textstellen ausführlicher unten Anm. 3135 .

12 Siehe dazu unten bei Anm. 19, 23-28 und 37.

13 Diese Blüten haben in der Regel vier Blätter, gelegentlich auch drei oder fünf. Gerade die blauen Blüten sind häufig einfach als Tupfer oder zweilippig ausgeführt worden. lich vorhanden und ebenso wie die Ranken ausschliesslich goldig.

Ähnlich gestaltete Rankenmuster kommen auf Bauten in Iran wiederholt vor, wie sich u.a. anhand von Beispielen aus der Timuridenzeit aufzeigen lässt. Es kann auf die Masğid-i Šāh in Mašhad hingewiesen werden. Sie wurde vermutlich vor $145^{1}$ errichtet. ${ }^{14}$ In Isfahan verzieren florale Rankenmuster von ähnlicher Feinheit und Eleganz das Nordportal des Darb-i Imām-Schreins. ${ }^{15}$ S. Aube macht überdies auf die Verzierungen in der Blauen Moschee in Tabriz aufmerksam, die 1465 von den Turkmenen errichtet worden ist. ${ }^{16}$ Die Kunst der Turkmenen stand unter dem Einfluss der Timuriden. Es ist aber auch bekannt, dass Handwerker aus Tabriz zur Zeit der Timuriden in Mašhad tätig waren. ${ }^{17}$ Der blaue Hintergrund und das feine Rankenmuster mit Blüten dieser allfälligen Parallelen könnten auf св 542 ausserdem in zwei Quadraten mit der Wendung al-'azama li-[A]llāh am Rollenanfang ein Echo gefunden haben (vgl.

14 Siehe dazu O'Kane, Timurid architecture 233; Blair und Bloom, Art and architecture 51, halten fest, dass der Baumeister Ahmad b. Šams ad-Dīn Muhammad aus Tabriz diese Moschee 1451 errichtet habe. Siehe auch Golombek und Wilber, Timurid architecture I, 334-336 (Nr. 95), und II, 26o-266 (Abb.).

15 Siehe dazu Blair und Bloom, Art and architecture 5253 (mit Abb. 70). Der Darb-i Imām-Schrein wurde 14531454 von Abu l-Muẓaffar Ǧahān Šāh, dem Qara QuyunluPatron aus Tabriz errichtet; er bzw. seine Frau Hāatun Ğān Begum baute dort 12 Jahre später die Blaue Moschee; siehe dazu gerade anschliessend Aube, Mosquée Bleue 242 (mit Anm. 1). Zum Darb-i Imām-Schrein siehe auch Golombek und Wilber, Timurid architecture I, 384-386 (Nr. 170), und II, Tafel XIV.

16 Aube, Mosquée Bleue; dieselbe, Tabriz - Blue Mosque, in EIr; Blair und Bloom, Art and architecture $5^{2-53}$ Siehe auch Eintrag „Masjid-i Muzaffariyya“ unter https:// archnet.org/sites/1676/media_contents/557 (Stand 15 . Oktober 2017).

Aube, Mosquée Bleue, weist mehrfach auf diese Abhängigkeiten hin (z. B. 253-254, 245-247); Aube, Tabriz - Blue Mosque, in EIr: „The extant tilework [of the Blue Mosque] documents artistic connections with contemporary architecture in Timurid Khorasan and in the Ottoman Empire.“ 
Авв. 103) ${ }^{18}$ Diese stilistischen Vergleiche legen nahe, dass Св 542 in der zweiten Hälfte des 15. Jh. oder am Anfang des 16. Jh. in einem timuridischen bzw. turkmenischen Umfeld entstanden ist.

Diese zeitliche Einordnung wird durch zwei von unterschiedlicher Hand notierte Einträge in der ersten rechteckigen Kartusche auf Св 542 gestützt (vgl. АВв. 104).$^{19}$ Sie sind offensichtlich nachträglich angebracht worden. Der erste Vermerk ist in ungelenkem Nash mit goldener Tinte ausgeführt worden; er ist gut leserlich und lautet Tärīh-i Sulțān Sulaymān sana $957 .{ }^{20}$ Ein Eintrag von einer andern Hand mit teilweise identischen Informationen lässt sich im Innern der Kartusche erkennen, steht hier aber auf dem Kopf. Klar lesbar ist Sana 957 Sulțān Sulaymān. Zwei Wörter am Schluss liessen sich nicht mit Sicherheit entziffern. Das in diesen beiden Vermerken erwähnte Jahr 957 h.q. stimmt weitgehend mit dem Jahr 155 o christlicher Zeitrechnung überein. Es ist damit naheliegend, den auf dem Dokument erwähnten Sulțān Sulaymān mit Sulțān Sulaymān al-Qānūnī zu identifizieren. Er ist im Westen als Sulaymān der Präch-

18 Vgl. damit auch eine illuminierte Seite und ein dībāǎa aus einem Dōwān Qāsims (Iran 863/1458-1459; Kat. Nr. 139); beachte als zusätzliches Beispiel Kat. Nr. 146: Panel aus Sa'dīs Būstān, datiert 893/1488; beide in Lentz und Lowry, Timur and the princely vision. Die beiden Seiten aus Qāsims Dīwān sind sehr sorgfältig gestaltet; sie weisen ein mit den beiden Vierecken auf Св 542 vergleichbares, mit Blüten verziertes Rankenmuster auf blauem Hintergrund auf (auf Св 542 mit etwas geringerer Aufmerksamkeit ausgeführt). In die beiden Vierecke von Св 542 ist jeweils ein zusätzliches, auf der Spitze stehendes Quadrat mit der bereits angeführten Inschrift al'azama li- $[A] l l a \bar{h}$ eingepasst worden. Beim ersten Quadrat lautet diese Wendung erstaunlicherweise Allāh al'azama, „Gott ist die Erhabenheit“. In sämtlichen andern Fällen auf Св 542 (insgesamt 15 Mal) und Ms. orient. A. 1372 (3 Mal) lautet die Wendung aber al-'azama li-[A]llāh. Siehe dazu ausführlicher unten nach Anm. 153. Es handelt sich um die abweichend gestaltete erste Kartusche mit einer Abschrift von Q 3 (Sürat Āl Imrān), vgl. Anm. 12, 23-28 und 37.

20 Der Schreiber hat sich bei der Zahl 957 an dieser Stelle verschrieben; die Zahl ist eine Zeile weiter unten aber deutlich erkennbar. tige bekannt und herrschte von 1520-1566. Diese Zuordnung lässt sich allerdings nicht abschliessend beweisen, könnte sie sich doch auf einen weiteren Machthaber namens Sulțān Sulaymān beziehen, der allerdings nur von lokaler Bedeutung gewesen wäre. ${ }^{21}$ Dieser mutmassliche Bezug des vorliegenden Dokuments zu Sulaymān dem Prächtigen wird in einem historischen Exkurs am Schluss dieses Kapitels präzisiert. ${ }^{22}$

Beschreibung im einzelnen: Die soeben angestellten Beobachtungen zielten auf eine erste Situierung des Dokuments in einen iranischen Kontext ab. Die weiteren Ausführungen gehen auf die einzelnen Elemente des Belegstücks ein; sie befassen sich in einem ersten Schritt mit Aufbau und Inhalt der insgesamt 30 rechteckigen Kartuschen auf CB 542.

Die erste rechteckige Kartusche (bzw. das 1. Rechteck; АВв. 104) ist gegenüber den 29 weiteren Kartuschen abweichend gestaltet. In dieser ersten Kartusche ist der Text in besonders kleiner mikroskopischer Schrift enthalten. ${ }^{23}$ Er bildet in diesem Rechteck allerdings keine übergeordneten Begriffe, wie dies danach der Fall ist. Im ersten Rechteck lässt sich vielmehr ein spiegelsymmetrisch angeordnetes netzartiges Rankenmuster erkennen, das aus drei grösseren Mandeln und weiteren Figuren gebildet wird. Die Ranken sind mit Blättern und Blüten verziert. In diesem ersten Rechteck lassen sich zwei Inschriften in grüner Tinte mit der Anrufung Gottes yā $\underline{d} \bar{u}($ sic) l-ğalāl bzw. wa-l-ikrām erkennen. ${ }^{24}$

Im komplex angeordneten Rankenmuster wurden in Gubār Stellen aus Q 3 (Sūrat Āl Imrān) notiert. Die Abschrift beginnt oben in der Mitte mit der basmala, die gegen links unten absteigt.

21 Vgl. zu ihm Veinstein, Süleymān, in $E I^{2}$.

22 Vgl. dazu den historischen Exkurs am Schluss (nach Anm. 180).

23 Vgl. die scans 58 und 57.

24 Die beiden Ausdrücke ğalïl und kāmil zählen zu den Schönen Namen Gottes (al-asmā’ al-husnā). Weitere Schöne Namen Gottes sind auf der Genfer Rolle in mehreren Zellenquadraten angeordnet (siehe dazu Anm. 96). 
Der Schreiber folgt bei der Abschrift der Fortsetzung dieser Ranke und wechselt mehrfach die Seite im Rechteck. Kurz vor der Anrufung Gottes mit Yā dī l-ğalāl (sic), beginnt in dieser Ranke Q 3:4; sie lautet: ${ }^{25}$

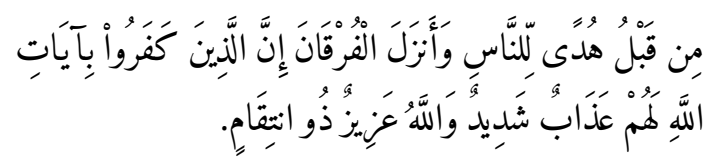

Erneut auf der rechten Seite in dieser Ranke angekommen beginnt der Kopist mit der Abschrift von Q 3:6. ${ }^{26}$ Er folgt danach weiter dem Verlauf dieser Ranke und erreicht zuletzt von rechts her kommend das untere Ende des Rechtecks. Er steigt danach sogleich wieder nach links empor. Nur wenig oberhalb des unteren Endes des Rechtecks beginnt Q 3:9. ${ }^{27}$ Wenig unterhalb der Anrufung Gottes mit wa-l-ikrām steht der Anfang von Q 3:10; dieser Vers umfährt die Anrufung Gottes rechts. ${ }^{28}$ Der Kopist erreicht schliesslich wieder das obere Ende, wobei er sich zuletzt von rechts unten kommend der Mitte des Rechtecks nähert; kurz vor dem Ende dieser aufsteigenden Ranke beginnt Q 3:15.

Die Fortsetzung der Abschrift liess sich nicht überall mit Sicherheit rekonstruieren, folgt aber weiterhin den hin- und herwogenden Ranken. Die Abschrift dürfte im vorliegenden Fall allerdings nicht lückenlos sein. Jedenfalls ist die doch lange

25 Der Schreiber erreicht hier auf der Höhe der Anrufung Gottes $Y a \bar{a} \underline{d u}$ (sic) al-ğalāl die linke Seite des Rechtecks. Er folgt der Ranke weiter nach unten und wechselt wieder auf die rechte Seite der Kartusche.

26

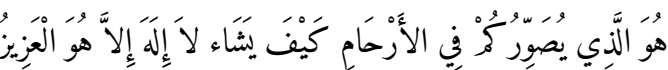

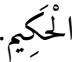

27

Q 3:9 lautet:

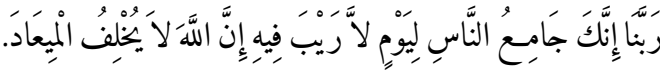

28 Q 3:10 lautet:

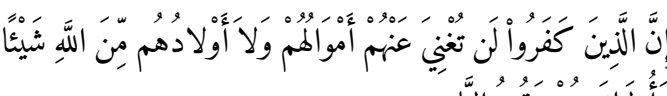

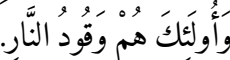

Sure 3 (200 Verse) in diesem Rankenmuster nicht vollständig kopiert worden. Wer den erheblichen Zeitaufwand für das Entziffern nicht scheut, dürfte grundsätzlich in der Lage sein, auch den weiteren Verlauf des Surentexts festzustellen.

Nach diesem abweichend gestalteten Rechteck mit Q 3 folgen 29 weitere Rechtecke. Neben den beiden bereits zuvor beschriebenen Gestaltungselementen (geometrisierendes Küfı̈, florales Rankenmuster) spricht gerade auch die besondere Anordnung von Textstellen in diesen 29 weiteren Kartuschen für einen iranischen Hintergrund von Св 542. Diese weiteren 29 Rechtecke sind ca. $20-25 \mathrm{~cm}$ lang und enthalten Textstellen in ungefähr $4 \mathrm{~cm}$ hoher Schrift. ${ }^{29}$ Es handelt sich um fromme Formeln und ausgewählte Passagen aus dem Koran. Bemerkenswert ist, dass diese Stellen in grosser Schrift ihrerseits aus Auszügen aus dem Koran in mikroskopischer Schrift gebildet werden. Diese $\dot{G} u b \bar{a} r$-Schrift ist dabei etwa $1 \mathrm{~mm}$ hoch. ${ }^{30}$ Die weitere Übersicht identifiziert zuerst den grossen Text in diesen Rechtecken; sie befasst sich danach mit dem Inhalt der Stellen in mikroskopischer Schrift: ${ }^{31}$

1. Rechteck (Scans 57-58):vgl. die Ausführungen oben bei Anm. 23-28; 2. Rechteck (Scan 55): سم الله

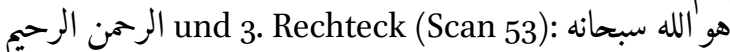
تعالى وتقدس. Siehe ABB. 105-106.

Die grossen Buchstaben in den Rechtecken 23 enthalten einen Auszug aus Q 4 (an-Nisä). Die Basmala des grossen Texts eröffnet hier nicht nur die Rolle, sondern leitet zugleich auch Q 4 ein. Im mikroskopischen Text beginnt Q 4:1. im Buchstaben $b \bar{a}^{\prime}$ des Ausdrucks bism: hier lässt sich die Anrufung ayyuhā n-nās erkennen. Am Ende des grossen Rechtecks stehen als grosser Text die Ausdrücke ar-rahmān ar-rahīm. Am Schluss des

29 Da diese Passagen in der Längsrichtung der Rolle notiert worden sind, wäre das vorliegende Dokument nicht als rotulus, sondern allenfalls als volumen zu charakterisieren. Zur Unterscheidung vgl. Gacek, Arabic Manuscripts, s.v. „Roll (scroll)“, 224-226. Höhe der Buchstaben alif und lām.

Die Ausführungen verweisen jeweils auf die von der Fondation M. Bodmer hergestellten scans der Rolle. 
Begriffs ar-rahmān wurde in den beiden Buchstaben mìm-nūn Q 4:9 kopiert. Im Artikel al bzw. ar von ar-rahim folgen Q 4:10a (alif) und 4:10b (lām). Im Begriff rahìm selbst stehen Stellen des langen Verses 4:11. Der Schreiber hat die Textfolge mehrfach aufgebrochen. Die einzelnen Versteile folgen nicht unmittelbar aufeinander; vielmehr macht der Schreiber wiederholt Sprünge. Die Satzfolge lässt sich grundsätzlich rekonstruieren; dies ist aber mit einem hohen Zeitaufwand verbunden. Der Schluss von Q 4:11 folgt erst im Begriff huwa im 3. Rechteck.

3. Rechteck: Im huwa des grossen Texts steht der Schluss von Q 4:11. Der Schreiber setzt die Abschrift in den Vokalisationszeichen fort (zuerst im damma und danach im fatha). Die letzten Wörter aus Q 4:11 folgen im rasm des $h \bar{a}^{3}$ von huwa (rechts absteigend). Darauf beginnt im Buchstaben $h \bar{a}$ ' Q 4:12. Es ist nicht angezeigt, den gesamten Text in diesen Abschnitten derart ausführlich aufzuschlüsseln. Es sei einfach festgehalten, dass im Schlussteil des sin von taqaddasa Q 4:20 zu erkennen ist (Scan $53)$.

4. Rechteck (Scan 51): 5. لا اله الا الله الملك الحق المبين 5 . وما [1][لنصر :مechteck (Scan 49; Auszug aus Q 3:126)

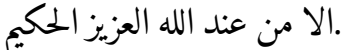

Beim Text in $\dot{G} u b \bar{a} r$ in diesen beiden Rechtecken 4-5 handelt es sich um einen Auszug aus Q 5 (al-Mằida); im lā und fatha dazu Vers 1. Im nün von al-mubin Q 5:6 (Schluss). Am Anfang des 5. Rechtecks folgt im fatha der Schluss von Q 5:6. Im letzten mim in diesem Rechteck (al-hakim): der Beginn von Q 5:18. DerText bricht darauf mitten im Vers ab.

6. Rechteck (Scan 47; aus Q 2:137, Schluss): اله . 7. Rechteck (Scan 45; aus Q 2:137, Schluss): هو السميع العليم.

Beim Text in $\dot{G} u b \bar{a} r$ in diesen beiden Rechtecken 6-7 handelt es sich um Q 6 (Sūrat al-An'ām); Beginn mit der basmala. Vers 1 zuerst in den drei fatha, dann im Punkt des $f \bar{a}^{3}$. Am Ende des 6 .

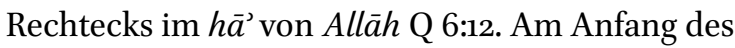
7. Rechtecks Q 6:52: Beginn im fatha über dem $w \bar{a} w$, Fortsetzung im $w \bar{a} w$, dann hä $\bar{a}^{\prime}$ etc. Im mim von al-'alìm Q 6:6o (Anfang).
8. Rechteck (Scan 43):الله مفتح الابواب. 9. Rechteck (Scan 41; aus Q 21:87, wo ohne subhāna): سبحانك اني : مechteck (Scan 39; aus Q 21:87) لا اله الا انت الت

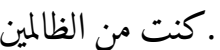

Beim Text in $\dot{G} u b \bar{a} r$ in den Rechtecken 8-10 (Scans 43, 41 und 39; hier gehören drei Rechtecke zusammen) handelt es sich um Q 7 (al-A'räf): Am Anfang im alif von Allāh: basmala; danach im lām Vers 1 (alif-lām-mìm-șād). Am Schluss des 8. Rechtecks im $b \bar{a}$ : Q 7:12 und Beginn von Q 7:13 (Auseinandersetzung mit Iblīs: fa-ı̌hbit); ausgesprochen komplexe Anordnung des Texts. 9. Rechteck: Im sin von subhāna-ka: Q 7:14; am Schluss dieses Rechtecks im $t \bar{a}^{\prime}$ und den beiden Punkten dazu: Q 7:22. Im $t \bar{a}^{\prime}$ springt der Text zwischen oberer und unterer Zeile hin und her. Schluss des Verses in den beiden Punkten des $t \bar{a}$. Das la-kumā ist nur einmal geschrieben, aber zwei Mal zu lesen. Der Text handelt immer noch von Adams und Evas Versuchung durch Iblīs. 10. Rechteck: Im alif des innī: Q 7:23 (Anfang). Im in von zälimīn: Q 7:30; der Text springt zwischen den einzelnen Zeilen hin und her.

11. Rechteck (Scan 37; aus Q 3:159, Schluss): فاذا عزمت فتوكل على الله

12. Rechteck (Scan 35; aus Q 3:159, Schluss): ان الله يحب المتوكلين.

Beim Text in $\dot{G} u b \bar{a} r$ in den Rechtecken 11-12 (Scans 37 und 35) handelt es sich um Q 8 (Sürat al-Anfāl); Beginn mit basmala. Am Schluss des 11. Rechtecks im $h \bar{a}^{3}$ von Allāh: Vers 10 (Schluss) und Vers 11 (Anfang). Im 12. Rechteck im alif von inna: Q 8:11 (Fortsetzung); im nūn von mutawakkilīn: Q 8:19 (Schluss). In den beiden Punkten des $y \bar{a}$ : Q 8:20 (Anfang); im Punkt des nūn: Q 8:20 (Fortsetzung).

13. Rechteck (Scan 33; Q 39:73, Schluss): ${ }^{32}{ }^{9}$ سل 14. Rechteck (Scan 31; vgl.

32 Man beachte, dass der Schreiber das $\sin$ durch drei Punkte unterhalb des Buchstabens kennzeichnet. Ein weiteres auffälliges Beispiel findet sich im 29. Rechteck, wo der Schreiber ebenfalls drei Punkte unter das sin von subhāna notierte. I. Afshar, Manuscripts in the domains of the Persian language $409 \mathrm{f}$., macht auf weitere Belege 


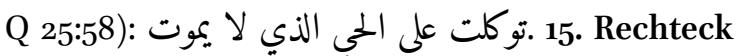

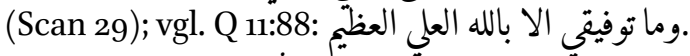

Beim Text in $\dot{G} u b \bar{a} r$ in "den Rechitecken 1315 (Scans 33, 31, 29, hier gehören drei Rechtecke zusammen) handelt es sich um Q 9 (at-Tawba, einzige Sure im Koran ohne basmala am Anfang); im sin von salām: Vers 1. Huălidīn: im nūn und im Punkt dazu: Q 9:8 und Beginn 9:9. Im 14. Rechteck: im $t \bar{a}$ von tawakkaltu und den beiden Punkten dazu: Q 9:18 (Anfang); der Text wohl hier nicht fortlaufend. La yamūt: im $t \bar{a}$ : Q 9:26; in den beiden Punkten dazu: Beginn von Q 9:27; dieser Vers wird aber nicht abgeschlossen (?). 15. Rechteck: am Anfang im wāw: Q 9:28; am Ende im mìm von 'azìm: Q 9.34. Die weiteren Verse von Q 9 fehlen.

16. Rechteck (Scan 27; Q 68:51): وان يكاد الذين

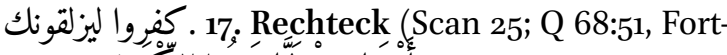

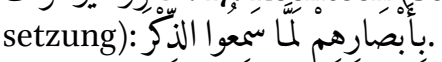

Beim Text in Gubâr in den Rechtecken 1617 (Scans 27 und 25) handelt es sich um Q 10 (Yūnus): im fatha zum wāw: basmala. Dann im $w \bar{a} w$ (Kreis, von unten nach oben zu lesen) Vers 1. Am Schluss des 16. Rechtecks: Q 10:14-15 (möglicherweise Lücke im Text). Im 17. Rechteck: am Anfang: Q 10:22 beginnt im kasra des $b \bar{a}$, dann im Punkt des $b \bar{a}$, danach im fatḥa des alif, darauf Fortsetzung im rasm; im $r \bar{a}^{3}$ von $\underline{\text { dikr: }}$ Q 10:32 (Schluss).

, 18. Rechteck (Scan 23; Q 68:51-52, Fortsetzung):

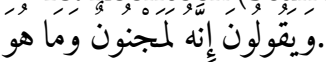

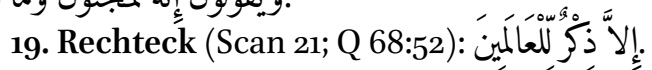

Beim Text in $\dot{G} u b \bar{a} r$ in den Rechtecken 18-19 (Scans 23 und 21) handelt es sich um Q $11(H \bar{u} d)$ : basmala im fatha des wāw, dann Vers 1 im zweiten fatha. Am Schluss im damma und fatha von huwa Vers 4 und Beginn von Vers 5. Der Text läuft also zuerst durch die Vokalisationszeichen, evtl.

für diese Schreibweise in einer Abschrift des Kitāb alabniya 'an haqāiq al-'adwiya' des Abū Manșūr aus dem Jahr 1056 aufmerksam. Siehe zur Frage ausserdem http:// www.reed.edu/persian-calligraphy/en/jafar-baysonghor i/1/index.html („Sin in Nastaliq“); auch J.J. Witkam, http://www.islamicmanuscripts.info/files/Neglect-negle cted.pdf (suche nach „sîn three dots underneath“) (Stand beide 20. Oktober 2017). teilweise durch die diakritischen Punkte. Danach Fortsetzung im rasm. Am Schluss des Rechtecks im huwa: Q 11:12 und Beginn 11.13. Im 19. Rechteck: Im alif: direkte Fortsetzung (Q 11:13). Am Schluss im nūn von 'älamìn: Q 11:27.

20. Rechteck (Scan 19; Q 2:255, Thronvers ${ }^{33}$ ): الله [لال : الا : 21. Rechteck (Scan 17) 22. Rechteck (Scan

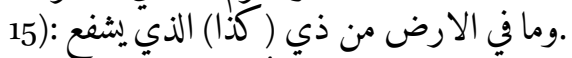

Beim Text in $\dot{G} u \bar{b} \bar{a} r$ in den Rëchtecken 20-22 (Scans 19, 17, 15; hier drei Rechtecke zusammen) handelt es sich um folgende Stellen: Im alif von Allāh basmala von Q 12 (Sūrat Yūsuf); im lām Vers 1. Im lā am Schluss: Q 12:8; die zwei letzten Wörter (ḍalāl mubìn) des Verses fehlen. 21. Rechteck: In den beiden Punkten am Anfang: Q 12:9. Im $t \bar{a}$ von as-samawāt: Q 12:18; in den beiden Punkten dazu: Anfang von Q 12:19. Der Vers wird nicht beendet. 22. Rechteck: Im wāw am Anfang der Beginn von Q 12:20. Q 12:19 aus dem vorherigen Rechteck ist, soweit ersichtlich, nicht abgeschlossen worden. Am Schluss im 'ayn: Q 12:26 (Ende) und die beiden ersten Wörter von Vers 27.

23. Rechteck (Scan 13; Fortsetzung von Q 2:255): 24. Rechteck (Scan 11): 25. Rechteck (Scan 9): 26. Rechteck (Scan

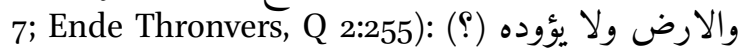
مفظهما وهو العلي العظيم.

Beim Text in $\dot{G} u b \bar{a} r$ in den Rechtecken $23-26$ (Scans 13, 11, 9, 7; hier vier Rechtecke zusammen) handelt es sich um folgende Stellen: Im 23. Rechteck (Scan 13): Q 13 (Sūrat $\left.a r-R a^{\prime} d\right)$ : Im Punkt des nūn zu 'inda: basmala. Dann im 'ayn Vers 1. Am Schluss übergeordnetes aydīhim: Im mìm und den beiden Punkten des $y \bar{a}$ : Q 13:5, nicht ganz fertig. Im 24. Rechteck (Scan 11): Am Anfang Q 13:16. Ganz am Schluss: Q 13:20 (Ende) und Q 13:21 (Anfang). 25. Rechteck (Scan 9): am Anfang Q 13:30 (Beginn). Im alif von samawāt beginnt Q 13:34. Im 26. Rechteck (Scan 7): in wa-l-ard: Q 13:36; am Schluss verteilt im

33 Die Abschrift des Thronverses erstreckt sich über die Rechtecke 20-26. 
mìm, im Punkt des $z \bar{a}^{3}$ und den beiden Punkten des $y \bar{a}^{\prime}$ (alle von al-'azim) der letzte Vers von Q 13 (Vers 43).

27. Rechteck (Scan 5):الله ولى التوفيق. 28. Rechteck (Scan 3-4): قال الله تبارك وتعال : 29 Rechteck

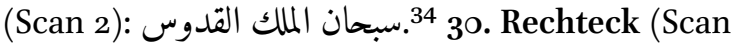

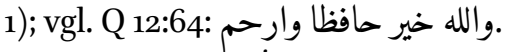

Beim Text in Gubār in den Rechtecken $27-30$ (Scans 5, 4, 3, 2, 1; hier vier Rechtecke zusammen) handelt es sich um folgende Stellen: Im 27. Rechteck (Scan 5): Q 14 (Sūrat Ibrāhìm): Im alif von Allāh die basmala und die Buchstabenfolge alif-lām-ră (Q 14:1); am Ende dieses Rechtecks im qāf von attawfiq: Q 14:9. Am Anfang des 28. Rechtecks (Scan 4): In den beiden Punkten des $q \bar{a} f$ von $q a \bar{l} l a \mathrm{Q}$ 14:23, Text aber wohl mit Lücken (z.B. ohne aṣ-șālihāāt); am Schluss dieses 28. Rechtecks (Scan 3): im alif maqșüra von ta'ālā Q 14:32. Im 29. Rechteck (Scan 2): im sin von subhāna: Q 14:35; der Text springt im Anfangsteil des sin zwischen oberer und unterer Zeile hin und her. Am Ende dieses Rechtecks im sin von al-qudūs: Q 14:43. Im 3o. Rechteck (Scan 1): im fatha des wāw der Ausdruck hawā' (letztes Wort in Q 14:43), dann Q 14:44. In den drei fathas zu arhama am Schluss dieses Rechtecks Text aus Q 14:49-51; der Schluss dieser Sure (Vers 52) nicht gefunden. Im ḥă von hăfiz: basmala von Q 15 (Sūrat al-Hiğr). Dann Q 15:1. Ganz am Schluss dieses letzten Rechtecks: Q 15:14 und Beginn Q 15:15; Text bricht nach sukirat mitten im Vers ab.

Wie soeben aufgezeigt ist der Korantext in den grossen Buchstaben bzw. Wörtern häufig nicht fortlaufend angeordnet (vgl. АВВ. 105-106). Wie-

34 Es fällt auf, dass ganz am Anfang dieses Rechtecks eine Zeile Text in roter und unmittelbar darunter eine Zeile Text in blauer Tinte kopiert worden sind. Dies stellt eine Abweichung gegenüber dem Vorgehen des Kopisten in allen andern Rechtecken dar. Beim roten Text handelt es sich um Q 72:28b, beim blauen um Q 106:4. Bei beiden Stellen handelt es sich um den Schluss der Abschriften der entsprechenden Suren im unmittelbar vorangehenden Quadrat (29. Quadrat, siehe dazu unten bei Anm. 155, auch bei Anm. 92). Dem Schreiber stand im Quadrat unmittelbar davor ganz offensichtlich nicht mehr genügend Platz zur Verfügung, worauf er sich zum soeben geschilderten Vorgehen entschied. derholt lassen sich Bruchstellen erkennen. So kann der Anfang eines Verses in den über dem dazugehörigen Buchstaben angebrachten Diakritika enthalten sein; die Fortsetzung folgt jedoch in einem Vokalisationszeichen, das - wie im Fall des kasras unterhalb der Buchstaben notiert wird. Der Kopist setzt den Korantext darauf u. U. im Buchstabenkörper (rasm) selbst fort. In den einzelnen Kartuschen wurden bei der Abschrift des Texts immer wieder andere Vorgehensweisen gewählt. Die Lektüre dieser Stellen wird damit nicht nur durch die mikroskopische Schrift, sondern gerade auch durch die vertrackte Anordnung des Texts erschwert. Bei der Überprüfung des durch die grossen Schriftzüge gebildeten Texts in diesen 29 Kartuschen zeigte sich, dass am Anfang der Rolle auf zwei - später dann aber auf drei oder vier - Kartuschen verteilt Text aus einer bestimmten Sure kopiert wurde. Die entsprechende Sure ist am Anfang der Rolle in den jeweils zusammengehörenden Rechtecken aber nicht vollständig enthalten, sondern bricht am Ende des letzten Rechtecks einfach ab. Nur Suren 13 und 14 am Schluss der Rolle scheinen nahezu vollständig kopiert worden zu sein. Am Anfang des Dokuments beginnt nach den jeweils zusammengehörenden Kartuschen einfach die nächste Sure mit der basmala. ${ }^{35}$

Auf св 542 laufen um die 3 o rechteckigen Kartuschen herum Schriftbänder mit Korantext (vgl. АВв. 104-106). ${ }^{36}$ Während es im Fall des Genfer Exemplars vier Bänder mit Text in Nash in normal grossem Duktus sind, lassen sich auf dem ähnlich aufgebauten Dokument aus Gotha nur zwei Bänder erkennen. Dieses vierteilige Schriftband beginnt bei der ersten rechteckigen Kartusche mit dem Netzmuster, ${ }^{37}$ wo unmittelbar übereinander

35 Fehlende basmala in Sure 9, die aber als einzige Sure im Koran keine basmala aufweist. Bei der ersten rechteckigen Kartusche mit Korantext bzw. frommen Formeln, die durch Passagen in $\dot{G} u b \bar{a} r$-Schrift entstehen, bildet der übergeordnete Text zugleich die basmala.

36 Vgl. Scans 59-57, für den Anfang der Rolle.

37 Also jene Kartusche, die Q 3 (Sūrat Āl Imrān) enthält, vgl. Anm. 19 und 23-28. 
die vier folgenden Suren mit der basmala einsetzen (vgl. AвB. 104): 1. Rahmen bzw. Band, blaue Tinte: ${ }^{38} \mathrm{Q}_{3} 6, Y \bar{a}-\sin ^{3}{ }^{39}$ sie wird wegen ihres apotropäischen Charakters geschätzt. ${ }^{40}$ 2. Rahmen, goldene Tinte: Q 48, al-Fath..$^{41}$ 3. Rahmen, grüne ${ }^{42}$ Tinte: Q 58, al-Muğādala. 4. Rahmen, rote Tinte: Q 67, al-Mulk.

Diese vier Suren beginnen hier gewissermassen synchron bzw. als vielstimmiger Kanon. Die beiden Bänder mit roter und grüner Schrift fahren jeweils nur um die einzelnen rechteckigen Kartuschen herum. Der darin enthaltene Text springt darauf unter Auslassung der zwischen den Kartuschen angebrachten Quadrate ${ }^{43}$ zum nächsten Rechteck. Das blaue und das goldene Aussenband mit Q 36 und Q 48 bzw. mit weiteren Stellen aus dem Koran in Anschluss daran aber läuft um die ganze Rolle herum und bildet einen Schutzring. ${ }^{44}$

Q 36 wurde in blauer Tinte im linken Aussenband absteigend kopiert. Die Abschrift dieser Sure endet am Anfang der rechteckigen Kartusche mit dem Text الا بعا شاء وسع كرسيه السموات (aus Thronvers, Q 2:255). ${ }^{45}$ Danach beginnt im blauen Aus-

$3^{8}$ Die Farben dürften ausschliesslich ästhetische Funktion haben.

39 Q 36 wurde gerade auf Dokumenten aus osmanischen Kontexten vielfach kopiert, u.a. auf Ms. or. 20 aus der Zentralbibliothek Zürich; vgl. Kapitel 6, bei Anm. 13-19. Vgl. dazu Canaan, Decipherment 131; Sürat Yā-sīn ist auch als Qalb al-Qur'ān bekannt.

Diese grüne Tinte hat den Beschreibstoff an mehreren Stellen angegriffen, was zu Textverlust geführt hat (Kupferfrass).

43 Siehe dazu Text nach Anm. 94.

44 Dadurch entsteht, ähnlich wie auf dem Basler Dokument (vgl. Kapitel 4.8), ein Band, das die gesamte Rolle einfasst. Im Fall von СВ 542 wechselt dieses Band allerdings erst am Schluss von der linken auf die rechte Seite. Es ist nicht wie auf dem Basler Belegstück ineinander verschlungen. Vgl. 25. Rechteck (Scan 9). In dieser Abschrift von Q 36 lassen sich verschiedene Ungereimtheiten feststellen: So fehlt Q 36:49b-53a (auf der Höhe des Rechtecks mit dem Text: وان يكاد الذين كفروا ليزلقونك 16. Rechteck: Scan 27, Q 68:51). Völlig fehlt sodann Q 36:66. Offensichtlich hat der Schreiber übersehen, dass Vers 66 und 67 denselben Anfang haben, und Vers 66 ausgelassen; dies auf der Höhe des 19. Rechtecks (Scan 21; Q 68:52): الا ذك للعالمين. senband Q 39 (Sūrat az-Zumar) mit der basmala. Auch in dieser Sure lassen sich wiederholt Ungereimtheiten feststellen; sie sollen hier allerdings nicht festgehalten werden. Q 39 umfährt unten das Rollenende und steigt auf der gegenüberliegenden Seite im rechten Aussenband wieder nach oben. Ganz am Rollenende steht im blauen Aussenband Q 39:7-8. Der Schreiber erreicht schliesslich wieder den Anfang der Rolle. Am Ende der Kartusche mit der Abschrift von Auszügen aus Q 3 in einem netzartigen Rankenmuster steht im blauen Aussenband zuletzt Q 39:62. ${ }^{46}$ Der Schreiber springt danach in das blaue Aussenband, das das erste Quadrat mit dem auf der Spitze stehenden Viereck im Innern umfährt; hier notiert er im Gegenuhrzeigersinn Q 39:63-65. Die Schlussverse von Q 39 (66-75) fehlen auf der Rolle. ${ }^{47}$

Auf der linken Seite der Rolle wurde auf dem zweiten Textband von aussen Q 48 in goldener Tinte kopiert. Diese Sure endet bereits vor Q 36 . Der Schluss von Q 48 (Vers 29) steht auf der Höhe ger rechteckigen Kartusche mit dem Text: وما 48 Danach beginnt Q 49 "(Sūrat al-Ḥuğurāt) mit der basmala. Auch dieses Band mit der Abschrift von Q 49 umfährt am Schluss die Rolle und steigt auf der gegenüberliegenden rechten Seite des Dokuments wieder nach oben. Ganz am Schluss der Rolle lässt sich in diesem zweiten Aussenband Q 49:11 (Schluss) und am Anfang des aufsteigenden Schriftbands Q 49:12 erkennen. Die Abschrift von Q 49 endet mit dem Schlussvers (Vers 18) unmittelbar unterhalb des وما خلفهم ولا يحيطون بشيء : Rechtecks mit dem Text  zweiten Schriftband von aussen Q 5o (Sūrat Qāf). Q 5 O endet sodann auf der Höhe des Rechtecks

$46 \quad$ Q 39:62 lautet:

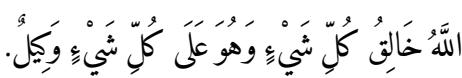

47 Vgl. Scans $5^{8}$ und 59 .

48 Vgl. 22. Rechteck (Scan 15).

49 24. Rechteck (Scan 11). 
mit dem Text 50 Danach beginnt

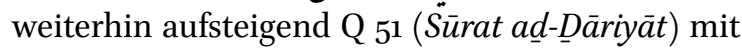
der basmala. Am Schluss dieses goldenen Schriftbands steht rechts aussen aufsteigend Q 51:43a. Danach springt der Schreiber ins erste Quadrat der Rolle und setzt die Abschrift dort im Gegenuhrzeigersinn fort. ${ }^{11}$ Die Abschrift von Q 51 endet mit Vers 47a; der Schluss von Q $5^{1}$ (Vers 47b-6o) fehlt auf der Rolle.

Unmittelbar oberhalb des ersten Zierquadrats am Anfang der Rolle befindet sich ein Titelbalken mit der Überschrift zu Q 36 in roter Tinte. ${ }^{52}$ Ein identisch gestalteter Titelbalken folgt unmittelbar unterhalb dieses ersten Quadrats und enthält in roter Schrift auf goldenem Grund die Überschrift zu Q $48 .^{53}$

Dieses aufwendiger gestaltete Quadrat am Rollenanfang wird später näher vorgestellt. Es steht am Anfang einer Serie von weiteren ähnlichen, aber etwas einfacher gestalteten 15 Quadraten. Diese 16 Quadrate bilden zusammen eine Serie, wie noch aufzuzeigen sein wird. ${ }^{54}$ Vorerst ist auf die Abfolge von 3 o Rechtecken zurückzukommen (1. Rechteck mit dem netzartigen Rankenmuster und die 29 folgenden Rechtecke). Sie werden innen jeweils von zwei zusätzlichen Schriftbändern eingefasst. Der Inhalt dieser beiden Schriftbänder wird im folgenden vorgestellt:

Beim 1. Rechteck mit der Abschrift von Auszügen aus Q 3 in einem netzartigen Rankenmuster beginnen am oberen Ende neben Q 36 und 48 zusätzlich Q $5^{8}$ und 67.55 Diese beiden zusätzlichen grünen bzw. roten Textbänder umfahren die einzelnen Rechtecke. Um das erste Rechteck

$5^{\circ}$ 10. Rechteck (Scan 39; aus Q 21:87).

$5^{1}$ Q 51:43 lautet:

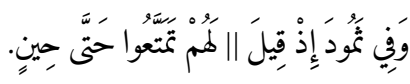

52 Diese Überschrift hält fest: سورة لس مكية وثلث ومثانون آئية

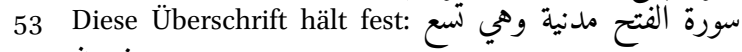
وششرون.

54 Vgl. unten nach Anm. 94.

55 Vgl. Scans 58 und 57 . herum wurde so einerseits Q 58:1-3 (grün) und Q 67:1-6a (rot) im Gegenuhrzeigersinn kopiert. Zurück am Anfang des ersten Rechtecks springt der Kopist ins zweite Rechteck darunter und setzt dort die Abschriften von Q 58 und 67 in den beiden entsprechenden Textbändern fort.

Zwischen diese Rechtecke sind jeweils Quadrate eingefügt worden, die ebenso von zwei Schriftbändern eingefasst werden. Die Schriftbänder um die Quadrate und jene um die Rechtecke enthalten jedoch eine je eigenständige Abfolge von Texten. Deshalb werden hier in einem ersten Durchgang nur die Schriftbänder um die Rechtecke herum vorgestellt: ${ }^{56}$

So steht im grünen Textband um das 2. Rechteck $^{57}$ zuerst das letzte Wort von Q 58:3 (habir). Danach folgen in diesem Rechteck die Verse 58:46a. Im roten Schriftband stehen hier Q 67:6b12a. Um das 3. Rechteck ${ }^{58}$ steht im grünen Schriftband Q 58:6 (Schluss)-8a. Im roten Schriftband folgen Q 67:12b-19 (Anfang). 4. Rechteck:59 grünes Schriftband: Q 58:8b-10a; rotes Schriftband: Q 67:19-23a. 5. Rechteck:60 grünes Schriftband: Q 58:1ob-12a; rotes Schriftband: Q 67:23b-28:61 6. Rechteck: ${ }^{62}$ grünes Schriftband: Q 58:12b-14; rotes Schriftband: Q 67:28 (Schluss)-30. ${ }^{63}$ Unmittelbar darauf beginnt Q 68 (Sūrat al-Qalam) mit der basmala; es folgen die Verse 1-6a. 7. Rechteck $^{64}$ : grünes Schriftband: Q 58:14 (Schluss)-18;

56 Die Schriftbänder um die Quadrate herum folgen später; siehe dazu unten nach Anm. 96.

57 Vgl. Scan 55; der Text in diesem Rechteck lautet: بسم الرحم الله الرحمن الرحميح.

58 Vو. Scan 53; der Text in diesem Rechteck lautet: هو الله سبحانه تعالى وتقدس.

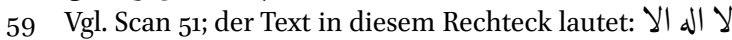
الله الملك الحت المبين.

6o Vgl. Scan 49; der Text in diesem Rechteck lautet: ومبن المان [النصر الا من عند الله العزيز الحكيم.

61 Der Schlussteil von al-käfirìn steht in roter Tinte im grünen Schriftband.

62 Vgl. Scan 47 der Text in diesem Rechteck lautet: فسيكفيكك الله

63 Vers 30: Schlussvers dieser Sure.

64 Vgl. Scan 45; der Text in diesem Rechteck lautet: هو السميع العليم. 
rotes Schriftband: Q 68:6b-18a. ${ }^{65}$ 8. Rechteck:66 grünes Schriftband: Q 58:18 (Schluss)-22a; rotes Schriftband: Q 68:18b-28. 9. Rechteck: ${ }^{67}$ grünes Schriftband: Q 58:22b (Schlussvers der Sure); darauf beginnt Q 59 (Sūrat al-Hašr) mit der basmala, es folgen Verse 1-2 (Anfang). Rotes Schriftband: Q 68:29-37. 10. Rechteck:68 grünes Schriftband; Q 59:2-4a; rotes Schriftband: Q 68:38-44 (Anfang). 11. Rechteck:69 grünes Schriftband: Q 59:4b-7a; rotes Schriftband: Q 68:44-5o. 12. Rechteck: ${ }^{70}$ grünes Schriftband: Q 59:7b-9a; rotes Schriftband; Q 68:51-52 (Schlussvers) und Q 69:1-7a (Sūrat alHāqa; Beginn mit der basmala). 13. Rechteck: ${ }^{71}$ grünes Schriftband: Q 59:9b-11a; rotes Schriftband: Q 69:7b-13a. 14. Rechteck: ${ }^{72}$ grünes Schriftband: Q 59:11b-13; rotes Schriftband: Q 69:13b20. 15. Rechteck:73 grünes Schriftband: Q 59:1418a; ${ }^{74}$ rotes Schriftband: Q 69:21-32a. 16. Rechteck: ${ }^{75}$ grünes Schriftband: Q 59:18b-22a; rotes Schriftband: Q 69:32b-43a. 17. Rechteck: ${ }^{76}$ grünes

65 Dem Kopisten unterlief hier beim Abschreiben ein Fehler. Er ergänzte die ausgelassenen Wörter einfach im Mittelstreifen in roter Tinte.

66 Vgl. Scan 43; der Text in diesem Rechteck lautet: الله مغتح

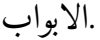

67 Vgl. Scan 41; der Text in diesem Rechteck lautet: سبحانك الوانك

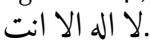

68 Vgl. Scan 39; der Text in diesem Rechteck lautet: اني كنت الطين من الظالمين

69 Vgl. Scan 37; der Text in diesem Rechteck lautet: فإلمنا عزمت فتوكل على الله.

70 Vgl. Scan 35; der Text in diesem Rechteck lautet: ان فتله يكب المتو كلين.

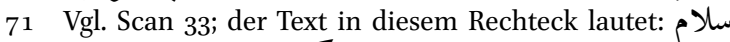
عليك طبتم فادخلو ها خالدين.

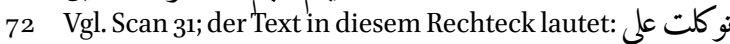
الحي الذي لا يموت

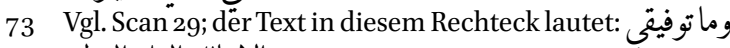
الا بالله العلى العظيح.

74 Der Köpist hat offensichtlich Vers 15 übersehen und ihn nachträglich in grüner Tinte im Mittelstreifen notiert; Vers 15 lautet:

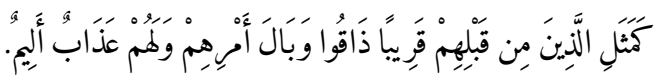

75 Vgl. Scan 27; der Text in diesem Rechteck lautet: وان الذين كفروا ليزلقونك.

76 Vgl. Scan 25; der Text in diesem Rechteck lautet:

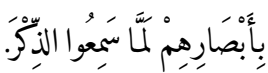

Schriftband: Q 59:22b-24 (Schlussvers); danach folgt Q 6o:1 (Anfang; Sūrat al-Mumtahina, Beginn mit der basmala). Rotes Schriftband: Q 69:43b$5^{2}$ (Schlussvers); danach folgt Q 70:1-2a (Sürat al-Mírāğ; Beginn mit der basmala). 18. Rechteck: ${ }^{77}$ grünes Schriftband: Q 6o:1-2a; rotes Schriftband: Q 70:2b-13. 19. Rechteck:78 grünes Schriftband: Q 60:2b-4a; rotes Schriftband: Q 70:14-27a. 20. Rechteck: ${ }^{79}$ grünes Schriftband: Q 6o:4b-7a; rotes Schriftband: Q 70:27b-34. 21. Rechteck: ${ }^{80}$ grünes Schriftband: Q 6o:7b-9;81 rotes Schriftband: Q 70:35-42a. 22. Rechteck:82 grünes Schriftband: Q 6o:9 (Schluss)-10; rotes Schriftband: Q 70:42b44 (Schlussvers); danach folgt Q 71:13a (Sürat Nūh, Beginn mit der basmala). 23. Rechteck:83 grünes Schriftband: Q 60:10 (Schluss)-12a; rotes Schriftband: Q 71:3b-8. 24. Rechteck: ${ }^{84}$ grünes Schriftband: Q 6o:12b-13 (Schlussvers); danach folgt Q 61:1-2a (Sūrat aș-Ṣaff, Beginn mit der basmala); rotes Schriftband: Q 71:8-15.25. Rechteck:85 grünes Schriftband: Q 61:2b-5; rotes Schriftband: Q 71:16-22. 26. Rechteck:86 grünes Schriftband: Q 61:6-8; rotes Schriftband: 71:23 ${ }^{87}-28$ a. 27. Recht-

77 Vgl. Scan 23; der Text in diesem Rechteck lautet:

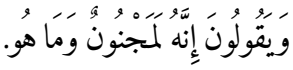

78 Vgl. Scan 21; der Text in diesem Rechteck lautet: الا ذكر للمالمين.

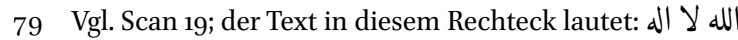

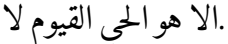

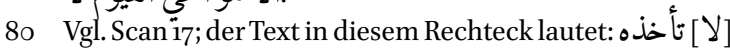
سنة ولا نوم له مافي السموات

81 Mit Ergänzung eines vergessenen Textteils aus Vers 9 im goldenen Aussenband.

82 Vgl. Scan 15; der Text in diesem Rechteck lautet: وما في الارض من ذي [ كذا] يشفع.

83 Vgl. Scan 13; der Text in diesem Rechteck lautet: عنده كن الأرض بإذنه يعلم ما بين ايديهم

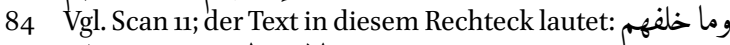
ولا يحيطون بشىء من علمه

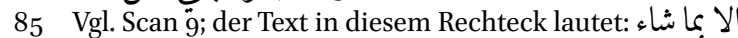
وسع كرسيه السموات

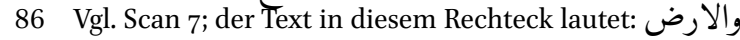
الا يؤوده (؟) حفظهما وهو العلى لبغظيم.

87 Ein Teîl des Verses ist in roter Tinte im Mittelstreifen notiert. 
eck:88 grünes Schriftband: Q 61:8 (Schluss)-12a; rotes Schriftband: Q 71:28 (Schlussvers); danach folgt Q 72:1-5a (Sürat al-Ǧinn; Beginn mit der basmala). 28. Rechteck:89 grünes Schriftband: Q 61: 12b-14; rotes Schriftband: Q 72:5b-10a. 29. Rechteck:90 grünes Schriftband: Q 61:14 (die beiden Schlusswörter); danach folgt Q 62:1-4a (Sūrat alĞum'a, Beginn mit der basmala); rotes Schriftband: Q 72:10b-14a. Im Mittelstreifen dieses Rechtecks zusätzlicher roter und blauer Text; vgl. dazu oben bei Anm. 34 und unten bei Anm. 155 (Ausführungen zum 29. Quadrat). 30. Rechteck:91 grünes Schriftband: Q 62:4b-6a; rotes Schriftband: Q 72:14b-19a. Q 72 wird danach im 26. Quadrat, also nicht mehr in einem weiteren Rechteck, fortgesetzt. $^{92}$

Bevor im folgenden diese Quadrate selbst vorgestellt werden, ist auf die Balken aufmerksam zu machen, die Überschriften zu ausgewählten Suren enthalten. Es lässt sich dabei unterscheiden zwischen:

a. Titelbalken mit Überschriften in roter Tinte: Unmittelbar vor und direkt in Anschluss an die Quadrate mit Text in geometrisierendem Kufi befindet sich jeweils ein Balken von etwa $1 \mathrm{~cm}$ Höhe. Diese Balken weisen innen eine goldene Kartusche auf; links und rechts ist der Hintergrund des Balkens blau und mit einem einfachen goldenen Rankenmuster versehen. In diesen zu den Quadraten mit Text in Schachbrett-Kufi gehörenden Titelbalken wurden die Surentitel (und Angaben zu Offenbarungsort und Anzahl Verse) auf dem goldenen Hintergrund in roter Farbe notiert. Diese 16 Quadrate mit Text in Schachbrett-Kufi

88 Vgl. Scan 5; der Text in diesem Rechteck lautet: الله ولي التوفيق.

89 Vgl. Scans 4 und 3; der Text in diesem Rechteck lautet: قال فين الله تبارك وتعالى

90 Vgl. Scan 2; der Text in diesem Rechteck lautet: سبحارك

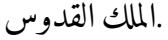

91 Vgl. Scan 1; der Text in diesem Rechteck lautet: والله خئ حافظا وارحم.

92 Die Fortsetzung von Q 72 folgt in den Quadraten; siehe dazu vor Anm. 155 . werden in der anschliessenden Zusammenstellung mit dem Kürzel GK kenntlich gemacht, also z.B. $1\left(\mathrm{GK}^{93}\right)$.

b. Titelbalken mit Überschriften in grüner Tinte: Auf dem Dokument gibt es ausserdem 13 Zellenquadrate. Auch vor und nach ihnen befindet sich ein Titelbalken mit einer goldenen Kartusche im Innern. In dieser Kartusche stehen ein Surentitel und gegebenenfalls weitere Angaben in grüner Tinte. Dieser grüne Text lässt sich auf dem goldenen Hintergrund oft nur noch schlecht lesen.

Verschiedene dieser in den Titelbalken aufgeführten Suren sind auf der Rolle tatsächlich enthalten. Andere scheinen zu fehlen. Indem der Kopist hier wenigstens ihren Titel erwähnt, hoffte er wohl, sie implizit dennoch in sein Dokument zu integrieren. ${ }^{94}$ Diese Titel der einzelnen Suren werden im folgenden bei der Diskussion des Inhalts der jeweiligen Quadrate aufgeführt.

Die Quadrate: Die weiteren Ausführungen stellen die bereits erwähnten Quadrate und ihren Inhalt vor. Das besonders aufwendig gestaltete Zierquadrat am Anfang des Dokuments ist bereits zuvor erwähnt worden (АВВ. 103). Es enthält ein zweites, auf der Spitze stehendes Viereck mit der Inschrift Allāh al-azama (sic) in geometrisierendem Kufi. Dieses erste Zierquadrat wird von drei Zierbändern mit Korantext eingefasst (blaugolden-rot). Später folgen nach jeweils zwei rechteckigen Kartuschen 15 weitere Quadrate in einfacherer Ausführung in normaler Stellung. ${ }^{95}$ Sie enthalten, ebenso in geometrisierendem Kufi, die Wendung al-'azama li-[A]llāh („Die Erhabenheit ist Gottes“). Es gibt also auf dieser Rolle insgesamt 16 Quadrate mit Text in Schachbrett-Kufi.

Die beiden zwischen den Quadraten mit der Inschrift al-'azama li-[A]llāh liegenden Rechtecke werden jeweils durch Quadrate mit $3 \times 3$ Zellen

93 GK steht für geometrisierendes Kufi.

94 Eine Aufzählung der Titel folgt in der Zusammenstellung der Quadrate. Die Überschriften in roter Tinte sind leicht zu lesen; die grünen Titel sind auf dem goldenen Hintergrund wiederholt nur schwer erkenntlich.

95 Nur noch das dritte Quadrat mit Text in Schachbrett-Kufi steht auf der Spitze. 
voneinander getrennt. ${ }^{96}$ Auf der Rolle gibt es insgesamt 13 Vierecke, die im Innern Zellenquadrate enthalten. Diese Zellenquadrate werden in der folgenden Übersicht in Anschluss an die Nummer durch das Kürzel zQ kenntlich gemacht, z.B. 4 (zQ).

Ein doppeltes Schriftband mit Korantext in normaler Schriftgrösse in den Farben Blau und Rot fasst sämtliche Quadrate, also sowohl jene mit der Inschrift al-'azama li-[A]llāh als auch die Zellenquadrate, ein. ${ }^{97}$ Bei den Zellenquadraten ist der Text im äusseren Band zumeist rot. Im innern Band blau. Bei den Quadraten mit Text in geometrisierendem Kufi ist es zumeist umgekehrt. Der Text der islamischen Offenbarung springt jeweils unter Auslassung der bereits zuvor analysierten Rechtecke von Quadrat zu Quadrat. ${ }^{98}$ Es gibt auf diesem Dokument insgesamt 29 Quadrate, 16 (GK) + 13 (ZQ). Die folgende Übersicht listet den Inhalt der einzelnen Quadrate auf:

1. Quadrat (GK) am Rollenanfang, aufwendige Ausführung (АВВ. 103):99 Es wird von drei Text-

96 Auf der Rolle sind insgesamt 14 solche Zellenquadrate vorhanden. Das erste umfasst $4 \times 4$ Zellen, alle andern $3 \times 3$ Zellen. Die einzelnen Zellen enthalten ausgewählte Schöne Namen Gottes. Sie sind hier von rechts oben nach links unten (schwarze Tinte) bzw. von rechts unten nach links oben (rote Tinte) notiert worden. Diese Begriffe sind in normal grosser Schrift geschrieben; vgl. auch Anm. 24

97 Der Text ist teilweise von Quadrat zu Quadrat abwechselnd auf dem inneren Band rot und auf dem äusseren Band blau kopiert; danach innen blau, aussen rot. Dies wurde allerdings nicht konsequent umgesetzt.

98 Zellenquadrate kommen auf Dokumenten in Rollenform häufig vor. Auf св 542 sind aber keine Buchstaben- oder Zahlenquadrate (wafq) enthalten, wie sie aus der magischen Literatur bekannt sind. Es gibt aber durchaus Rollen mit Buchstaben- und Zahlenquadraten (vgl. Is 1624: Kapitel 4.6, bei Anm. 214-219; Is 1625: Kapitel 4.7, nach Anm. 174). Die von Tezcan, Tilısmlılı Gömlekler, untersuchten Schutzhemden enthalten oft Buchstaben- und Zahlenquadrate. Zu diesen Quadraten vgl. Sesiano, Wafk, in $E I^{2}$ (mit Literaturangaben); Canaan, Decipherment 79, 92, 98-110; Doutté, Magie et religion 191-195; El-Gawhary, Gottesnamen 184-197. Cammann, Magic squares, mit Angaben der Sekundärliteratur in Teil 1, 181 (Anm. 1).

99 Vgl. Scan 59; für die kunsthistorische Würdigung dieses Quadrats mit dem Text Allāh al-'azama (sic) und des Anfangszierfelds davor vgl. bei Anm. 7-10. bändern eingefasst. a. Im blauen Band zuäusserst steht Q 39:63-65; dies ist die Fortsetzung des Texts im blauen Aussenband auf der rechten Seite des 1. Rechtecks darunter (Rechteck mit netzartigem Rankenmuster). ${ }^{100} \mathrm{~b}$. Im goldenen Band steht Q 51:43-47; es handelt sich um die Fortsetzung des Texts im goldenen, aufsteigenden Aussenband auf der rechten Seite des Rechtecks darunter. ${ }^{101} \mathrm{c}$. im roten Band zuinnerst steht Q 78:1-7 (Sürat an$N a b a$, beginnend mit basmala), Fortsetzung beim 2. Quadrat (GK). Titelbalken davor: Sürat Yā-sin (Q 36);102 danach Sūrat al-Fath (Q 48).103

2. Quadrat (GK):104 Ab hier werden die Quadrate von zwei Schriftbändern (blau und rot) eingefasst: a. Im blauen Schriftband (aussen) steht Q 86:1-7a (Sūrat at-Ṭāriq, Beginn mit basmala). b. Im roten Schriftband (innen) steht Q 78:8-13 (Fortsetzung des roten Textbands im 1. Quadrat). Titelbalken: davor: Grüne Tinte auf goldenem Grund; erkennen lässt sich nur Sūrat, der Rest ist unleserlich. Danach: rote Tinte auf goldenem Grund: Sūrat al-Mulk makkiyya wa-talätūn (sic). Es handelt sich um Q 67, die 30 Verse hat. ${ }^{105}$

3. Quadrat (GK): ${ }^{106}$ In diesem Quadrat steht das Viereck mit dem Eintrag al-'azama li-[A]llāh nochmals auf der Spitze. a. Im blauen Schriftband (aussen) steht Q 86:7b-14 (Fortsetzung von a. im 2. Quadrat). b. Im roten Schriftband (innen) steht Q 78:14-18 (Fortsetzung von b. im 2. Quadrat). Titelbalken in roter Schrift auf goldenem Hin-

100 Die Schlussverse von Q 39 (Verse 66-75) fehlen auf der Rolle.

101 Vers 47: Die kopierte Stelle bricht kurz vor Schluss des Verses ab. Die Schlussverse (Q 51:48-6o) fehlen.

102 Die Abschrift von Q 36 beginnt beim 1. Rechteck, vgl. nach Anm. 47. Zum ganzen Eintrag im Titelbalken siehe bei Anm. $5^{2}$.

103 Die Abschrift von Q 48 beginnt beim 1. Rechteck, vgl. nach Anm. 47. Zum ganzen Eintrag im Titelbalken siehe Anm. 53 .

104 Vgl. Scan 56.

105 Vgl. zur Abschrift von Q 67 auf der Rolle bei Anm. 5563.

106 Vgl. Scan 54. 
tergrund. Davor: Sūrat al-Mã̀ida wa-hiya madaniyya (Q 5). ${ }^{107}$ Danach Sūrat al-An'ām makkiyya wa-hiya ${ }^{108}(\mathrm{Q} 6) .{ }^{109}$

4. Quadrat (zQ): ${ }^{110}$ Quadrat mit $4 \times 4$ Zellen. In den Zellen wurden Anrufungen Gottes in rotem und schwarzem Nash notiert. Diese Anrufungen enthalten 16 Attribute Gottes, die von seinen Schönen Namen bekannt sind. Der Text in roter Tinte verläuft in den Quadraten von rechts unten nach links oben; der schwarze Text von rechts oben nach links unten. a. Im roten Schriftband (aussen) steht Q 78:19-24 (Fortsetzung von b. im 3. Quadrat); im blauen Schriftband (innen) steht Q 86:15-18 (Schlussvers), es folgt Q 87:1-2a (Fortsetzung von a. beim 3. Quadrat; Q 87: Sūrat al-A`ā ). Titelbalken in grüner Tinte auf goldenem Hintergrund. Davor: Sūrat al-A'rāf makkiyya wa (Q 7); danach: Sūrat alAnfāl madaniyya (Q 8).111

5. Quadrat (GK): ${ }^{12}$ a. Im blauen Schriftband (aussen) steht Q 87:2b-9a (Fortsetzung von b. im 4. Quadrat); b. Im roten Schriftband (innen) steht Q 78:25-30a (Fortsetzung von a. im 4. Quadrat). Titelbalken in roter Tinte auf goldenem Grund: Davor: Sūrat at-Tawba madaniyya wa-hiya (Q 9); danach: Sūrat Yūnus makkiyya wa-hiya (Q 10). ${ }^{113}$

6. Quadrat (zQ): ${ }^{114}$ Quadrat mit $3 \times 3$ Zellen. In den Zellen wurden Anrufungen Gottes in rotem und schwarzem Nash notiert (zumeist zwei Anrufungen). Diese Anrufungen enthalten weitere Attribute Gottes, die von seinen Schönen Namen bekannt sind. Der Text in roter Tinte verläuft in

107 Ein Auszug aus Q 5 war in den Stellen in $\dot{G} u b \bar{a} r$ im 4. Rechteck kopiert worden; vgl. zwischen Anm. 31 und 32.

108 Der Platz zur Angabe der Verszahl fehlte hier offensichtlich. Rechteck kopiert worden; vgl. zwischen Anm. 31 und 32. Vgl. Scan $5^{2}$.

Beide Titel schlecht lesbar (grüne Tinte auf goldenem Hintergrund); dem Schreiber fehlte der Platz für die vollständigen Zusatzinformationen.

Vgl. Scan 5 o.

Der Platz für sämtliche Angaben fehlt auch in diesen Kartuschen.

Vgl. Scan 48. den Quadraten von rechts unten nach links oben; der schwarze Text läuft von rechts oben nach links unten. a. Im roten Schriftband (aussen) steht Q 78:3ob-37a (Fortsetzung von b. im 5. Quadrat); im blauen Schriftband (innen) steht Q 87:9b-14 (Fortsetzung von a. im 5. Quadrat). Titelbalken in grüner Tinte auf goldenem Hintergrund: Die beiden Titel sind hier nicht mehr lesbar; mutmasslich stehen hier die Überschriften zu Q 11 (Sūrat Hūd) und 12 (Sūrat Yūsuf).

7. Quadrat (GK): $:^{115}$ a. Im blauen Schriftband (aussen) steht Q 87:15-19 (Schlussvers), es folgt Q 88:1 (Sūrat al-Ġāšiya, mit basmala); dies alles ist Fortsetzung von b. im 6. Quadrat. b. Im roten Schriftband (innen) steht Q 78:37b-39a (Fortsetzung von a. im 6. Quadrat). Titelbalken: Text in roter Tinte auf goldenem Hintergrund. Davor: Sūrat ar-Ra'd makkiyya wa-hiya (?) țalat (sic) (Q 13); danach: Sūrat Ibrāhìm makkiyya wa-itnā (sic) (Q 14). ${ }^{116}$

8. Quadrat (zQ):117 Quadrat mit $3 \times 3$ Zellen; für eine Beschreibung vgl. 6. Quadrat. ${ }^{118}$ a. Im roten Schriftband (aussen) steht Q 78:39-40 (Schlussvers); es folgt Q 79:1 (Sūrat an-Nāzicāt, Beginn mit basmala). b. Im blauen Band (innen) steht Q 88:1b7a. Titelbalken: Text in grüner Tinte auf goldenem Hintergrund, kaum mehr erkenntlich; es muss sich um die Überschriften von Q 15 und 16 handeln. Q 15: Sūrat al-Hiğr; Q 16: Sūrat an-Nahl.

9. Quadrat (GK): ${ }^{119}$ Der Text in geometrisierendem Kufi erscheint hier in rot eingefassten goldenen Buchstaben auf einem blauen Hintergrund; in diesem Feld wurden also die Farben von Schrift und Hintergrund vertauscht. a. Im blauen Schriftband (aussen) steht Q 88:7b-15a; b. im roten Schriftband (innen) steht Q 79:1b-9 (jeweils Fortsetzungen der Stellen im 8. Quadrat). Titelbalken: Text in roter Tinte auf goldenem Hintergrund.

\footnotetext{
115 Vgl. Scan 46.

116 Erneut fehlt der Platz für sämtliche Zusatzinformationen.

117 Vgl. Scan 44.

118 Siehe nach Anm. 114.

119 Vgl. Scan 42.
} 
Davor Sūrat Banī Isrā̄il makkiyya wa-mia (Q 17); danach: Sūrat al-Kahf makkiyya wa-hiya ? (ein Wort unleserlich; Q 18).

10. Quadrat (zQ): ${ }^{120}$ Quadrat mit $3 \times 3$ Zellen; für eine Beschreibung vgl. 6. Quadrat. ${ }^{121}$ a. Im roten Schriftband (aussen) steht Q 79:10-16a; im blauen Schriftband (innen) steht Q 88:15b-20a (jeweils Fortsetzung der Stellen im 9. Quadrat). Titelbalken: Text in grüner Tinte auf goldenem Hintergrund (schlecht leserlich): Davor: Sūrat Maryam (Q 19); danach: Sūrat Țā-Hā (Q 20).

11. Quadrat (GK): ${ }^{122}$ Der Text in geometrisierendem Kufi erscheint hier in rot eingefassten goldenen Buchstaben auf einem blauen Hintergrund (wie Quadrat 9); in diesem Feld wurden also die Farben von Schrift und Hintergrund vertauscht. a. Im blauen Schriftband (aussen) steht Q 88:2ob26 (Schlussvers); im blauen Schriftband (innen) steht Q 79:16b-22a (jeweils Fortsetzung der Stellen im 1o. Quadrat). Titelbalken: Text in roter Tinte auf goldenem Hintergrund. Davor: Sūrat al-Ğinn makkiyya wa-tamānī (Q 72); danach: Sūrat al-Hağğ madaniyya wa-hiya tamān (Q 22). Hier wird die übliche Abfolge der Koransuren unterbrochen; der Titel von Q 72 (Sürat al-Ğinn) ist klar leserlich.

12. Quadrat (zQ): ${ }^{123}$ Quadrat mit $3 \times 3$ Zellen; für eine Beschreibung vgl. 6. Quadrat. ${ }^{124}$ Im blauen Schriftband (aussen) steht Q 90:1-5a (Sūrat alBalad, Beginn mit basmala); ${ }^{125}$ im roten Schriftband (innen) steht Q 78:22b-27 (jeweils Fortsetzung der Stellen im 11. Quadrat). Titelbalken: Text in grüner Tinte auf goldenem Hintergrund (schlecht leserlich): Davor: Sürat al-Mu'min (Q 23); danach: grundsätzlich müsste hier Q 24 folgen (Sürat an-Nūr), dieser Titel lässt sich aber nicht mehr lesen.

\footnotetext{
120 Vgl. Scan 40.

121 Siehe nach Anm. 114

122 Vgl. Scan 38.

123 Vgl. Scan 36.

124 Siehe nach Anm. 114.

125 Nach dem bisherigen Vorgehen des Kopisten würde man hier Q 89 erwarten; sie fehlt aber an dieser Stelle. Hier beginnt Q 90 mit der basmala.
}

13. Quadrat (GK): ${ }^{126}$ Die Formel al-'azama li[A]llāh steht hier in rot eingefassten blauen Buchstaben auf einem goldenen Hintergrund. a. Im blauen Schriftband (aussen) steht Q 90:5b-13a; im roten Schriftband (innen) steht Q 79:27 (Schluss)32 (jeweils Fortsetzung der Stellen im 12. Quadrat). Titelbalken: Text in roter Tinte auf goldenem Hintergrund. Davor: Sūrat al-Furqān makkiyya wasab' (Q 25); danach: Sūrat aš-Šu'arā’ makkiyya wamiatān (Q 26). ${ }^{127}$

14. Quadrat (zQ; ABB. 107):128 Quadrat mit $3 \times 3$ Zellen; für eine Beschreibung vgl. 6. Quadrat. ${ }^{129}$ In der Hauptdiagonale von rechts oben nach links

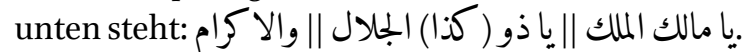
a. Im roten Schriftband (aussen) steht Q 79:33-39; im blauen Schriftband (innen) steht Q 9o:13b-17 (jeweils Fortsetzung der Stellen im 13. Quadrat). Titelbalken: Text in grüner Tinte auf goldenem Hintergrund, unleserlich. Grundsätzlich müssten hier die Titel von Q 27 und 28 folgen (Sürat anNaml bzw. Sūrat al-Qașaș).

15. Quadrat (GK): ${ }^{130}$ Die Wendung al-'azama li-[A]llāh steht hier in rot eingefassten blauen Buchstaben auf goldenem Hintergrund. Im blauen Schriftband (aussen) stehen hier Q 90:17-20 (Schlussvers); es folgt Q 91:1-2 (Sūrat aš-Šams, Beginn mit basmala). Im roten Schriftband (innen) steht Q 79:39 (Schluss)-43a (jeweils Fortsetzung der Stellen im 14. Quadrat). Titelbalken: Text in roter Tinte auf goldenem Hintergrund, davor: Sūrat al-Ankabūt makkiyya wa (Q 29); danach: Sūrat ar-Rūm makkiyya wa-hiya (Q 30).

16. Quadrat (zQ): ${ }^{131}$ Quadrat mit $3 \times 3$ Zellen; für eine Beschreibung vgl. 6. Quadrat. ${ }^{132}$ a. Im roten Schriftband (aussen) steht Q 79:43b-46 (Schlussvers); es folgt die basmala zur nächsten Sure (vgl.

\footnotetext{
126 Vgl. Scan 34.

127 Dem Schreiber steht in diesen Titelbalken weiterhin zu wenig Platz zur Verfügung, um sämtliche Zusatzinformationen einzufügen. 
17. Quadrat, hier noch kein Surentext). b. Im blauen Schriftband (innen) steht Q 91:3-8 (jeweils Fortsetzung der Stellen im 15. Quadrat). Titelbalken: Text in grüner Tinte auf goldenem Hintergrund, unleserlich. Grundsätzlich müssten hier die Titel von Suren 31 und 32 folgen (Sūrat Luqmān bzw. Sūrat as-Sağda).

17. Quadrat (GK): ${ }^{133}$ Die Wendung al-'azama li$[A] l l a \bar{h}$ in rot eingefassten blauen Buchstaben auf goldenem Hintergrund. a. Im blauen Schriftband (aussen) steht Q 91:9-14a; im roten Schriftband (innen) steht Q 80:1-7a (Sūrat 'Abasa, die basmala dazu steht bereits im 16. Quadrat; jeweils Fortsetzung der Stellen im 16. Quadrat). Titelbalken: Text in roter Tinte auf goldenem Hintergrund. Davor: Sūrat al-Ahzāb madaniyya wa-talāt (Q 33); danach: Sūrat Saba' makkiyya wa-arba' (Q 34).

18. Quadrat (zQ): ${ }^{134}$ Quadrat mit $3 \times 3$ Zellen; für eine Beschreibung vgl. 6. Quadrat. ${ }^{135}$ a. Im roten Schriftband (aussen) steht Q 8o:7b-16a; im blauen Schriftband (innen) steht Q 91:14b-15 (Schlussvers), es folgt Q 92:1-3a (Sūrat al-Layl, Beginn mit der basmala; jeweils Fortsetzung der Stellen im 17. Quadrat). Titelbalken: Text in grüner Tinte auf goldenem Hintergrund, unleserlich. Grundsätzlich müssten hier die Titel von Q 35 und 37 folgen (Sūrat al-Malāika bzw. Sūrat aṣ-Ṣâffāt). ${ }^{136}$

19. Quadrat (GK):137 Die Wendung al-'́azama li$[A]$ llāh in rot eingefassten blauen Buchstaben auf goldenem Hintergrund. a. Im blauen Schriftband (aussen) steht Q 92:3b-10a; im roten Schriftband (innen) steht Q 8o:16b-22 (jeweils Fortsetzung der Stellen im 18. Quadrat). Titelbalken: Text in roter Schrift auf goldenem Hintergrund. Davor: Sūrat

\footnotetext{
133 Vgl. Scan 26.

134 Vgl. Scan 24

135 Siehe nach Anm. 114

136 Es ist davon auszugehen, dass der Titel von Q 36 (Sūrat $Y \bar{a}-\sin )$ hier fehlt. Dieser Titel steht bereits ganz am Anfang der Rolle. Der Surentext beginnt dann auch unmittelbar über dem ersten Rechteck am Anfang der Rolle. Siehe auch Q $3^{8}$ als nächster Text beim 19. Quadrat gerade anschliessend.

Șād makkiyya wa-țamān (Q 38); danach: Sūrat azZumar makkiyya wa-hams wa (Q 39).

2o. Quadrat (zQ): ${ }^{138}$ Quadrat mit $3 \times 3$ Zellen; für eine Beschreibung vgl. 6. Quadrat. ${ }^{139}$ a. Im roten Schriftband (aussen) steht Q 80:23-30a; im blauen Schriftband (innen) steht (Q 92:10b-15; jeweils Fortsetzung der Stellen im 19. Quadrat). Titelbalken: Text in grüner Tinte auf goldenem Hintergrund, unleserlich. Grundsätzlich müssten hier die Titel von Q 40 und 41 folgen (Sürat $\dot{G} \bar{a} f i r$ bzw. Sūrat Fușsilat).

21. Quadrat (GK): ${ }^{140}$ Die Wendung al-'azama $l i-[A] l l a \bar{h}$ in rot eingefassten goldenen Buchstaben auf blauem Hintergrund. a. Im blauen Schriftband (aussen) steht Q 92:16-21 (Schlussvers); es folgt noch die basmala zur nächsten Sure. b. Im roten Schriftband (innen) steht Q 80:30b-37a. Titelbalken: Text in roter Tinte auf goldenem Hintergrund. Davor: Sūrat aš-Šūrā makkiyya wa-țalāt (Q 42); danach: Sūrat az-Zuhruf makkiyya wa-tisa wa-țamānūn (Q 43).

22. Quadrat (zQ): ${ }^{141}$ Quadrat mit $3 \times 3$ Zellen; für eine Beschreibung vgl. 6. Quadrat. ${ }^{142}$ a. Im roten Schriftband (aussen) steht Q 8o:37b-42 (Schlussvers); es folgt noch die basmala zur nächsten Sure (ohne Surentext); b. Im blauen Schriftband (innen) steht Q 93:1-6a (Sūrat aḍ-Dūhāa). Titelbalken: Text in grüner Tinte auf goldenem Hintergrund, unleserlich. Grundsätzlich müssten hier die Titel von Q 44 und 45 folgen (Sūrat ad-Duhān bzw. Sūrat alĞätiya).

23. Quadrat (GK): ${ }^{143}$ Die Wendung al-'azama li$[A]$ llăh in rot eingefassten blauen Buchstaben auf goldenem Hintergrund. a. Im roten Schriftband (aussen) steht Q 81:1-9a (Sūrat at-Takwìr, basmala bereits im vorangehenden Quadrat); im blauen Schriftband (innen) steht Q 93:6b-11 (ohne letztes Wort). Titelbalken: Text in grüner Tinte auf

\footnotetext{
138 Vgl. Scan 20.

139 Siehe nach Anm. 114.

140 Vgl. Scan 18.

141 Vgl. Scan 16.

142 Siehe nach Anm. 114.

143 Vgl. Scan 14.
} 
goldenem Hintergrund, unleserlich. Grundsätzlich müssten hier die Titel von Q 46 und 47 folgen (Sūrat al-Aḥqāf bzw. Sūrat Muḥammad).

24. Quadrat (zQ): ${ }^{144}$ Quadrat mit $3 \times 3$ Zellen; für eine Beschreibung vgl. 6. Quadrat. ${ }^{145}$ a. Im roten Schriftband (aussen) steht Q 81:9b-19. Im blauen Schriftband (innen) steht Q 93:11 (letztes Wort); es folgt Q 94:1-5a (Sūrat aš-Šarh, Beginn mit basmala). Titelbalken: Text in grüner Tinte auf goldenem Hintergrund, unleserlich.

25. Quadrat (GK): ${ }^{146}$ Die Wendung al-'azama li-[A]llāh in rot eingefassten goldenen Buchstaben auf blauem Hintergrund. a. Im blauen Schriftband (aussen) steht Q 94:5b-8 (Schlussvers); es folgt Q 95:1-4a (Sürat at-Tìn, Beginn mit basmala). Im roten Schriftband (innen) steht Q 81:20-25a. Titelbalken: Text in roter Tinte auf goldenem Hintergrund, davor: Sūrat Wa-ț-Tür makkiyya tisa' waarbaūn (Q 52); danach: Sūrat wa-n-Nağm makkiyya wa-sittūn āya (kad̄ā).

26. Quadrat(zQ): ${ }^{147}$ Quadrat mit $3 \times 3$ Zellen; für eine Beschreibung vgl. 6. Quadrat. ${ }^{148}$ a. Im roten Schriftband (aussen) steht Q 81:25b-29 (Schlussvers); es folgt in diesem roten Schriftband noch ein Auszug aus Q 72:19. ${ }^{149} \mathrm{Im}$ blauen Schriftband (innen) steht Q 95:4b-8a. Titelbalken: Text in grüner Tinte auf goldenem Hintergrund, unleserlich.

27. Quadrat (GK): ${ }^{150}$ Die Wendung al-'azama li-[A]lläh in rot eingefassten blauen Buchstaben auf goldenem Hintergrund. a. Im blauen Schriftband (aussen) steht Q 95:8b (Schlussvers); es folgt Q 103:1-3 (dies ist die ganze Sure; Beginn mit

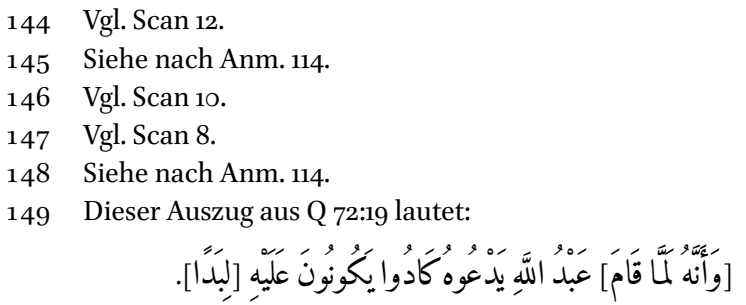

Der Anfang von Q 72 (Vers 1-19) steht bereits bei den Rechtecken 27-30; siehe dazu oben nach Anm. 34 und bei Anm. 155 .

$15^{\circ} \quad$ Vgl. Scan 6. basmala; Sūrat al-Așr). b. Im roten Schriftband (innen) steht Q 72:19 (letztes Wort)-23 (erstes Wort). Titelbalken: Text in roter Tinte auf goldenem Hintergrund. Davor: Sūrat al-Wāqi'a makkiyya wa-sitt wa-arba ūn (kad̄a $)$ (Q 56, sie hat allerdings 96 Verse); danach: Sūrat al-Hadìd madaniyya watisa'wa-išrīn (Q 57).

28. Quadrat (zQ): ${ }^{151}$ Quadrat mit $3 \times 3$ Zellen; für eine Beschreibung vgl. 6. Quadrat. ${ }^{152}$ a. Im roten Schriftband (aussen) steht Q 72:23a-25a;im blauen Schriftband (innen) steht Q 105:1-3 (Sūrat al-Fül, Beginn mit basmala). Titelbalken mit goldenem Hintergrund, soweit ersichtlich ohne Texteintrag.

29. Quadrat (GK): ${ }^{153}$ Die Wendung al-'azama li-[A]llāh in rot eingefassten blauen Buchstaben auf goldenem Hintergrund. a. Im roten Schriftband (aussen) steht Q 72:25b-28a. ${ }^{154}$ Im blauen Schriftband (innen) steht Q 105:4-5 (Schlussvers); es folgt Q 106:1-3 (Sūrat Qurayš, Beginn mit basmala). Der Schlussteil von Q 72:28 (28b) folgt in roter Tinte im anschliessenden Rechteck. Dieselbe Lösung wählte der Schreiber für den letzten Vers von Q 106 (Vers 4); er folgt im anschliessenden Rechteck in blauer Tinte. Der Schreiber wählte hier also ein sehr pragmatisches Vorgehen, um sein Platzproblem zu lösen. ${ }^{155}$ Titelbalken mit goldenem Hintergrund, soweit ersichtlich ohne Texteintrag.

Der in den Zellenquadraten $(\mathrm{zQ})^{156}$ kopierte Text enthält mutmasslich zwei Gebete (АВ B. 107108). Das eine Gebet ist in roter, das andere in

\section{Vgl. Scan 4.}

$15^{2}$ Siehe nach Anm. 114.

153 Vgl. Scan 3.

154 Q 72:28 (Schlussvers); der kopierte Text bricht kurz vor Versschluss ab, da dem Schreiber der Platz ausging. Q 72:28 lautet:

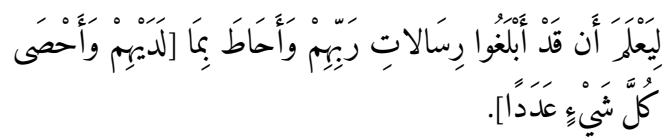

Vgl. dazu die Ausführungen zum 29. Rechteck, oben bei Anm. 34 und 92.

156 Es sind dies die Quadrate 4, 6, 8, 10, 12, 14, 16 (1. Serie) und $18,20,22,24,26,28$ (2. Serie). 
schwarzer Tinte kopiert. Die Quadrate 4, 6, 8, 10, 12, 14, 16 (1. Serie) enthalten jedoch nahezu ausschliesslich Anrufungen Gottes bei unterschiedlichen seiner Schönen Namen. Sie können gut auch einzeln gelesen werden.

Erst in der 2. Serie lassen sich zwei eigenständige Textfolgen erkennen: Der Text in roter Tinte in ZQ 18 (ABB. 108), 20, 22, 24 lässt sich nachweisen bei Makkī, Qūt al-qulūb. ${ }^{157}$ Danach weichen Vorlage und Text auf der Rolle voneinander ab. Es fällt aber auf, dass danach eine Wiederholung des bereits bekannten Texts aus dem Gebet folgt. Auf der Rolle steht hier: ${ }^{158}$

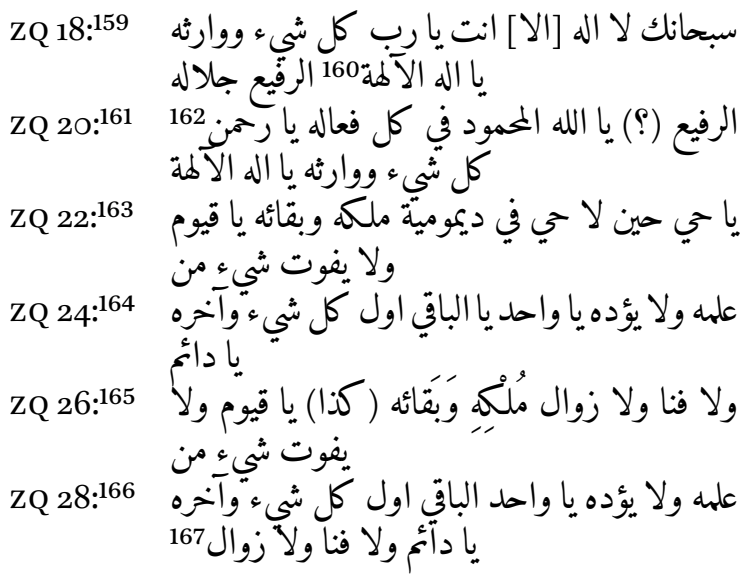

157 Vgl. http://islamport.com/w/akh/Web/239/99.htm (Stand 9. Februar 2017).

$15^{8}$ Der Text lässt sich ebenso nachweisen bei Mağlisī, Bihāar al-anwār 92.168 (Aufl. 1403/1983); er wird hier als Du' 'ã' Idrīs bezeichnet; vgl. http://lib.eshia.ir/7186o/92/ 168 (Stand 19. Oktober 2017).

159 Scan 24.

160 Auf der Rolle steht آلهة.

161 Scan 20.

162 Auf der Rolle steht آلهة

163 Scan 16. Am Schluss dieses Quadrats ist klar ersichtlich, dass die Fortsetzung in der Stelle in roter Tinte im nächsten Quadrat erfolgt. Nur so ergibt sich ein zusammenhängender Satz.

164 Scan 12

165 Scan 8

166 Scan 4

167 Auch hier erfordert die Syntax eine Lektüre in der nächsten Stelle in roter Tinte im nachfolgenden Quadrat.
In schwarzer Tinte steht in den angeführten Quadraten weiterer Text, der sich ebenso bei Makkī, Qūt al-qulūb, nachweisen lässt.

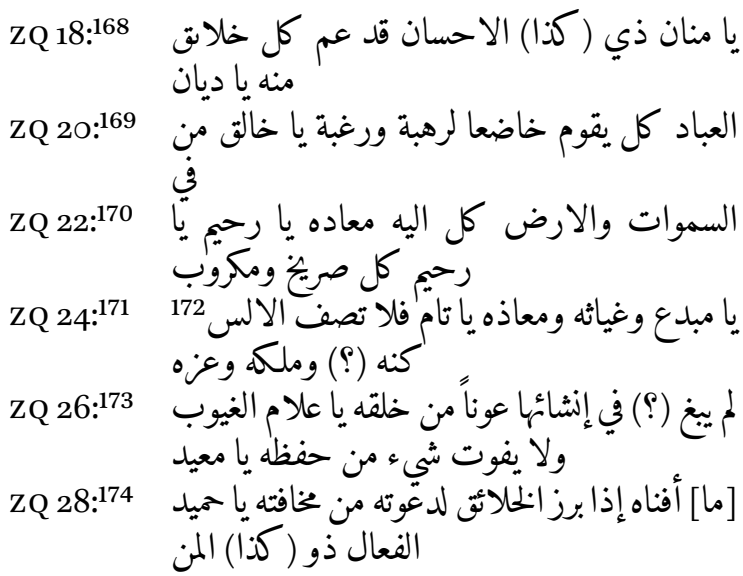

Nach den Anrufungen Gottes am Anfang folgt in diesen Zellenquadraten also ein Gebet, von dem sich mehrere Elemente bei Makkī, Qūt al$q u l u ̄ b$, nachweisen lassen. Bei Makkī stehen zuerst jene Stellen, die auf der Rolle in roter Schrift notiert worden sind, darauf folgen jene in schwarzer Schrift. Makkī führt das Gebet letztlich auf Hasan al-Bașrī zurück. Gott habe die im Gebet enthaltenen vierzig Namen Idrīs offenbart, als er ihn zu seinem Volk schickte. Gott habe diese Namen auch Muhammad gelehrt, der sie bei der $\dot{G} a z w a t$ $a l-A h z \bar{a} b$ rezitiert habe. Hasan al-Bașrī selbst habe dank diesem Gebet Schutz vor den Verfolgungen al-Ḥağğāğs gefunden. ${ }^{175}$ Hasan al-Bașrī (gest. 728) war ein bekannter Mystiker. Makkīs Qūt al-qulūb gilt ebenso als bedeutender Text der islamischen Mystik. ${ }^{176}$ Wenn auf der vorliegenden Rolle also

\footnotetext{
168 Scan 24.

169 Scan 20.

170 Scan 16 .

171 Scan 12

172 Die Vorlage bei Makkī liest hier: جا تام فلا تصف الألس كل جلال ملكه وعز.

173 Scan 8.

174 Scan 4.

175 Vgl. dazu http://islamport.com/w/akh/Web/239/99 .htm (Stand 9. Februar 2017). Zu al-Hağğăğ (gest. 95/714), vgl. Dietrich, al-Ḥadjdjādj b. Yūsuf, in $E I^{2}$.

176 Vgl. dazu Knysh, Islamic mysticism 85, 87, 121.
} 
ein Gebetstext steht, der sich ansonsten in einem für die Mystik massgeblichen Werk nachweisen lässt, legt dies den Schluss nahe, dass auch der oder die Hersteller der vorliegenden Rolle aus einem mystik-nahen Umfeld stammen.

Schlussfolgerungen: Diese Ausführungen zeigen auf, dass der Kopist von св 542 eine Vielzahl von gestalterischen und textlichen Elementen einsetzte. Neben besonderen Formen (Spiegel, Schutznetz etc.) und der Verwendung von $\dot{G} u b \bar{a} r-$ Schrift vertrauten der oder die Hersteller in erster Linie auf die Wirkung der islamischen Offenbarung. Sie griffen aber wiederholt auch auf die Schönen Namen Gottes zurück; sie werden gerade in den Zellenquadraten aufgeführt (АВв. 107). ${ }^{177}$ Auch lässt sich darauf ein Gebet nachweisen, das sich bei Makkī, Qūt al-qulūb belegen lässt (vgl. vorangehender Abschnitt). Bei der Untersuchung des Dokuments zeigte sich, dass der Korantext darauf nicht vollständig enthalten ist. Die einzelnen Suren brechen gerade in den rechteckigen Kartuschen nach jeweils zwei oder drei Rechtecken einfach ab. ${ }^{178}$ Auch scheinen auf diesem Belegstück erstaunlicherweise u.a. Q 1 (al-Fätiha) und die beiden Zufluchtssuren (al-Mu'awwidatān) ${ }^{179}$ zu fehlen. Auf derartigen Dokumenten in Rollenform lässt sich immer wieder beobachten, dass den Erfordernissen der Form ein höherer Stellenwert zukommt als der getreuen Wiedergabe des Wortlauts des Korans. Dieser Primat der Form über den offenbarten Text verdient besondere Beachtung. Diese inhaltlichen Beobachtungen sollen durch einen Exkurs ergänzt werden, der auf eine historische Kontextualisierung des Dokuments abzielt.

Historischer Exkurs zur Einordnung von СB 542 (АВ В. 103): ${ }^{180}$ Zwei nachträglich angebrachte handschriftliche Einträge bringen dieses Beleg-

\footnotetext{
177 Vgl. Anm. 96 und bei Anm. 110.

178 Vgl. dazu oben vor Anm. 35.

179 Es handelt sich um Q 113 (Sürat al-Falaq) und Q 114 (Sūratan-Nās). Es kann allerdings nicht ausgeschlossen werden, dass diese Suren auf dem Dokument doch enthalten sind.

180 Diese Ausführungen ähnlich auch in Nünlist, Entzauberte Amulettrollen 265-270.
}

stück mit einem Sulțān Sulaymān in Verbindung, bei dem es sich mit grosser Wahrscheinlichkeit um Salomon den Prächtigen (reg. 15201566) selbst handelt. ${ }^{181}$ Die genannten Vermerke erwähnen überdies das Jahr 957/155o. Die genauen Umstände der Entstehung dieses Dokuments und seine Beziehung zu Sulțān Sulaymān lassen sich nicht abschliessend rekonstruieren. Ebenso ungeklärt ist die Frage, wie dieses Belegstück in die Fondation M. Bodmer gelangte. ${ }^{182}$ Vor dem Hintergrund der bereits zusammengetragenen Informationen bieten sich zur Erklärung der Herkunft des Genfer Exemplars zwei Möglichkeiten an; sie sollen im folgenden vorgestellt werden. Beiden Alternativen gemeinsam sind die Auseinandersetzungen zwischen den Osmanen und den Safawiden in der ersten Hälfte des 16. Jh. Die weiteren Überlegungen haben hypothetischen Charakter.

A. Die Osmanen unter Selim I. ${ }^{183}$ und die Safawiden unter Šāh Ismāî̄ll184 stiessen 1514 in der Schlacht von Čăldirān aufeinander. ${ }^{185}$ Die Safawiden erlitten dabei eine vernichtende Niederlage und verloren Tabriz, damals ihre Hauptstadt, vorübergehend an die Osmanen. Sie verlegten ihr Zentrum gerade auch wegen der osmanischen Bedrohung weiter ostwärts, zuerst nach Qazwin und später nach Isfahan. ${ }^{186}$ Es ist bekannt, dass Selim I. in Anschluss an die Schlacht von Čāldirān ungehindert in Tabriz einmarschierte (7. September), dort aber nur eine Woche lang blieb (Abzug

\footnotetext{
181 Vgl. bei Anm. 2of.

182 Der Standortkatalog enthält keine Angaben dazu.

183 Selim I. war der Vater Sulaymāns des Prächtigen.

184 Vgl. zu ihm Savory und Karamustafa, Esmāēll ı Șafawī, in EIr; Savory und Gandjeï, Ismācill, in $E I^{2}$.

185 Die Schlacht selbst fand am 23. August 1514 statt; vgl. dazu Özgüdenli, Ottoman Persian relations: I. Under Sultan Selim I and Shah Esmāil I, in EIr; McCaffrey, Čalderān, in EIr, jeweils mit leicht abweichenden Datumsangaben. Siehe ausserdem Walsh, Čāldirān, in $E I^{2}$.

Tabriz blieb bis 1555 Hauptstadt der Safawiden (siehe Aube, Tabriz - Blue Mosque, in EIr). Šāh Țahmāsp verlegte die Hauptstadt 962/1555 nach Qazwin (siehe Lambton, Kazwīn, in $E I^{2}$ ). Unter Šāh 'Abbās wurde Isfahan Zentrum des Safawidenreichs (1005/1596-1597; vgl. Lambton, Artikel Iṣfahān, in $E I^{2}$ ).
} 
am 15. September). Er brachte 1000 Handwerker und Künstler aus Tabriz nach Istanbul zurück. ${ }^{187}$ Auch E. Atıl macht darauf aufmerksam, dass im Naqqāš-hূāna in Istanbul im 16. Jh. zahlreiche Spezialisten aus Iran tätig waren. In Istanbul hergestellte Manuskripte liessen sich häufig nicht von jenen aus Herat oder Tabriz unterscheiden. ${ }^{188}$ Überhaupt galt Persien im 16. und 17. Jh. im Osmanischen Reich als Leitkultur. Die Rolle св 542 könnte vor diesem Hintergrund nach 1514 durch iranische Handwerker und Künstler in Istanbul selbst angefertigt worden sein. ${ }^{189}$

B. In dieser ersten Erklärung zur Entstehung von Св 542 spielt der auf dem Dokument selbst erwähnte Sulțān Sulaymān keine Rolle. Obwohl im gegenwärtigen Zeitpunkt schlüssige Beweise dafür fehlen, ist deshalb eine zweite Alternative reizender. Auch dabei spielen die Auseinandersetzungen zwischen Safawiden und Osmanen eine zentrale Rolle. An der Spitze der beiden Lager stehen jetzt aber nicht mehr Šāh Ismā̄̄il bzw. Sulțān

187 Minorsky und Bosworth, Tabrīz, in $E I^{2}$, halten fest, dass sich die Osmanen nach der Schlacht in Čāldirān in Tabriz der Schätze der Perser bemächtigten und tausend begabte Handwerker (skilled artisans) nach Istanbul brachten. Identische Informationen bei Özgüdenli, Ottoman-Persian relations: I. Under Sultan Selim I and Shah Esmāil I, in EIr, der auch auf ein Dokument mit den Namen der damals deportierten Spezialisten aufmerksam macht; vgl. İsmail Hakki Uzunçarşılı, Osmanlı sarayında Ehl-i Hıref (sanatkarlar) defterleri, in Belgeler 11 (1986), 23-76, hier zitiert gemäss Özgündenli in EIr.

Atıl, Sultan Süleyman 66, z.B.: „The development of the local [Ottoman] style of painting [in Istanbul] was overshadowed by the influx of artisans from Herat and Tabriz, who arrived in the nakkaşhane in 1514 as a result of the eastern campaigns of Selim I and were immediately put to work." Mit Präzisierungen danach.

189 Atıl, op. cit. 66, macht darauf aufmerksam, dass im Zusammenhang mit dem Aufstieg der Safawiden verschiedene abgesetzte Herrscher aus Iran bei den Osmanen Zuflucht suchten. Sie seien mit ihrem Gefolge und ihren Schätzen nach Istanbul gekommen. Darunter hätten sich auch wertvolle Manuskripte befunden. Erwähnt wird Alwand, der letzte Sultan der Aq Quyunlu, und Badī` az-Zamān, der letzte TimuridenSultan, der nach Tabriz flüchtete, als die Usbeken 1507 Herat eroberten.
Selim, sondern ihre beiden Söhne Šāh Ṭahmāsp I. $(1524-1576)^{190}$ bzw. Sulțān Sulaymān. ${ }^{191}$ Sulaymān griff bekanntlich wiederholt selbst in die Kämpfe ein. 192

Auf Anraten des abtrünnigen Ulāma aus dem turkmenischen Stamm der Tekke besetzten Sulaymāns Truppen unter dem Befehl des Gross-Wesirs Ibrāhīm Pāšā Tabriz am 13. Juli 941/1534. ${ }^{193}$ Die Osmanen übertrugen die Macht über Aserbaidschan in Anschluss daran Ulāma, der diese Stellung bereits unter Šāh Ṭahmāsp innegehabt hatte. Am 27. September erreichte Sulaymān selbst Tabriz. Er unternahm einen Vorstoss bis nach Sulțāniyya und besetzte Bagdad. Auf dem Rückweg verbrachte er vierzehn Tage in Tabriz und kümmerte sich um Verwaltungsangelegenheiten. Die Kälte zwang die Türken allerdings zum Rückzug. Die Safawiden rückten darauf bis nach Van vor.

Im Jahr 955/28. Juli 1548 besetzte Sulțān Sulaymān Tabriz erneut, doch blieb er selbst nur fünf Tage in der Stadt. Nachschubprobleme und die schwierige Trinkwasserversorgung vor Ort zwangen die Osmanen zum raschen Rückzug. Alqās Mīrzā, ein Bruder Šāh Ṭahmāsps, hatte die Osmanen zum Einmarsch in Tabriz veranlasst. ${ }^{194}$ Er hatte anfänglich auf der Seite Ṭahmāsps gegen die Osmanen gekämpft. Die Truppen der Safawiden hatten beim osmanischen Vorstoss im Jahr 1534 unter seinem Befehl gestanden. Țahmāsp allerdings übertrug seinem Bruder Alqās Mīrzā und Badr Huān Ustāğlū im März 944/1538 die Niederschlagung des Aufstands des Šìrwān-Šāh. Im Herbst desselben Jahres wurde Alqās zum Gouver-

\footnotetext{
190 Vgl. Mitchell, Țahmāsp I, in EIr.

191 Vgl. Veinstein, Süleymān, in $E I^{2}$.

192 Diese Angaben gemäss Minorsky und Bosworth, Tabrīz, in $E I^{2}$.

193 Diese Angaben stützen sich auf Minorsky und Bosworth, Tabrīz, in $E I^{2}$.

194 Die weiteren Angaben gemäss Fleischer, Alqās Mīrzā, in EIr. Alqās Mīrzā lebte vom 1o. Șafar 922/15. März 1516 bis am 21. Rabī' I 957/9. April 1550. Er war der zweite von Šāh Ismāēils überlebenden Söhnen. Zu Alqās Mīrzā siehe ausserdem Walsh, The Revolt of Alqās Mīrzā; am ausführlichsten zu ihm Posch, Alkâs Mîrzâ.
} 
neur über Šīrwān ernannt, wo er während der nächsten acht Jahre blieb (bis 952/1546).

Aus ungeklärten Gründen widersetzte sich Alqās seinem Bruder Šāh Ṭahmāsp Anfang 953/ 1546. Zwar renkt sich das Verhältnis der beiden im Mai-Juni 1546 vorübergehend wieder ein. Alqās greift die Tscherkessen an, unterliegt ihnen jedoch. Er erhält darauf den Auftrag, Darband zu halten. Dort widersetzt er sich seinem Bruder aber offen. Er lässt Münzen prägen und die huțba in seinem eigenen Namen lesen. Țahmāsp greift Darband deshalb im Frühjahr 954/1547 an und dezimiert die Truppen seines Bruders. ${ }^{195}$ Alqās selbst flieht mit einigen Dutzend Anhängern auf die Krim, von wo er zu Schiff nach Istanbul reist. Er schildert dem aus Edirne herbeigeeilten Sulțān Sulaymān seine Notlage und ist bereit, auf Seiten der Osmanen gegen die Safawiden zu kämpfen. Er bekehrt sich möglicherweise zur Sunna und verspricht den Osmanen starke Unterstützung durch die Qizilbāš.

Die Osmanen bereiten darauf einen weiteren Feldzug gegen die Safawiden vor. Alqās wird unter der Aufsicht von Ulāma Pāšā Takalū ${ }^{196}$ an die Ostgrenze des Reichs gesandt. Sulaymāns eigene Truppen schliessen sich ihnen in Hōōị7 an. Die Osmanen besetzen Tabriz am 20. Ğumādā 955/27. Juli 1548. TTahmāsp hatte die Stadt verlassen, nachdem er alle Lebensmittelvorräte vernichtet und die Trinkwasserversorgung beschädigt hatte. Da die Qizilbāš bei weitem nicht im erwarteten Ausmass zu den Osmanen überlaufen, zweifeln diese an Alqās' Zuverlässigkeit. Die Osmanen ziehen sich wegen der schwierigen Versorgungssituation nach vier Tagen nach Van zurück.

Sulaymān hält sich im Spätsommer in Diyarbakr auf, wo der Gross-Wesir Rustam Pāšã seinen Missmut über Alqās offen kundtut. Alqās selbst bezichtigt die Qizilbāš des Wortbruchs. Er führt darauf einen Angriff gegen Iran an und dringt über Kir-

195 Nachdem Ṭahmāsp in Šīrwān die Ordnung wieder hergestellt hat, kehrt er nach Tabriz zurück. Er eliminiert dort die Alqās-treuen Elemente unter den Qizilbāš.

196 Ein früherer Qizilbāš und neu ernannter beylerbey von Erzerum.

197 Vgl. Savory, Hōòi, in $E I^{2}$. kuk (Oktober 1548) mit 8'ooo Stammeskämpfern auf safawidisches Gebiet vor. In Hamadan setzt er am 3. Šawwāl 955/5. November 1548 den Sohn und Haushalt seines Bruders Bahrām Mīrzā gefangen. ${ }^{198}$ Alqās Mīrzā plündert Qum und Kashan und greift erfolglos Isfahan an. Țahmāsp beauftragt Bahrām Mīrzā mit Alqās' Verfolgung. Dieser kann seine inzwischen meuternden Truppen zum Weiterzug nach Fārs und von dort nach Hūzistān überreden. Alqās' Armee zieht sich von lokalen Qizilbāš behelligt von Dizfül aus auf osmanisches Gebiet zurück und löst sich dort auf (nach 19. Dū l-Hiğğa 955/19. Januar 1549).

Sulaymān erfährt in seinem Winterlager Aleppo von Alqās' Scheitern. Dieser lässt sich in Mandalī nieder, wo er seine Situation evaluiert (ca. Muharram 956/Februar 1549). Er startet von hier aus Verhandlungen mit seinem Bruder Ṭahmāsp und möchte wieder als Statthalter über Šìrwān eingesetzt werden. Zugleich sendet er aber seinen wakil 'Azīzullāh Šīrwānī und die in Iran erbeuteten Schätze der Safawiden an Sulaymān nach Aleppo.

Alqās' Suche nach Unterstützung gestaltet sich schwierig. Da ihm der Zugang nach Bagdad verwehrt wird, besucht er die Pilgerorte Kāẓimayn, Nağaf und Karbalāe. Gemäss osmanischen Quellen hat er sich dabei wieder zur Schia bekehrt. Dieser Vorwurf würde betonen, dass sich die Osmanen Alqās' Unzuverlässigkeit bewusst waren. Im Frühjahr flieht Alqās nach Šahrazūr, wo ihm Bīga Ardalān, der kurdische Vasall der Osmanen, aber keine Zuflucht gewährt. Țahmāsp bricht jetzt aus Qazwin nach Šahrazūr auf. Seine Verhandlungen mit Alqās führen dazu, dass dieser Badī‘ uz-Zamān, Bahrām Mīrzās Sohn, freilässt.

Wenig später zieht Sulțān Sulaymān nach Diyarbakr, wo er auf Rustam Pāšās Drängen hin endgültig mit Alqās Mīrzā bricht und seine Truppen in die Region Šahrazūr schickt. Da Alqās von Mehmed Pāšās Truppen angegriffen (17. Ša bān/10. September) und von den Qizilbāš unter Bahrām Mīrzā verfolgt wird, sucht er Zuflucht in Marīwān bei Surhāb Ardalān, Bruder und Rivale von Bīga Arda-

198 Vgl. Mitchell, Bahrām Mīrzā, in $E I^{2}$. 
lān. ${ }^{199}$ Bahrām umzingelt Marīwān und verlangt, dass Alqās kapituliert. Da Surhāb um die Gunst der Safawiden fürchtet, ergibt sich Alqās schliesslich zusammen mit 21 Gefolgsleuten. Bahrām Mīrzā bringt ihn am nächsten Tag an Šāh Ṭahmāsps Hof. Wenige Tage später wird Alqās zusammen mit seinen beiden Söhnen durch Mittelsleute ins Gefängnis von Qahqaha überstellt. Sechs Monate danach, am 21. Rabī‘ 957/9. April 1550, wird Alqās, vermutlich mit Țahmāsps Duldung, von den Mauern Qahqahas in den Tod gestürzt. Dafür unmittelbar verantwortlich waren Leute, deren Väter Alqās umgebracht hatte. ${ }^{200}$

$\mathrm{Ob}$ die hier diskutierte Amulettrolle direkt etwas mit den soeben geschilderten Ereignissen zu tun hat, muss offen bleiben. Es könnte aber gut sein, dass Sulțān Sulaymān unter den genannten Umständen in den Besitz dieses Dokuments kam. C. Fleischer weist darauf hin, dass Alqās eine poetische Ader besass. Er habe sich für die bildenden Künste interessiert. Wahrscheinlich seien in Šīrwān zwei Manuskripte für ihn hergestellt worden. ${ }^{201} \mathrm{C}$. Fleischer hält in seinen Ausführungen abschliessend fest, dass der grösste Teil von Alqās' kulturellem Vermächtnis an die Osmanen gegangen sei. Er habe die bei den Auseinandersetzungen erbeuteten Kulturgüter aus dem Schatzhaus der Safawiden als Tributleistungen seinen osmanischen Verbündeten zukommen lassen. Sie seien in den Topkapi-Palast gelangt, wo sie den Handwerkern am Hof als Vorlage gedient hätten. ${ }^{202}$

199 Alqās Mīrzā gilt als zentrale Figur im Wettlauf der Safawiden und Osmanen um die Kontrolle über Kurdistan.

200 Gemäss C. Fleischer unterstreicht Alqās' gescheiterte Rebellion den Erfolg von Šāh Țahmāsps Zentralisierungspolitik. Die Osmanen hätten darauf keinen weiteren Versuch unternommen, ihr Problem mit den Safawiden durch subversives Taktieren zu lösen.

201 Karatay, Yazmalar 197-198; Robinson, A descriptive catalogue 87; Togan, On the miniatures in Istanbul libraries 35; alle zitiert gemäss den Angaben bei Fleischer, Alqās Mīrzā, in EIr.

202 Vgl. Fleischer, Alqās Mīrzā, in EIr: „Alqās' major cultural legacy went to the Ottomans; his tributary gift of royal Safavid treasures remained in Topkapi palace and provided models for the palace artisans." 


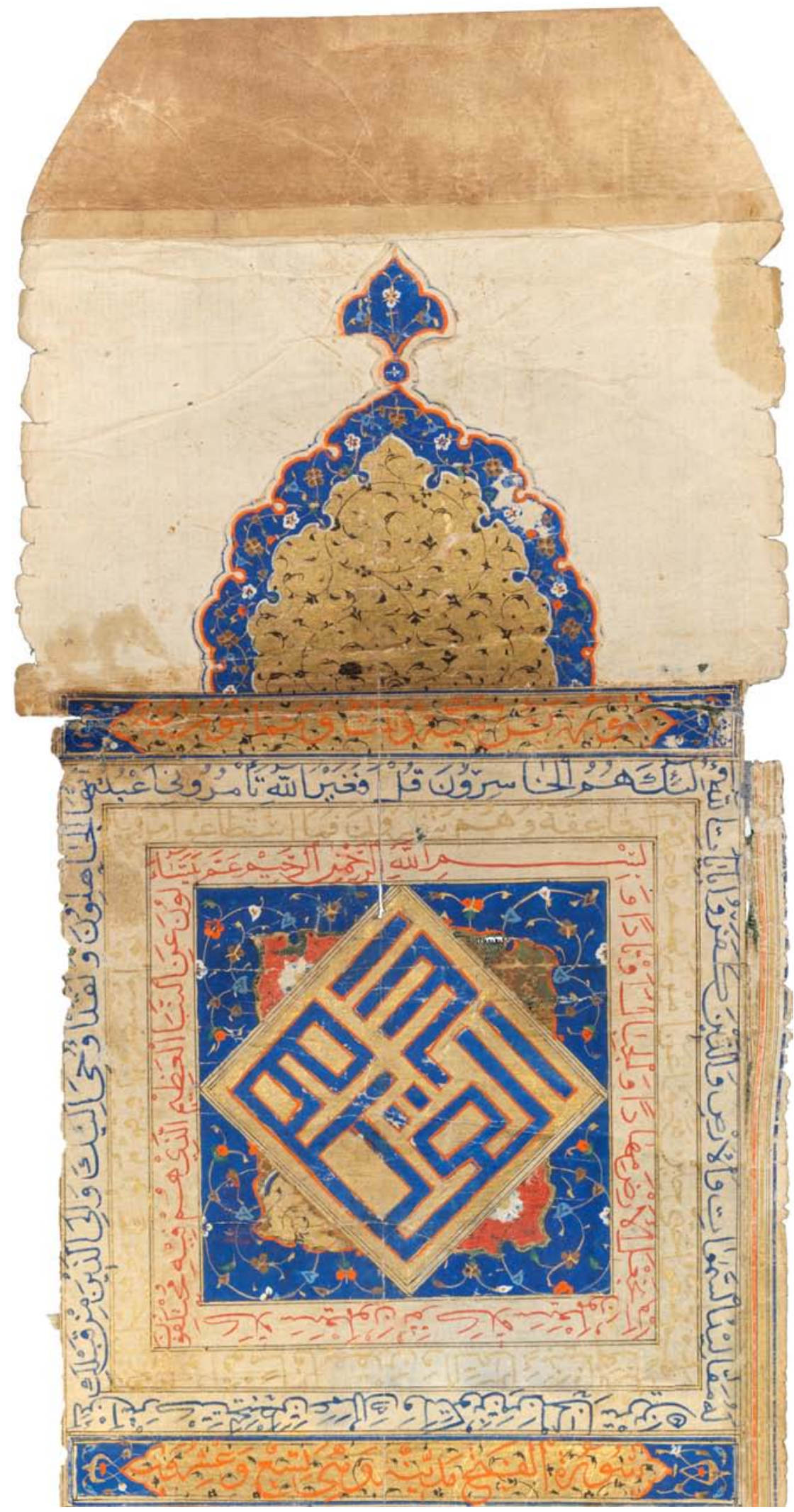

ABB. 103

Fondation Martin Bodmer, Cologny (Genève), С 542 (vgl. vor Anm. 7, nach Anm. 180): Der Beginn der Rolle mit einem besonders aufwendig gestalteten Anfangszierfeld. Im auf der Spitze stehenden Quadrat lässt sich in Zierkufi die Aussage Allāh al-'azama (sic, „Gott ist die Majestät“) erkennen. Auf weiteren ähnlich gestalteten Quadraten steht al-'azama li-[A]llāh („Die Majestät ist Gottes“). Um dieses Zierfeld im Innern sind auf Schriftbändern folgende Auszüge aus dem Koran enthalten: Blau: Q 39:63-65; braun: Q 51:43-47; rot: Q 78:17. Im horizontalen Titelbalken darüber steht die Überschrift zu Q 36: Sūrat Yā-sīn (rot). Im horizontalen Titelbalken darunter steht die Überschrift zu Q 48: Sūrat al-Fath (beide in roter Tinte). 


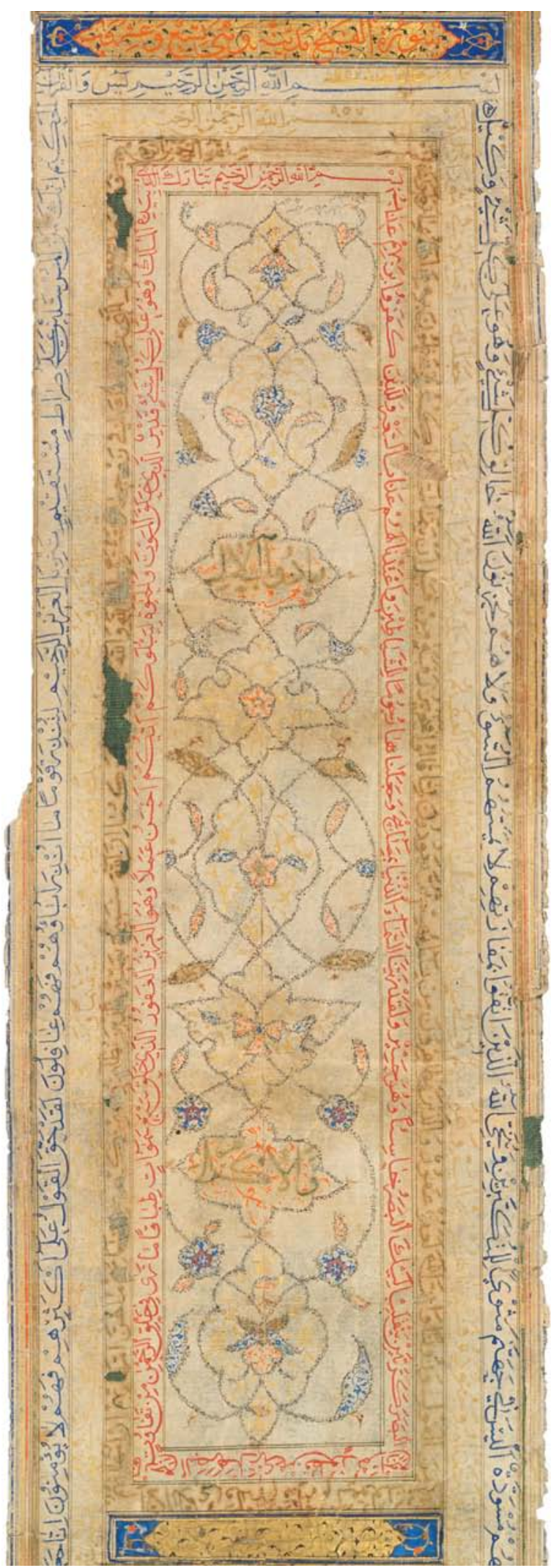

ABB. 104

Fondation Martin Bodmer, Cologny (Genève), с в 542 (vgl. bei Anm. 19-22, 23-28, 38-42, nach Anm. 180): Der Kunsthandwerker hatte auf der Rolle insgesamt 30 rechteckige Kartuschen angebracht. Die erste Kartusche (hier abgebildet) ist gegenüber den weiteren 29 Kartuschen abweichend aufgebaut. Der Schreiber hat hier Q 3 (Sūrat $\bar{A} l$ Imrān $)$ in Ġubār-Schrift kopiert und entlang eines Rankenmusters angeordnet. Der Text beginnt oben in der Mitte mit der Basmala und steigt dann gegen links ab. Die Abschrift lässt sich grundsätzlich verfolgen. In grösserer Schrift sind in dieser Kartusche auch zwei Anrufungen Gottes enthalten (hier sichtbar: Yā d̄ū (sic) l-ğaläl wa-likrām). Im blauen und goldenen Schriftband (oben) lassen sich Hinweise auf die chronologische Einordnung des Dokuments erkennen. 

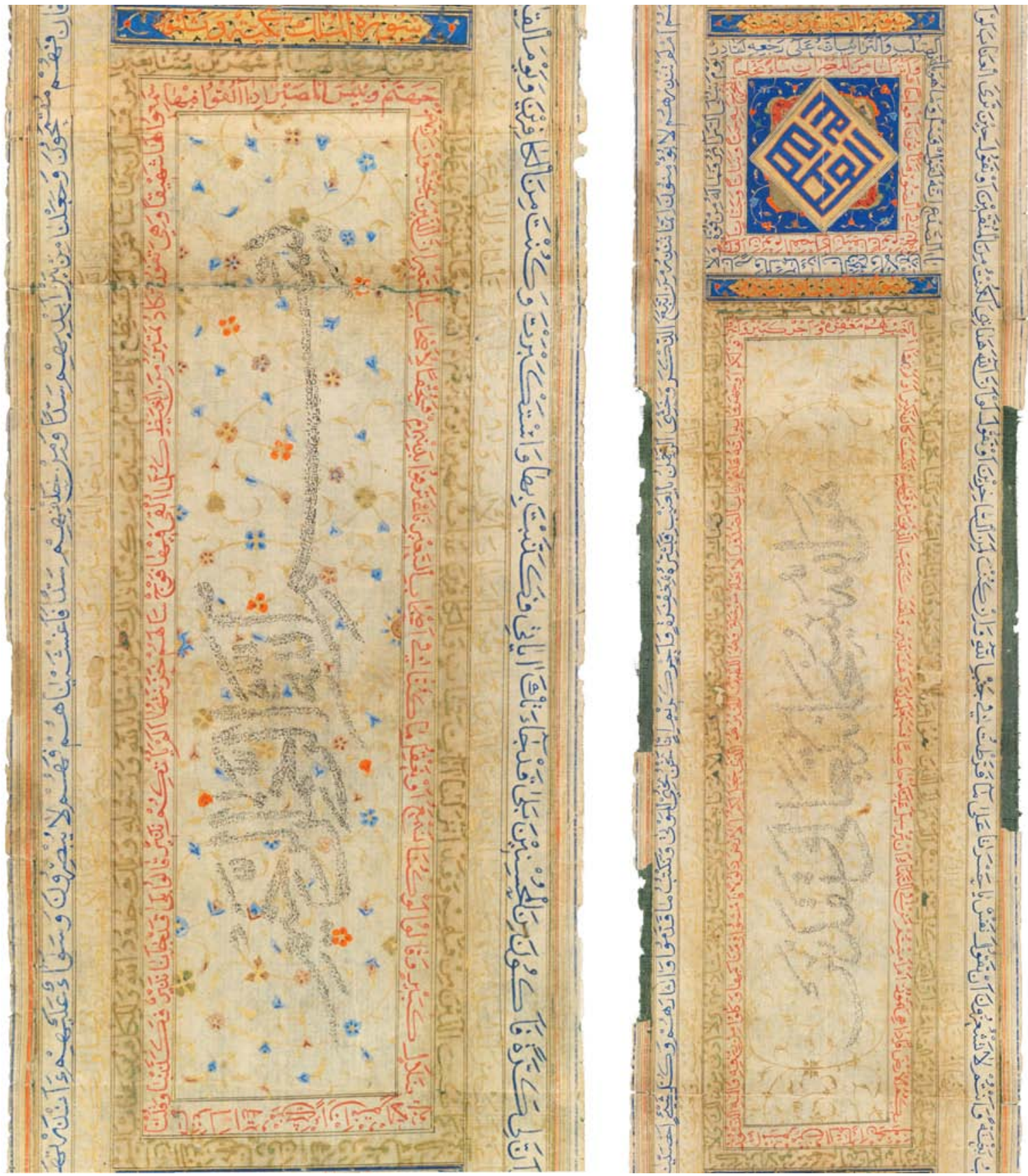

ABB. 105-106 Fondation Martin Bodmer, Cologny (Genève), CB 542 (vgl. nach Anm. 31): Die weiteren 29 rechteckigen Kartuschen sind gegenüber der 1. Kartusche mit der Abschrift von Q 3 abweichend aufgebaut. Der Kunsthandwerker kopierte hier Text in $\dot{G} u b \bar{r} r$-Schrift und ordnete die Begriffe derart an, dass ein übergeordneter Text entsteht. ABв. 105 zeigt die Basmala; Ав В. 106 enthält die Aussage Huwa Allāh subhana-hū wa-ta'ālà wa-taqaddasa. Die Stellen in $\dot{G} u b \bar{a} r$ enthalten eine Abschrift aus dem Koran. Für die Einzelheiten siehe die Beschreibungen. 


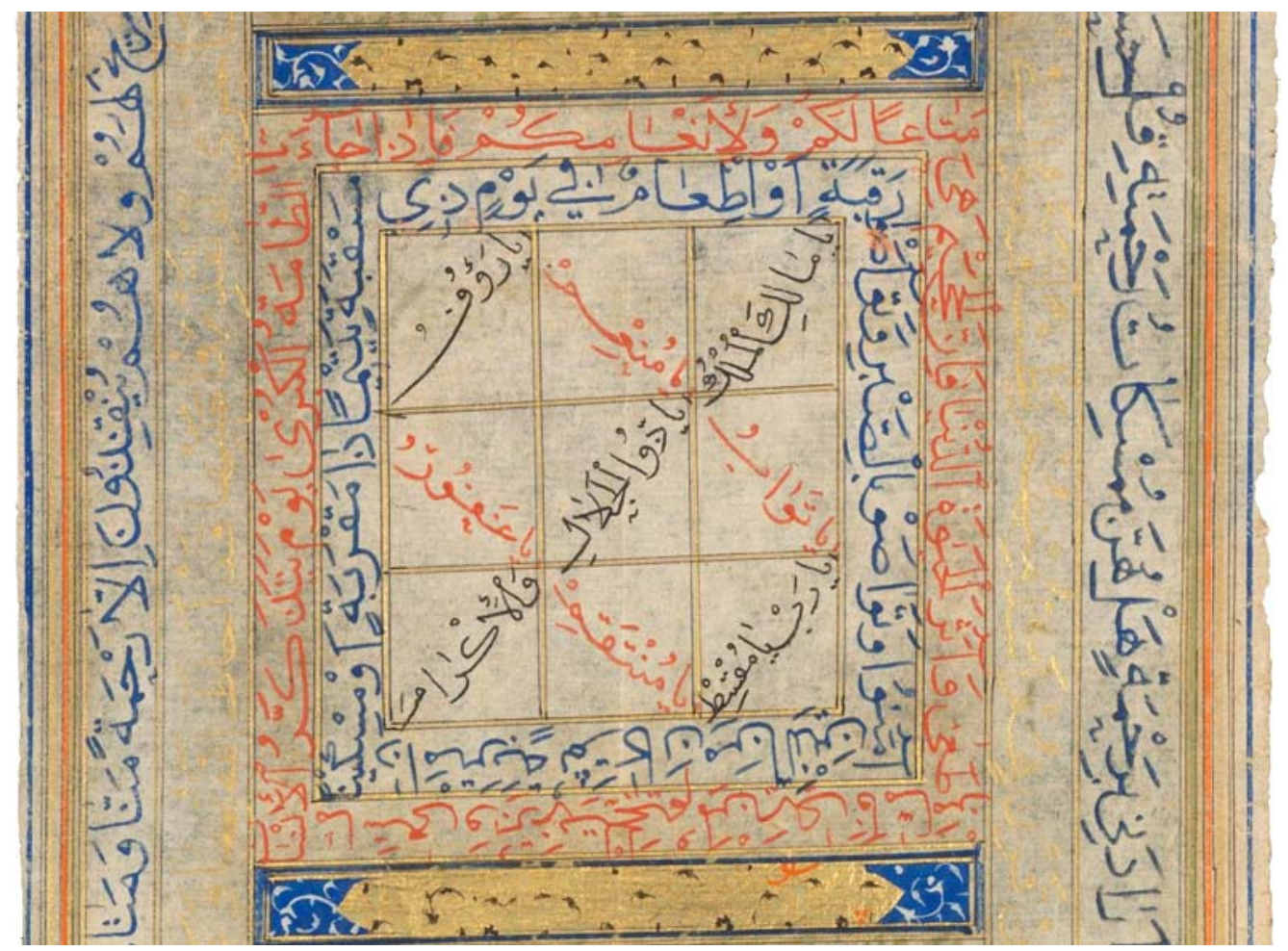

ABB. 107 Fondation Martin Bodmer, Cologny (Genève), СB 542 (vgl. bei Anm. 128-130): Der Kunsthandwerker fügte zwischen die 30 rechteckigen Kartuschen Quadrate ein. Hier gezeigt: Das 14. Quadrat mit $3 \times 3$ Zellen. Der Text in den Zellen enthält Anrufungen Gottes. In der Diagonalen von rechts oben nach links unten lässt sich die Aussage erkennen: Yã mālik almulk, yā d̄ū (sic) l-ğalāl, wa-l-ikrām. 


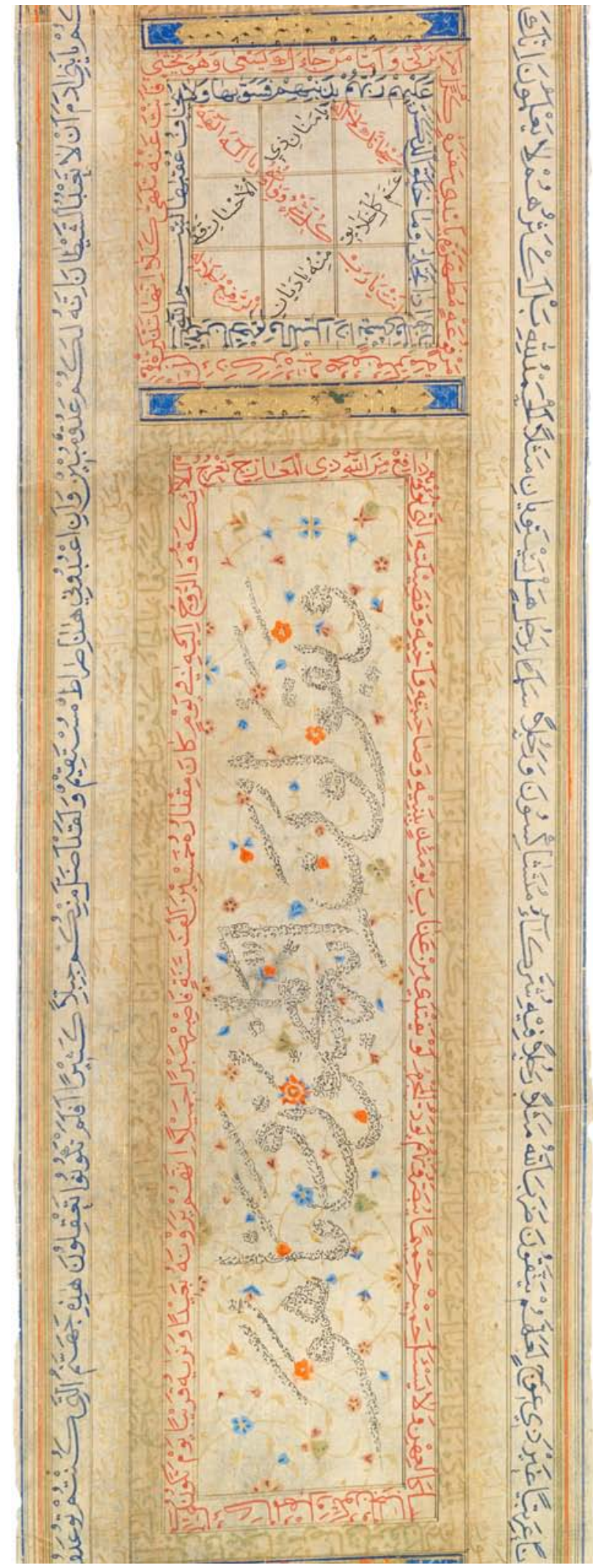

ABB. 108

Fondation Martin Bodmer, Cologny (Genève), Св 542 (vgl. bei Anm. 157-176): Während eine erste Serie von Zellenquadraten (ZQ 4, 6, 8, 10, 12, 14 [ABB. 107], 16) einfach Anrufungen Gottes enthält, kopierte der Schreiber in einer zweiten Serie ein Gebet, das sich bei Makkī, Qūt al-qulūb, nachweisen lässt. Die Abbildung zeigt ZQ 18, wo das Gebet in roter Schrift beginnt. Für den Aufbau im einzelnen siehe die Beschreibung. 
Die Rolle ist vollständig erhalten; sie misst 7.0× 66 o cm. Die Abschrift datiert aus dem Jahr 986/ 1578. Schreiber: Muẓaffar b. 'Abdallāh al-Hasanī alMāzandarānī. ${ }^{1}$

Die Rolle besteht aus einem Schutzteil aus Leder am Anfang und 14 aneinander geklebten Papierstreifen. ${ }^{2}$ Beim Beschreibstoff handelt es sich um sehr dünnes, gut geglättetes Papier. Die Überlappungen zwischen den einzelnen Papierstreifen betragen jeweils nur einige Millimeter. Die Herstellung von Papier von dieser Qualität und Feinheit war offensichtlich erst ab dem 16.Jh. überhaupt möglich. Jedenfalls wurde für ältere Rollen ausschliesslich deutlich stärkeres Papier verwendet. Die Abmessungen des Schutzteils aus Leder und der einzelnen Papierstreifen lauten wie folgt: ${ }^{3}$ o. Schutzteil: $11.6 \mathrm{~cm}$ (aus Leder); 1. Streifen: 40.0 cm; 2. Streifen: $58.6 \mathrm{~cm} ;{ }^{4} 3$. Streifen: $55.1 \mathrm{~cm}$; 4. Streifen: $55.7 \mathrm{~cm}$; 5 Streifen: $53.8 \mathrm{~cm}$; 6 . Streifen: $56.8 \mathrm{~cm}$; 7. Streifen: $13.1 \mathrm{~cm}$; 8. Streifen: $17.1 \mathrm{~cm} ; 9$. Streifen: $49.6 \mathrm{~cm}{ }^{5}$ 10. Streifen: $42.2 \mathrm{~cm}$; 11 . Streifen: $55.1 \mathrm{~cm} ; 12$. Streifen: $55.4 \mathrm{~cm}$; 13 . Streifen: $55.4 \mathrm{~cm} ; 14$. Streifen: $50.0 \mathrm{~cm}$.

Bemerkung zur Dokumentation und den Quellenverweisen: Die Chester Beatty Library hat von

1 Zu diesem Dokument siehe auch Nünlist, Devotion and protection: Four amuletic scrolls from Safavid Persia. Beachte ausserdem die Beschreibung in Arberry, Koran illuminated $5^{2}$ (Nr. 170).

2 Am Anfang Lederschutzteil bzw. Zunge aus Leder, jetzt nahezu schwarz, keine Verzierungen (weder innen noch aussen). Darauf aber Schildchen mit Bibliothekssignatur M Is 1623 (darüber frühere Signatur durchgestrichen: K.R.10).

3 Zusammengezählt ergibt sich gemäss dieser Zusammenstellung eine Länge von $669.8 \mathrm{~cm}$. Diese Längenangabe weicht von der Messung des Dokuments durch die CBL ab $(66 \circ \mathrm{cm}) \mathrm{ab}$. Die Differenz dürfte sich durch Ungenauigkeiten beim Messen erklären oder auch damit, wo genau die sich überschneidenden Papierstreifen gemessen werden.

4 Reparaturen mehrerer Risse (auf der Rückseite gut sichtbar); am Anfang des Dokuments mehrfach Reparaturen an beiden Rändern.

5 Reparatur eines Risses am Anfang dieses Blatts. dieser Rolle im Dezember 2013 insgesamt 14 Abbildungen erstellt (2 Aufnahmen pro Meter). Auf diese Aufnahmen wird in der folgenden Beschreibung mit CBL 1-14 verwiesen. ${ }^{6}$ Im Januar 2015 konnten zusätzlich eigene Aufnahmen angefertigt werden, sodass die Rolle vollständig dokumentiert ist. Bei Verweisen auf diese eigenen Abbildungen wird präzisiert, bei welchen Aufnahmen der Chester Beatty Library sie einzuordnen sind.

Die Beschreibung des Dokuments orientiert sich an den beiden folgenden Einteilungen:

1. Es lässt sich folgende Dreiteilung des Belegstücks erkennen:

A. Anfangszierfeld, sehr sorgfältig gearbeitet; $6.0 \times 12.0 \mathrm{~cm}$ (Aufnahme CBL 1$){ }^{7}$

B. Teil mit Text in drei Spalten (Aufnahmen CBL $1-5) \cdot{ }^{8}$

C. Teil mit Text in einer einzigen Spalte (Aufnahmen CBL $\left.5^{-14}\right){ }^{9}$

2. Es lassen sich aber v.a. auch 18 Textfelder feststellen, die die Einteilung des Dokuments mitbestimmen. Der Text wurde in diesen Feldern in grossem Nastaliq in Längsrichtung

6 Die Aufnahmen verteilen sich wie folgt: O-1 Meter: CBL 1 (Anfangszierfeld) und CBL 2; 1-2 Meter: CBL 3 und CBL 4; 2-3 Meter: CBL 5 und CBL 6; 3-4 Meter: CBL 7 und CBL 8; 4-5 Meter: CBL 9 und CBL 10; $5^{-6}$ Meter; CBL 11 und CBL 12; 6-7 Meter: CBL 12 und CBL 14. Die Beschreibung macht oft auf eigenes Abbildungsmaterial aufmerksam; zum Zeitpunkt der Untersuchung dieser Rolle standen keine anderen Reproduktionen zur Verfügung.

N.B.: Die Chester Beatty Library erstellte die im Abbildungsteil verwendeten Digitalisate der vollständigen Rolle erst 2019, als die vorliegende Untersuchung abgeschlossen war. Die hier in den Anmerkungen aufgeführten Stellenverweise beziehen sich auf im Lauf der Arbeit an diesem Belegstück in den Jahren 2014-2015 gemachte Aufnahmen; sie genügen professionellen Ansprüchen nicht (vgl. auch Einleitung zu Teil II, bei und mit Anm. 10).

7 Aufnahme Is 1623.CBL.1: Die Höhenangabe schliesst auch die Kartusche (Höhe ca. $0.9 \mathrm{~cm}$ ) unmittelbar unter dem Anfangszierfeld ein.

8 Aufnahmen Is 1623.CBL.1-5 (Schluss); dieser Teil der Rolle mit Anordnung des Texts in drei Spalten endet ca. $246 \mathrm{~cm}$ nach dem Anfang der Rolle.

9 Teil B beginnt ganz am Schluss von Aufnahme CBL 5 . 
kopiert. Diese Textfelder werden numeriert mit I-XVIII. Sie verteilen sich wie folgt:

A. Keine Textfelder; nur Anfangszierfeld.

B. Textfelder I-VII.

C. Textfelder VIII-XVIII und zusätzliche Abschnitte zur Verzierung.

A. Anfangszierfeld (АВ B. 109): Die Rolle beginnt mit einem ausgesprochen sorgfältig gearbeiteten Zierfeld (Länge $12.0 \mathrm{~cm}$ ). Es ist symmetrisch aufgebaut und erinnert an einen mihrāab. Ein roter Rahmen (Breite ca. $2 \mathrm{~mm}$ ) fasst diesen Anfangsteil ein. Er wird innen und aussen seinerseits von je einer blauen Linie eingefasst. Gegen aussen folgt ein goldener Streifen (Breite ca. $3 \mathrm{~mm}$ ), der ebenso von einer blauen Linie eingefasst wird. Dieser äussere goldene Rahmen setzt sich bis ans Ende des Dokuments fort. Auf der ganzen Länge der Rolle wurde dem linken und rechten Rand entlang ein Streifen von ca. $7 \mathrm{~mm}$ Breite freigelassen.

Im Anfangszierfeld selbst lassen sich die drei folgenden Teile erkennen: a. In der oberen Hälfte wurde auf neutralem Hintergrund eine achsialsymmetrisch aufgebaute goldene Verzierung angebracht, in der sich unterschiedliche pflanzliche Elemente erkennen lassen (Blätter, Blüten, Ranken). b. Der Hintergrund der unteren Hälfte des Anfangszierfelds ist golden; er ist mit unterschiedlichen pflanzlichen Elementen (Blüten, Blätter, Ranken) in den Farben Blau, Rot, Grün und Rosarot versehen. In der Mitte lässt sich ein blau ausgefülltes kreuzförmig aufgebautes Zierelement erkennen, aus dem oben und unten je zwei auffällig gestaltete Blüten herauswachsen. Diese Blüten in den Farben Orange, Rötlich, Weiss, Blau, sind auffällig aufgebaut. Sie erinnern an die Hațẳ $\bar{\imath}$-Blüten, die L. Uluç bei ihren Untersuchungen von Handschriften aus Shiraz beschrieben hat, die zwischen ca. 1570 und 158 o entstanden sind. L. Uluç bezeichnet diese Hațā' $\bar{l}$-Blüten als „one of the hallmarks of Shiraz manuscripts [produced between 1570 and 1580]“. ${ }^{10}$ L. Uluç's Beobachtung anhand der Blüten ist neben der nisba des Kopisten (al-Māzandarānī)

10 Vgl. Uluç, Turkman governors 353, mit den Abb. 18o-182 (236-238) und Abb. 269-27o (366-367). nur ein weiterer Hinweis darauf, dass das vorliegende Dokument aus Iran stammen muss. Diese Rolle kann in Shiraz selbst angefertigt worden sein; dies lässt sich aber nicht abschliessend beweisen. c. Unmittelbar unterhalb des Anfangszierfelds folgt ein rechteckiger Balken von ca. $1.5 \mathrm{~cm}$ Höhe. Er weist einen goldenen Hintergrund auf und wird am rechten und linken Rand von Verzierungen auf blauem Hintergrund eingefasst. Anfängliche Vermutungen, dass in diesem Balken jetzt verlorener Text gestanden hatte, liessen sich nicht erhärten. ${ }^{11}$

B. Unmittelbar unterhalb des soeben beschriebenen Abschnitts mit dem Anfangszierfeld beginnt der Textteil der Rolle. Die Breite des Schriftspiegels beträgt in Teil B ca. $5 \cdot 1 \mathrm{~cm}$. Der Text ist in drei Spalten angeordnet, die von einem schmalen Streifen voneinander getrennt werden; dieser Streifen ist nicht beschrieben. Die Mittelspalte ist am breitesten und misst ca. $3.9 \mathrm{~cm}$. Die beiden Seitenspalten messen je ca. $0.5 \mathrm{~cm}$. Der Hintergrundtext in diesen drei Streifen wurde in winzigem $\dot{G} u b \bar{a} r$ notiert (Schrifthöhe ca. $1 \mathrm{~mm}$, alif). Im Mittelstreifen steht der Text zumeist auf horizontalen bzw. annähernd horizontalen Linien. In den beiden Seitenstreifen ist der Text geneigt und verläuft von rechts unten nach links oben.

Teil B enthält die Textfelder I-VII. Ihnen ist in der Mittelspalte zumeist eine kreisförmige Verzierung mit einem Durchmesser von ca. $4 \mathrm{~cm}$ vorangestellt. Diese sieben Textfelder enthalten grossen Text in Nastaliq. Er entsteht, indem bei der Herstellung zuerst dieser grosse Nastaliq-Text als Leerraum festgelegt und danach der Hintergrund in $\dot{G} u b \bar{a} r$-Schrift ausgefüllt wurde. Der oder die

11 Bei der Untersuchung am Original stand auch ein fibre optic light sheet zur Verfügung. Bei den Untersuchungen an diesen Dokumenten stellte sich immer wieder die Schwierigkeit, Textstellen auf goldenem Hintergrund überhaupt noch entziffern zu können. Gerade die Pigmente der weissen Farbe haften auf goldenem Hintergrund sehr schlecht und dürften sich mit der Zeit losgelöst haben. Dies führte unweigerlich zu Textverlust. Diese Schwierigkeit stellte sich u.a. auch bei der Untersuchung des Belegstücks aus Basel (vgl. dazu Kapitel 4.8, bei Anm. 203-205). 
Hersteller wählten dieses Vorgehen in den Textfeldern I-V und VII. ${ }^{12}$ In Textfeld VI entschieden sie sich für die umgekehrte Lösung: hier entsteht der übergeordnete Text durch Wörter in grossem Nastaliq, die ihrerseits durch Stellen in winzigem $\dot{G} u b \bar{r} r$ gebildet werden. Man könnte hier gewissermassen von einem ġubār-farbenen Nastacliq sprechen. ${ }^{13}$ Der Erfassung des Inhalts der einzelnen Textfelder ist die Bemerkung vorauszuschicken, dass ihr Anfang und Schluss durch eine Art Klammer gekennzeichnet werden. Sie entsteht ebenso durch das Aussparen eines nicht beschriebenen Teils auf dem Hintergrund in $\dot{G} u b \bar{r} r$-Schrift. Dieser Hintergrund wird aus einer mit grosser Wahrscheinlichkeit vollständigen Abschrift des Korans gebildet.

Textfeld I (ABB. 110): ${ }^{14}$ Länge ca. $33 \mathrm{~cm}$ (inkl. vorangestelltes Medaillon). Die $\dot{g} u b a \bar{r} r$-freien Stellen lassen die Basmala entstehen: بسم الله الرمن الرحيم Im Hintergrund dieses grossen Texts lässt sich ausserdem ein einfaches $\dot{g} u b \bar{a} r$-freies Rankenmuster erkennen, aus dem vereinzelt fünfblättrige goldene Blüten hervorspriessen, die im Innern blau ausgefüllt sind.

Vor diesem Textteil befindet sich ein achtteiliges Medaillon (Durchmesser ca. $3.8 \mathrm{~cm}$ ). Darin lassen sich acht Teile bzw. Schnitze erkennen, die golden ausgefüllt und an der Spitze durch eine rote Verzierung markiert sind. Auch auf dem Hintergrund dieses Medaillons lässt sich Text in $\dot{G} u b \bar{a} r-$ Schrift erkennen. Ähnlich gestaltete Medaillons lassen sich vor den Textfeldern II-VI feststellen.

Wie bereits angetönt wurde auf dem Hintergrund der Rolle der Korantext in winzigem $\dot{G} u b \bar{a} r$ kopiert. In Textfeld I lassen sich im Mittelstreifen am Anfang folgende Stellen erkennen (АВв. 111):

12 Diese Technik war bereits im Jahr 1362 bekannt, wie sich anhand von Is 1624 aus der Chester Beatty Library belegen lässt (vgl. Kapitel 4.6, zwischen Anm. 30 und 31; nach Anm. 75; zwischen Anm. 120 und 121; bei Anm. 142144; Abschnitt vor Anm. 340).

13 Dieses Vorgehen liess sich bereits auf der Rolle Св 542 aus der Fondation M. Bodmer Cologny (Genève), beobachten (vgl. Kapitel 5.2, bei Anm. 29-34).

14 Vgl. die Aufnahmen Is 1623.CBL.1 und Is 1623.1686 (eigene).
Der Text beginnt auf den horizontalen Zeilen, wo sich in der rechten Ecke die Basmala zu Q 1 (Sūrat al-Fātiḥa) befindet. Q 1 verläuft zuerst im dreieckigen Zwickel unmittelbar rechts oberhalb des Medaillons. Der Schluss von Q 1 steht auf der ersten Zeile auf der linken Seite dieses ersten Medaillons. Am Ende dieser ersten Zeile links steht das Bism Allāh zu Q 2 (Sūrat al-Baqara); die Fortsetzung (arrậmān ar-rahīm) auf der zweiten Zeile unmittelbar darunter. Q 2:1-4 folgt links auf den absteigenden Zeilen ausserhalb des Medaillons. Q 2:5-22a wurde im Medaillon selbst kopiert und darin auf komplexe Art auf dessen einzelne Elemente verteilt (vgl. ABB. 111).

Textfeld II (АВB. 112): 15 Länge $25 \cdot 3 \mathrm{~cm}$ (Klammer über Klammer). Auch diesem Abschnitt ist ein Medaillon vorangestellt (Durchmesser ca. $4 \mathrm{~cm}$ ). Die $\dot{g} u b \bar{a} r$-freien Stellen lassen in Nasta liq folgenden Text entstehen:16 اللهم صل على النبى والوصى. Im Hintergrund dieses grossen Texts erneut ein einfaches, $\dot{g} u b \bar{a} r$-freies Rankenmuster mit vereinzelten fünfblättrigen goldenen Blüten, die im Innern blau ausgefüllt sind.

Das diesem Abschnitt vorangestellte Medaillon enthält einen achtstrahligen Stern. Seine Strahlen werden von schmalen Bändern mit Text in $\dot{G} u b \bar{a} r-$ Schrift voneinander getrennt. Auch im Zentrum des Medaillons ist Text in $\dot{G} u b \bar{a} r$ auf vier Zeilen enthalten. Weiterer $\dot{G} u b \bar{a} r$-Text umfährt das Zentrum des Medaillons und lässt sich an der Basis der einzelnen Strahlen des Sterns erkennen. Diese acht Strahlen sind golden ausgefüllt und an der Spitze mit einer roten Verzierung versehen. Auf der Höhe des Allāhumma lässt sich im schmalen Textstreifen am rechten Rand ein Viereck (nahezu ein Quadrat) mit goldenem Hintergrund erkennen. Es enthält in roter Tinte den Eintrag Sürat Āl Imrān. Es handelt sich um die Überschrift zu Q 3, die im Mittelstreifen mit der Basmala auch tatsächlich beginnt.

\footnotetext{
15 Vgl. die Aufnahmen Is 1623.CBL.2 und Is 1623.1688 (eigene).

16 Auch im Hintergrund dieses grossen Texts lässt sich ein einfaches $\dot{g} u b \bar{a} r$-freies Rankenmuster erkennen, aus dem vereinzelt fünfblättrige goldene Blüten hervorspriessen, die im Innern blau ausgefüllt sind.
} 
Textfeld III: ${ }^{17}$ Länge ca. $25.5 \mathrm{~cm}$ (Klammer über Klammer). Diesem Abschnitt ist ein achtteiliges Medaillon (Durchmesser ca. $4 \mathrm{~cm}$ ) vorangestellt. Die $\dot{g} u b \bar{a} r$-freien Stellen lassen folgenden Text in Nastaliq entstehen:18 والبتول والسبطين 19 والعباد والباقر Im Hintergrund dieses grossen Texts ein einfaches $\dot{g} u b \bar{a} r$-freies Rankenmuster, aus dem vereinzelt fünfblättrige goldene Blüten hervorspriessen, die im Innern blau ausgefüllt sind.

Das dem Abschnitt mit dem Text in grossem Nastacliq vorangestellte Medaillon enthält einen achtstrahligen Stern. ${ }^{20}$ Die einzelnen Strahlen des Sterns enthalten Text in $\dot{G} u b \overline{a r}$. An der Basis der Strahlen lässt sich je eine kleine goldene Verzierung erkennen. Auch die Kreissegmente zwischen Medaillonrand und Strahlen sind golden ausgefüllt. Im Zentrum des Medaillons Text in $\dot{G} u b \bar{a} r$ Schrift.

Unmittelbar vor dem Beginn dieses Textfelds II I lässt sich im schmalen Streifen am rechten Rand ein goldenes Viereck mit rotem Text $(\dot{G} u b \bar{a} r)$ erkennen. Es handelt sich um den Titel von Q 4 (Sūrat an-Nisā').

Textfeld IV:21 Länge ca. $23.8 \mathrm{~cm}$ (Klammer über Klammer). Diesem Abschnitt ist ein Medaillon vorangestellt (Durchmesser ca. $4.0 \mathrm{~cm}) .{ }^{22}$ Die $\dot{g} u b a \bar{r}$-freien Stellen lassen folgenden Text in Nastaliq-Schrift entstehen: والصادق والكاظم والرضاء. Im Hintergrund dieses grossen Texts ein einfaches $\dot{g} u b \bar{a} r$-freies Rankenmuster mit vereinzelten fünfblättrigen goldenen Blüten, die im Innern blau ausgefüllt sind.

Am Anfang des Textfelds IV im schmalen Textstreifen am rechten Rand ein Viereck mit dem Eintrag Sūrat Mẩida (Q 5) in rotem $\dot{G} u b \bar{a} r$. Ganz am

17 Vgl. dazu die Aufnahme Is 1623.1692 (eigene).

18 Vgl. Anm. 16.

19 Der Schreiber hat das sin im Ausdruck as-Sibtayn durch drei Punkte unterhalb der Zeile markiert. Von diesem Stern ist keine vollständige Einzelabbildung vorhanden; siehe dazu Aufnahmen CBL 5 und 8 sowie Is 1623.1691 (19 und 21) und CBL 2, die jeweils nur einen kleinen Ausschnitt des Medaillons zeigen.

21 Vgl. Abbildungen Is 1623.CBL.3 und Is 1623.1694 (eigene); Hauptzählung 27 und 29.

22 Inkl. $\dot{g} u b \bar{a} r$-freier Ring um das Medaillon herum.
Ende dieses Textfelds ein weiteres Viereck mit goldenem Hintergrund. Hier steht in rotem $\dot{G} u b \bar{a} r$ der Eintrag Sūrat An`ām (Q 6). In beiden Überschriften fehlt der Artikel beim Surennamen. Diese Eigenheit deutet auf einen iranischen Hintergrund dieses Belegstücks hin, erfordert die persische Grammatik hier doch keinen Artikel, sondern begnügt sich mit dem Setzen der ị̂ăfa.

Das diesem Abschnitt vorangestellte Medaillon enthält einen achtstrahligen Stern. Die Kreissegmente zwischen Stern und Medaillonrand sind mit Stellen in $\dot{G} u b \bar{r} r$ ausgefüllt. Auch im Zentrum dieser Figur vier Zeilen Text in $\dot{G} u b a \bar{r}$. Ebenso sind vier Strahlen des Sterns grösstenteils mit Text in $\dot{G} u b \bar{a} r$ ausgefüllt. An ihrer Basis enthalten sie eine goldene Verzierung. In den vier andern Strahlen ist das Verhältnis Text-Verzierung gerade umgekehrt.

Textfeld v: ${ }^{23}$ Länge ca. $25 \cdot 3 \mathrm{~cm}$ (Klammer über Klammer). Im Hintergrund des grossen Texts ein einfaches $\dot{g} u b \bar{a} r$-freies Rankenmuster, aus dem vereinzelt fünfblättrige goldene Blüten hervorspriessen, die im Innern blau ausgefüllt sind. Die jubārfreien Stellen lassen folgenden Text in Nastaliq entstehen:24 والتقى والنتي 25 والعسكري. Auf der Höhe des Namens ,an-Naqī“lässt sich im schmalen Streifen am rechten Rand ein Viereck mit goldenem Hintergrund erkennen. Es enthält in rotem $\dot{G} u b \bar{a} r$ den Eintrag Sūrat A'rā $f\left(\mathrm{Q}_{7}\right) .{ }^{27}$

Auch diesem Abschnitt mit dem Text in Nastacliq ist ein Medaillon vorangestellt (Durchmesser ca. $4.0 \mathrm{~cm})$. Es enthält erneut einen achtstrahligen Stern. Die Kreissegmente zwischen den goldenen Spitzen der einzelnen Strahlen und dem Medaillonrand sind mit Text in $\dot{G} u b \bar{a} r$ ausgefüllt. Auch die einzelnen Strahlen des Sterns werden durch

23 Vgl. Abb. Is 1623.1695 (Hauptzählung: 3o).

24 Auch die beiden Klammern vor und nach dem Textfeld entstehen durch $\dot{g} u b \bar{a} r$-freien Raum.

25 Man beachte die sehr deutlich nach rechts, also gegen die Schriftrichtung, ausholende Unterlänge des Schluss-Ya in diesen beiden Namen.

26 Auch hier wurde das sin von al-'Askarī mit drei Punkten unterhalb der Zeile kenntlich gemacht.

27 Wohl ohne Artikel; vgl. die Hinweise zu den Überschriften von Q 5 und 6 (zwischen Anm. 22 und 23). 
eine Zeile Text in $\dot{G} u b \bar{a} r$ voneinander getrennt. Das Zentrum des Medaillons wird durch einen goldenen Punkt hervorgehoben. Auch die Spitzen der Strahlen sind golden ausgefüllt und enthalten eine rote Verzierung. An der Basis enthalten diese Strahlen Text in $\dot{G} u b \bar{a} r$.

Textfeld VI (ABB. 113): 28 Länge $24.5 \mathrm{~cm}$ (Klammer über Klammer). Diesem Abschnitt ist ein weiteres Medaillon vorangestellt (Durchmesser ca. $4.0 \mathrm{~cm}$ ). Der grosse Eintrag entsteht hier nicht durch das Aussparen von Leerräumen auf einem Hintergrund mit Text in Gubār. Der Künstler wählte vielmehr das umgekehrte Vorgehen: Der Hintergrund ist in diesem Abschnitt leer bzw. neutral. Der übergeordnete Text in Nastacliq entsteht durch das Ausfüllen der Buchstaben mit kleinem Text in $\dot{G} u b \bar{a} r$. Der grosse Text ist somit sozusagen $\dot{g} u b \bar{a} r$-farben. Auch die Ranken werden hier oft durch Zeilen mit Text in $\dot{G} u b \bar{a} r$-Schrift gebildet. Daraus spriessen Blüten hervor, deren Blätter durch Stellen in $\dot{G} u b \bar{a} r$ gebildet werden. Sie sind im Innern golden markiert. Zusätzlich lassen sich goldene Ranken mit ebenso goldenen Blättern und Blüten erkennen. Der $\dot{g} u b \bar{a} r$-farbene Text

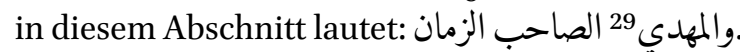
Vielleicht hat der Künstler den Eintrag in $\dot{g} u b \bar{a} r-$ farbenem Nastacliq notiert, da er die Bedeutung des Mahdī als 12. Imam hervorheben wollte.

Am Ende des $y \bar{a}$ von al-Mahdī lässt sich im schmalen Streifen am rechten Rand ein Viereck erkennen. Es enthält in rotem $\dot{G} u b \bar{a} r$ den Eintrag Sūrat al-Anfāl (Q 8). Es wäre reizvoll, die Anordnung des Korantexts in diesem Abschnitt zu rekonstruieren. Es lässt sich beispielsweise feststellen, dass das Textfeld zu beiden Seiten von einer Zeile Text in $\dot{G} u b a \bar{r}$ eingefasst wird. Die Verteilung des Korantexts in den Wörtern und Pflanzenranken in diesem Abschnitt dürfte sich grundsätzlich ebenso rekonstruieren lassen.

28 Vgl. Aufnahme Is 1623.CBL.4 und Abbildungen 35, 36 und 37 (Hauptzählung).

29 Das $y \bar{a}^{3}$ von al-Mahdī wird hier übermässig gedehnt und erstreckt sich über nahezu die Hälfte dieses Textfelds.
Auch diesem Abschnitt ist ein Medaillon vorangestellt. Es enthält erneut einen achtstrahligen Stern. Die Kreissegmente zwischen den goldenen Spitzen der einzelnen Strahlen und dem Medaillonrand sind mit Text in $\dot{G} u b \bar{a} r$ ausgefüllt. Auch die einzelnen Strahlen sind durch eine Zeile Text in $\dot{G} u b \bar{a} r$ voneinander getrennt. Aussen umfährt eine Zeile Text in $\dot{G} u b \bar{a} r$ den ganzen Stern. Die Mitte dieses Sterns und des Medaillons wird durch eine achtteilige goldene Verzierung markiert, deren Zentrum durch einen farbigen Punkt hervorgehoben wird. Es könnte sein, dass es sich dabei um eine von oben betrachtete Derwischmütze handelt. Diese Vermutung liess sich aber nicht beweisen.

Textfeld VII ${ }^{30}$ und Textfeld viII: ${ }^{31}$ Diese beiden Textfelder gehören inhaltlich zusammen und stellen die unmittelbare Fortsetzung von Textfeld vi dar. Die Länge dieser beiden Textfelder zusammen beträgt $51.0 \mathrm{~cm}$. Hier entsteht der übergeordnete Text in Nasta liq-Schrift wieder durch entsprechende Auslassungen auf dem $\dot{g} u b \bar{r} r$-farbenen Hintergrund. Die $\dot{g} u b \bar{a} r$-freien Stellen lassen folخليفت الرحمن genden Text in Nastaliq entstehen . صلوات الله || عليه وعليهم اجمعين. Auf dem Hintergrund dieses grossen Texts ein einfaches $\dot{g} u b \bar{a} r-$ freies Rankenmuster, aus dem vereinzelt fünfblättrige goldene Blüten hervorspriessen.

Auf der Höhe des Ausdrucks halïfa lässt sich im schmalen Streifen am rechten Rand ein goldenes Viereck erkennen. Es enthält in rotem $\dot{G} u b \bar{a} r$ den Eintrag Sūrat Barāa (Q 9). ${ }^{32}$ Auf der Höhe des Ausdrucks 'alay-hi im nächsten Textfeld (VIII) folgt

30 Vgl. Abb. Is 1623.1697 (Hauptzählung 41); vor diesem Textfeld wurde kein Medaillon eingefügt. Der Eintrag hier gehört inhaltlich noch zum vorangehenden Textfeld und charakterisiert den 12. Imam als Halīfat ar-Rahmānn. Vgl. Abb. Is 1623.1698 (Hauptzählung 42) und Is 1623.CB L.5 (Hauptzählung 43). Auch vor diesem Textfeld befindet sich kein Medaillon, da es inhaltlich direkt an Textfeld vi I anschliesst.

32 Es handelt sich um eine alternative Bezeichnung von Q 9, die in der Regel unter dem Namen Sūrat at-Tawba bekannt ist. 
das nächste Viereck mit goldenem Hintergrund. Es enthält in rotem $\dot{G} u b \bar{a} r$ den Eintrag Sūrat Yūnus (Q 10). 33

Den beiden Textfeldern VII und VIII ist kein Medaillon vorangestellt. Erwähnenswert ist auch, dass die Anordnung des Korantexts in drei Spalten nach der Eulogie im Textfeld viII endet. Mit Textfeld viII beginnt Teil C der Rolle; ab diesem Textfeld ist der Text in $\dot{G} u b \bar{a} r$ nur noch in einer Spalte angeordnet. Er verläuft auf horizontalen Zeilen, die sich über die gesamte Breite des Schriftspiegels erstrecken.

Feld IX (АВв. 114): ${ }^{34}$ ohne Text in grossem Nasta'liq. Dieses Feld enthält nur Verzierungen. Sie werden durch Stellen in $\dot{G} u b \bar{a} r$ und ein pflanzliches Rankenmuster gebildet. Der Abschnitt wird hier dennoch in die Zusammenstellung der Textfelder aufgenommen. Länge dieses Abschnitts: ca. $35.0 \mathrm{~cm}$; unmittelbar davor ein kurzer Abschnitt von ca. $1.8 \mathrm{~cm}$ Länge, in dem der Korantext in nur einer einzigen Spalte angeordnet ist.

Dieser Abschnitt wird dem Rand entlang durch eine einzige Zeile mit Text in $\dot{G} u b \bar{a} r$-Schrift eingefasst. Sie umrahmt die Verzierung, die im wesentlichen aus sechs $\dot{g} u b \bar{a} r$-farbenen Elementen besteht. Diese sind weitgehend, aber nicht gänzlich identisch gestaltet. Es handelt sich um eine Art Dreiblatt, das gegen oben spitz zuläuft. Diese Dreiblätter werden durch breitere Stellen in $\dot{G} u$ $b \bar{a} r$-Schrift gebildet. Bei den Dreiblättern 1, 3, 4 und 6 (von unten gezählt) lassen sich seitlich je eine nach unten spitz zulaufende Blattspitze erkennen. Bei den Dreiblättern 2 und 5 verlaufen diese Ausbuchtungen horizontal nach aussen. Im Innern aller sechs grossen Dreiblätter lässt sich ein zusätzliches kleineres Zierelement mit drei Blättern erkennen, das ebenso aus Stellen in $\dot{G} u b \bar{a} r$ gebildet wird. Diese dreiteiligen Blätter im Innern sind untereinander durch Ranken verbunden, die aus einer einzelnen Zeile Text in $\dot{G} u b \bar{a} r$ bestehen. Aus dieser einzeiligen Ranke spriessen gerade zwi-

Die Basmala zu Q 10 befindet sich oberhalb der Blüte am rechten Rand des Mittelstreifens. schen den grossen Zierelementen $\dot{g} u b \bar{a} r$-farbene Blätter oder Blüten hervor. Zusätzlich lassen sich in diesem Abschnitt goldene Zierelemente (Blätter und Blüten) erkennen, die aus einer feinen schwarzen Ranke herauswachsen.

In diesem Abschnitt lassen sich zwei goldene Vierecke erkennen, in die in roter Tinte die Überschriften zu Q 12 und 13 (Sürat Yūsuf bzw. Sūrat $R a^{c} d^{35}$ ) notiert worden sind. Der Titel von Q 12 befindet sich im obersten Zierelement auf der rechten Seite. Der Titel von Q 13 folgt im untersten Zierelement ebenso auf der rechten Seite. Q 11 (Sürat Hūd) liess sich nicht lokalisieren.

Textfeld X (AвB. 115): ${ }^{36}$ Mit diesem Textfeld (Länge ca. $24.2 \mathrm{~cm}$, Klammer über Klammer) beginnt in grossem Nastaliq auf einem Hintergrund in Gubār die Abschrift des Nādi-Alì-Gebets. Es erstreckt sich über die nächsten 4 Textfelder (Textfelder X-XIV, ohne Feld XII). Anfang und Schluss dieses Abschnitts werden durch eine $\dot{g} u b \bar{a} r$-freie Klammer gekennzeichnet. Die $\dot{g} u b \bar{a} r-$ freien Stellen lassen folgenden Text in Nastaliq entstehen: ناد عليا مظهر العجايب. Goldene Vierecke markieren die Punktierungen in diesem Text. ${ }^{37}$ Der Text in $\dot{G} u b \bar{a} r$ wurde zumeist auf horizontalen Zeilen notiert, die durch die grossen Buchstaben in Nastaliq unterbrochen werden. Unterhalb der oberen Klammer dieses Abschnitts ist der Text schräg ausgerichtet und verläuft von rechts unten nach links oben.

In diesem Abschnitt lassen sich am rechten Rand drei goldene Vierecke erkennen, die in rotem $\dot{G} u b \bar{a} r$ die Überschriften zu Suren 14, 15 und 16 enthalten: Q 14: Sūrat Ibrāhīm ${ }^{38}$; Q 15: Sūrat-i Hiğrr ${ }^{39}$ und Sūrat an-Nahl. ${ }^{40}$

35 Der Name der Sure wurde hier ohne Artikel notiert, was auf einen persischen Hintergrund des Schreibers hinweist; vgl. zur Frage bereits oben zwischen Anm. 22 und 23.

36 Vgl. Abb. Is 1623.1699 (Hauptzählung 48-5o).

37 Der Punkt zum $z \bar{a}^{\text {’ }}$ von mazhar folgt erst über der Verbindung zwischen $h \bar{a}$ ' und $r \bar{a}$ '.

38 Auf der Höhe des 'ayn von 'Alī.

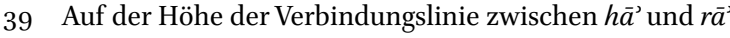
im Ausdruck mazhar.

40 Am Anfang des Ausdrucks al-'ağâàib. 
Textfeld XI: ${ }^{41}$ Länge ca. $24.2 \mathrm{~cm}$ (Klammer über Klammer). Die Zeilen des $\dot{G} u b \bar{a} r$-Texts im Hintergrund sind gerade am Anfang und am Schluss von rechts unten nach links oben geneigt. In der Mitte des Abschnitts fällt die Neigung geringer aus. Auch hier ein übergeordneter Text in Nastacliq auf dem تجده تجونا لك في النوايب.

Am rechten Rand lassen sich in diesem Abschnitt zwei goldene Vierecke mit Text in rotem $\dot{G} u b a \bar{r}$ erkennen. Es handelt sich um die Überschriften von Q 17 und 18. Q 17: hier Sūrat Banī Isrā̄ill; ${ }^{44} \mathrm{Q}$ 18: Sūrat al-Kahf mi'a. ${ }^{45}$

Feld XII (AB B. 116): ${ }^{46}$ Länge ca. $65.5 \mathrm{~cm} .{ }^{47}$ Kein übergeordneter Text in Nastaliq. Das Feld weist vielmehr einen Hintergrund auf, der durch Text in $\dot{G} u b \bar{a} r$ gebildet wird. Auf diesem Abschnitt lassen sich zwei auffällige goldene Verzierungen erkennen:

a. Am Anfang lässt sich eine vierteilige goldene Verzierung erkennen; sie enthält in geometrisierendem Küfı vier Mal den Namen 'Alī. Der Aufbau der Verzierung ruft eine Swastika in Erinnerung (Länge dieses Abschnitts: ca. $6 \mathrm{~cm}$ ).

b. Dieses vierfache 'Alī wird unten durch eine Art Kelch eingefasst. Aus diesem Kelch geht darauf eine insgesamt 16-teilige goldene Verzierung hervor (Länge ca. $58.5 \mathrm{~cm}$ ). Diese 16-teilige Verzierung entsteht durch eine achtmalige Wiederholung

41 Vgl. Abb. Is 1623.c B L.7 (Hauptzählung 51-53) und Abb. Is 1623.1700 (Hauptzählung 54).

42 Die Punktierungen werden hier erneut durch goldene Vierecke markiert.

43 Man beachte, dass der Schreiber die beiden Begriffe $l a-k a$ $f \imath$ direkt übereinander notiert hat.

44 Auf der Höhe des Ausdrucks tağid-hū.

45 Am Ende von laka fi. Das mia am Schluss bezieht sich auf die Anzahl Verse von Q 18. Sie hat 110 Verse; dem Schreiber fehlte in diesem Viereck der Platz, um auch die Zehner zu notieren.

46 Vgl. Abb. Is 1623.CBL.7-8 und Is 1623.1700-1703 (Hauptzählung 51 und 54-61); siehe auch Abb. 19 und 21 (A4 Sepia).

47 Von der vorangehenden bis zur nächsten Klammer. einer Abfolge eines Rechtecks ${ }^{48}$ und eines unregelmässigen Achtpasses. ${ }^{49}$ Diese Figuren werden durch goldene Linien gebildet. An den Übergängen zwischen den einzelnen Figuren überschneiden sich die Linien, indem sie sich über- bzw. unterfahren. Beim Betrachten entsteht der Eindruck, es könnte sich um einen 16-teiligen Gürtel oder Kette $(8 \times 2$ Glieder $)$ handeln.

Am rechten Rand dieses Abschnitts befinden sich 7 goldene Vierecke mit den Überschriften zu den Suren 19-25:1. Q 19: Sūrat Maryam; ${ }^{50}$ 2. es folgt ein goldenes Viereck ohne Texteintrag; ${ }^{51}$ 3. Q 20: Sūrat Ṭa-hāa; ${ }^{52}$ 4. Q 21: Sūrat al-Anbiya $\bar{a}^{3}{ }^{53}$ 5. Q 22: Sūrat al-Hağğ ;54 6. Q 24: Sūrat an-Nūr;55 7. Q 25: Sürat al-Furqān. ${ }^{56}$

Textfeld XIII: ${ }^{57}$ Länge $24.6 \mathrm{~cm}$ (Klammer über Klammer). Der übergeordnete Text in Nastaliq wird durch Auslassungen auf einem $\dot{g} u b \bar{a} r$-farbenen Hintergrund gebildet. Die Zeilen des $\dot{G} u b \bar{a} r-$ Texts verlaufen hier weitgehend horizontal über die gesamte Breite des Mittelstreifens. Goldene Vierecke markieren die Punktierungen der grossen

48 Dieses horizontal ausgerichtete Rechteck weist auf allen vier Seiten halbkreisförmige Ausbuchtungen auf.

49 Die Ausbuchtungen dieses Achtpasses in der Horizontalen und Vertikalen sind deutlich geringer als die vier Ausbuchtungen dazwischen.

50 Auf der Höhe des vierfachen 'Alī.

51 Auf der Höhe des ersten Achtpasses in der 16-teiligen Verzierung.

52 Auf der Höhe des zweiten Achtpasses; der Text ist auf dem zur Verfügung stehenden Abbildungsmaterial nur sehr schlecht erkenntlich.

53 Auf der Höhe des dritten Achtpasses; der Eintrag des Titels ist klar erkenntlich.

54 Am Anfang des fünften Achtpasses.

55 Am Anfang des sechsten Achtpasses. Ein Viereck mit dem Titel von Q 23 (Sūrat al-Múminūn) fehlt soweit ersichtlich. Unmittelbar über dem Viereck mit dem Titel von Q 24 steht aber der Schluss von Q 23 (Verse 116-118).

56 Am Schluss des siebten Achtpasses; der Eintrag lässt sich auf dem zur Verfügung stehenden Abbildungsmaterial nicht mit Sicherheit erkennen.

57 Vgl. Abb. Is 1623.1704 und Is 1623.CBL.9 (Hauptzählung $62-66)$. 
Buchstaben. ${ }^{58}$ Beim übergeordneten Text handelt es sich um die Fortsetzung des Nādi-'Alī-Gebets: كل هم وغم سينجلي

Am rechten Rand lassen sich entlang dieses Abschnitts drei goldene Vierecke erkennen, die in rotem $\dot{G} u b \bar{a} r$ die Überschriften zu den Suren $26-$ 28 enthalten: Q 26: Sūrat aš- ̌̌u'arä',59 Q 27: Sūrat an-Naml; ${ }^{60}$ Q 28: Sūrat al-Qașaș (Sūrat-i Qașaș geschrieben: beachte die persische Grammatik). ${ }^{61}$

Die Einträge in den Titelfeldern (Vierecke) und der in $\dot{G} u b \bar{a} r$ notierte Surentext passen hier nicht mehr zusammen. Q 28 (Sürat al-Qașaș) endet unmittelbar oberhalb des für sie vorgesehenen Titelfelds mit Vers 88. ${ }^{62}$ Danach folgt eine Basmala und der Beginn von Q 29 (Sürat al-Ankabūt). Die Unregelmässigkeit dürfte auf einen Fehler des Kopisten zurückgehen, der bereits unterhalb des vierfachen 'Alī ein goldenes Viereck am rechten Rand leergelassen hat.

Textfeld XIV: ${ }^{63}$ Länge $24.1 \mathrm{~cm}$ (Klammer über Klammer). Identische Gestaltung wie vorangehendes Textfeld. Als übergeordneter Text erscheinen in Nastaliq Fortsetzung und Schluss des Gebets: • بولا يتك يا على يا على يا على

Am rechten Rand dieses Abschnitts lassen sich vier goldene Rechtecke erkennen. Sie enthalten die Titel von Suren 29-32: Q 29: Sūrat al-'Ankabūt, sie geht unmittelbar davor zu Ende; Q 30: Sūrat ar-Rūm; Q 31: Sūrat Luqmān; und Q 32: Sūrat asSağda. Die Divergenzen zwischen dem Eintrag im Titelfeld und dem anschliessenden Surentext dürften auch hier auf den Fehler jenes Schreibers zurückgehen, der die roten Titel anbrachte und bereits zuvor ein dafür vorgesehenes Feld übersprang.

$5^{8}$ Das sin im Ausdruck sa-yanğalī wird auch hier mit drei Punkten unterhalb der Zeile gekennzeichnet.

59 Unterhalb des $h \bar{a}$ 'von hamm.

6o Auf der Höhe des Ausdrucks wa-ġamm.

61 Direkt unterhalb der Klammer, die diesen Abschnitt abschliesst.

62 Vgl. Abb. 66 (Hauptzählung).

63 Vgl. Abb. Is 1623.1705 (Hauptzählung 67-69).
Textfelder XV und XVI: ${ }^{64}$ Es schliessen sich zwei Textfelder an, deren Anfang und Ende durch je zwei Klammern markiert werden. Sie gehören inhaltlich zusammen und werden zusammen vorgestellt. Die Länge von Textfeld xv beträgt $9 \mathrm{~cm}$, jene von Textfeld XIV $26.2 \mathrm{~cm}$. Die Klammern am Anfang und Ende dieser Textfelder werden durch Auslassungen auf dem „gubār-farbenen“ Hintergrund gebildet. Auch der zwischen diesen Klammern enthaltene grosse Text in Nastaliq entsteht durch entsprechende Auslassungen. Die Punktierung der Buchstaben erfolgt durch auf der Spitze stehende goldene Quadrate. Beim kopierten Text handelt es sich um ein Prophetenwort; der Eintrag lautet:65 ومن كلامه ||66 من لا يرحم الناس لايرحمه الله

Am rechten Rand dieses Abschnitts lassen sich fünf goldene Rechtecke erkennen (1 und 4). Das goldene Rechteck auf der Höhe von Textfeld XV enthält den Titel von Q 33 (Sūrat al-Aḥzāb). ${ }^{67}$ Am rechten Rand des Textfelds folgen die Überschriften von Suren $35^{-38}$. Der Schreiber muss sich hier bewusst geworden sein, dass ihm beim Notieren der Überschriften der Suren ein Fehler unterlaufen war. Er lässt deshalb die Überschrift zu Q 34, Sūrat Saba', aus; der Text der Sure ist aber sehr wohl vorhanden. Am Anfang von Textfeld Xvi folgt die Überschrift von Q 35 (Sūrat Fāțir; Spuren von Korrekturen erkenntlich). Der Surentext selbst wurde darauf auf weitgehend horizontal ausgerichteten Zeilen kopiert. Auf der Höhe des in die Länge gezogenen $h \bar{a}^{3}$ von lā yarhamu folgt in einem goldenen Viereck am rechten Rand die Überschrift von Q 36

64 Vgl. Abb. Is 1623.C B L.10 und Is 1623.1706-1707 (Hauptzählung 70-75).

65 Dieses Prophetenwort lässt sich nachweisen bei Muslim, Șahīh, Kitāb al-Faḍāill, Hadīt Nr. 4290 (vgl. http://library .islamweb.net/hadith/display_hbook.php?bk_no=158\&h id=429o\&pid=1080o1; mit der Zusammenstellung von insgesamt 10o Stellen mit derselben Aussage unter dem Reiter tahrǐğ; Stand 6. Januar 2018); vgl. auch Anm. 95.

66 Wechsel von Textfeld Xv zu Textfeld XVI.

67 Der Titel ist hier ohne Artikel notiert worden (Sūrat-i $A h z \bar{a} b)$, was auf eine persische Herkunft des Belegstücks schliessen lässt; siehe zur Frage bereits oben zwischen Anm. 22 und 23. 
(Sūrat Yā-sìn). Der Text von Q 36 lässt sich hier auch klar erkennen und ist auf mehr oder weniger horizontal ausgerichteten Zeilen notiert worden, die sich unter Auslassung der für den übergeordneten Text vorgesehenen Stellen zumeist über die gesamte Breite der Rolle erstrecken. Auf der Höhe des Buchstabens sin im Ausdruck an-nās folgt ein weiteres goldenes Viereck mit der Überschrift zu Q 37 (Sūrat-i Șäffāt). ${ }^{68}$ Auf der Höhe der stark gedehnten Länge des $h \bar{a}$ im zweiten Textfeld mit lā yarhamu-hū folgt in einem goldenen Viereck am rechten Rand die Überschrift zu Q 38 (Sūrat $S \bar{a} d)$. Der Text der Sure folgt auch hier in $\dot{G} u b \bar{a} r-$ Schrift, wobei der Kopist bei der Abschrift nicht immer auf derselben Zeile bleibt, sondern wiederholt zwischen den Zeilen hin- und herspringt.

Feld XVII (АВB. 117):69 Dieses Feld enthält keinen übergeordneten Text. Es wird vielmehr von einer sechsteiligen blauen und goldenen Verzierung auf einem $\dot{g} u b \bar{a} r$-farbenen Hintergrund dominiert. Anfang und Ende dieses Abschnitts werden auch hier von einer $\dot{g} u b \bar{a} r$-freien Klammer markiert. Länge dieses Abschnitts über die beiden Klammern: $35.0 \mathrm{~cm}$.

Die sechsteilige Verzierung in diesem Abschnitt ist ähnlich aufgebaut wie jene in Feld $\mathrm{IX}^{70}$ erscheint gegenüber dieser allerdings entlang der horizontalen Achse gespiegelt. Während die sechs Teilfiguren in Feld IX nach oben ausgerichtet sind, sind jene in diesem Feld nach unten ausgerichtet. Die sechs mehrteiligen Figuren werden durch goldene Linien gebildet und weisen mit der Spitze in Richtung Dokumentende. Die Übergänge zwischen den einzelnen Figuren sind zusätzlich dunkelblau markiert. Ausserdem werden die sechs Figuren auch seitlich durch blaue Verzierungen mit einem goldenen Muster hervorgehoben.

Entlang dieses Abschnitts lassen sich am rechten Rand fünf goldene Rechtecke mit den Über-

68 Dieser Titel hier erneut ohne Artikel; vgl. dazu oben zwischen Anm. 22 und 23.

69 Vgl. Abb. Is 1623.CBL.10-11 und Is 1623.1708-1709 (Hauptzählung 73-84).

70 Vgl. nach Anm. 34 und Abb. Is 1623.CBL.6. schriften zu den hier kopierten Suren erkennen. Ganz am Anfang des Abschnitts die Überschrift Sūrat az-Zumar ${ }^{71}$ (Q 39). Auf der Höhe der zweiten Teilfigur folgt die Überschrift zu Q 40 (Sürat al-Mu'min, auch als Sūrat $\dot{G} \bar{a}$ fir bekannt). Auf der Höhe der vierten Teilfigur folgt der Titel von Q 41 (Sūrat Fușșilat). Auf der Höhe der fünften Teilfigur das nächste Titelfeld mit goldenem Hintergrund; der Eintrag ist hier kaum noch zu erkennen. $\mathrm{Zu}$ erwarten ist Q 42 (Sūrataš-Šūrā); sie beginnt unterhalb des goldenen Titelfelds. Ganz am Ende dieses Felds XVII ein weiteres goldenes Viereck; es enthält die Überschrift Sūrat-i Zuhruf (Q 43). ${ }^{72}$ Diese Sure folgt auf den weitgehend horizontal ausgerichteten Zeilen. Auch hier immer wieder Bruchstellen in der Textabfolge; der Schreiber springt zwischen den einzelnen Zeilen hin und her.

Textfelder XVIII-XIX (АВB. 118-119): ${ }^{73}$ Es schliessen sich zwei weitere Textfelder mit einem übergeordneten Text in Nastaliq an, die inhaltlich zusammengehören. Die beiden Felder enthalten Informationen zum Kopisten des Dokuments, die man üblicherweise im Kolophon erwartet, hier aber sehr prominent notiert worden sind. Auch diese beide Abschnitte werden von je zwei Klammern eingefasst. Ihre Länge beträgt $24.2 \mathrm{~cm}$ (Textfeld XVIII) bzw. 31.0 cm (Textfeld XIX), wobei zwischen den beiden Textfeldern ein gewisser Abstand ausgelassen wurde. Der Inhalt der beiden كتبه العبد الفقير الم الله الغني ||74 مظفر . بن عبد اللهّ الحسني 75 المازندراني.

71 Hier mit Artikel.

72 Hier erneut ohne Artikel (vgl. oben zwischen Anm. 22 und 23).

73 Vgl. die Abb. Is 1623.1710-1711 und Is 1623.CBL.12 (Hauptzählung 82-90).

74 Wechsel von Textfeld XviII zu Textfeld XIX.

75 Die anfänglich ins Auge gefasste Lesung al-Husayn wurde verworfen. Die Stelle ist punktiert, wobei sich am rechten Rand drei auf der Spitze stehende goldene Vierecke erkennen lassen. Sie gehören zum Buchstaben sin der auf diesem Dokument durch drei Punkte unterhalb der Zeile markiert wird. Wäre Husaynī zu lesen, müssten irgendwo noch zwei zusätzliche Punkte zur Markierung des $y \bar{a}^{\prime}$ folgen; diese Punkte fehlen aber. Das nūn in 
Der Schreiber erwähnt seinen Namen hier sehr prominent; er stellt sich damit implizit auf dieselbe Stufe wie die Čahārdah Mașūm, die in ähnlich gestalteten Textfeldern am Anfang des Dokuments angeführt werden.

Entlang dieser beiden Abschnitte lassen sich am rechten Rand weitere Vierecke mit goldenem Hintergrund erkennen. Sie enthalten die Überschriften zu den nächsten 15 Suren. Am rechten Rand von Textfeld XVIII stehen die Titel von Suren $44-49 .{ }^{76}$ Danach folgen am rechten Rand von Textfeld XIX die Überschriften von Suren $5 \mathrm{O}^{77}$ $59^{78}$.

Schlussteil Xx: ${ }^{79}$ Mit Textfeld XIX gehen jene Abschnitte zu Ende, die einen übergeordneten Text in Nastacliq enthalten. Die Länge dieses Schlussteils beträgt $74 \mathrm{~cm}$; ganz am Schluss folgt ein querliegendes Rechteck ohne Inhalt, dessen Höhe ca. $5 \mathrm{~cm}$ beträgt (zusätzlich zu den $74 \mathrm{~cm}$ davor). Am Anfang dieses Abschnitts fällt eine dreiteilige goldene Verzierung auf, die ähnlich gestaltet ist wie die 16-teilige Kette in Feld XII. Ansonsten wurde ab hier einfach noch der Surentext in $\dot{G} u b \bar{a} r$ kopiert, wobei die Zeilen horizontal ausgerichtet sind. Die Surentitel werden weiterhin in goldenen Vierecken notiert. Nach der dreiteiligen Verzierung sind diese Vierecke aber nicht mehr am rechten Rand angeordnet, wie dies zuvor der Fall gewesen war, sondern sie können durchaus auch im Innern des Schriftspiegels stehen, wenn es die Textfolge erfordert. Diese goldenen Vierecke enthalten ab hier nur noch den Surennamen. Der Begriff Sūra selbst wird in diesem Schlussteil weggelassen. Ganz am Schluss des Dokuments steht Q 114 (Sūrat an-Nās), die letzte Sure im Koran. Das vorliegende Belegstück sollte somit - allfällige

Hasan̄ wird dann wieder durch einen Punkt oberhalb der Zeile markiert. al-ganī. Bei der Abschrift des Texts springt der Kopist wiederholt zwischen den einzelnen Zeilen hin und her.

77 Sūrat Qāf.

78 Sūrat al-Hašr.

79 Vgl. Abb. Is 1623.1712-1716 und Is 1623.CBL.13-14 (Hauptzählung 90-102).
Kopistenfehler ausgenommen - eine Abschrift des gesamten Korantexts enthalten.

Ganz am Ende des Dokuments folgt eine Schlussformel und die Datierung (Jahr 986 h.q.; beginnt am 10. März 1578); danach folgt das bereits erwähnte Rechteck von $5 \mathrm{~cm}$ Höhe ohne Texteintrag. Der hier notierte Teil des Kolophons lautet (АBB. 12O):

$$
\text { والشاهدين سنه سته الله العظيم وصدق رسوله الكريم ونحن على ذلك من }
$$

Eintrag Rückseite: Auf der Rückseite befinden sich am Schluss des Dokuments zwei später angebrachte und teilweise getilgte Einträge, die sich nicht mit Gewissheit entziffern liessen. Der obere Eintrag dürfte auf Osmanisch-Türkisch abgefasst worden sein. Deutlich erkenntlich ist eigentlich nur der Name Ṣāliḥ Sulțān, auf der Zeile darunter steht allenfalls „Allāh tacāāa“. Die Entzifferung gestaltet sich auch schwierig, da der Eintrag gerade am Anfang mehrfach durchgestrichen worden ist. Die Entschlüsselung des zweiten Vermerks ist mit noch grösseren Schwierigkeiten verbunden.

Schlussfolgerungen: Das vorliegende Belegstück ist aus unterschiedlichen Gründen besonders interessant. Die darauf kopierten Textstellen und ausgewählte weitere Elemente gestatten eine recht präzise Einordnung dieser Rolle. Die folgenden Ausführungen stellen in einem ersten Schritt die darauf enthaltenen Textstellen nochmals zusammen. Dieses Dokument enthält:

a. eine mutmasslich vollständige Abschrift des Korans in $\dot{G} u b \bar{a} r$. Dieser Text ist wiederholt vertrackt angeordnet. Diese Feststellung trifft gerade auf Stellen in $\dot{G} u b \bar{a} r$ in den einzelnen Medaillons zu. Auch an andern Stellen lassen sich aber Textanordnungen nachweisen, die nicht den horizontalen Zeilen folgen.

Ausserdem lassen sich in den über die Länge der gesamten Rolle verteilten Rechtecken die folgenden weiteren Textstellen nachweisen: 
b. Eine Anrufung der bzw. Euologie auf die Čahārdah Mașūm. ${ }^{80}$ Es handelt sich um jene Gruppe von 14 Personen, zu der neben den zwölf schiitischen Imamen Muhammad und Fāṭima, hier al-Batūl genannt, zählen. Auch die Imame werden mit ihren Beinamen angerufen:81

$$
\begin{aligned}
& \text { I. بسم الله الرمن الرحيم II II. اللهم صل على النبى82 }
\end{aligned}
$$

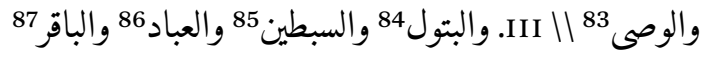

$$
\begin{aligned}
& \text { IV || والصادق والكاظم والرضاء88 || V. V. والتتي والنتي }
\end{aligned}
$$

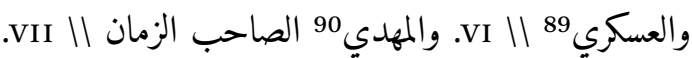

$$
\begin{aligned}
& \text { خليفت الرحمن صلوات الله || VIII. عليه وعليهم اجمعين ||. }
\end{aligned}
$$

c. Das nächste Textelement ist das Nädi-'Alī-Gebet. Es ist über vier Textfelder verteilt. Es wird unterbrochen durch eine auffällige goldene Verzierung. Sie befindet sich zwischen den Textfeldern XI und XIII und besteht aus den beiden folgenden Teilen: a. ein vierfaches 'Alī, das durch eine Art Kelch getragen wird; $b$. aus diesem kelchartigen Zierelement geht absteigend eine sorgfältig gestaltete sechzehngliedrige Kette hervor. Diese Elemente erlauben Rückschlüsse auf die Zuordnung dieser Rolle. Beim Nādi-'Alī-Gebet handelt es sich gemäss M.A. Amir-Moëzzi um einen in der Zwölferschia

8o Vgl. dazu Algar, Čahārdah Ma'ṣūm, in EIr.

81 Die römischen Ziffern in der folgenden Übersicht beziehen sich auf die Textfelder.

82 Also den Propheten Muhammad.

83 Mit al-wașī ist 'Alī, der erste Imam der Schiiten und vierte rechtgeleitete Kalif der Sunniten gemeint.

84 Mit al-batūl („die Jungfrau“) ist Fāțima, Muhammads Tochter und 'Alīs Frau, gemeint.

85 Der Ausdruck as-sibțān („die beiden Enkel“) bezieht sich auf Hasan und Husayn, den 2. und 3. Imam der Schiiten. Es sind die beiden Enkel des Propheten Muhammad. $A l$-'Abbād ist der Beiname von 'Alī Zayn al-'Ābidīn, dem 4. Imam.

87 Al-Bāqir: 5. Imam.

88 6.-8. Imam: aṣ-Ṣādiq, al-Kāẓim, ar-Riḍā.

89 Es folgt die Erwähnung des 9.-11. Imams mit ihren jeweiligen Beinamen: at-Taqī, an-Naqī, al-'Askarī.

9o Al-Mahdī, der 12. Imam. weit verbreiteten $\underline{\text { dikr. }} .^{91}$ In der Dahabiyya wird er Dikr al-walāya genannt. Dieser dikr wird hier vollständig erwähnt und lautet: ${ }^{92}$

$$
\begin{aligned}
& \text { | ناد عليا مظهر العجايب ||X | تجده عونا لك في النوايب. } \\
& \text { XIII }
\end{aligned}
$$

Oft werden nur die beiden ersten Begriffe $N a \bar{d} i$ 'Alī erwähnt; sie rufen dem Rezitierenden den gan-

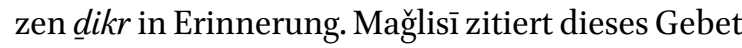
übrigens im Bihar al-anwār. ${ }^{93}$ Eine unsichtbare Stimme (hätif) oder der Erzengel Gabriel soll dieses Gebet vor der Schlacht von Uhud Muhammad übermittelt haben. Es ist sogleich nochmals auf diesen Abschnitt mit dem Nādi-'Alī-Gebet zurückzukommen. ${ }^{94}$

d. Die Aussage in den beiden nächsten Textfeldern (XV-XVI) kann Muhammad selbst zugeschrieben werden. Es handelt sich somit um ein Prophetenwort; es lautet: ${ }^{95}$

91 Siehe Amir-Moëzzi, The spirituality of Shii Islam 352, der die folgende Übersetzung vorschlägt „Invoke 'Alī, locus of manifestation of wonders / In him you will find support in all trials / All your worries and hardships will vanish / By the grace of your walāya. O 'Alī, o 'Alī, o 'Alī."

92 Dieses Gebet steht ebenso auf der Rolle Arabe 5102 aus dem 18. Jh. in der Bibliothèque Nationale de France; siehe dazu unten Kapitel 5.4 (vor Anm. 74 und bei Anm. 114116). Es lässt sich ebenso auf einem Belegstück aus dem Osmanischen Reich in der Staatsbibliothek zu Berlin nachweisen, wo es um ein Element angeordnet worden ist, das als Šakl-i 'ayn-i 'Alī bekannt ist (vgl. Ms. or. oct. 403, Mikrofilm, Aufnahme 15).

93 Mağlisī, Bihāar al-anwār xx, 73. Bayrūt, 1403/1983. Aufrufbar unter http://www.yasoob.org/books/htmı/mo13/ 12/no1299.html (Stand 4. Oktober 2017).

94 Vgl. unten vor Anm. 97.

95 "Jene Person, die gegenüber den Leuten kein Mitleid zeigt, gegenüber der zeigt Allāh kein Mitleid.“ Dieses Prophetenwort lässt sich nachweisen bei Muslim, Saḥīh, 44 Kitāb al-Fadāìl, 15 Bāb Rahmati-hī, Hadīt 6172; cf. Wensinck, Concordance, s.v. rahima (II, 236). Gelegentlich mit leicht abweichendem Wortlaut: لا يرحم الله من لا يرحم الناس; z. B. Buhārī, Ṣahịh, 98 Kitāb at-Tawhì̄, 2 Bāb Qawl Allāh tabāraka wa-ta'ālā, Hadīt 7465; vgl. auch Anm. 65 . 


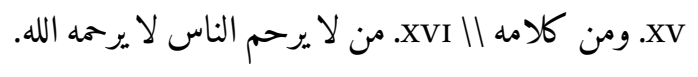

e. Der Vollständigkeit halber sei hier erneut darauf hingewiesen, dass der Kopist in den beiden Textfeldern XVIII und XIX sehr prominent seinen Namen erwähnt; dies stellt gewissermassen den ersten Teil des Kolophons dar. Die Datierung der Abschrift ins Jahr 986/1578 folgt im Mittelstreifen selbst ganz am Schluss.

$$
\text { الله الحسني } 96 \text { المازندراني. كVIII }
$$

Die Aufzählung der zwölf Imame, das NādiAlī-Gebet und die beiden golden ausgeführten Verzierungen (vierfache Erwähnung 'Alīs in der Form einer Swastika und die sechzehngliedrige Kette) gestatten interessante Rückschlüsse auf die Einordnung dieses Belegstücks. Während der Abschnitt mit dem vierfachen 'Alī eher kurz ist (ca. 6.o cm), ist der Teil mit der Kette lang (ca. $58.5 \mathrm{~cm})$. Diese Kette trägt das vierfache 'Alī darüber.

Die goldene Kette selbst wird durch zwei Elemente gebildet: Unterhalb des vierfachen 'Alis befindet sich ein flaches, horizontal ausgerichtetes Rechteck mit einer Ausbuchtung auf jeder Seite (Höhe dieses Rechtecks ca. $2.2 \mathrm{~cm}$ ). Das nächste Glied in dieser Kette ähnelt einem unregelmässigen Achtpass (Höhe ca. $4.6 \mathrm{~cm}$ ). Diese beiden Elemente werden acht Mal wiederholt und bilden so die erwähnte sechzehngliedrige Kette. Die Überschneidungen zwischen den einzelnen Gliedern der Kette, wo sich vorwärtslaufendes und rückwärtslaufendes Band kreuzen, sind ausgesprochen sorgfältig gearbeitet worden.

Diese beiden Verzierungen (vierfaches 'Alī, sechzehngliedrige Kette) müssen bewusst hier platziert worden sein, wo sie das Nādi-'Alī-Gebet unterbrechen. Ihre Erklärung führt uns in einem ersten Schritt zu M.A. Amir-Moëzzis Bemerkung zurück, dass das Nādi-Ali-Gebet unter zwölfer-

96 Vgl. Anm. 75 . schiitischen Mystikern weit verbreitet war und in der Dahabiyya Dikr al-walāya genannt wird.

Die Dahabiyya ist aus dem Sufi-Orden der Kubrāwiyya hervorgegangen; sie war gerade zur Zeit der Safawiden in Iran aktiv. ${ }^{97}$ A. Anzali bezeichnet die Dahabiyya und die Ni'matullāhiyya als die beiden aktuell bedeutendsten schiitischen Sufi-Orden in Iran. ${ }^{98}$ Seit der Qāğāren-Zeit ist Shiraz das Hauptzentrum der Dahabiyya. Doch dieser Orden war dort bereits zuvor etabliert.

Der Begriff Dahabiyya reiht sich nicht unter die üblichen Bezeichnungen von mystischen Orden ein, die zumeist nach ihren charismatischen Gründern benannt werden. ${ }^{99}$ Die Dahabiyya leitet ihren Namen vom arabischen Begriff dahab, „Gold“, ab. Quellen aus dem Umfeld der Dahabiyya heben den Symbolismus von Gold hervor, bei dem es sich um eine wertvolle, reine Substanz handelt. ${ }^{100}$ Die an der Herstellung von Is 1623 beteiligten Kunsthandwerker müssen sich dieses Symbolismus bewusst gewesen sein und machten ausgiebigen Gebrauch von goldener Tinte. Diese Feststellung trifft gerade auf den hier diskutierten Abschnitt mit den beiden Verzierungen zu. Zusätzlich rahmen aber auch zwei goldene Zierbänder das Dokument zur Linken und Rechten auf seiner gesamten Länge ein.

Dahabiyya-Quellen betonen den besonderen Wert ihrer spirituellen Überlieferungskette (silsila). Sie vergleichen sie mit reinem Gold (dahab), da sie gänzlich frei von sunnitischen Gewährs-

97 Vgl. Anzali, Emergence 149. Zur Dahabiyya vgl. auch Gramlich, Derwischorden Persiens. Erster Teil: Die Affiliationen 4-26; Dritter Teil: Brauchtum und Riten, u.a. 41-44, $78 \mathrm{f}$.

98 Vgl. Anzali, op. cit. 15 o.

99 Für die weiteren Ausführungen siehe Anzali, op. cit. $153^{-156 .}$

100 Gemäss Anzali, op. cit. 153, leiten der Dahabiyya nicht wohlgesinnte Quellen den Namen dieses Ordens vom arabischen Verb dahaba, „gehen, weggehen“, ab. Diese Erklärung würde darauf anspielen, dass Sayyid 'Abdullāh Barzišābādī (gest. ca. 1467) seinen Lehrer Isḥāq Huuttalānī (gest. 1423) verliess, als dieser Sayyid Muḥammad Nūrbahš (gest. 1440) vorzog und ihn als seinen Nachfolger einsetzte. 
leuten sei. ${ }^{101}$ Sie nennen diese Überlieferungskette deshalb die "Goldene Kette“ (as-silsila addahabiyya). A. Anzali führt ausserdem frühere Belege dafür an, die die besondere Bedeutung dieser goldenen Überlieferungskette betonen. ${ }^{102}$ Schiitische Quellen aus dem 13. Jh. berichten von einem Samaniden-Herrscher, der von der ausserordentlichen Qualität der Überlieferungskette mit den ersten acht schiitischen Imamen von 'Alī b. Abī Ṭālib (gest. 661) bis 'Alī b. Mūsā ar-Riḍā (gest. 818) weiss. Er habe diese Kette deshalb mit Gold niederschreiben lassen. Im 15. Jh. hat der bekannte schafiitische Hadīt-Gelehrte Ibn Ḥağar al-Asqalānī (gest. 1449) eine Sammlung von Überlieferungen mit einer ausserordentlich kurzen und damit besonders zuverlässigen Garantenkette zusammengestellt. A. Anzali betont allerdings, dass dieser Ausdruck erst nach den ersten Dekaden des 15 . Jh. zur Bezeichnung einer auf 'Alī zurückgehenden Kette überhaupt in Gebrauch kam.

M.H. Faghfoory interessiert sich in der Einleitung zu seiner Übersetzung von Mu'adddins (gest. 1667) Tuhfa-i 'Abbāsī103 ebenso für den Begriff $a s$ silsila ad-dahabiyya. ${ }^{104}$ Er verweist auf den Standpunkt gewisser weiterer Historiker, die glauben „that since in the genealogy of the order the names and titles of the Shicite Imams who were considered as the Poles of their time were written in gold, the order became known as Silsilat adh-dhahab (Chain of Gold) from which the titles Dhahabi and Dhahabiyya are derived." ${ }^{05}$ M.H. Faghfoory fügt eine Liste hinzu, die weitere bedeutende Pole (quṭb) des Dahabiyya-Ordens nach 'Alī b. Mūsā arRiḍā (8. Imam) anführt, die vor dem Verfasser der Tuhfa-i 'Abbāsī lebten.

\footnotetext{
101 Anzali, op. cit. 153, betont, dass sich diese Auffassung aus historisch-kritischer Perspektive unmöglich beweisen lasse. Anzali, op. cit. 154. Bei Mu'addins Tuhfa-i 'Abbāsī handelt es sich um einen Text, der für das Verständnis des schiitischen Sufismus besonders wichtig ist.

104 Faghfoory, Tuḥfah-yi 'Abbāsī X-XIII.

105 Faghfoory, op. cit. XI. M.H. Faghfoory identifiziert diese „other historians“ nicht.
}

Die soeben festgehaltenen Beobachtungen laufen darauf hinaus, dass das vorliegende Belegstück im Umfeld des Dahabiyya-Ordens, mit grosser Wahrscheinlichkeit in Shiraz, entstanden sein muss. Dies ergibt sich aus der Kombination der folgenden Feststellungen:

- L. Uluç weist auf die Bedeutung der Hațầ $\bar{l}-$ Blüten hin und bezeichnet sie als Charakteristikum der Miniaturmalerei in Shiraz zwischen 1570 und 1580. ${ }^{106}$

- M.A. Amir-Moëzzi betont sodann die Wichtigkeit des Nādi-Ali-Gebets als bedeutender Dikr unter imamitischen Sufis. Es sei in der Dahabiyya als Dikr al-walāya bekannt. ${ }^{107}$

- A. Anzali weist auf die Entwicklungen der Dahabiyya zwischen dem 15 . und 17. Jh. hin. ${ }^{108}$

- M.H. Faghfoory macht in seiner Einführung zu Mu'addins Tuhfa-i 'Abbāsī bei der Diskussion des Begriffs as-silsila ad-dahabiyya ausserdem auf weitere Zusammenhänge aufmerksam.

Es ist schwierig, den unwiderlegbaren Beweis dafür führen zu wollen, unter welchen konkreten Umständen das vorliegende Belegstück entstanden ist. Wir haben vor dem Hintergrund der angeführten Überlegungen aber sehr gute Gründe zur Annahme, dass Muẓaffar b. 'Abdallāh al-Hasanī alMāzandarānī, der Schreiber dieser Rolle, in engem Austausch mit dem Dahabiyya-Orden in Shiraz stand und dieses Belegstück allenfalls in Shiraz selbst herstellte.

106 Vgl. bei Anm. 10.

107 Vgl. bei Anm. 91 und vor Anm. 97.

108 Vgl. bei Anm. 103-105. 


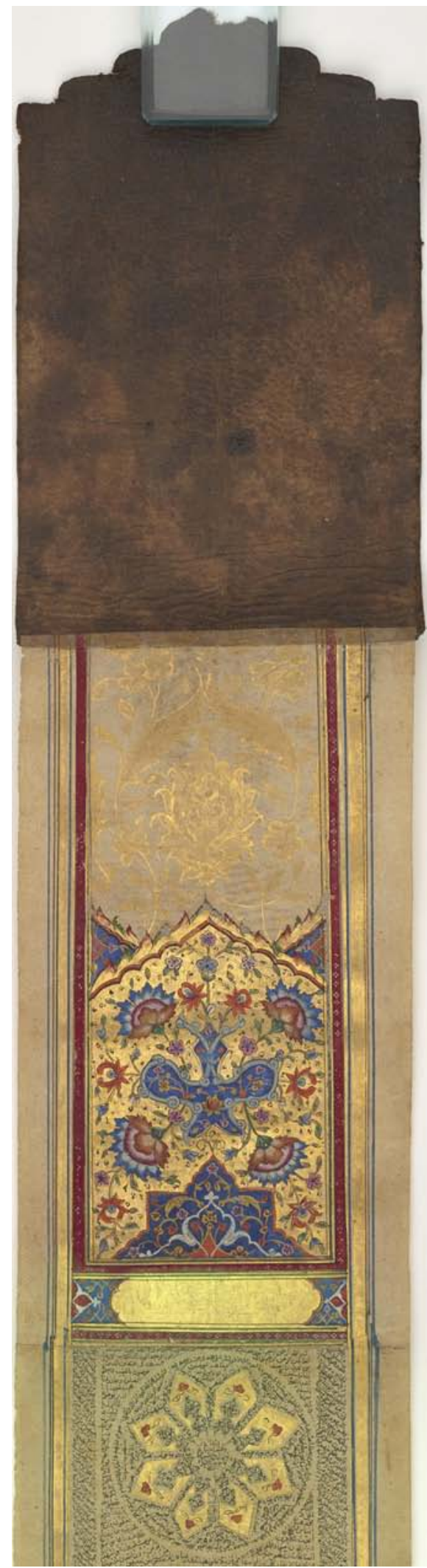

ABB. 109

Dublin, Chester Beatty Library, Is 1623 (vgl. bei Anm. 9-11): Die Rolle beginnt mit einem ausgesprochen sorgfältig gearbeiteten Anfangszierfeld von ca. $12 \mathrm{~cm}$ Höhe. Es enthält Elemente, die eine Herstellung in Shiraz nahelegen (siehe Beschreibung). Darunter beginnt der Abschnitt mit der Abschrift des Korans in $\dot{G} u b a \bar{r}$. Der Text ist am Anfang in drei Spalten angeordnet.

(C) THE TRUSTEES OF THE CHESTER BEATTY LIBRARY, DUBLIN (CHESTER BEATTY, DUBLIN. CC BY-NC 4.0) 


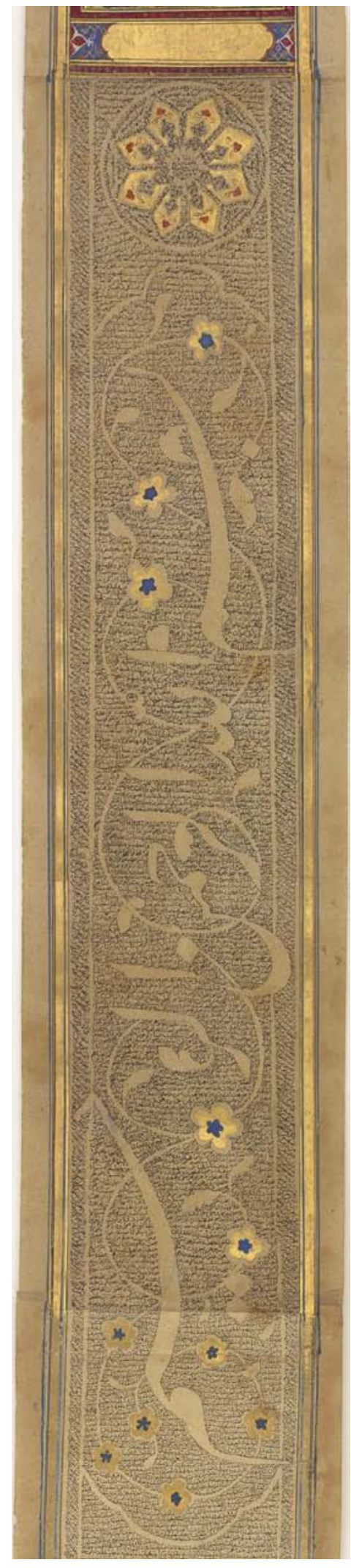

ABB. 110

Dublin, Chester Beatty Library, Is 1623 (vgl. bei Anm. 14): Die Rolle enthält Abschnitte, in denen der Schreiber Stellen derart ausgespart hat, dass übergeordneter Text entsteht. Im 1. Textfeld lässt sich als übergeordneter Text die Basmala erkennen. Auf dem $\dot{g} u b \bar{a} r$-farbenen Hintergrund stehen hier Q 1-2. (C) THE TRUSTEES OF THE CHESTER BEATTY LIBRARY, DUBLIN (CHESTER BEATTY, DUBLIN. CC BY-NC 4.0) 


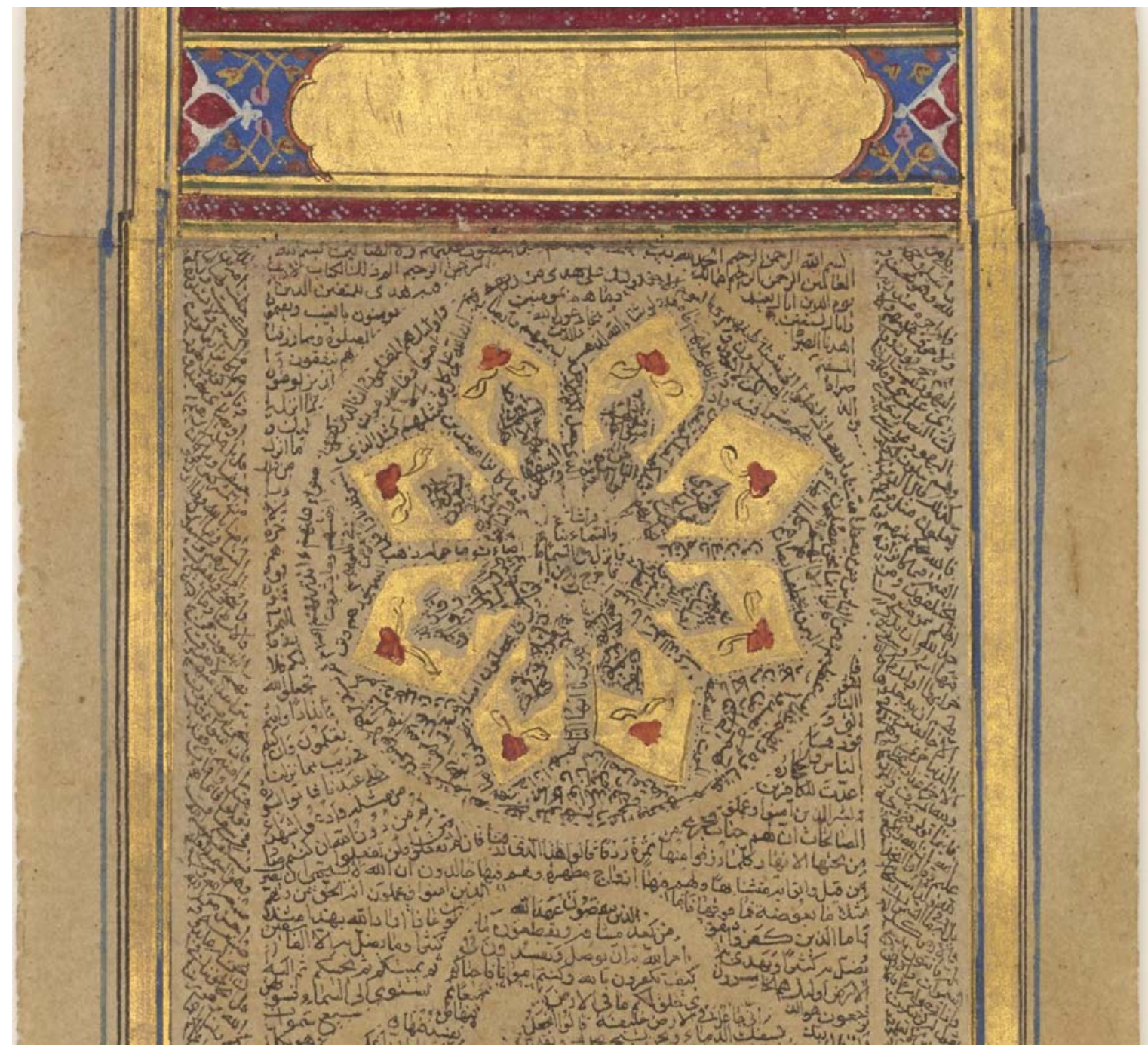

ABB. 111

Dublin, Chester Beatty Library, Is 1623 (vgl. nach Anm. 14 und zwischen Anm. 114 und 115): In der Mittelspalte beginnt rechts oben Q 1 (Sürat al-Fātih̆a). Oben links steht die Basmala von Q 2. Der Schreiber kopiert hier links absteigend ausserhalb des Medaillons Q 2:1-4. Er springt darauf zuoberst ins Medaillon und umfährt es auf der äussersten Zeile mit Text im Gegenuhrzeigersinn (Q 2:5-8a). Bei den weiteren Textstellen im Medaillon handelt es sich um die Fortsetzung der Abschrift von Q 2 (Verse 8b-22a).

(C) THE TRUSTEES OF THE CHESTER BEATTY LibRARY, DUblin (CHESTER BEATTy, DUBLIN. CC BY-NC 4.0) 


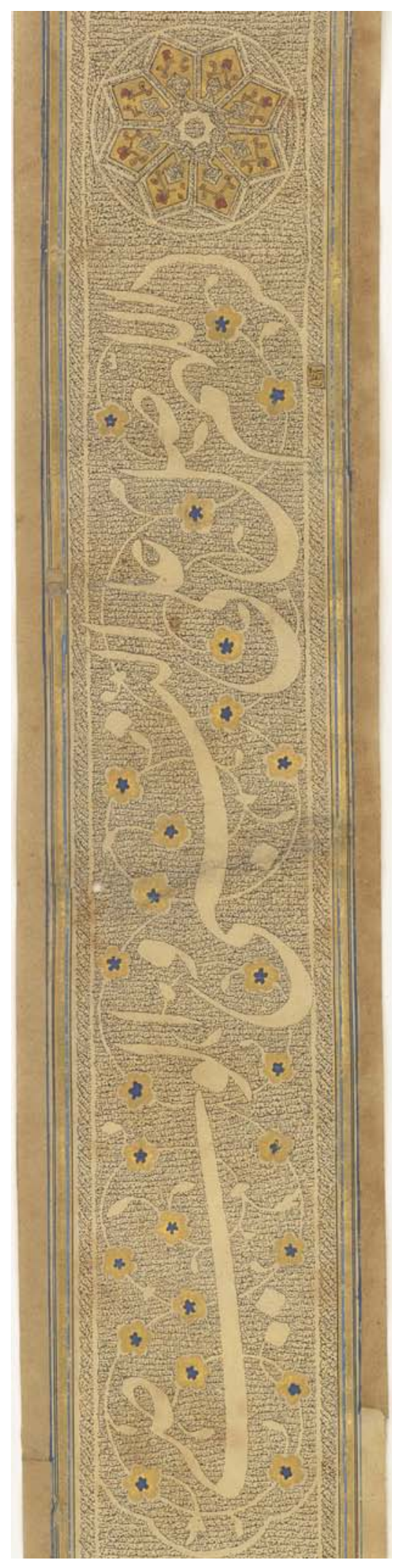

ABB. 112

Dublin, Chester Beatty Library, Is 1623 (vgl. bei Anm. 15): Mit Textfeld II beginnt die Anrufung der Čahārdah Mașūm (Muhammad, Fāṭima und die 12 Imame). Hier der Anfang: Allāhumma șalli 'alā n-nabī wa-l-wașì. Der übergeordnete Text wird durch Aussparungen auf dem $\dot{g} u b \bar{a} r$-farbenen Hintergrund gebildet. Man beachte auch das Rankenmuster mit den gold-blauen Blüten. Auf der Höhe des Allāhumma lässt sich in der rechten Aussenspalte ein goldenes Viereck erkennen. Es enthält die Überschrift zu Q 3 (Sürat Āl Imrān).

(C) THE TRUSTEES OF THE CHESTER BEATTY LIBRARY, DUBLIN (CHESTER BEATTY, DUBLIN. CC BY-NC 4.0) 


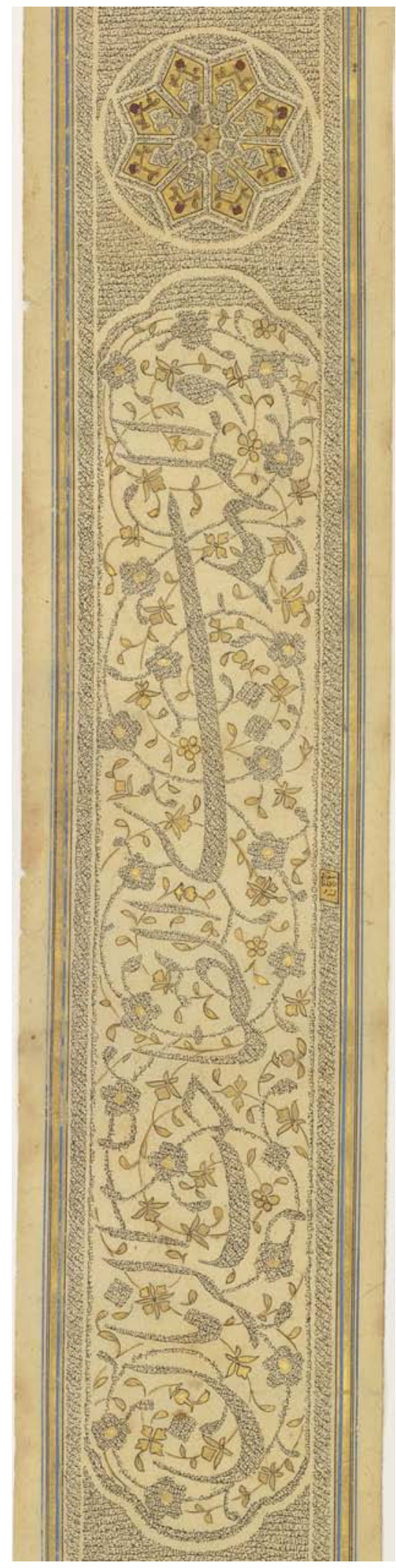

ABB. 113

Dublin, Chester Beatty Library, Is 1623 (vgl. bei Anm. 28-29): Die Anrufung der Čahārdah Ma șūm schliesst mit der Erwähnung des Mahdī. Der Künstler hat hier den Text in $\dot{g} u b a \bar{r}$-farbenem Nastaliq kopiert; der Hintergrund dieses Textfelds wird durch ein Rankenmuster gebildet, das ebenso aus Text in $\dot{G} u b \bar{a} r$ besteht.

(C) THE TRUSTEES OF THE CHESTER BEATTy LIBRARY, DUbLiN (CHESTER BEATTY, DUBLIN. CC BY-NC 4.0) 


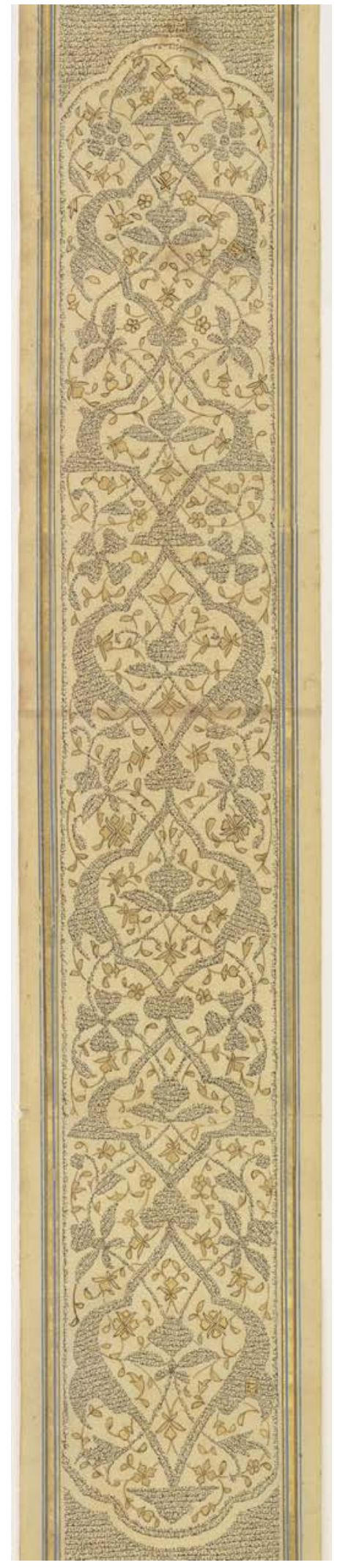

ABB. 114

Dublin, Chester Beatty Library, Is 1623 (vgl. bei Anm. 34-35): Nach dem Abschluss der Anrufung der Čahārdah Ma șūm folgt ein Abschnitt (Feld IX) ohne übergeordneten Text. Die Länge dieses Abschnitts beträgt $35 \mathrm{~cm}$. Oben rechts lässt sich in einem goldenen Quadrat die Überschrift zu Q 12 (Sürat Yüsuf) erkennen; unten rechts steht die Überschrift zu Q 13 (Sürat [ar-] Ra'd).

(C) THE TRUSTEES OF THE CHESTER BEATTy LibRARY, DUBLIN (CHESTER BEATTy, DUBLIN. CC BY-NC 4.0) 


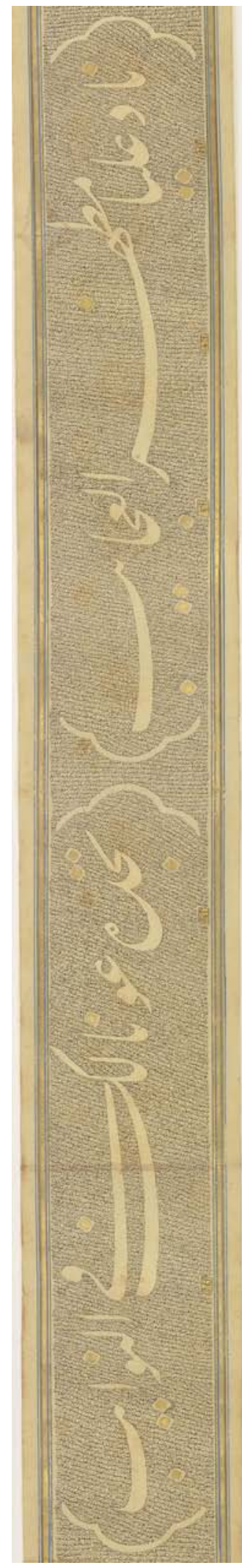

ABB. 115

Dublin, Chester Beatty Library, Is 1623 (vgl. bei Anm. 36-40): Mit Textfeld x beginnt die Abschrift des Nādi-Ali-Gebets, das unter Schiiten sehr beliebt ist. Man beachte, dass die Abschrift des Korans im Hintergrund hier nur noch in einer Spalte angeordnet ist. Die hier kopierten Koranstellen werden in der Beschreibung bestimmt.

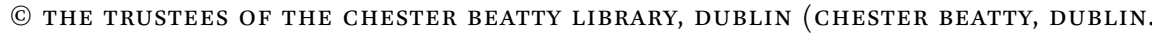
CC BY-NC 4.0) 


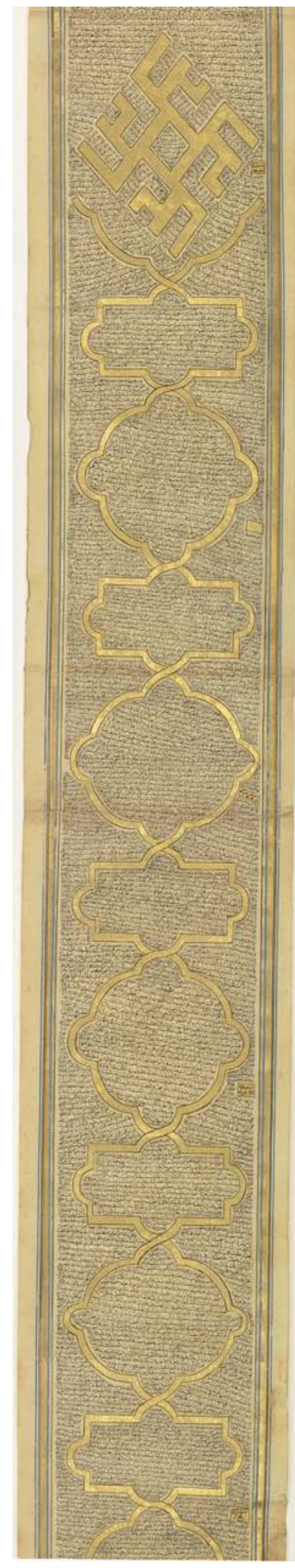

ABB. 116

Dublin, Chester Beatty Library, Is 1623 (vgl. bei Anm. 46-56): Feld XII ist ca. $65 \cdot 5 \mathrm{~cm}$ lang. Darauf dominieren goldene Verzierungen. Zuoberst lässt sich ein vierfaches 'Al̄̄ erkennen. Darunter befindet sich eine 16-gliedrige Kette $(8 \times 2$ Glieder $)$. Diese Verzierungen sind in Gold ausgeführt.

(C) THE TRUSTEES OF THE CHESTER BEATTY LIBRARY, DUBLIN (CHESTER BEATTY, DUBLIN. CC BY-NC 4.0) 


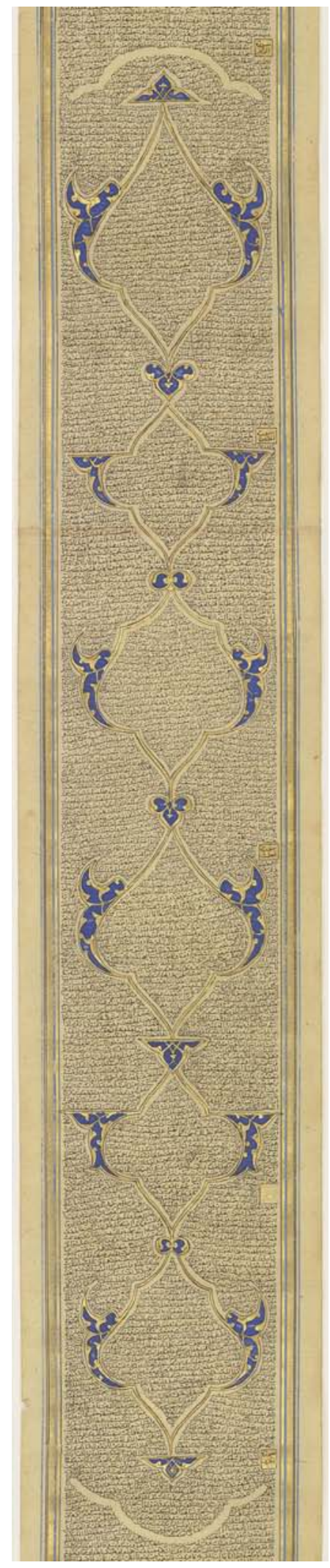

ABB. 117

Dublin, Chester Beatty Library, Is 1623 (vgl. bei Anm. 69-72): Feld XVII (Länge ca. $35.0 \mathrm{~cm}$ ) enthält keinen übergeordneten Text, sondern nur eine sechsfache Verzierung. Der Schreiber notierte den Korantext auf horizontalen Zeilen. Die Überschriften zu den Suren in roter Schrift auf goldenem Hintergrund.

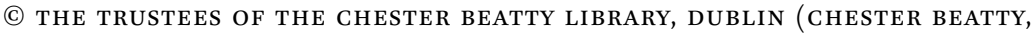
DUBLIN. CC BY-NC 4.0) 

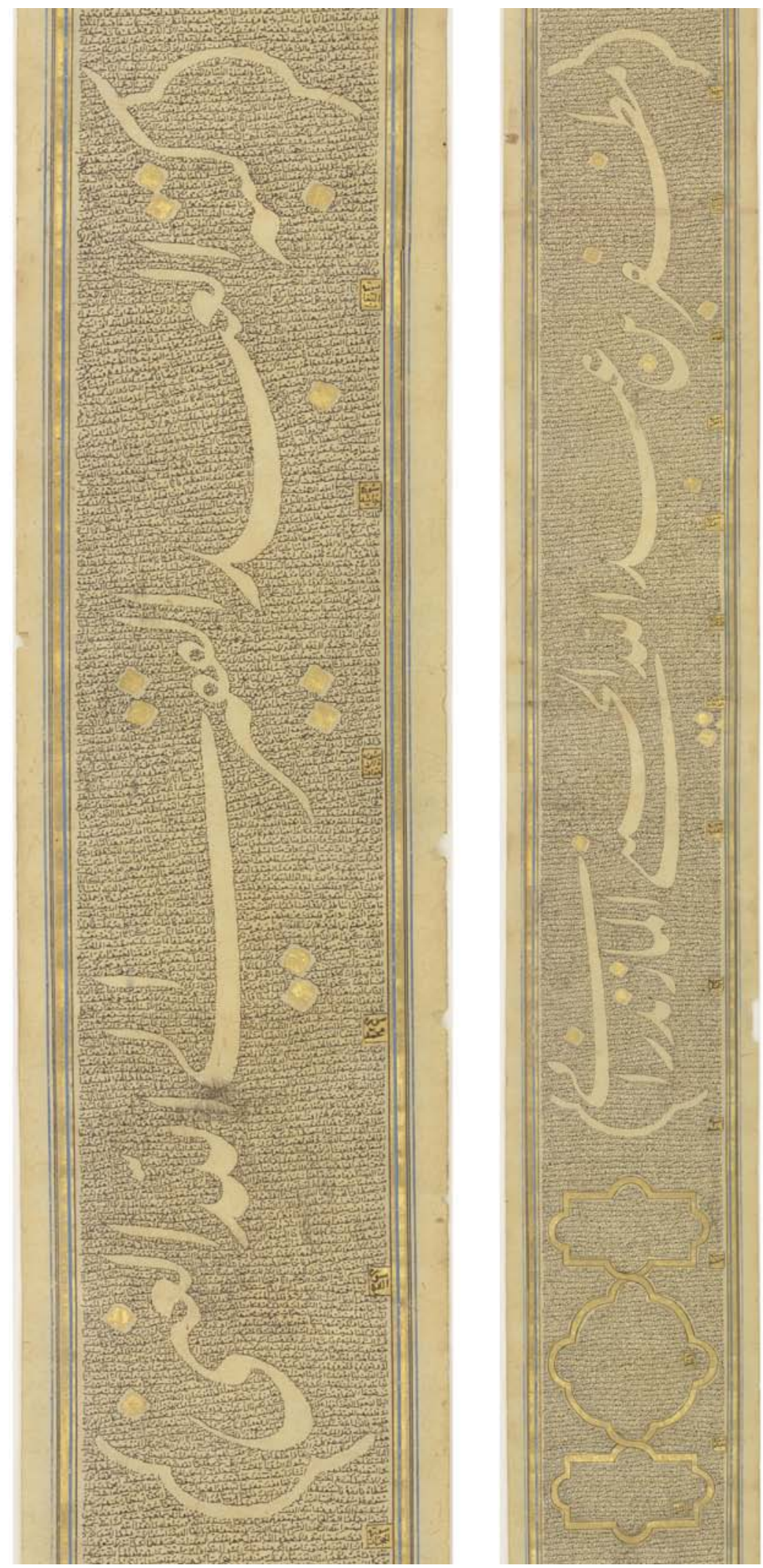

ABB. 118-119

Dublin, Chester Beatty Library, Is 1623 (vgl. bei Anm. 73-78): Textfelder XVIII-XIX enthalten Angaben, die üblicherweise im Kolophon zu erwarten sind: Katabahū al-'abd al-faqīr ilā [A]llāhi l-ġani // Muzaffar b. 'Abd Allāh alHasanī al-Māzandarānī (Name des Kopisten).

(C) THE TRUSTEES OF THE CHESTER BEATTY LIBRARY, DUBLIN (CHESTER BEATTY, DUBLIN. CC BY-NC 4.0) 


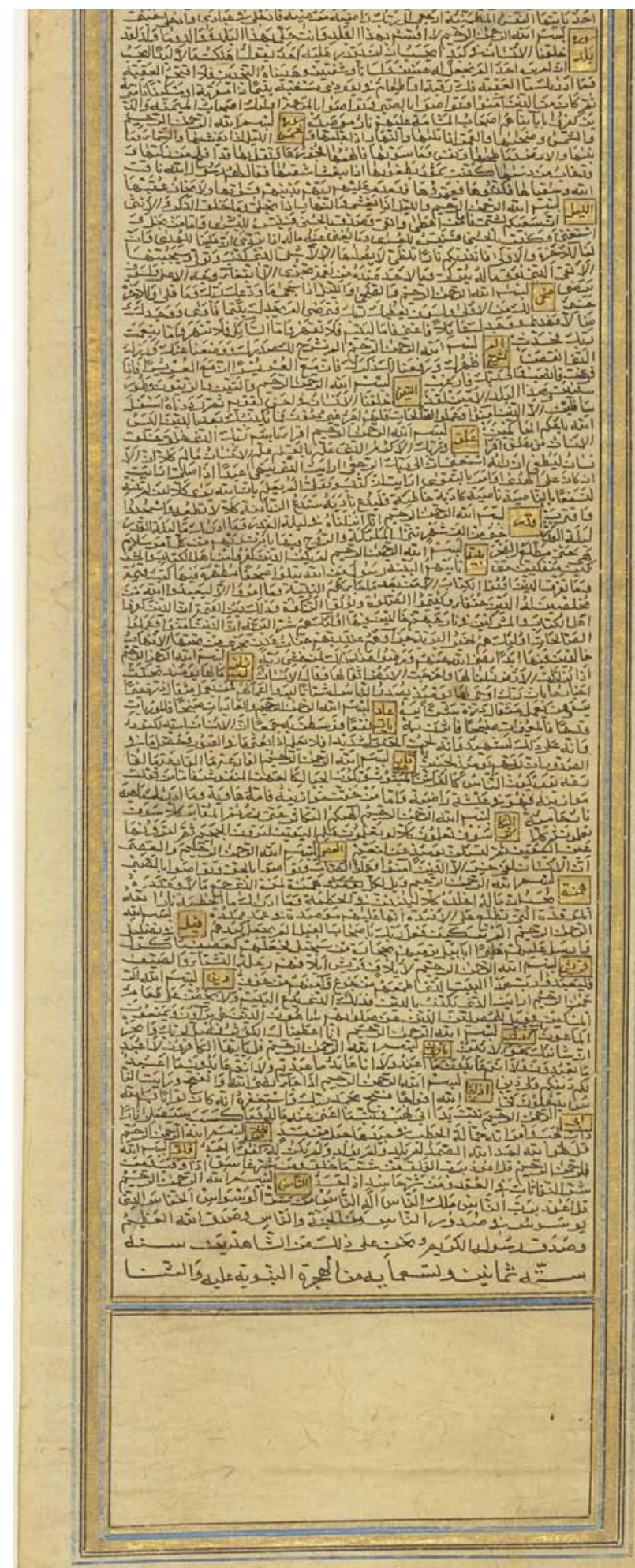

ABB. 120

Dublin, Chester Beatty Library, Is 1623 (vgl. zwischen Anm. 79 und 8o): Das Ende der Rolle. Auf den beiden letzten Zeilen die Datierung ins Jahr 986/1578. Im Text davor die Suren am Ende des Korans, zuletzt Q 114.

(C) THE TRUSTEES OF THE CHESTER BEATTY LIBRARY, DUBLIN (CHESTER BEATTY, DUBLIN. CC BY-NC 4.0) 
Paris, Bibliothèque Nationale de France, Arabe 5102

$10.7 \times 543 \mathrm{~cm} ;^{1}$ datiert ins 18. Jh. ${ }^{2}$ Beim Beschreibstoff handelt es sich um sehr dünnes, sehr gut geglättetes Papier, das nahezu transparent ist. ${ }^{3}$ Derartiges Papier stand ab der 2. Hälfte des 16. Jh. zur Verfügung. Ein Papier von ähnlicher Qualität wurde bereits zur Herstellung von Is 1623 (Chester Beatty Library, Dublin) verwendet, das aus dem Jahr 1578 datiert. ${ }^{4}$ Auf der Rückseite von Arabe 5102 sind keine Einträge vorhanden.

Bei der Herstellung von Arabe 5102 wurden zehn Papierstreifen zusammengeklebt; am Anfang des Dokuments befindet sich ein zusätzlicher Streifen aus violettem Papier, der nicht beschrieben ist. Die folgende Übersicht vermittelt einen Überblick über die Länge der einzelnen Streifen: o. Violetter Papierstreifen am Anfang separat: ca. $16 \mathrm{~cm}$; 1 . Streifen: ca. $57.2 \mathrm{~cm}$ (Überlappung $3 \mathrm{~mm}$ ); 2. Streifen (beginnt in Textfeld II): ca. $57.2 \mathrm{~cm}$ (Überlappung $3 \mathrm{~mm}$ ); 3. Streifen (beginnt nach Textfeld IV): ca. $57.2 \mathrm{~cm}$ (Überlappung $3 \mathrm{~mm}$ ); 4 . Streifen (beginnt bei Textfeld VII): ca. $57.0 \mathrm{~cm}$ (Überlappung $3 \mathrm{~mm}$ ); 5 . Streifen (beginnt am Schluss von Textfeld Ix): ca. $56.5 \mathrm{~cm}$

1 Abbildungen der gesamten Rolle sind im Internet zugänglich unter https://gallica.bnf.fr/ark:/12148/btvib84192247 (Stand 21. Februar 2017).

Vergleiche zu diesem Dokument auch die Ausführungen bei Déroche, Les manuscrits du Coran du Maghreb à l'Insulinde 135 (Nr. 547); Katalog zur Ausstellung Trésors d'Orient [exposition, Bibliothèque Nationale, Paris, 1972] 68 (Nr. 185).

2 Zur Datierung siehe auch die Ausführungen unten zu „B. Titelbalken“, bei Anm. 7-9.

3 Mit einem light sheet überprüft: Keine Wasserzeichen; sehr feines Siebmuster von parallel zueinander verlaufenden Linien. Sie sind zumeist vertikal zur Rollenrichtung ausgerichtet. Auf vereinzelten Streifen verlaufen diese Linien in der Rollenrichtung. Für einen Papiervergleich ist Supplément Persan 843 (BNF) aufschlussreich: Dafür wurde ebenso dünnes Papier verwendet; jenes von Arabe 5102 ist allerdings noch feiner. Supplément Persan 843 ist datiert: Ǧumādā I 1147 (Tag nicht mehr deutlich erkenntlich); Beginn Ğumādā I 1147: 3. Juni 1734. Auch dieser Vergleich stützt eine Zuordnung von Arabe 5102 ins 18. Jh.

4 Vgl. dazu oben, Kapitel 5.3.
(Überlappung $3 \mathrm{~mm}$ ); 6. Streifen (beginnt zwischen Textfeld XI und XII): ca. $57.2 \mathrm{~cm}$ (Überlappung $3 \mathrm{~mm}$ ); 7. Streifen (beginnt am Anfang von Textfeld XIV): ca. $43.0 \mathrm{~cm}$ (Überlappung $3 \mathrm{~mm}$ ); 8. Streifen (beginnt vor Textfeld XVI): ca. $47.2 \mathrm{~cm}$ (Überlappung $3 \mathrm{~mm}$ ); 9. Streifen (beginnt zwischen Textfeld XVII und XVIII): ca. $56.5 \mathrm{~cm}$ (Überlappung $3 \mathrm{~mm}$ ); 10. Streifen (beginnt in Textfeld XX, mit Textfeld XXI): ca. $31.0 \mathrm{~cm}$ (letzter Streifen). Am Schluss jedes Streifens ein Besitzstempel der BNF (mit Initialen R.F. ${ }^{5}$ in roter Tinte).

\section{A. Schutzteil und Anfangszierfeld}

Die Rolle beginnt mit einem violetten Schutzteil (Beschreibstoff: Papier) von ca. $16 \mathrm{~cm}$ Länge. Darunter schliesst sich ein aufwendig gestaltetes Anfangszierfeld an, das ca. $14.2 \mathrm{~cm}$ lang ist. Unmittelbar darunter ein dunkelrot eingefasster Titelbalken (Höhe ca. 2.5 cm; Авв. 121).

Das Anfangszierfeld ist achsialsymmetrisch aufgebaut. Es wird von einem Blatt- und Blütenmuster dominiert. Als wichtigstes Element lassen sich in diesem Abschnitt jedoch zwei blaue Pfauen erkennen, die sich gegenseitig den Rücken zukehren. ${ }^{6}$ Sie stehen in einer golden ausgefüllten Kartusche, in der sich Blüten in den Farben Rot und Blau erkennen lassen. Im oberen Teil dieser goldenen Kartusche befindet sich ein dunkelrot eingefasstes, achsialsymmetrisch aufgebautes blaues Zierelement; es läuft oben spitz zu. Ausserhalb der Kartusche ist der Hintergrund des Anfangszierfelds durch feine Wirbelfiguren ausgefüllt. Zusätzlich lassen sich oberhalb und unterhalb dieser Kartusche je zwei federförmige Verzierungen erkennen. Zuoberst wird das Anfangszierfeld durch einen spitz zulaufenden Aufsatz mit goldenem Hintergrund ausgefüllt; auch dieser Aufsatz ist mit einem Blüten- und Rankenmuster versehen. Die Blüten sind in den Farben Rot und Blau ausgeführt worden.

5 Für République Française.

6 Zur allfälligen Bedeutung dieser beiden Pfauen vgl. die Bemerkungen zur Kontextualisierung dieses Belegstücks ganz am Schluss (bei Anm. 116-124). 


\section{B. Titelbalken}

Unterhalb des aufwendig gestalteten Anfangszierfelds folgt ein Titelbalken. Er enthält in roter Tinte auf goldenem Hintergrund folgenden Eintrag:

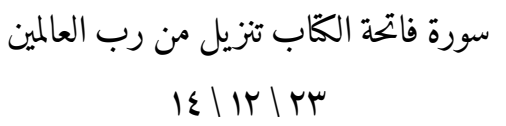

Die Entzifferung der angeführten Zahlenfolge (14. 12. $23^{7}$ ) ist nicht gänzlich gesichert. Ungewiss ist auch, ob es sich dabei um eine Datumsangabe handelt, werden diese auf Dokumenten aus dem islamischen Kulturraum derart früh, doch nie auf diese heute gängige Art notiert. Sollte es sich doch um ein Datum handeln, wäre bei der Jahreszahl wohl [11] 23 zu ergänzen. ${ }^{8}$ Dabei handelt es sich um den 14. D̄ū l-Hiğğa 1123 (23. Januar 1712). Eine Datierung um hundert Jahre später, also 14. 12. [12]23 (31. Januar 1809) wäre nicht auszuschliessen. Die BNF zieht allerdings eine Datierung ins 18. Jh. vor, wobei sie nicht auf diese Abfolge von Ziffern hinweist. $^{9}$

\section{Hauptteil}

Der Hauptteil der Rolle wurde in drei Spalten mit Text angeordnet: Die Mittelspalte ist am breitesten und misst ca. $4.4 \mathrm{~cm}$. Sie wird oben und zu beiden

7 Falls die Angabe von links nach rechts zu lesen ist.

8 Für Paralleldokumente, die ebenso eine Datierung um 18oo nahelegen vgl.: Bayani et al., Decorated word: Qur'ans of the 17th to 19th centuries, darin v.a. 274f. (Nr. 71): Iran, wahrscheinlich Shiraz, datiert: 1206/1791-1792; 278f. (Nr. 73): Iran, möglicherweise Shiraz, datiert 1268/1851-1852. Beachte der Vollständigkeit halber auch $276 \mathrm{f}$. (Nr. 72): Osmanisches Reich oder Indien (sic), wahrscheinlich 18. Jh. Ebenso hierhin gehört AKM 492 aus der Agha Khan Foundation; es datiert aus dem Jahr 1236/1847 und wurde von Zayn al-'̄̄bidīn, einem Kaligraphen in den Diensten Fath 'Alī Šāh Qāḡārs für eine Drittperson angefertigt (vgl. dazu Kapitel 5.5, Anm. 5).

9 Vgl. http://gallica.bnf.fr/ark:/12148/btvıb84192247 (Stand 3o. Juli 2017); auch bei Déroche, Les manuscrits du Coran 135 (Nr. 547: Arabe 5102), fehlt ein Hinweis auf diese Folge von Ziffern.
Seiten zwei Mal von einem Paar feiner schwarzer Linien und einem leeren Rahmen von ca. $2.5 \mathrm{~mm}$ Breite dazwischen eingefasst. Diese Mittelspalte enthält Text in $\dot{G} u b \bar{a} r$ auf zumeist horizontal ausgerichteten Zeilen. Diese Stellen in $\dot{G} u b \bar{a} r$ bilden einen teppichartigen Hintergrund, auf dem wiederholt Stellen ausgespart, also nicht mit Text in $\dot{G} u b \bar{a} r$-Schrift beschrieben, worden sind.

Diese Aussparungen lassen einerseits ein Gitter (Netzwerk) entstehen, in dem die Mittelachse durch auf der Spitze stehende Figuren betont wird. Dieses Muster wiederholt sich auf der gesamten Länge der Rolle. Die Maschen des Gitters haben die Form von auf der Spitze stehenden Rauten. Die Verbindungen zwischen den Ecken der Rauten verlaufen nicht gerade, sondern sind leicht geschwungen. Anderseits wurden auf dieser Rolle insgesamt 21 Kartuschen eingestreut, die Text in grosser, an Tulut erinnernder Schrift enthalten. Dieser grosse Text entsteht durch entsprechende Aussparungen auf dem ġubār-farbenen Hintergrund. Diese Technik liess sich bereits auf jenem Teil von Is 1624 (Chester Beatty Library) beobachten, der aus dem Jahr 1362 datiert. ${ }^{10}$

Auf beiden Seiten und oberhalb dieses Hauptteils befindet sich ausserdem je eine $1 \mathrm{~cm}$ breite Seitenspalte, in der der Text in $\dot{G} u b \bar{a} r$-Schrift schräg ausgerichtet ist und von rechts unten nach links oben verläuft. Es fällt auf, dass die Rolle nicht auch ganz am Schluss durch einen solchen Rahmenteil mit Text in $\dot{G} u b \bar{a} r$ abgeschlossen wird. Am unteren Ende wird die Rolle nur durch jene Abfolge von Linien eingefasst, die das Dokument auch auf beiden Seiten umrahmt. Es handelt sich um folgende Linien: Nach aussen wird die Seitenspalte mit Text in $\dot{G} u b \bar{a} r$ durch ein Paar haarfeiner schwarzer Linien eingefasst. Nach einem schmalen Leerraum folgt eine rote Linie. Danach schliesst sich ein goldener Streifen an, der gegen aussen erneut von zwei haarfeinen schwarzen Linien eingerahmt wird. Nach einem schmalen Zwischenraum folgt zuäusserst eine blaue Linie. Die Rolle

10 Vgl. Kapitel 4.6. 
weist danach auf beiden Seiten einen verhältnismässig breiten Streifen $(1.4 \mathrm{~cm})$ auf, der gänzlich leer belassen worden ist.

Die weiteren Ausführungen analysieren die formale Anordnung und den textlichen Inhalt dieser Rolle in zwei Schritten: Sie unterscheiden zwischen dem grossen Text einerseits, der auf 21 Kartuschen verteilt ist. Er entsteht durch entsprechende Aussparungen auf dem teppichartigen Hintergrund in $\dot{G} u b \bar{a} r$-Schrift und verläuft in der Rollenrichtung (Teil C.1). Erst danach werden auch Inhalt und Anordnung des Texts in $\dot{G} u b a \bar{r}-$ Schrift selbst erfasst. Es sei hier einzig die Beobachtung vorweggenommen, dass auch diese als Hintergrund kopierten Stellen in mikroskopischer Schrift eine in sich geschlossene Abfolge von Textelementen enthalten. Es handelt sich um eine Abschrift des Korans. Diese Stellen sind in der Mittelspalte zumeist horizontal ausgerichtet und verlaufen in den beiden Seitenspalten schräg von rechts unten nach links oben (Teil C.2).

C.1 (ABB. 122): Die 21 Kartuschen mit den Textfeldern: Zentrales Merkmal des vorliegenden Belegstücks sind die insgesamt 21 über die gesamte Länge der Rolle verteilten Textfelder. Sie enthalten eine Textfolge in grosser Schrift, die grosse Ähnlichkeiten zu Tulut aufweist. Diese Textfolge entsteht durch Aussparungen von entsprechenden Leerstellen auf dem teppichartigen $\dot{g} u b \bar{a} r-$ farbenen Hintergrund. Diese Auslassungen weisen heute die bräunliche Farbe des verwendeten Papiers auf. Es lassen sich allerdings mehrfach Hinweise darauf feststellen, dass diese Stellen in grosser Schrift ursprünglich golden hervorgehoben worden sind. Besonders deutlich ist dies in Textfeld v erkenntlich. ${ }^{11}$ Reste von goldener (?) Farbe lassen sich aber auch in weiteren Textfeldern erkennen. ${ }^{12}$ An andern Stellen lassen sich

11 Vgl. http://gallica.bnf.fr/ark:/12148/btvıb84192247/f5.im age (Stand 27. Februar 2017).

12 Vgl. Textfelder III und IV (http://gallica.bnf.fr/ark:/12148/ btvib84192247/f3.image und http://gallica.bnf.fr/ark:/ 12148/btvib84192247/f4.image; Stand 27. Februar 2017).
Hinweise feststellen, dass die grossen Buchstaben anfänglich weiss ausgefüllt waren. ${ }^{13}$

C.1: Die Stellen in grosser Schrift in den 21 Textfeldern:

Textfeld I (АВB. 122): ${ }^{14}$

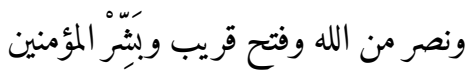

Textfeld II: ${ }^{15}$

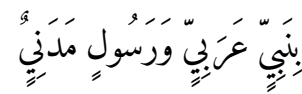

Textfeld II $:^{16}$

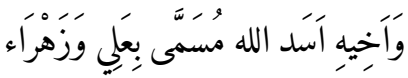

Textfeld IV (АВB. 125): ${ }^{17}$

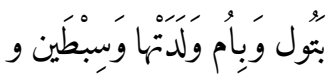

Textfeld v:18

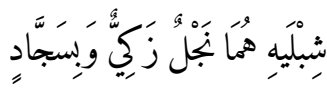

Textfeld vi: ${ }^{19}$

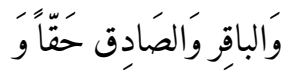

Textfeld VII: ${ }^{20}$

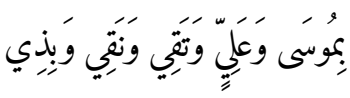

Textfeld ViII: ${ }^{21}$

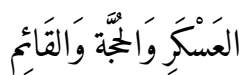

13 Vgl. z.B. die Textfelder XI-XII: http://gallica.bnf.fr/ark:/ 12148/btvıb84192247/f9.image; Textfeld xv: http:/galli ca.bnf.fr/ark:/12148/btvib84192247/fi1.image; Textfelder XVII-XVIII: http://gallica.bnf.fr/ark:/12148/btvıb841922 47/fi3.image (Stand 27. Februar 2017).

14 Q 61:13, wo ohne das einleitende wa (wa-nașr); vgl. die Abb. unter http://gallica.bnf.fr/ark:/12148/btvıb841922 47/f2.image.r=Arabe\%205102.

15 Vgl. für den Text: http://www.alsarh.info/showthread.php ?t=18377; siehe die Abb. unter: http://gallica.bnf.fr/ark:/ 12148/btvib84192247/f3.image.r=Arabe\%205102

(Stand 21. Februar 2017).

16 http://gallica.bnf.fr/ark:/12148/btvib84192247/f3.image .r=Arabe\%205102 (Stand 21. Februar 2017).

17 In diesem Textfeld lassen sich noch deutliche Hinweise darauf erkennen, dass diese grossen Buchstaben anfänglich golden bemalt waren; vgl. http://gallica.bnf.fr/ark:/ 12148/btvib84192247/f4.image.r=Arabe\%2O 5102 (Stand 21. Februar 2017).

18 Vgl. dazu Gramlich, Derwischorden Persiens, Dritter Teil: Brauchtum und Riten 43, wo abweichend; Abb. unter http://gallica.bnf.fr/ark:/12148/btvib84192247/f5.image .r=Arabe\%205102 (Stand 21. Februar 2017).

19 Vgl. http://gallica.bnf.fr/ark:/12148/btvib84192247/f5.im age.r=Arabe\%205102 (Stand 21. Februar 2017).

20 Vgl. http://gallica.bnf.fr/ark:/12148/btvib84192247/f6.im age.r=Arabe\%205102 (Stand 21. Februar 2017).

21 Die Funktion des $w \bar{a} w$ vor al-qā’im ist nicht klar. Vgl. 
Textfeld IX: ${ }^{22}$

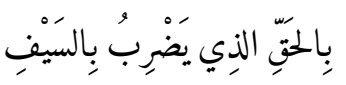

Textfeld XIX: ${ }^{32}$

Textfeld $x:^{23}$

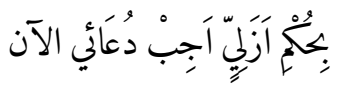

Textfeld XI: ${ }^{24}$ وترحم حضراتي (؟) واقض حاجات لَنَا إلَينا (؟) بِكُلِّ بالِهِ وَوَلِي

Textfeld XII: ${ }^{25}$

Textfeld XIII (unklar): ${ }^{26}$

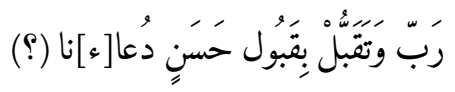

Textfeld XIv: ${ }^{27}$

بنبى وعلى وعلى وعلى (؟)

Textfeld XV (Авв. 123): ${ }^{28}$

Textfeld xvi: ${ }^{29}$

Textfeld XVII: ${ }^{30}$

Textfeld XVIII: ${ }^{31}$
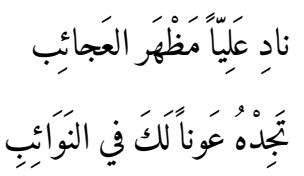

- o, - - - w , \&

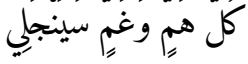

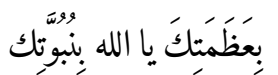

Textfeld $x x:^{33}$

Textfeld Xxi: ${ }^{34}$

واحفظ حامل هذا القران

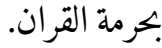

C.2: Der teppichartige Hintergrund in $\dot{G} u b \bar{a} r-$ Schrift: Die folgende Beschreibung orientiert sich an der Abfolge des Korantexts auf diesem teppichartigen Hintergrund:

C.2.1a (АВ B. 124; Text in $\dot{G} u b \bar{a} r$ in den beiden schmalen Seitenspalten rechts und links): Unmittelbar unterhalb des rot eingerahmten Titelbalkens lässt sich in der Mitte des horizontal ausgerichteten Rahmenteils mit Text in $\dot{G} u b \bar{a} r$ ein auf der Spitze stehendes Dreieck erkennen. Es wird von goldenen, rot eingefassten Blättern ausgefüllt. Rechts davon beginnt die Abschrift des Korans mit Suren 1 und 2. Der Surentext selbst in schwarzer Tinte. Die Überschriften der einzelnen Suren ${ }^{35}$ und Einteilungsvermerke ${ }^{36}$ in roter Tinte hervorgehoben. Q 1 wurde zusammen mit dem Titel auf sechs Zeilen notiert und beansprucht inkl. Abstände zwischen den Zeilen ca. 2 cm; dies ergibt eine Buchstabenhöhe von weniger als $2 \mathrm{~mm}$. Der Text ist punktiert und teilweise vokalisiert.

Der Schreiber setzt die Abschrift des Korans in dieser schmalen, rechts absteigenden Spalte fort. Nach Q 1 folgt die Überschrift von Q 2 (Sūrat al-Baqara). Wenig danach in roter Tinte der Eintrag al-hizb al-awwal. Beim Übergang in

(Stand 21. Februar 2017).

Vgl. Gramlich, op. cit. 43; vgl. die Abb. unter http://gallica .bnf.fr/ark:/12148/btvib84192247/f9.image.r=Arabe\%205 102 (Stand 21. Februar 2017).

25 Vgl. http://gallica.bnf.fr/ark:/12148/btvıb84192247/f9.im age.r=Arabe\%205102 (Stand 21. Februar 2017).

26 Vgl. http://gallica.bnf.fr/ark:/12148/btvıb84192247/fio.im age.r=Arabe\%205102 (Stand 21. Februar 2017).

27 Vgl. http://gallica.bnf.fr/ark:/12148/btvıb84192247/fu1.im age (Stand 2. August 2017).

28 Vgl. http://gallica.bnf.fr/ark:/12148/btvıb84192247/fi1.im age.r=Arabe\%205102 (Stand 21. Februar 2017).

29 Vgl. http://gallica.bnf.fr/ark:/12148/btvıb84192247/fi2.im age.r=Arabe\%205102 (Stand 21. Februar 2017).

30 Vgl. http://gallica.bnf.fr/ark:/12148/btvıb84192247/fi3.im age.r=Arabe\%2O5102 (Stand 21. Februar 2017).

31 Vgl. http://gallica.bnf.fr/ark:/12148/btvıb84192247/fiz.im age.r=Arabe\%2O5102 (Stand 21. Februar 2017).

32 Vgl. http://gallica.bnf.fr/ark:/12148/btvib84192247/fi4.im age.r=Arabe\%205102 (Stand 21. Februar 2017).

33 Vgl. http://gallica.bnf.fr/ark:/12148/btvıb84192247/fi5.im age.r=Arabe\%205102 (Stand 21. Februar 2017).

34 Vgl. http://gallica.bnf.fr/ark:/12148/btvıb84192247/fi6.im age.r=Arabe\%205102 (Stand 21. Februar 2017).

35 Q 1, hier einfach mit Sūra gekennzeichnet: unmittelbar rechts neben dem soeben erwähnten Zierdreieck. Der Titel von Q 2 (Sürat al-Baqara) folgt auf Zeile 7 in roter Tinte und ist golden hinterlegt.

36 Die Rolle enthält Hinweise auf die Einteilung in $\check{g} u z^{\prime}$ (hier ğuzw') und nisf al-ğuzw'. Siehe z. B. ganz am Anfang in der schmalen Spalte rechts aussen: al-ğuzw' al-awwal; dieser Vermerk ist golden hinterlegt. Im breiten Mittelstreifen ein weiterer roter Eintrag nișf al-ğuzw'. 
den absteigenden Ast der Aussenspalte ändert der Kopist die Schriftrichtung und notiert den Surentext schräg von rechts unten nach links oben. Ende der Abschrift von Q 2 auf der Höhe des Textfelds XI. ${ }^{37}$ Hier folgt in roter Tinte die Überschrift zu Q 3 (Sürat Āl Imrān). ${ }^{38}$ Q 3 endet in der rechten Aussenspalte kurz vor Textfeld XVII im Mittelstreifen; danach Beginn von Q 4 (Titel in roter Tinte: Sürat an-Nisāj). ${ }^{39}$ Am Schluss der Rolle steht in dieser schmalen Aussenspalte rechts Q 4:145 ohne die drei letzten Wörter. Diese drei letzten Wörter folgen in der breiten Mittelspalte, wo der Schreiber sie und Verse Q 4:146-147 auf knapp drei horizontal ausgerichteten Zeilen kopiert. Am Anfang der dritten Zeile die beiden Ausdrücke šakīran 'alìman (die beiden letzten Wörter in Q 4:147, auf der Höhe der letzten Zeile in der rechten Aussenspalte).

C.2.1b: Danach springt der Schreiber zurück an den Anfang der Rolle. Er setzt die Abschrift von Q 4 links des dreieckigen Zierteils oben in der Mitte fort und steigt in der schmalen Aussenspalte auf der linken Seite nach unten. ${ }^{40}$ Die Zeilen sind stets schräg ausgerichtet und verlaufen von rechts unten nach links oben. Q 4 endet am Schluss des Textfelds I. Direkt danach beginnt Q 5 (Sürat alMẩida: Titel in roter Tinte). Q 6 (Sūrat al-An`ām; Überschrift in roter Tinte): Beginn oberhalb von Textfeld vir in der linken Aussenspalte. ${ }^{41} \mathrm{Q}_{7}$ (Sürat al-A'rāaf; Surenname fehlt, nur Ausdruck Sūra in roter Tinte): Beginn oberhalb von Textfeld XII in

37 Vgl. http://gallica.bnf.fr/ark:/12148/btvıb84192247/f9.im age.r=Arabe\%205102 (Stand 22. Februar 2017).

38 Davor steht Q 2:286 (Schlussvers von Q 2). Kurz nach dem Titel von Q 3 der Vermerk nisf al-ğuzw' in roter Tinte. Anschluss an Sürat an-Nisä' steht wa-hiya; dies läss vermuten, dass der Kopist auch weitere Angaben (Offenbarungsort, Anzahl Verse) notieren wollte, dies dann aber unterliess. Zuoberst lässt sich Q 4:148 erkennen.

Oberhalb von Textfeld x (vgl. Abb. http://gallica.bnf.fr/ ark:/12148/btvib84192247/f8.image.r=Arabe\%205102) in der linken Spalte ein Eintrag in roter Tinte: es müsste sich um einen $\breve{G} u z^{\prime}$-Vermerk handeln. Der Schreiber notierte allerdings Sūrat und einen korrigierten, aber unleserlichen Begriff. der linken Aussenspalte. ${ }^{42}$ Q 8 (Sūrat al-Anfāl; Überschrift in roter Tinte): Beginn auf der Höhe von Textfeld XVIII in der linken Aussenspalte. ${ }^{43}$

Q 9 (Sūrat at-Tawba; Überschrift in roter Tinte, einzige Sure im Koran ohne Basmala): Beginn nach Textfeld $\mathrm{xx}$ in der linken Aussenspalte. ${ }^{44} \mathrm{Am}$ Schluss dieser linken Aussenspalte steht Q 9:27. Die drei letzten Wörter dieses Verses (Allāh ġafür rahìm) folgen allerdings erst in der Mittelspalte; sie stehen dort gerade nach dem Zwischenraum nach dem Schluss von Q 4:147. Der Schreiber setzt die Abschrift von Q 9 danach absteigend fort, zuerst auf den sich gegen unten in einem Dreieck verjüngenden Zeilen, dann auf den drei breiten Zeilen ganz am Schluss. Zuletzt steht hier Q 9:31.45 Die Fortsetzung folgt darauf ganz am Anfang dieses Mittelstreifens, wo sich Q 9:32 erkennen lässt. ${ }^{46}$

Ganz am Schluss des Dokuments steht in mikroskopischer roter Schrift rechts und links des Dreiecks am Rollenende ausserdem folgender persischer Vers (Ав اين نوشتم تا بماند يادكار // من نمانم خط بماند يادكار.

C.2.2: Der Text in $\dot{G} u b \bar{a} r$-Schrift in der breiten Mittelspalte ausserhalb der 21 Textfelder: Ganz am Anfang lässt sich in der breiten Mittelspalte die direkte Fortsetzung von Q 9 erkennen (Q 9:32). ${ }^{48}$ Der Schreiber notiert darauf die weiteren Verse

42 Vgl. http://gallica.bnf.fr/ark:/12148/btvıb84192247/fg.im age.r=Arabe\%205102 (Stand 22. Februar 2017).

43 Vgl. http://gallica.bnf.fr/ark:/12148/btvıb84192247/fiz.im age.r=Arabe\%205102 (Stand 22. Februar 2017).

44 Vgl. http://gallica.bnf.fr/ark:/12148/btvib84192247/fi5.im age.r=Arabe\%205102 (Stand 22. Februar 2017).

45 Vgl. http://gallica.bnf.fr/ark:/12148/btvib84192247/fi6.im age.r=Arabe\%205102 (Stand 22. Februar 2017).

46 Vgl. http://gallica.bnf.fr/ark:/12148/btvib84192247/f2.im age.r=Arabe\%205102 (Stand 22. Februar 2017).

47 „Ich habe dies geschrieben, damit es als Erinnerung [an mich] bleibe. Wenn auch ich selbst nicht [ewig] lebe, soll doch meine Schrift [an mich] erinnern."Vgl. dazu: http:// historylib.com/index.php?action=article/view/1424 (Stand 22. Februar 2017).

48 Q 9:32 lautet:

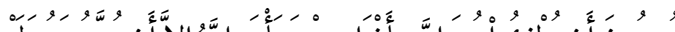

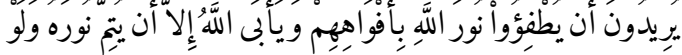

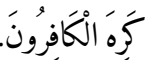


auf den horizontalen Zeilen in den beiden als Dreiecke nach unten ragenden halben Rauten am Anfang der Mittelspalte. ${ }^{49}$ Er überspringt vorerst die erste ganze Raute in der Mitte der breiten Mittelspalte. In Vers 9:36 springt er in den kleinen $\dot{G} u b \bar{a} r$-Zwickel rechts oben. Die letzten Wörter und der Anfang von Q 9:37 folgen im Zwickel links oben in der Mittelspalte. Nach ca. der Hälfte von Q 9:37 ${ }^{50}$ setzt der Schreiber die Abschrift in der obersten ganzen Raute in der Mitte der breiten Mittelspalte fort und fährt darin Zeile um Zeile nach unten. In der unteren Spitze der Raute in der Mittelspalte steht Q 9:40. In diesem Vers wechselt der Schreiber in die Figur rechts aussen, in der die Zeilen von rechts unten nach links oben geneigt sind. Es fällt auf, dass er einzelne Teile von Q 9:40 wiederholt und vom Text der Kairiner Druckausgabe abweicht. ${ }^{51}$ Kurz vor Text-

49 Am Anfang der Mittelspalte lässt sich auf der obersten Zeile rechts aussen der rote Vermerk nişf al-ğuzw erkennen. In den Druckausgaben folgt dieser Halb- $\breve{G} u z^{\prime}$ vor Q 9:34. Der Schreiber wollte mit diesem Eintrag offensichtlich auch den Anfang der Mittelspalte hervorheben.

Q 9:37 lautet:

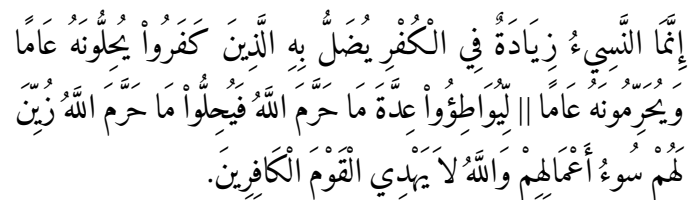

Die Markierung || kennzeichnet den Übergang vom Zwickel links aussen in die Raute in der Mitte.

Q 9:40 lautet:

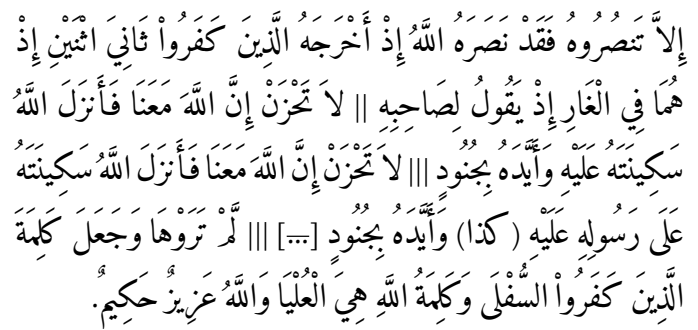

Ein zusätzliches Wort durchgestrichen, unleserlich […]. Die Markierung || kennzeichnet den Übergang von der Raute in der Mitte zur Figur rechts aussen. Die zwei feld $\mathrm{I}^{52}$ lässt sich links aussen die rote Markierung für den 11. Ğuz’ erkennen. Vers 9:93 beginnt mit inna-mā bereits am Schluss der halben Raute rechts aussen und wird danach vor dem $\breve{G} u z^{\prime}$ Vermerk links aussen fortgesetzt. ${ }^{53}$ Der Kopist steigt bei der Abschrift des Korantexts in dieser Figur links aussen Zeile um Zeile nach unten. Er beendet Q 9:99 und notiert noch den ersten Begriff von Q 9:100. ${ }^{54}$

In Anschluss daran folgt auf der Rolle Textfeld I, in dem ebenso Stellen aus dem Koran in $\dot{G} u b \bar{r} r$ kopiert worden sind. Wie noch aufzuzeigen sein wird, sind diese als Hintergrund in den Textfeldern in $\dot{G} u b \bar{a} r$ notierten Koranstellen Teil eines nächsten Durchgangs der Abschrift der islamischen Offenbarung (vgl. C.2.3). Die direkte Fortsetzung der Abschrift von Q 9 folgt erst unmittelbar nach Textfeld I. In der halben Raute rechts aussen steht Q 9:10o. Q 9 dürfte auf diesem Dokument also vollständig kopiert worden sein. Jedenfalls lässt sich wenig unterhalb von Textfeld I am linken Rand der Mittelspalte eine weitere Überschrift Sūra in roter Tinte erkennen; hier beginnt Q 10 (Sūrat Yūnus). Auf der Zeile mit dieser Überschrift endet auch Q 9 (Q 9:129: Schlussvers). 55

Der Schreiber setzt darauf die Abschrift von Q 10 (Sūrat Yünus) in den zumeist rauten-förmigen Figuren vor Textfeld III fort. In der angeschnittenen Raute auf der rechten Seite der Mittelspalte lässt sich zuunterst der erste Teil von Q 10:43

Markierungen ||| grenzen darauf den Einschub in den Korantext ab.

52 Vgl. http://gallica.bnf.fr/ark:/12148/btvib84192247/f2.im age.r=Arabe\%2O5102 (Stand 22. Februar 2017).

53 Q 9:93 lautet:

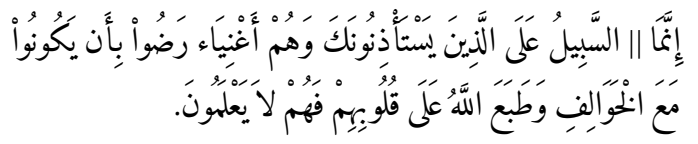

Die Markierung || kennzeichnet den Übergang vom Ende der halben Raute rechts aussen zum Anfang der halben Raute links aussen.

54 Wa-ṣ-șābiqūn.

55 Vgl. http://gallica.bnf.fr/ark:/12148/btvib84192247/f2.im age.r=arabe\%205102 (Stand 23. Februar 2017). 
erkennen. Der Schreiber setzt die Abschrift darauf zuoberst in der angeschnittenen Raute auf der linken Seite der Mittelspalte fort. ${ }^{56}$ Am Ende dieser Raute stehen Q 10:51 und die ersten beiden Wörter von Q 10:52. Der Kopist springt in Q 10:52 ans Ende von Textfeld II und setzt die Abschrift von Vers 10.52 dort in der rechten Aussenspalte fort. ${ }^{57}$

Q 10 endet wenig unterhalb der Mitte des Abschnitts zwischen Textfeld II und III mit Vers 109 (Schlussvers). Hier steht auch der Titel von Q 11 (Sūrat Hūd, hier Sūrat Fușşilat genannt). Die Fortsetzung der Abschrift von Q 11 folgt in den weiteren rauten-förmigen Figuren vor Textfeld III; sie überspringt danach dieses Textfeld und fährt mit der Abschrift des fortlaufenden Korantexts weiter.

Bei Textfeld III $^{58}$ erfolgt der Übergang von Q 11:59-6o. Unmittelbar vor Textfeld III lassen sich am Ende der angeschnittenen Raute auf der linken Seite Q 11:59 und die drei ersten Wörter von Q 11:6o erkennen. Unterhalb von Textfeld III steht am Anfang der angeschnittenen Raute am rechten Rand die unmittelbare Fortsetzung von Vers 6o.59 Auch hier überspringt der Schreiber also das Textfeld III dazwischen.

56 Die Übergangsstelle lautet:

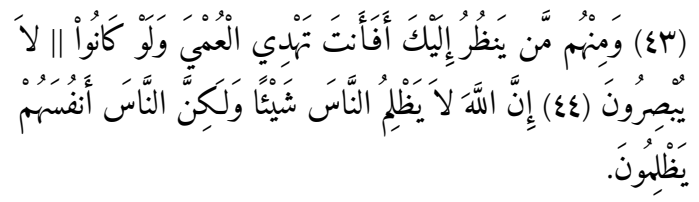

Bei der Markierung || springt der Kopist von der Raute rechts in die Raute links.

Die Übergangsstelle lautet:

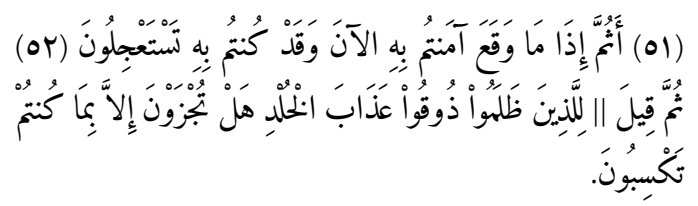

Bei der Markierung || springt der Kopist ans Ende von Textfeld II und setzt die Abschrift von Q 10:52 dort in der rechten Aussenspalte fort.

$5^{8}$ Vgl. http://gallica.bnf.fr/ark:/12148/btvıb84192247/f3.im age (Stand 27. Februar 2017).

59 Der Übergang Q 11:59-6o ist wie folgt aufgebaut (bei der Markierung || überspringt der Schreiber Textfeld III):
Q 11 endet ungefähr in der Mitte des Abschnitts zwischen Textfeld III und IV in der Raute auf der linken Seite der Mittelspalte (Q 11:123) ${ }^{60}$ Hier steht in roter Tinte auch der Titel von Q 12 (Sürat Yūsuf). ${ }^{61}$ Der Kopist notiert den Anfang von Q 12 im Rest der angeschnittenen Raute auf der linken Seite und im Einsprengsel unmittelbar darunter. Darauf springt er nach oben in die Mittelspalte, wo sich eine vollständige Raute erkennen lässt und setzt die Abschrift an deren Spitze fort. ${ }^{62}$ Am Ende dieser vollständigen Raute springt er erneut nach oben an die Spitze der angeschnittenen Raute auf der rechten Seite der Mittelspalte. An dieser Übergangsstelle steht Q 12:9. ${ }^{63}$

Der Schreiber erreicht schliesslich den Einschub mit Text in grosser Schrift (Textfeld IV). Am Schluss der angeschnittenen Raute vor Textfeld IV steht auf der linken Seite Q 12:37. In diesem Vers überspringt der Schreiber Textfeld IV und setzt

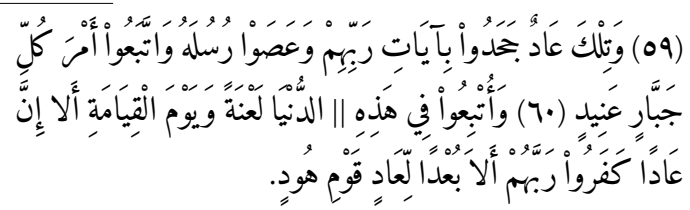

6o Q 11:123 lautet:

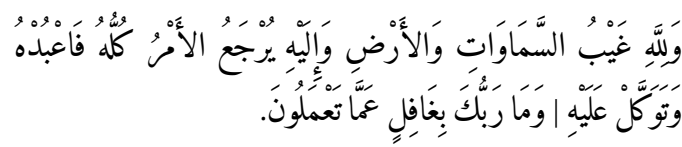

Die Markierung | kennzeichnet den Beginn der Schlusszeile, auf der auch der Titel von Q 12 steht.

61 Vgl. Abb.http://gallica.bnf.fr/ark:/12148/btvib84192247/f4 .image (Stand 24. Februar 2017).

62 An dieser Übergangsstelle steht Q 12:3. Bei den Markierungen || springt der Schreiber jeweils in die nächste Figur:

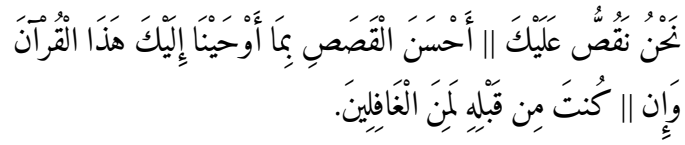

63 Q 12:9 lautet:

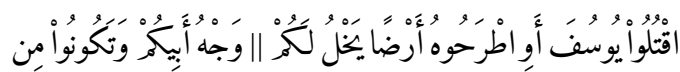
بعده قَومَا صَالحِينَ.

Bei der Markierung || erfolgt der Übergang vom unteren Ende der vollständigen Raute in der Mitte an den Anfang der angeschnittenen Raute am rechten Rand. 
die Abschrift unmittelbar darunter auf der rechten Seite an der Spitze der angeschnittenen Raute fort. ${ }^{64}$ Unterhalb von Textfeld IV steht in der dritten angeschnittenen Raute auf der linken Seite in roter Tinte die Überschrift von Q 13 (Sürat ar-Ra'd). Auf diesem teppichartigen Hintergrund mit Text in $\dot{G} u b \bar{a} r$-Schrift lassen sich immer wieder Hinweise auf die Einteilung des Korans in $\breve{G} u z^{\prime}$ und HalbĞuz' (nisf al-ǧuz') in roter Tinte feststellen.

Vor Textfeld $v^{65}$ steht in der angeschnittenen Raute auf der linken Seite zuletzt Q 13:23 Der Schreiber überspringt Textfeld $\mathrm{V}$ und setzt die Abschrift des erwähnten Verses auf der rechten Seite unmittelbar darunter fort. ${ }^{66} \mathrm{Q} 13$ endet kurz danach; auf der rechten Seite lässt sich in roter Tinte der Eintrag Sūra erkennen (Überschrift zu Q 14, Sūrat Ibrāhìm). Q 13 endet unmittelbar davor mit dem Schlusswort al-kitāb; der grösste Teil von Q 13:43 (Schlussvers) steht allerdings auf derselben Höhe am linken Rollenrand. Q 14 endet vor Textfeld vi. Direkt nach dem Schlussvers von Q 14 folgt die Basmala von Q 15 (Sürat al-Hiğr). Hier fehlt allerdings die sonst übliche Hervorhebung des Surentitels in roter Tinte; auch der Eintrag Süra fehlt.

Der nächste rote Eintrag zur Hervorhebung eines Surentitels folgt in der angeschnittenen Raute auf der rechten Seite direkt unterhalb von Textfeld vi. ${ }^{67}$ Hier steht in roter Tinte der Eintrag

64 Q 12:37 lautet:

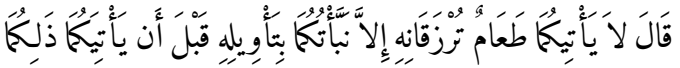

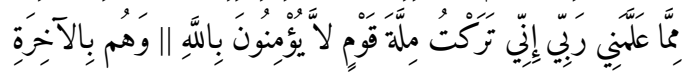

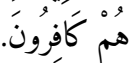

Die Markierung || kennzeichnet den Übergang.

65 Vgl. http://gallica.bnf.fr/ark:/12148/btvib84192247/f5.im age (Stand 27. Februar 2017).

66

Q 13:23 lautet:

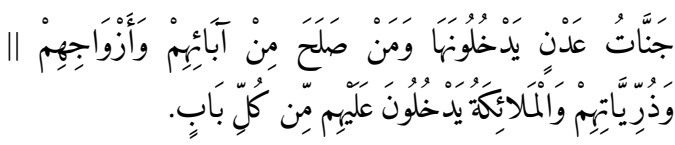

Die Markierung || kennzeichnet die Übergangsstelle.

67 Vgl. http://gallica.bnf.fr/ark:/12148/btvib84192247/f6.im age.r=arabe\%205102 (Stand 2. März 2017).
Sūrat an-Nahl (Q 16). Sie endet unmittelbar nach diesem Textfeld in der angeschnittenen Raute auf der linken Seite der Mittelspalte, wo in roter Tinte die Überschrift Sūrat al-Isrā' (Q 17) steht. Q 18 (Sürat al-Kahf) beginnt zwischen Textfeld viı und IX. Ihre Überschrift wurde in roter Tinte hervorgehoben. ${ }^{68}$ Der Anfang von Q 19 (Sürat Maryam) in roter Tinte zwischen den Textfeldern IX und $\mathrm{x} .{ }^{69}$ Ein Zusatz nach dem roten Surentitel liess sich nicht mit Sicherheit entziffern. Unmittelbar vor Textfeld $\mathrm{x}$ steht auf der rechten Seite in roter Tinte Sürat Tă $h \bar{a}$ ( $\mathrm{Q} 20)$. Zwischen den Textfeldern $\mathrm{x}$ und XI auf der linken Seite der teilweise rot hervorgehobene Eintrag zu Q 21 (Sürat al-Anbiyā). Sūrat al-Hağğ (Q 22) beginnt in der ersten vollständigen Raute in der Mittelspalte unterhalb von Textfeld XI. ${ }^{70}$ Der Titel der nächsten Sure (Q 23, Sürat al-Mu'minūn) steht in der angeschnittenen Raute unmittelbar vor Textfeld XII; die Zeilen verlaufen hier nach links unten geneigt. ${ }^{71}$ Der Anfang von Q 24 (Sūrat an-Nūr, Titel rot hervorgehoben) zwischen den Textfeldern XII und XIII. ${ }^{72}$ Die Überschrift von Q 25 (Sūrat al-Furqān) in roter Tinte zwischen den Textfeldern XIII und XIV. Q 26 steht unmittelbar vor und nach Textfeld XIV. ${ }^{73}$

Nach dem rot hervorgehobenen Titel (Sürat ašŠ́ $\left.{ }^{\prime} a r a \bar{\prime}\right)$ lassen sich die Anfangsverse von Q 26 erkennen. Direkt nach Textfeld XIV steht am linken Rand der Mittelspalte vor dem Titel von Q 27 Q 26:225-227 (Schlussverse). Der Schreiber weicht hier von seinem üblichen Vorgehen ab. Soweit ersichtlich kopierte er Q 26 in den Rauten

68 Vgl. http://gallica.bnf.fr/ark:/12148/btvib84192247/f7.im age.r=arabe\%2O5102 (Stand 2. März 2017).

69 Vgl. http://gallica.bnf.fr/ark:/12148/btvıb84192247/f8.im age.r=arabe\%205102 (Stand 2. März 2017). Man beachte die Reste weisser Farbe in den grossen Buchstaben in diesem Textfeld $\mathrm{x}$.

70 Vgl. http://gallica.bnf.fr/ark:/12148/btvıb84192247/fg.im age.r=arabe\%205102 (Stand 2. März 2017).

71 Vgl. http://gallica.bnf.fr/ark:/12148/btvib84192247/fg.im age.r=arabe\%205102 (Stand 2. März 2017).

72 Vgl. http://gallica.bnf.fr/ark:/12148/btvıb84192247/fio.im age.r=arabe\%2O5102 (Stand 2. März 2017).

73 Vgl. http://gallica.bnf.fr/ark:/12148/btvıb84192247/fu1.im age.r=arabe\%2O5102 (Stand 2. März 2017). 
entlang des rechten Rands; er erreicht unmittelbar vor Textfeld xv (Beginn des Nādi-'Alī-Gebets) Q 26:222-224. Er springt jetzt zurück nach oben und ergänzt die Schlussverse (Q 26:225-227) direkt unterhalb von Textfeld XIv. Dort beginnt auch Q 27 (rote Überschrift: Sürat an-Naml), die konsequenterweise am linken Rand nach unten steigt. ${ }^{74}$ Die nächste Sure (Q 28, Sūrat al-Qașaș) beginnt zwischen den Titelfeldern XV und XVI; ihr Titel ist rot hervorgehoben.

Kurz nach Textfeld Xvi beginnt in der Mittelspalte zuerst Q 29 (Sürat al-'Ankabūt, Titel rot hervorgehoben). In der angeschnittenen Raute am linken Rand unmittelbar darunter steht der Beginn von Q 30 (Sürat ar-Rūm), wobei der Schreiber hier nur den Ausdruck Sūra zur Hervorhebung in roter Tinte notierte. ${ }^{75}$ Auch hier steht Q 29 im wesentlichen in den angeschnittenen Rauten am rechten Rand der Mittelspalte und zum Teil in den vollständigen Rauten in der Mitte. Der Schreiber erreicht direkt vor Textfeld XVII am Schluss der angeschnittenen Raute am rechten Rand der Mittelspalte Q 29:54. In der Mitte dieses Verses springt der Kopist wieder nach oben und setzt die Abschrift direkt unterhalb von Textfeld XVI am linken Rand der Mittelspalte fort. ${ }^{76}$ Q 29 endet in der angeschnittenen Raute darunter, wo die nächste Sure (Q 3o: Sūrat ar-Rūm) beginnt.

Der Kopist setzt dieses Vorgehen bei der Abschrift des Korans zwischen den Textfeldern XVII und XVIII fort und notiert die Suren zuerst im wesentlichen entlang des rechten und danach entlang des linken Rands der Mittelspalte. ${ }^{77}$ Hier lassen sich am rechten Rand zuerst die Überschrif-

74 Vgl. http://gallica.bnf.fr/ark:/12148/btvib84192247/fi1.im age.r=arabe\%205102 (Stand 2. März 2017).

75 Vgl. http://gallica.bnf.fr/ark:/12148/btvıb84192247/fi2.im age.r=Arabe\%205102 (Stand 6. März 2017).

76 Q 29:54 lautet:

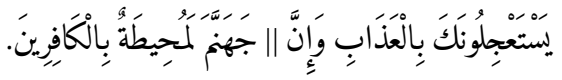

Bei der Markierung || springt der Schreiber zurück nach oben.

77 Vgl. http://gallica.bnf.fr/ark:/12148/btvıb84192247/fi3.im age.r=Arabe\%205102 (Stand 6. März 2017). ten zu Q 31 (Sūrat Luqmān) ${ }^{78}$ und unmittelbar vor Textfeld XVIII von Q 32 (Sürat [as-] Sağda ${ }^{79}$ ) und deren Anfangsverse erkennen. Der Titel der nächsten Sure, Sūrat al-Aḥzāb (Q 33), in roter Tinte etwa in der Mitte zwischen Textfeld XVII und XVIII in einer angeschnittenen Raute am linken Rand.

Unmittelbar nach Textfeld XVIII steht in der angeschnittenen Raute am linken Rand in roter Tinte der Titel von Q 34 (Sürat as-Saba'80 wa-hiya). Direkt davor endet Q 33, die aber im wesentlichen entlang des rechten Rands der Mittelspalte kopiert worden ist. Der Schreiber setzt die Abschrift von Q 34 nach Textfeld XIx fort. ${ }^{81}$ Hier lässt sich in einer vollständigen Raute in der Mitte der Mittelspalte der rot hervorgehobene Titel von Q 35 (Sūrat al-Fātir ${ }^{82}$ ) erkennen. Q 35 endet in der angeschnittenen Raute unmittelbar darüber (Schlussvers: Q 35:45). Direkt danach beginnt die Abschrift von Q 36 (Sürat Yā-sìn, hier allerdings anderer Titel). Q 36 wurde sodann entlang des linken Rands der Mittelspalte kopiert.

Q 36 endet kurz nach Textfeld $x x .{ }^{83}$ Es folgt die Überschrift von Q 37 (Sūrat aș-Șäffāt). Sie ist rot hervorgehoben und steht am rechten Rand der Mittelspalte. Auf derselben Höhe steht auf der linken Seite die Überschrift von Q 38 (Sürat Șād). Auch diese Überschrift wurde rot hervorgehoben. Die Abschrift von Q 38 endet auf der linken Seite der Mittelspalte unmittelbar vor dem letzten Textfeld (Textfeld XXI) ${ }^{84}$ Hier steht auch der Titel der nächsten Sure (Q 39: Sūrat az-Zumar), der rot her-

78 Hier steht nur der rot hervorgehobene Begriff Sūra.

79 Diese Überschrift erneut in roter Tinte. Es ist nicht klar, ob der Surentitel hier tatsächlich Sağda lautet. Er wäre jedenfalls ohne Artikel notiert worden. Dies würde angesichts des persischen Hintergrunds des Dokuments nicht erstaunen. Der anschliessende Text gehört jedenfalls zum Beginn von Q 32.

8o Hier in der Tat mit Artikel.

81 Vgl. http://gallica.bnf.fr/ark:/12148/btvıb84192247/fi4.im age.r=Arabe\%205102 (Stand 6. März 2017).

82 Hier erneut mit Artikel; üblicherweise wird der Artikel nicht erwähnt.

83 Vgl. http://gallica.bnf.fr/ark:/12148/btvıb84192247/fi5.im age.r=Arabe\%205102 (Stand 6. März 2017).

84 Vgl. http://gallica.bnf.fr/ark:/12148/btvıb84192247/fi6.im age.r=Arabe\%205102 (Stand 6. März 2017). 
vorgehoben ist. Der Anfang dieser Sure steht noch vor dem letzten Textfeld (Textfeld XxI), die Fortsetzung folgt unmittelbar danach. Der Schreiber notierte die Fortsetzung von Q 39 in $\dot{G} u b \bar{a} r$-Schrift auf den horizontal ausgerichteten Zeilen unmittelbar unterhalb von Textfeld XxI. Als letzte Stelle aus Q 39 lassen sich Q 39:30-31 erkennen. Jetzt springt der Schreiber erneut nach oben und setzt die Abschrift von Q 39 am Anfang von Textfeld I selbst fort. ${ }^{85}$ Dort steht Q 39:32. Auf die Anordnung des Surentexts in diesem Textfeld I wird sogleich einzugehen sein. ${ }^{86}$

Vorerst ist aber der restliche Text am Rollenende zu untersuchen. Es fällt auf, dass nach dem Schluss von Q 39:31 am Ende der Rolle zwei Balken folgen (Höhe je ca. $1 \mathrm{~cm}$ ), in denen Text in $\dot{G} u b \bar{a} r$-Schrift in einem Winkel von ca. $45^{\circ}$ jeweils von rechts unten nach links oben kopiert worden ist. Nach einem kurzen Leerraum folgen sechs horizontal ausgerichtete Zeilen in $\dot{G} u b \bar{r}$, die die gesamte Spaltenbreite ausfüllen. Die Zeilen verjüngen sich danach gegen unten und laufen in einem Dreieck spitz zu. Es schliessen sich nochmals drei Zeilen Text an. Die Textstellen ab hier sind bereits zuvor identifiziert worden. Es handelt sich zuerst um Q 4:145-147. Nach einem kurzen Zwischenraum folgt auf derselben Zeile Q 9:27. Ganz zuunterst steht Q 9:31 (Schluss). ${ }^{87}$

Q 4 beginnt vor Textfeld XVII in der rechten Seitenspalte, wo in roter Tinte die Überschrift steht Sūrat an-Nisā ${ }^{88}$ Der Schreiber kopierte sie in der schmalen Seitenspalte rechts; hier steht ganz zuletzt Q 4:145. Allerdings stehen die Verse 4:126b4:142a nicht in dieser Seitenspalte. Sie sind vielmehr in den beiden Textbalken mit den schräg ausgerichteten Zeilen in der Mittelspalte und den sechs horizontalen Zeilen direkt darunter notiert worden.

Im ersten Textbalken (АВВ. 126) mit den schräg ausgerichteten Zeilen stehen Q 4:126b-130. Im

85 Vgl. http://gallica.bnf.fr/ark:/12148/btvıb84192247/f2.im age.r=Arabe\%205102 (Stand 6. März 2017).

86 Vgl. dazu unten C.2.3; bei Anm. 9o.

87 Für die Einzelheiten siehe oben bei Anm. 45-46.

88 Vgl. dazu bereits oben bei Anm. 39. zweiten Balken mit Text auf den schräg ausgerichteten Zeilen folgen Q 4:131 ${ }^{89}-136 \mathrm{a}$. Darauf setzt der Schreiber die Abschrift von Q 4 in der Mittelspalte auf den sechs horizontal ausgerichteten Zeilen unmittelbar darunter fort (Q 4:136b-142a). In $Q$ 4:142 springt der Schreiber erneut in die schmale Seitenspalte rechts und setzt die Abschrift dort auf der Höhe der ersten horizontalen Zeile mit Q 4:136b in der Mittelspalte fort. Hier lässt sich direkt nach Q 4:125-126 Q 4:142b-145a erkennen. In Q 4:145 selbst springt der Schreiber erneut zurück in die Mittelspalte und setzt die Abschrift unterhalb der soeben diskutierten sechs horizontal ausgerichteten Zeilen fort. Ab hier verjüngen sich die Zeilen nach unten zu einem Dreieck. Auf dessen drei ersten Zeilen stehen noch Q 4:145b147 (Schluss). Nach Q 4:147 springt der Schreiber wieder zurück an den Anfang der Rolle und setzt die Abschrift in der schmalen Seitenspalte oben links fort. In der Mitte des Dokuments neben dem kleinen Zierdreieck steht hier in der Tat Q 4:148. Nach einem kleinen Zwischenraum steht auf dieser Zeile Q 9:27. Dies ist die Fortsetzung des Textes aus der linken Seitenspalte. Ganz zuunterst in der Mittelspalte steht Q 9:31. ABB. 126 zeigt den komplexen Aufbau dieses Abschlusses der Rolle.

C.2.3: Die weiteren Ausführungen machen auf den Inhalt der in $\dot{G} u b \overline{a r}$-Schrift kopierten Stellen auf dem Hintergrund der 21 Textfelder aufmerksam: Es ist daran zu erinnern, dass der Schreiber am Schluss der Rolle nach dem letzten Textfeld mit grossem Text Q 39:30-31 erreicht hatte. ${ }^{90}$ Er hatte zuvor bei der Abschrift des Korans alle 21 Textfelder übersprungen. Jetzt aber beginnt er mit dem dritten und letzten Durchgang seiner Abschrift und füllt den Hintergrund der 21 Textfelder mit grossem Text aus.

In Textfeld I lässt sich am Anfang Q 39:32 erkennen. Der Schreiber umfährt bei der weiteren Abschrift des Korans in diesen 21 Textfeldern die für den grossen Text vorgesehenen Leerstellen.

\footnotetext{
89 Ohne li- $[A] l l a \bar{h}$, das noch am Schluss des vorangehenden Textfelds steht.

$90 \quad$ Vgl. dazu oben bei Anm. 84-86.
} 
Am Ende von Textfeld I steht in der Mitte der rot hervorgehobene Eintrag Sūra. Hier beginnt Q 40 (Sürat $\dot{G} \bar{a}$ fir). ${ }^{91}$ Ав В. 125 vermittelt anhand von Textfeld IV einen Eindruck vom Aufbau dieser Stellen.

In Textfeld II lässt sich in der Mitte an der Spitze Q 40:13b-14 erkennen. ${ }^{92}$ Am Schluss dieses Textfelds stehen in $\dot{G} u b \overline{a r}$-Schrift die Schlussverse von Q 40. Auf der rechten Seite stehen zuunterst die Verse 40:79-81, auf der linken Seite folgen die Verse 40:82-85. Ganz zuunterst in diesem Textfeld II steht die Basmala zu Q 41.

Q 41 selbst beginnt zuoberst in Textfeld III. ${ }^{93}$ In Textfeld III lässt sich am Anfang des unteren Drittels auf der linken Seite die rot hervorgehobene Überschrift von Q 42 erkennen (Sūrat ašŠūrā). Sie beginnt danach mit der Basmala. Q 43 (Sürat az-Zuhruf) beginnt gegen Ende von Textfeld IV. Ihr Titel wurde rot hervorgehoben. Unmittelbar nach dem Titel steht die Basmala. In Textfeld v folgt auf der linken Seite die Überschrift zu Q 44 (Sūrat ad-Duhān), wobei der Ausdruck Sūra rot hervorgehoben ist; der Surenname selbst fehlt. Ganz am Schluss dieses Textfelds v steht auf der rechten Seite die Überschrift der nächsten Sure (Q 45: Sūrat al-Ǧātiya). ${ }^{94}$ In der Spitze zuunterst in diesem Textfeld v steht Q 45:19a. Die Fortsetzung des Verses folgt zuoberst in Textfeld vi. ${ }^{95}$

91 Vgl. http://gallica.bnf.fr/ark:/12148/btvıb84192247/f2.im age.r=Arabe\%205102 (Stand 7. März 2017).

92

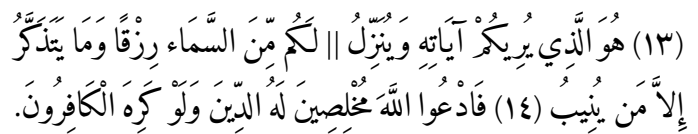

Beim ersten kopierten Wort in diesem Textfeld handelt es sich um la-kum (nach der Markierung ||).

Vgl. http://gallica.bnf.fr/ark:/12148/btvib84192247/f3.im age.r=Arabe\%205102 (Stand 7. März 2017).

94 Vgl. http://gallica.bnf.fr/ark:/12148/btvib84192247/f5.im age.r=Arabe\%205102 (Stand 7. März 2017).

95

Q 45:19 lautet:

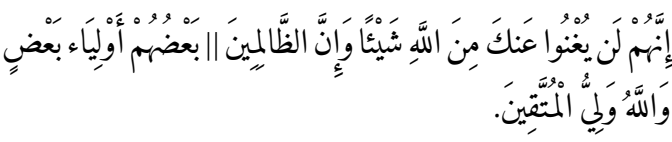

Die Markierung || kennzeichnet den Übergang von Textfeld v zu Textfeld vi.
In Textfeld vi lässt sich auf der rechten Seite deutlich die rot hervorgehobene Überschrift $\mathrm{zu}$ Q 46 (Sūrat al-Aḥqāa) erkennen. Auf derselben Höhe des Textfelds steht ebenso in roter Tinte ein Ğuz'-Vermerk (26. $\breve{G} u z^{\prime}$, der hier gemäss der Kairiner Ausgabe auch beginnt). In Textfeld vi lassen sich die Überschriften von Q 47 (oben: Sürat alQitāl, rot hervorgehoben) und Q 48 (unten: Sūrat al-Fath, rot hervorgehoben) erkennen. ${ }^{96}$ In Textfeld VIII folgen die rot hervorgehobenen Überschriften von Suren 49-51 (Q 49: Sūrat al-Huğurāt; Q 50: Sūrat Qāf; Q 51: Sūrat ad-Dāriyāt). ${ }^{97}$ In Textfeld IX stehen die rot hervorgehobenen Überschriften von Suren 52-54 (Q 52: Sürat aț-Tür; Q 53: Sūrat an-Nağm; Q 54: Sūrat al-Qamar). Bei Q 53 und 54 wurde jeweils nur der Ausdruck Sūra notiert. ${ }^{98}$ In Textfeld $\mathrm{x}$ folgen die rot hervorgehobenen Überschriften zu Suren 55-56 (Q 55: Sūrat ar-Rạ̣mān, beide Begriffe rot hervorgehoben; Q 56: Sūrat alWāqi'a, beide Begriffe rot hervorgehoben). ${ }^{99}$ In Textfeld XI schliessen sich Suren $57-58$ an, deren Titel rot hervorgehoben werden (Q 57: Sürat alHadid, hier aber ein anderer Titel; beim kopierten Text handelt es sich jedoch um Q 57). Am Anfang des unteren Drittels dieses Textfelds die Überschrift von Q 58 (Sūrat al-Muğādala). ${ }^{100} \mathrm{In}$ Textfeld XII folgen zwei weitere, rot hervorgehobene Überschriften. Zu erwarten sind Suren $59^{-6}$ o. Bei Q 59 steht einfach die Überschrift Sūra. Sie ist allgemein als Sūrat al-Hašr bekannt. Dieser Text steht hier dann auch; er beginnt direkt unter der Basmala. Bei Q 6o steht die rot hervorgehobene Überschrift Sūrat al-Mumtahina. ${ }^{101}$

96 Vgl. http://gallica.bnf.fr/ark:/12148/btvıb84192247/f6.im age.r=Arabe\%205102 (Stand 7. März 2017).

97 Vgl. http://gallica.bnf.fr/ark:/12148/btvib84192247/f7.im age.r=Arabe\%205102 (Stand 7. März 2017).

98 Vgl. http://gallica.bnf.fr/ark:/12148/btvib84192247/f7.im age.r=Arabe\%205102 (Stand 7. März 2017).

99 Vgl. http://gallica.bnf.fr/ark:/12148/btvib84192247/f8.im age.r=Arabe\%205102 (Stand 7. März 2017).

Vgl. http://gallica.bnf.fr/ark:/12148/btvıb84192247/f9.im age.r=Arabe\%2O5102 (Stand 7. März 2017).

101 Vgl. http://gallica.bnf.fr/ark:/12148/btvıb84192247/f9.im age.r=Arabe\%205102 (Stand 7. März 2017). 
Der Logik des Aufbaus der Abschrift folgend sind in Textfeld XIII Suren 61-63 zu erwarten. Jedenfalls lassen sich hier drei rot hervorgehobene Überschriften erkennen. Allerdings liess sich Q 61 (Sūrat aș-Ṣaff) an dieser Stelle nicht mit Sicherheit lokalisieren. Es steht hier vorerst vielmehr Q 62 (Sūrat al-Ğum'a, nur Überschrift Sūra; kein Titel). ${ }^{102}$ Wenig später folgt die Überschrift von Q 63 (Sürat al-Munāfiqūn). Zuletzt steht in diesem Textfeld die rot hervorgehobene Überschrift von Q 64 (Sūrat at-Taḡābun, hier nur Sūra). Die Überschrift zu Q 61 liess sich nicht nachweisen. Allerdings lassen sich Q 61:1b-5 am rechten Rand der Mittelspalte klar identifizieren. Nicht klar ist, wo die Basmala von Q 61 und Q 61:1a stehen. Aus den soeben festgehaltenen Beobachtungen lässt sich jedoch ableiten, dass auch Q 61 auf diesem Dokument kopiert worden ist. ${ }^{103}$

In Textfeld XIV folgen die Überschriften von Q 65-67 (rot hervorgehoben). Q 65 (Sürat atTalā $q$ ) wurde zusammen mit ihrem Titel notiert; die ganze Überschrift rot. Bei Q 66 steht nur die Überschrift Sūra. Bei der Überschrift zu Q 67 (Sūrat al-Mulk) wurde die gesamte Überschrift rot hervorgehoben. Q 67 endet ganz am Schluss dieses Textfelds; darunter steht noch die Basmala zu Q 68, die am Anfang des nächsten Textfelds beginnt. ${ }^{104}$

In Textfeld Xv lassen sich erneut drei rot hervorgehobene Überschriften erkennen. Es handelt sich um Suren 68 bzw. 69-71. Die Basmala von Q 68 (Sürat al-Qalam) steht ganz am Ende des vorangehenden Textfelds. Q 68 beginnt zuoberst in Textfeld xv. Der Titel von Q 69 (Sūrat al-Hāqqqa) steht rot hervorgehoben nach dem ersten Drittel dieses Textfelds am rechten Rand der Mittelspalte. Es folgt erneut am rechten Rand die rot hervorgehobene Überschrift zu Q 71 (Sūrat al-Ma'āriğ). Die Überschrift zu Q 72 (Sūrat al-Ǧinn) folgt etwas wei-

\footnotetext{
102 Auf der Zeile mit der Überschrift Sūra stehen auch die letzten Begriffe aus Q 60:13 (Schlussvers).

103 Vgl. http://gallica.bnf.fr/ark:/12148/btvıb84192247/fio .image.r=Arabe\%2O5102 (Stand 7. März 2017).

104 Vgl. http://gallica.bnf.fr/ark:/12148/btvıb84192247/fiı .image.r=Arabe\%205102 (Stand 7. März 2017).
}

ter unten auf der linken Seite. Allerdings ist dem Schreiber hier ein Fehler unterlaufen, denn beim nach der Basmala kopierten Text handelt es sich um den Anfang von Q 71 (Sürat Nüḥ). Zuunterst in diesem Textfeld steht Q 70:28; Q 70 endet mit Vers 44 unmittelbar vor dem Beginn von Q 71, die hier einen falschen Titel hat. ${ }^{105}$

In Textfeld XVI ${ }^{106}$ folgt $Q 72$. Sie beginnt auf der rechten Seite; ihre rot hervorgehobene Überschrift lautet Sūrat al-Ğinn wa-hiya makkiyya. In der Mitte dieses Textfelds folgt auf der rechten Seite die Überschrift zur nächsten Sure (Q 73: Sürat al-Muzammil, rot hervorgehoben). Danach steht die Überschrift zu Q 74 (Sūrat al-Mudattir). Am unteren Ende dieses Textfelds XVI beginnt Q 75 . Sie ist eigentlich als Sürat al-Qiyāma bekannt; hier steht aber wahrscheinlich nochmals der Name Sūrat al-Mudattir. Beim kopierten Text handelt es sich jedoch um jenen von Q 75. In der unteren Spitze dieses Textfelds steht Q 75:11-12. ${ }^{107}$

In Textfeld XVII auf der linken Seite der rot hervorgehobene Eintrag Sūra. Hier beginnt Q 76 (Sūrat al-Insān). Q 77 beginnt ein wenig weiter unten in der Mitte; ihre Überschrift ist rot hervorgehoben (Sūrat al-Mursalāt). Die Überschrift zu Q 78 (Sürat an-Naba') wiederum steht am rechten Rand der Mittelspalte (rote Hervorhebung). Etwa auf derselben Höhe beginnt auf der linken Seite Q 79 (Sürat an-Nāzi āat, rot hervorgehoben). ${ }^{108}$

Da die Suren gegen den Schluss des Korans immer kürzer werden, enthalten die weiteren Textfelder auch immer mehr Überschriften. In Textfeld XVIII lassen sich sieben rot hervorgehobene Überschriften erkennen. Es handelt sich um Suren 8o-86. Der Surentext in $\dot{G} u b \bar{a}$-Schrift wurde hier eigentlich unter Auslassung der Leerräume für den

\footnotetext{
105 Vgl. http://gallica.bnf.fr/ark:/12148/btvib84192247/fi1 .image.r=Arabe\%205102 (Stand 8. März 2017).

106 Vgl. http://gallica.bnf.fr/ark:/12148/btvib84192247/fi2 .image.r=Arabe\%205102 (Stand 8. März 2017).

107 Q 75:11-12 lautet:

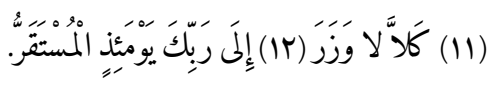

108 Vgl. http://gallica.bnf.fr/ark:/12148/btvib84192247/fi3 .image.r=Arabe\%205102 (Stand 8. März 2017).
} 
übergeordneten grossen Text stets auf horizontal ausgerichteten Linien notiert. ${ }^{109}$

In Textfeld XIx folgen die Suren 87-96, deren Überschriften ebenso rot hervorgehoben sind. Im Fall von Q 88 unterliess der Schreiber allerdings die Hervorhebung in roter Schrift. Sie beginnt auf der rechten Seite der Mittelspalte mit der Basmala. Auf der linken Seite dieser Mittelspalte lassen sich in roter Tinte die Überschriften $\mathrm{zu}$ Q 87 und 89 erkennen. Q 96 beginnt am Ende dieses Textfelds auf der linken Seite. Der Schreiber springt hier nach der Basmala etwas nach oben, um die Abschrift dieser Sure fortzusetzen. Beim untersten roten Eintrag in diesem Textfeld beginnt Q 94. ${ }^{110}$

Am Anfang von Textfeld xx endet Q 96 (Schlussvers: 96:19). Es schliessen sich die Abschriften von Suren 97-114 an, deren Überschriften zumeist rot hervorgehoben sind. Q 114 wurde zuunterst auf der rechten Seite dieses Textfelds notiert. Zuunterst auf der linken Seite lässt sich auch Q 112 erkennen. Sie wurde in diesem Feld mehr als einmal kopiert. Der Schreiber musste offensichtlich den Hintergrund dieses Felds noch ganz ausfüllen und wählte dazu Q 112. ${ }^{111}$ Soweit ersichtlich besteht auch der Hintergrund des letzten Textfelds (XXI) ausschliesslich aus Abschriften von Q 112 (Sürat alIhlās $).{ }^{112}$

Schlussfolgerungen: Die vorangehende Zusammenstellung zeigt auf, dass auf der vorliegenden Rolle der gesamte Text der islamischen Offenbarung kopiert worden ist. Bei einer abschliessenden Würdigung des Vorgehens des Kopisten fällt auf, dass er das Dokument in vier Durchgängen von oben nach unten ausfüllte:

Er beginnt mit der Abschrift im rechten Rahmenteil (rechts aussen) und kopiert hier Q 1:1-

\footnotetext{
109 Vgl. http://gallica.bnf.fr/ark:/12148/btvıb84192247/fi3 .image.r=Arabe\%205102 (Stand 8. März 2017).

110 Vgl. http://gallica.bnf.fr/ark:/12148/btvib84192247/fi4 .image.r=Arabe\%205102 (Stand 8. März 2017).

111 Vgl. http://gallica.bnf.fr/ark:/12148/btvıb84192247/fi5 .image.r=Arabe\%2O5102 (Stand 8. März 2017).

112 Vgl. http://gallica.bnf.fr/ark:/12148/btvıb84192247/fi6 .image.r=Arabe\%205102 (Stand 8. März 2017).
}

Q 4:125. Am Schluss der Rolle setzt er die Abschrift von Q 4 in den beiden Textbalken mit diagonaler Textanordnung in der Mittelspalte fort (Q 4:126136a); er fährt dann weiter auf den sechs horizontalen Zeilen unmittelbar darunter (Q 4:136b-142). In Vers 4:142 springt er nochmals in den Rahmen rechts aussen (Q 4:142-145). Auf den drei obersten Zeilen, des sich gegen unten verjüngenden Dreiecks folgt die Fortsetzung von Q 4:145-147. Der Schreiber verweilt hier also gewissermassen in der Mittelspalte, bevor er wieder an den Anfang der Rolle springt.

Er füllt dort den linken Rahmenteil aus (links aussen; Beginn in der Mitte mit Q 4:148). Im linken Rahmenteil steht zuunterst am Schluss Q 9:27. Der Schreiber springt auch hier in die Mittelspalte, wo er gewissermassen kurz verweilt. Auf den letzten horizontalen Zeilen im sich gegen unten verjüngenden Dreieck steht Q 9:27-29a. Auf den drei letzten horizontalen Zeilen folgen Q 9:29b-31.

Jetzt springt der Kopist ein weiteres Mal an den Anfang der Rolle zurück und setzt die Abschrift des Korans in der Mittelspalte fort, wo sich zuoberst Q 9:32 erkennen lässt. Bei der weiteren Abschrift der islamischen Offenbarung überspringt der Schreiber jeweils die 21 Felder mit Text in grosser Schrift. Am Ende der Rolle erreicht er bei der Abschrift des Korans ausserhalb der 21 Textfelder zuletzt Q 39:30-31.

Der Schreiber springt jetzt ein letztes Mal an den Anfang der Rolle zurück und kopiert die Fortsetzung der islamischen Offenbarung im $\dot{g} u b \bar{a} r-$ farbenen teppichartigen Hintergrund in den 21 Textfelder selbst. Zuoberst in Textfeld I lässt sich Q 39:32 erkennen. Der Schreiber springt danach bei der Abschrift des Korans Textfeld um Textfeld nach unten, bis er erneut das Ende der Rolle erreicht.

Der Schreiber füllte das vorliegende Dokument bei der Abschrift des Korans also in vier Durchgängen nach und nach von oben nach unten aus. Dieses Auf und Ab bei der Niederschrift des Korans erinnert in einem gewissen Sinn an die Bewegungen des Betenden beim islamischen Ritualgebet. Auch beim Ritualgebet wirft sich der Gläu- 
bige beim suǧūd mehrfach vor Gott nieder, um sich sogleich erneut aufzurichten. Nachdem er eine Weile gestanden hat, folgt eine erneute Niederwerfung. Es lässt sich natürlich nicht beweisen, ob für den Schreiber bei der Konzeption der vorliegenden Rolle die soeben ins Auge gefasste Analogie mit dem islamischen Ritualgebet von Bedeutung war. Allerdings lässt sich diese Parallelität nicht $a$ priori in Abrede stellen.

Neben der wohl vollständigen Abschrift des Korans enthält dieses Belegstücks in den 21 Feldern auch weitere Textelemente frommen Inhalts; sie werden hier zusammenfassend nochmals aufgeführt: a. ونصر من الله وفتح قريب وبشَّرَ المؤمنين (Textfeld I: Q 61:13 $\left.{ }^{113}\right)$. b́. Es schliesst sich eine Anrufung der Čahārdah Mașūm an, wobei die vorliegende Aufzählung zusätzlich an Fāțimas Mutter als 15. Person appelliert. Dieser Text bringt am Schluss die Hoffnung zum Ausdruck, dass Gott dieses Gebet erhören möge (Entzifferung im einzelnen nicht gesichert; Textfelder II-XIV). c. Es folgt darauf das Nādi-A Ali-Gebet. ${ }^{114}$ Es endet hier allerdings gegenüber der Fassung auf Is 1623 aus der Chester Beatty Library abweichend und ruft der Reihe nach Gott bei seiner Erhabenheit ('azama), Muhammad bei seiner Prophetschaft (nubuwwa) und 'Alī bei seiner walāya an (Textfeld XV-XIX). d. Ganz am Schluss folgt die wohl an Gott gerichtete Anrufung, er möge den Träger (ḩāmil) dieses Korans bzw. dieser Koranrolle beschützen (Textfeld XX-XXI).

Anhand dieser in den 21 Feldern kopierten Textelemente lässt sich aufzeigen, dass die Rolle aus einem zwölferschiitischen Umfeld stammt. Die Abschrift des Nädi-'Alì-Gebets legt zudem eine Entstehung in einem mystisch orientierten Umfeld nahe, handelt es sich dabei doch um einen unter imamitischen Sufis bekannten dikr. $^{115}$ Vorläufig ist eine präzisere Einordnung dieses Belegstücks nicht mit Sicherheit möglich. Es könnte aber sein,

\footnotetext{
113 In Q 61:13 ohne das einleitende wa (wa-nașr).

114 Vgl. dazu Kapitel 5.3 (Is 1623, Chester Beatty, Dublin), nach Anm. 36 f., 57 f., bei Anm. 9o-94.

115 Vgl. dazu Kapitel 5.3 (Is 1623, Chester Beatty, Dublin), bei Anm. 9o-94.
}

dass die beiden im Anfangszierfeld abgebildeten Pfauen zur Kontextualisierung beitragen. Die weiteren Überlegungen haben allerdings hypothetischen Charakter.

Zur Erklärung der Abbildung der beiden adossierten blauen Pfauen wurden mehrere Möglichkeiten in Betracht gezogen, aber wieder verworfen:116 a. Grundsätzlich ist es erstaunlich, dass eine Abschrift des Korans an derart prominenter Stelle mit der Abbildung von zwei Pfauen versehen wurde. Gerade die 'ulamä’ beharrten auf dem Verbot der Darstellung von Lebewesen. ${ }^{117}$ Der Pfau ist in einem islamischen Kontext zudem übel beleumdet, soll er doch Iblīs dabei behilflich gewesen sein, ins Paradies einzudringen und dort Eva und Adam zu verführen. ${ }^{118} \mathrm{~b}$. Es wurde sodann Versuche angestellt, in dieser Abbildung des Pfaus eine Anspielung auf den Melek Tââūs der Jesiden zu sehen. Auch diese Überlegungen wurden aber wieder verworfen. ${ }^{119} \mathrm{c}$. Versuche, diese beiden Pfauen auf der Rolle mit dem Pfauenthron in Verbindung zu bringen sind m. E. ebenso gescheitert. Auf den Abbildungen dieses verschollenen Throns lassen sich zwar auf dem Baldachin zwei Pfauen erkennen. Sie sind darauf allerdings nie adossiert, sondern schauen sich gegenseitig an. ${ }^{120}$

d. Nachdem die soeben aufgezählten Erklärungsansätze zu verwerfen sind, bleibt eine letzte Möglichkeit als einstweilen überzeugendste Alternative. Sie bringt uns zurück zu den aus Südiran im 18. Jh. bekannten mystischen Gruppierungen. Aus Abarqūh (ca. 16okm nördlich von Shiraz) ist eine mystische Gruppierung namens

\footnotetext{
116 Grundsätzliche Überlegungen zur Bedeutung von Pfauen stellt an Green, Ostrich eggs and peacock feathers.

117 Vgl. Naef, Bilder und Bilderverbot 11-32 (zur Ausgangslage: „Die heiligen Schriften und ihre klassischen Interpretationen").

118 Awn, Satan's tragedy and redemption 40-44, v.a. 42.

119 Zum Melek Ṭāwūs bei den Jesiden siehe Kreyenbroek, Yezidism 94f., und darin Index s.v. „Melek Tavus“ (S. 341); ders., Yazīdī, in $E I^{2}$; Asatrian und Arakelova, Malak-Tāwūs.

120 Für erste Hinweise zum Pfauenthron siehe https://en .wikipedia.org/wiki/Peacock_Throne (Stand 12. Oktober 2017).
} 
Ṭāwūsiyya bekannt. ${ }^{121}$ Der allfällige Bezug zu dieser Ṭāwūsiyya und den beiden Pfauen ergibt sich auf rein sprachlicher Ebene, heisst der Pfau auf Arabisch doch țāwūs. Diese Gruppierung soll auf Abu l-Hayr Iqbāl zurückgehen, der vom Propheten Ṭāwūs al-Ḥaramayn genannt worden war und in Abarqūh gestorben sein soll. Bei der nach ihm benannten Țāwūsiyya ${ }^{122}$ handelt es sich um einen Zweig der Ğunaydiyya. ${ }^{123} \mathrm{Im}$ Ithậf al-aşfya $\vec{a}^{3} b i$ salāsil al-awlìy $\bar{a}^{3}$ wird die Țāwūsiyya als Zweig der 'Alawiyya bezeichnet. ${ }^{124}$ Es muss einstweilen offen bleiben, ob der soeben hergestellte Bezug der vorliegenden Rolle zur Țāwūsiyya gesichert ist. Es scheint allerdings im jetzigen Zeitpunkt der überzeugendste Erklärungsansatz. Die Abbildung der beiden Pfauen würde somit auf Țāwūs al-Ḥaramayn bzw. die Țāwūsiyya verweisen.

In diesem Titelfeld fallen zusätzlich vier Federn auf, die um den Ausschnitt mit den beiden Pfauen herum angeordnet sind. Sie rufen jene Federn in Erinnerung, die von den Handwerksgilden (șinf, Pl. aṣnāf) u.a. bei den 'Āšūrā-Prozessionen mitgetragen werden. ${ }^{125}$ Auch dieser allfällige zusätzliche Bezug lässt sich einstweilen aber noch nicht mit Gewissheit beweisen.

121 Es lässt sich nicht feststellen, ob es sich um einen Orden (țarīa) stricto sensu oder vielmehr eine lose Gruppierung handelt.

122 Siehe auch die knappe Erwähnung dieser Gruppierung bzw. dieses Ordens bei Reichmuth, Murtadā al-Zabīdī 20 (Anm. 117, Schluss). Siehe dazu indirekt auch Massignon, Passion II, 200-203. Siehe überdies Nikitine, Țāwūsiyya, in $E I^{2}$.

123 Vgl. A.Y. Koçak Al-Murtażā al-Zabìdī ve Ikd al-Cavhar al-samin'ı $102 \mathrm{f}$. Ph. Diss. İstanbul Üniversitesi Edebiyat Fakültesi, İstanbul, 1986. Mit bestem Dank an Prof. Dr. St. Reichmuth (Bochum) für diesen Quellenverweis.

124 Vgl. Reichmuth, op. cit. 110, wo Verweis auf folgende Quelle (v.a. 223), die St. Reichmuth dem Verfasser freundlicherweise zur Verfügung stellte (Mai 2017): 64 . Ithāa f al-aşfiyā' bi-salāsil al-awliy $\bar{a}$ : On the țuruq and their chains of transmission which lead to the Prophet. Mss.: a) Ankara, Türk Tarih Kurumu Ktph, Muhammed Tancî Kısmı, Mecmua, 167-26o; copied by 'Abd alMun'im Šaraf al-Minyataynī aš-Šāfīì, dated Sunday, 9 Muḥarram 1205/Saturday, 18 September 179 o.

125 Vgl. ausführlicher dazu unten Kapitel 5.5 (zu Is 1622 aus der Chester Beatty Library), vor Anm. 220. 


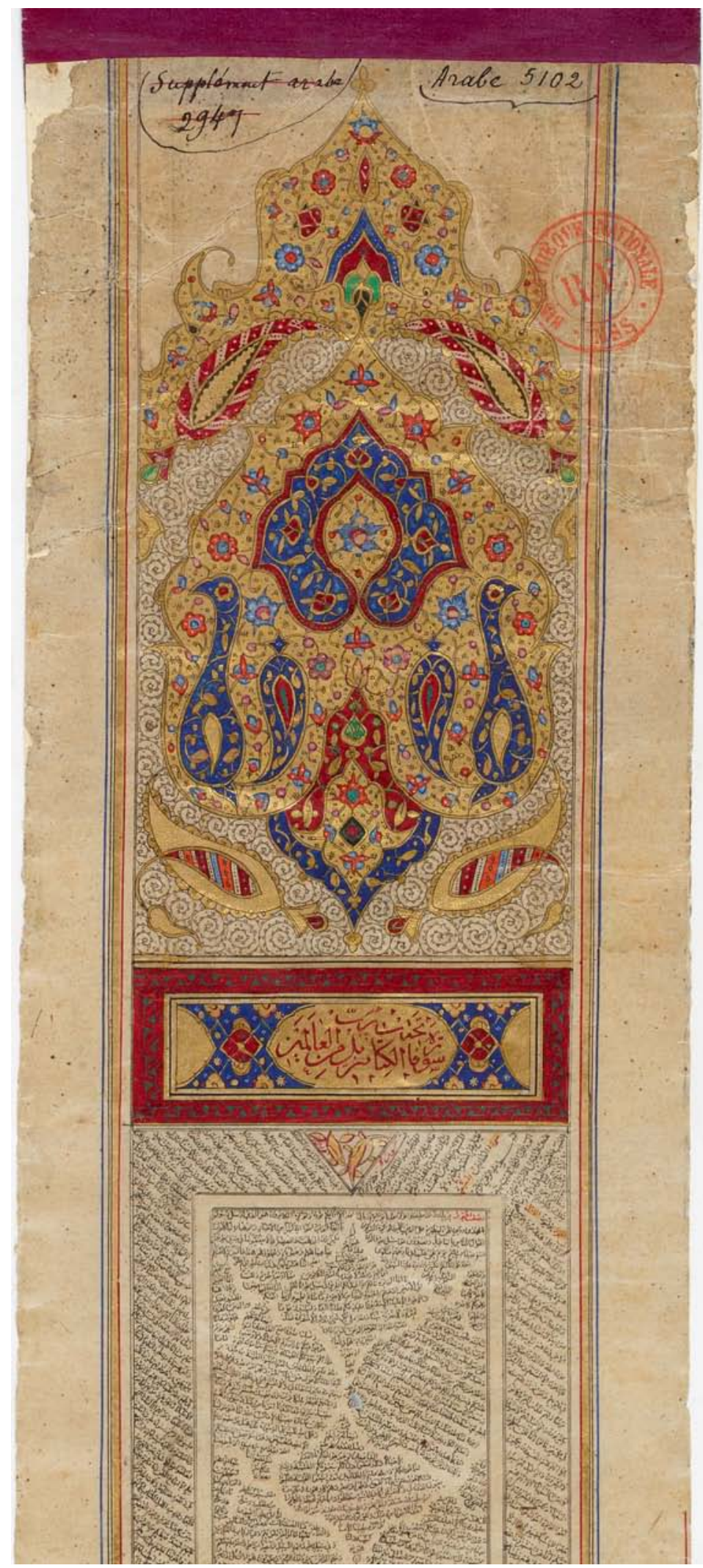

ABB. 121

Paris, Bibliothèque Nationale de France, Arabe 5102 (vgl. zwischen Anm. 5 und 9; A. Schutzteil und Anfangszierfeld): Arabe 5102 beginnt mit einem aufwendig gestalteten Anfangszierfeld. Im achsialsymmetrisch angeordneten Zierfeld lassen sich zwei adossierte Pfauen erkennen. Im Titelbalken darunter steht in roter Schrift auf goldenem Hintergrund: Sūrat Fātihat al-Kitāb tanzül min rabbi al‘ălaminn. Die Länge des Anfangszierfelds beträgt ca. $14.2 \mathrm{~cm}$. 


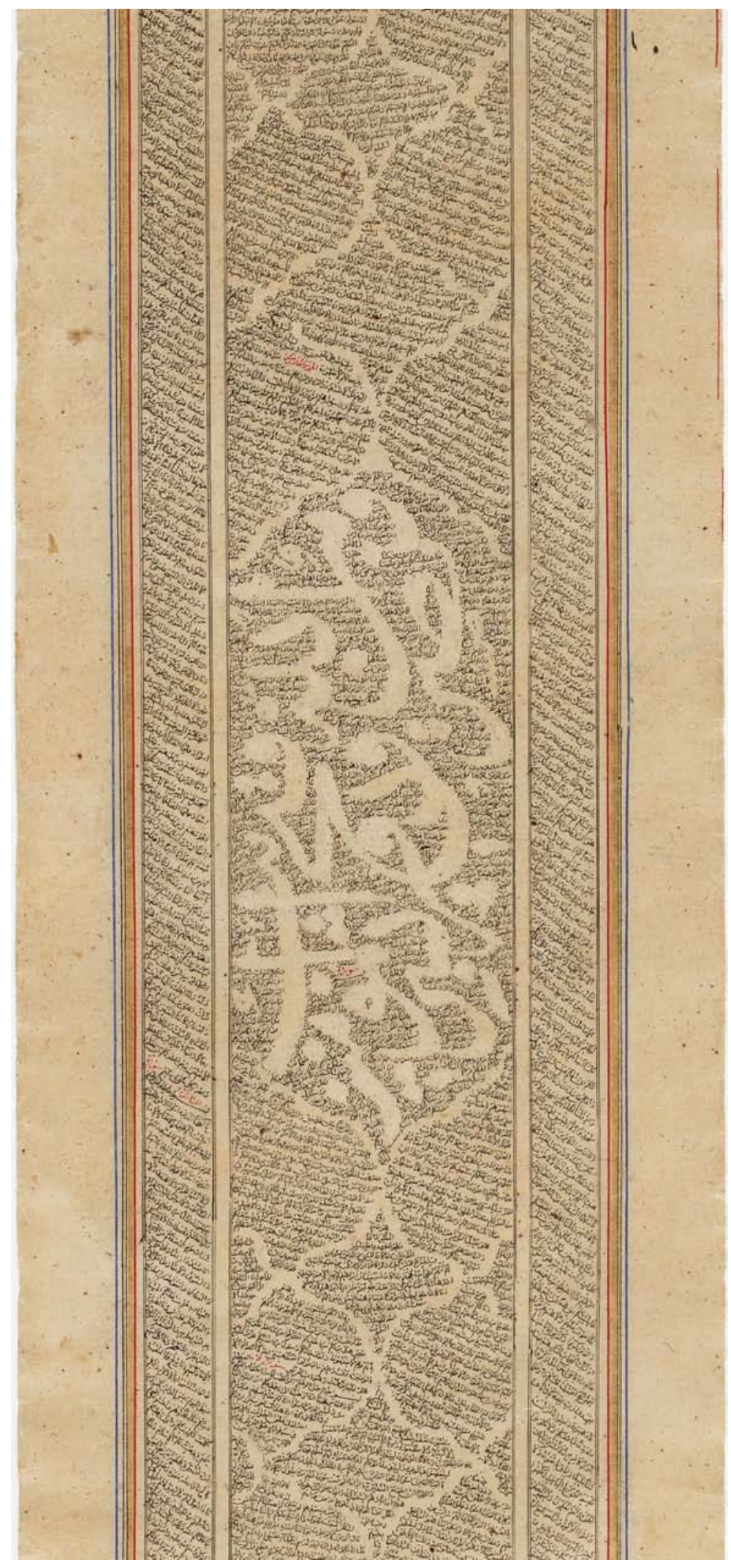

ABB. 122

Paris, Bibliothèque Nationale de France, Arabe 5102 (vgl. bei Anm. 14): Über die gesamte Länge dieser Rolle sind 21 Kartuschen mit grossem Text auf einem $\dot{g} u b \bar{a} r$-farbenen Hintergrund verteilt. Der Text in Feld I (hier gezeigt) lautet: Wa-nașr min Allāh wa-fath qarīb wabaššir al-mu'minin (vgl. Q 61:13). 


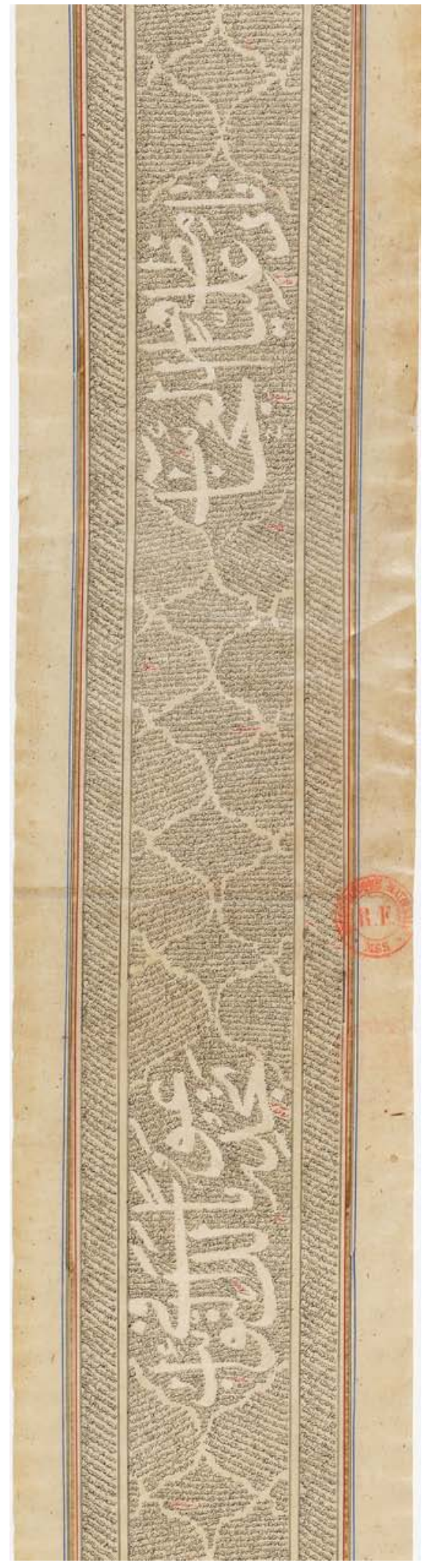

ABB. 123

Paris, Bibliothèque Nationale de France, Arabe 5102 (vgl. bei Anm. 28, vor Anm. 74, bei Anm. 114): Im Textfeld xv beginnt das Nādi-'Ali-Gebet, das unter Schiiten besonders beliebt ist. Es lässt sich mit modifiziertem Wortlaut am Schluss auch auf Is 1623 (Dublin) feststellen (vgl. Авв. 115). 


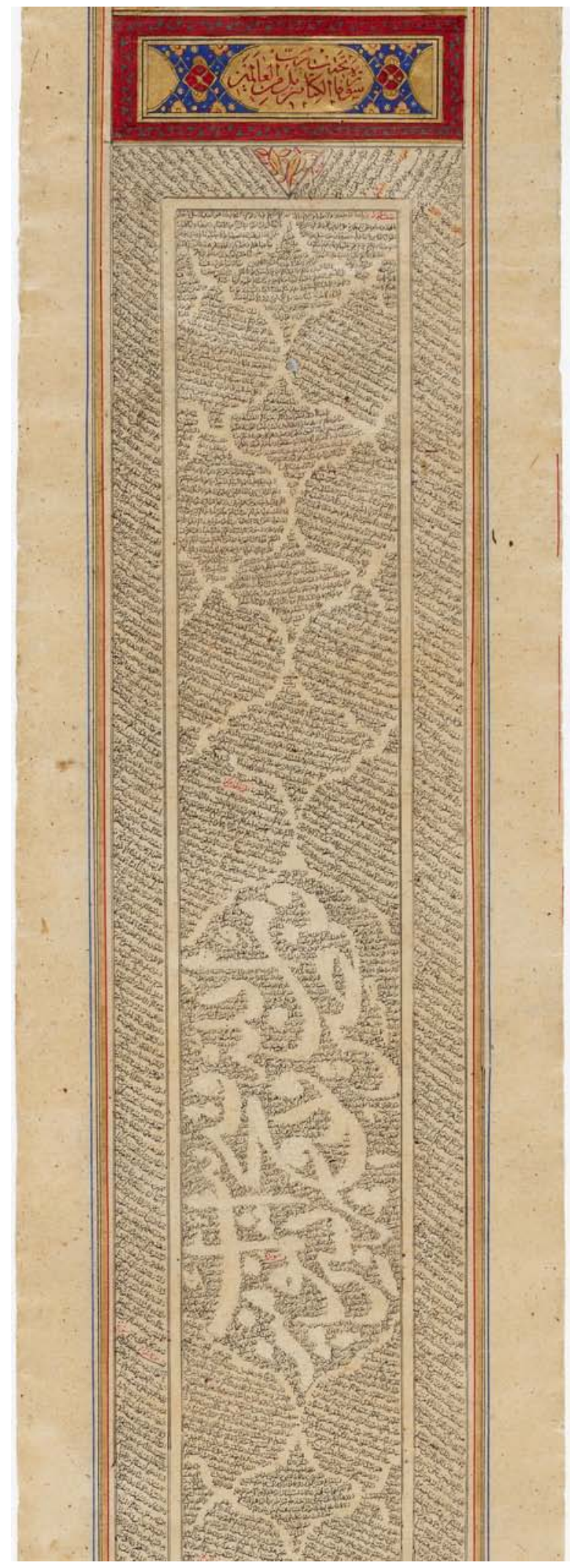

ABB. 124

Paris, Bibliothèque Nationale de France, Arabe 5102 (vgl. bei Anm. 35-46): Nach dem Anfangszierfeld beginnt die Abschrift des Korans in $\dot{G} u b a \bar{r}$-Schrift. Zur Rechten des Zwickels lässt sich Q 1 (al-Fätiha) und dann der Beginn von Q 2 (al-Baqara) erkennen. Der Schreiber füllt zuerst die rechte Seitenspalte bis an den Schluss des Dokuments aus. Er springt dann wieder nach oben und füllt die linke Aussenspalte aus. Ganz zuoberst lässt sich zur Linken des Zwickels Q 4:48 erkennen. In der breiten Mittelspalte selbst steht Q 9:32. Davor in roter Tinte der Eintrag nisf alǧuzw (Halb-Ǧuz'). Der Schreiber kopiert den Koran jetzt zuerst ausserhalb der 21 Textfelder. Erst am Schluss füllt er auch die 21 Felder mit übergeordnetem Text aus. 


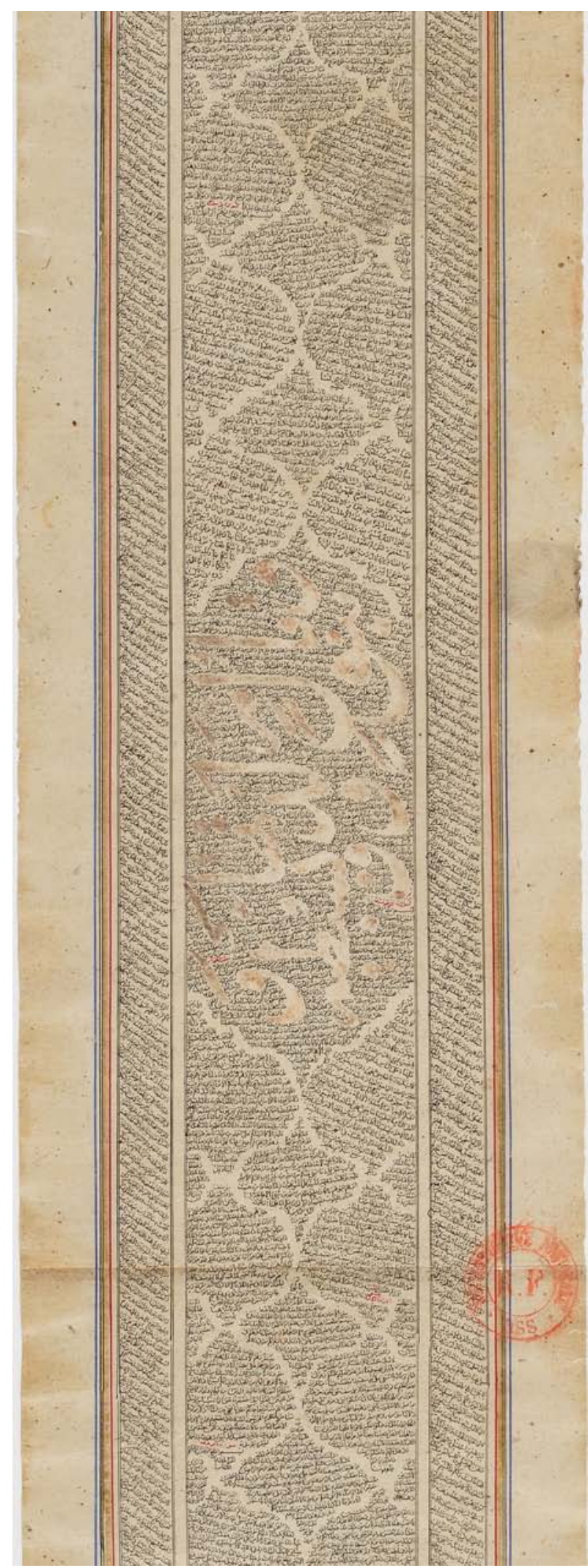

ABB. 125

Paris, Bibliothèque Nationale de France, Arabe 5102 (vgl. bei Anm. 17): Der Schreiber hatte den Text des Korans zuerst in der rechten Spalte kopiert, dann setzte er die Abschrift in der linken Spalte fort. Im dritten Durchgang füllte er den teppichartigen Hintergrund ausserhalb der 21 Kartuschen mit übergeordnetem Text aus. Im letzten Durchgang kopiert er die Fortsetzung der islamischen Offenbarung in diesen 21 Kartuschen mit übergeordnetem Text selbst. Für die Einzelheiten des Vorgehens beachte die vollständige, Beschrejibung.

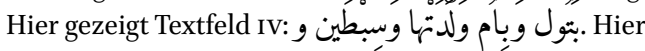
lassen sich auch Hinweise daraúf feststellén, dass die Buchstaben anfänglich bemalt waren. 




ABB. 126

Paris, Bibliothèque Nationale de France, Arabe 5102 (vgl. bei Anm. 89-9o): Das Ende der Rolle ist komplex aufgebaut; vgl. die Einzelheiten in der Beschreibung. Man beachte auch den Eintrag des Schreibers in roter Tinte, der festhält, er habe diese Abschrift des Korans angefertigt, damit sie ihn selbst überleben möge (vgl. zu diesem Eintrag bei Anm. 47). 


\section{Dublin, Chester Beatty Library, Is 1622; mit ergänzenden Hinweisen zu Is 1621}

Die Chester Beatty Library, Dublin, besitzt zwei Rollen, die grosse Ähnlichkeiten aufweisen, miteinander aber nicht identisch sind. Es handelt sich um Is 1621 und 1622 . Is 1622 ist besser erhalten. Auch wurde bei dessen Herstellung ein etwas grösserer Aufwand betrieben. Die weiteren Ausführungen beschreiben hauptsächlich Is 1622; sie machen aber wiederholt auch auf dessen Parallelstück Is 1621 aufmerksam.

Is 1621: $9.2 \times 511 \mathrm{~cm}$ (Bibliotheksmessung). Vollständig erhalten; Anfangszierfeld beschädigt. Kein Kolophon. Mutmasslich 18. Jh., iranischer Hintergrund (Shiraz?). Bei der Herstellung von Is 1621 wurde ein sehr feines Papier verwendet. Das Anfangszierfeld wurde nachträglich auf ein stärkeres Papier aufgezogen. ${ }^{1}$ Dieses Belegstück ist am Anfang mit einem Schutzteil aus bräunlichem Leder versehen.

Is 1622: $9.2 \times 585.0 \mathrm{~cm}$ (Bibliotheksmessung). Breite des Schriftspiegels: $7.6 \mathrm{~cm}$ (inklusive Rahmen). Am Anfang sorgfältig zugeschnittenes Schutzteil aus braunem Leder (Länge ca. $13 \mathrm{~cm}$ ). Das Dokument ist vollständig erhalten und in gutem Zustand. Kein Kolophon. Mutmasslich 18. Jh., iranischer Hintergrund (Shiraz?). ${ }^{2}$ Bei der Herstellung von Is 1622 wurde ein sehr feines, aus-

1 Vgl. Arberry, Koran illuminated 56 (Nr. 182). Die Chester Beatty Library hat von Is 162112 Abbildungen angefertigt und dem Verfasser zur Verfügung gestellt (2 pro Meter). Diese Ausführungen stützen sich zusätzlich auf eigenes Abbildungsmaterial. Bei der Abfassung dieses Beitrags stand Abbildungsmaterial des gesamten Dokuments zur Verfügung. Die Beschreibung von Is 1622 stützt sich ausschliesslich auf eigenes Abbildungsmaterial, da diese Rolle im Januar 2014 in der Ausstellung gezeigt wurde.

N.B.: Die Chester Beatty Library erstellte die im Abbildungsteil verwendeten Digitalisate der vollständigen Rolle erst 2019, als die vorliegende Untersuchung abgeschlossen war. Die hier in den Anmerkungen aufgeführten Stellenverweise beziehen sich auf im Lauf der Arbeit an diesem Belegstück in den Jahren 2014-2015 gemachte Aufnahmen; sie genügen professionellen Ansprüchen nicht (vgl. auch Einleitung zu Teil II, bei und mit Anm. 10).

2 Vgl. Arberry, Koran illuminated 56 (Nr. 183). gezeichnet geglättetes Papier verwendet. Wasserzeichen fehlen. ${ }^{3}$

Es sind weitere Dokumente bekannt, die grosse Ähnlichkeiten mit Is 1621 und 1622 aufweisen, hier aber nicht eingehender beschrieben werden. Es kann einerseits verwiesen werden auf zwei Belegstücke aus der Khalili Collection. ${ }^{4}$ Ebenso hierhin gehört AKM 492 aus der Agha Khan Foundation; es datiert aus dem Jahr 1236/1847 und wurde von Zayn al-'Ābidīn, einem Kaligraphen in den Diensten Fatḥ ‘Alī Šāh Qāḡārs für eine Drittperson angefertigt. ${ }^{5}$

3 Auch für Is 1621 wurde ein sehr feines Papier verwendet.

4 Sie sind beschrieben und abgebildet in Bayani et al., Decorated word: Qur'ans of the 17th to 19th centuries 2, $274 \mathrm{f}$. (Nr. 71): Iran, wahrscheinlich Shiraz, datiert 1206/1792, und 278f. (Nr. 73): Iran, wahrscheinlich Shiraz, datiert 1268/1831.

5 Das Dokument misst $12.5 \times 575 \mathrm{~cm}$. Es konnte im Juni 2012 im Zollfreilager in Genf summarisch untersucht werden. Es handelt sich um eine Koranrolle. Auf diesem Dokument sind als grosser Text Q 61:13 und Q 24:35 (Lichtvers) kopiert worden. Abbildung aufrufbar unter https://www .agakhanmuseum.org/collection/artifact/quran-scroll-ak m492 (Stand 6. Oktober 2017). Gedruckt in Spirit and Life: Masterpieces of Islamic Art from the Aga Khan Museum Collection (Katalog zu folgenden Ausstellungen: Pilotta, Parma, 3o. März-3. Juni 2007: darin 42 (Nr. 11); und Ismaili Centre, London, 14. Juli-31. August 2007: darin 39, Nr. 11). Published by Aga Khan Trust for Culture, Geneva, 2007. Mit folgender Legende: 39 (Nr. 11): „Qur'an scroll with selected verses and pious phrases. Iran, dated $1236 \mathrm{~h} / 1847$. Opaque watercolour, gold and ink on paper; $575 \times 12.5 \mathrm{~cm}$. Written in minute ghubari script on finely burnished paper, this Qajar Qur'an extends to about 5.75 metres in length. Ghubari comes from ghubar, or dust, in Arabic, and indeed words written in this script appear as fine as dust on a page. Originally used for texts where space was at a premium, such as pigeon post, the script was also used to demonstrate the virtuoso skills of a calligrapher in the preparation of Qur'ans, scrolls, as well as talismanic and magical compositions (Safwat and Zakariya 1996, pp. 184-185). This lavishly decorated scroll, which was probably prepared for a traveller, is by the calligrapher Zayn al-'Abidin, a master of naskh and a private scribe to Fath 'Ali Shah. The text has been laid out to form patterns of alternating geometric and floral cartouches with pious phrases and selected verses of the Qur'an, including the famous 'Light Verse' from Surat al-Nur in reserve." 
Behältnis (АВ B. 129): Zusammen mit den beiden Belegstücken aus der Chester Beatty Library ist ein metallenes Behältnis erhalten geblieben (Signatur: CBL Is X33). Es lässt sich nicht abschliessend klären, ob es zu Is 1621 oder Is 1622 gehört. Auch bestehen angesichts seines Durchmessers (ca. $2.2 \mathrm{~cm}$ ) grundsätzliche Zweifel daran, dass es sich um das ursprüngliche Behältnis zur einen oder andern Rolle handelt. Die Dokumente hätten äusserst satt aufgewickelt werden müssen, damit sie überhaupt in dieses Behältnis passten. Es soll gemäss einer Notiz aus dem 18. Jh. stammen. Es ist achteckig und mit drei Ösen versehen, durch die sich eine Schnur oder Kette ziehen lässt. Dies weist darauf hin, dass solche Dokumente am Körper getragen wurden. Das Behältnis ist auf beiden Seiten durch zwei abgerundete Deckel verschlossen, ${ }^{6}$ die mit einem goldenen Blatt- und Rankenmuster verziert sind. Die Länge dieses Behältnisses beträgt $11.0 \mathrm{~cm}$ (über die beiden Deckel gemessen).

Anfangszierfeld (AB B. 127): Is 1622 ist mit einem aufwendig gestalteten Anfangszierfeld versehen (Höhe ca. $16.9 \mathrm{~cm}$ ). Es wird auf beiden Seiten durch ein schmales goldenes Band eingefasst, das das Dokument auch auf seiner gesamten weiteren Länge einrahmt und an seinem unteren Ende abschliesst. Im Anfangszierfeld schliesst sich gegen innen eine dreiteilige Zierleiste an. Hier fassen zwei schmale rote, mit weissen Tüpfelchen versehene Seitenbänder ein goldenes Mittelband ein. Schwarze Linien strukturieren dieses goldene Mittelband und lassen ein Flechtband entstehen. Die Breite des eigentlichen Anfangszierfelds beträgt ca. $6.3 \mathrm{~cm}$. Als zentrales Element lässt sich darauf eine federförmige Verzierung erkennen, deren Spitze nach rechts unten geneigt ist. Diese Verzierung wird durch ein dreiteiliges Band eingefasst. Der Hintergrund des breiten Mittelstreifens ist blau und wurde mit einem Blüten- und Rankenmuster ausgefüllt (Blüten: rot und rosarot; Ranken: golden). Die beiden Seitenbänder sind viel schma-

6 Die beiden Deckel wurden bei der Untersuchung nicht geöffnet. ler und golden bemalt. Gegen innen schliesst sich ein roter Streifen an, der die Form der grossen Feder aufgreift und an der Spitze nach rechts geneigt ist. Auf diesem roten Streifen lässt sich ein feines weisses Rankenmuster erkennen.

Im Innern dieser grossen, an der Spitze nach rechts geneigten Feder lässt sich eine goldene Feder erkennen, deren Spitze sich leicht nach links neigt, aber nicht nach unten weist. Diese goldene Feder weist einen blauen Kern auf, der unten abgerundet ist und gegen oben spitz zuläuft. Diese Feder im Innern wurde sowohl auf ihrem goldenen als auch auf ihrem blauen Hintergrund mit farbigen Blüten (rot, rosarot, blau) und einem Rankenmuster versehen.

Die soeben beschriebene Doppelfeder ruht auf einer achsialsymmetrisch aufgebauten Basis, deren Höhe ca. ein Viertel der Höhe des Anfangszierfelds erreicht. Die Doppelfeder füllt ihrerseits nahezu den ganzen Rest dieses Anfangszierfelds aus. Die Hersteller griffen bei der Verzierung dieser Basis auf Elemente zurück, die auch bei der Gestaltung der Doppelfeder selbst zum Einsatz kamen.

Zwischen dem Basiselement und der Doppelfeder lassen sich am linken und rechten Rand zwei goldene, im Innern blau ausgefüllte und mit Blüten- und Rankenmustern ausgefüllte Verzierungen erkennen. Ein ähnliches, allerdings einfacher gestaltetes Zierelement befindet sich am oberen rechten Rand des Anfangszierfelds. Auf der linken Seite lässt sich ein goldenes Blüten- und Rankenmuster erkennen. Die soeben erwähnten seitlichen Zierelemente dienen ganz offensichtlich zum Ausfüllen des Hintergrunds des Zierfelds. Dieselbe Funktion kommt auch den feinen schwarzen Spiralen zu, die den restlichen Hintergrund des Anfangszierfelds ausfüllen. Diese schwarzen Spiralen auf Is 1622 und Is 1621 weisen auffällige Gemeinsamkeiten mit jenen auf Arabe $5^{102}$ (Paris) auf. ${ }^{7}$ Es ist damit davon auszugehen, dass die drei soeben angeführten Dokumente aus derselben Tradition hervorgegangen sind. Bei der Her-

7 Vgl. Kapitel 5.4. 
stellung von Arabe 5102 wurde einfach besonders viel Sorgfalt angewendet. Da die beiden Belegstücke aus der Khalili Collection mit Shiraz in Verbindung gebracht werden, könnte ein solcher Bezug auch bei Is 1621 und 1622 im Vordergrund stehen. ${ }^{8}$

Im Anfangszierfeld von Is 1622 lassen sich auf der rechten und linken Seite des Basiselements zwei kleine Kartuschen mit Text erkennen, die golden eingefasst und oben grün abgeschlossen sind. Beide Kartuschen (Höhe ca. $0.9 \mathrm{~cm}$ ) enthalten Text in sehr feinem $\dot{G} u b a \bar{r}$. In der rechten Kartusche steht die gesamte Fātiha (Q 1:1-7). ${ }^{9}$ In der Kartusche auf der linken Seite steht Q 2:1-4 (Sūrat al-Baqara). Q 2:5 steht sodann im Mittelstreifen rechts oben (АВ В. 128). ${ }^{10}$ Dies lässt vermuten, dass das vorliegende Belegstück eine Abschrift der islamischen Offenbarung enthält. Die weitere Abschrift des Korantexts wird erst später analysiert. In einem ersten Schritt steht der übergeordnete Text im Vordergrund, der auf Is 1622 auf insgesamt 35 Textfelder verteilt worden ist.

Textfelder (АВ В. 128 und 130-133): Die weiteren Beschreibungen stützen sich auf Is 1622 . Sie erfassen in einem ersten Schritt den Text, der in den über die gesamte Länge der Rolle verteilten 35 Textfeldern von unterschiedlicher Gestalt und Länge kopiert worden ist. Die in die Herstellung des vorliegenden Belegstücks involvierten Personen übernahmen das u.a. bereits von Arabe 5102 (BNF, Paris; vgl. Kapitel 5.4) bekannte Vorgehen. Der grosse Text entsteht also durch Auslassung von Leerräumen auf einem Hintergrund in $\dot{G} u b \bar{a} r-$ Schrift. Bei der Schrift des grossen Texts handelt es sich um Tulut. Der Text in den Leerräumen ist häufig mit heller Farbe aufgemalt; an diesen Stellen ist nicht einfach das neutrale Papier sichtbar.

8 Die Zuschreibung zu Shiraz wird im Fall der beiden Belegstücke aus der Khalili Collection einfach als wahrscheinlich erachtet („possibly Shiraz“); siehe Anm. 4.

9 Die Fātiha wurde hier auf sieben Zeilen kopiert. Die Höhe der Schrift erreicht also gerade etwa $1 \mathrm{~mm}$.

10 Sowohl bei der linken als auch bei der rechten Kartusche steht zuunterst Text ausserhalb der Kartusche selbst.

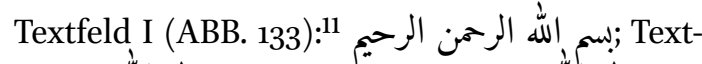

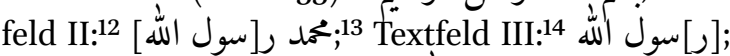
Textfeld IV:15 صلى الله عليه واله امامى Textfeld V:16 الله Textfeld VII:18 بنت رسول Texteld VI:17 ;فاطمة

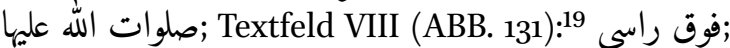

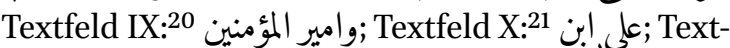

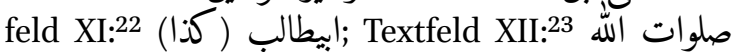

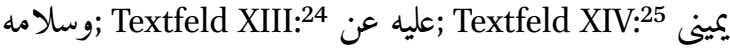
; Textfeld XV:26 وقالحسن والحسين وعنى: Textfeld

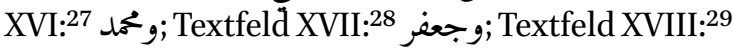

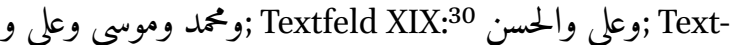

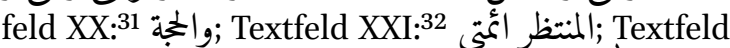

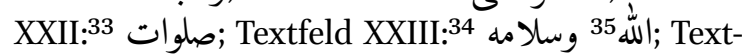
feld XXIV:36 عليهم اجمعين عن; Textfeld XXV:37 شهماتى

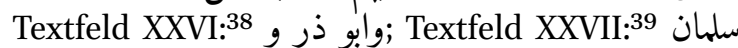
;ومقداد وحذيفة Textfeld XXVIII:40 وعماره; Textfeld

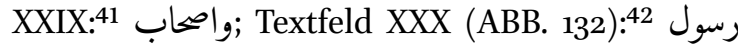

\footnotetext{
11 Abb. Is 1622.2.1.

12 Abb. Is 1622.2.1 und 1622.2.2

13 Man beachte, dass das $r \bar{a}$ ' von rasūl noch in Textfeld II steht, aber natürlich zu Textfeld II I gehört. Abb. Is 1622.2.2.

Abb. Is 1622.2.5 und 6.

Abb. Is 1622.2.6.

Abb. Is 1622.3.2.

Abb. Is 1622.3.4.

Abb. Is 1622.3.5-6.

Abb. Is 1622.4.1 und 2.

Abb. Is 1622.4.3.

Abb. Is 1622.4.4.

Abb. Is 1622.4.7.

Abb. Is 1622.4.7.

Abb. Is 1622.4.8.

Abb. Is 1622.5.1.

Abb. Is 1622.5.2.

Abb. Is 1622.5.2.

Abb. Is 1622.5.4.

Abb. Is 1622.5.5.

Abb. Is 1622.5.5 und 6.1.

Abb. Is 1622.6.3.

Abb. Is 1622.6.6.

Abb. Is 1622.6.7.

Auf der Rolle hier offensichtlich لله.

Abb. Is 1622.6.9.

Abb. Is 1622.6.10.

Abb. Is 1622.7.2.

Abb. Is 1622.7.4-5.

Abb. Is 1622.7.5.

Abb. Is 1622.7.6-7.

Abb. Is 1622.7.9 und 7.12.
} 


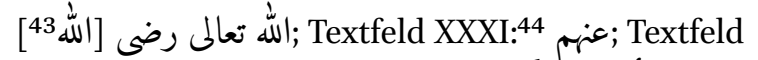

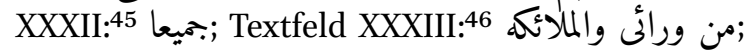
Textfeld XXXIV:47 عليهم; Textfeld XXXV (ABB. 133):48 السد[آم حولى والله تعالى ربى

Der gesamte Text in den 35 Feldern auf Is 1622 lautet also:

بسم الله الرممن الرحيم محمد رسول الله صلى الله عليه واله

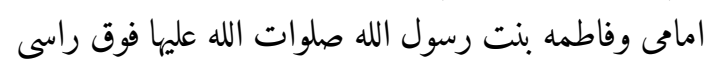

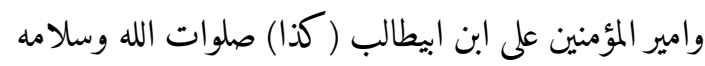
عليه عن يمينى والحسن والحسين وعلى ومحمد وجعفر ومحمد

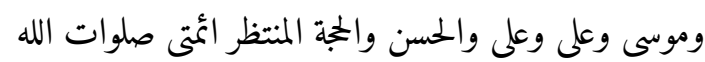

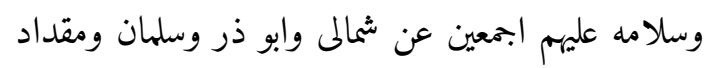
وحذيفة وعماره واصحاب رسول الله تعالى رضى [الله] عنهم جميعا من ورائى والملائكك عليهم السلام حولى والله تعالى وحسئل

ر)

Auf Is 1621 ist ebenso Text in grosser Schrift enthalten. Er verteilt sich in diesem Fall über insgesamt 30 Felder und lautet:

Textfeld I:49 السم الله الرحمن الرحيم; Textfeld II:50

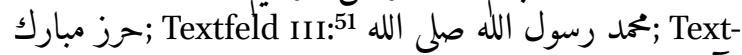
feld IV:52 عرليه رابوات ألله

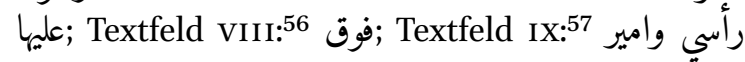

Der Ausdruck Allāh steht in diesem Textfeld zwar nur einmal; er dürfte aber wohl zweimal zu lesen sein.

Abb. Is 1622.7.15.

Abb. Is 1622.7.15.

Abb. Is 1622.7.18.

Abb. Is 1622.9.2.

Abb. Is 1622.9.2.

Abb. Is 1621.1.4 und 2.1.

Abb. Is 1621.2.1.

Abb. Is 1621.2.4.

Abb. Is 1621.3.1.

Abb. Is 1621.3.1.

Abb. Is 1621.3.2-3.

Abb. Is 1621.4.1.

Abb. Is 1621.4.1.

Abb. Is 1621.4.4-7.

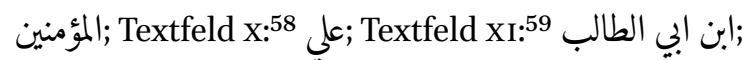
Textfeld XII:60 صؤلينوات:

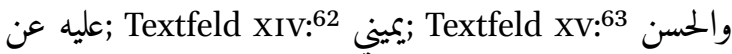

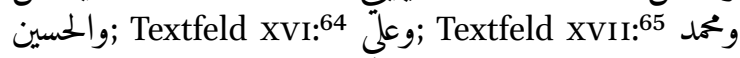

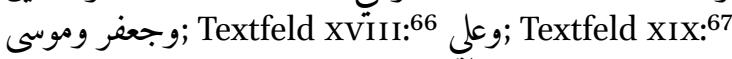

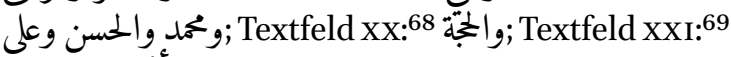

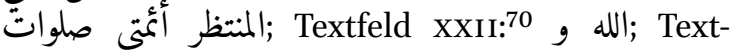
feld XXIII: سلامه عليهم اجمعين; Textfeld XXIV: Textfeld Xxv:73 شمين :مextfeld xxvi:

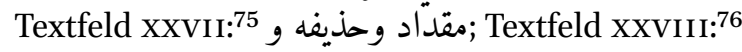

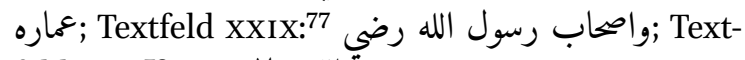
feld xxx:78 الله تعالى عههم."

Hier ist die Rolle fertig. Der fortlaufende Text auf Is 1621 ist somit mit jenem auf Is 1622 teilweise identisch, bricht aber früher ab; er lautet:

بسم الله الرحمن الرحيم حرز مبارك محد رسول الله صلى الله عليه وآله امامي وفاطمة بنت رسول الله صلوات الله عليها فوق رأسي وامير المؤمنين علي ابن ابي الطالب صلوات الله

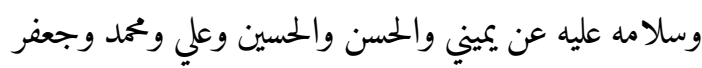

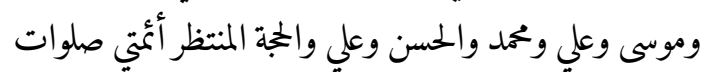

58 Abb. Is 1621.4.8.

59 Abb. Is 1621.5.1.

6o Abb. Is 1621.5.3.

61 Abb. Is 1621.5.4.

62 Abb. Is 1621.6.1.

63 Abb. Is 1621.6.3.

64 Abb. Is 1621.7.1.

65 Abb. Is 1621.7.1.

66 Abb. Is 1621.7.8.

67 Abb. Is 1621.7.9.

68 Abb. Is 1621.8.1.

69 Abb. Is 1621.8.5.

70 Abb. Is 1621.9.1.

71 Abb. Is 1621.9.1.

72 Abb. Is 1621.9.3.

73 Abb. Is 1621.10.1.

74 Abb. Is 1621.10.1.

75 Abb. Is 1621.10.6.

76 Abb. Is 1621.11.1.

77 Abb. Is 1621.11.7.

78 Abb. Is 1621.12.1. 


$$
\text { وحديفه وعماره واصحاب ومه علهم اجمعين عن شمالي وابو ذر وسلمان ومقداد الله رضي الله تعالى عنهم. }
$$

Aufbau und Gestaltung Mittelstreifen (Is 1622): Die inhaltlich soeben erfassten 35 Textfelder stellen ein wichtiges Gestaltungselement im zweiten Teil der Rolle dar. Der übergeordnete Text entsteht durch Auslassungen von entsprechenden Leerstellen auf dem teppichartigen Hintergrund in $\dot{G} u b \bar{a} r$-Schrift. Auf diesem Hintergrund lassen sich allerdings auch zusätzliche Gestaltungselemente erkennen, auf die im folgenden hingewiesen wird.

Die Breite des Schriftspiegels von Is 1622 beträgt ca. $7.6 \mathrm{~cm}$ (inkl. goldenem Rahmen rechts und links). Das Dokument weist auf beiden Seiten einen leeren Rand von ca. $0.8 \mathrm{~cm}$ Breite auf. Der Schriftspiegel selbst weist einen dreiteiligen Aufbau auf: Die Mittelspalte ist am breitesten und misst ca. $5.1 \mathrm{~cm}$. Diese Mittelspalte wird auf ihrer gesamten Länge sowie oben und unten von einem feinen goldenen Rahmen eingefasst. Ausserdem verläuft um diesen Mittelstreifen mit den 35 Feldern mit Text ein deutlich schmalerer Rahmen, der Text in $\dot{G} u b a \bar{r}$ enthält. Die Zeilen sind in diesem seitlichen Rahmen steil geneigt und verlaufen von rechts unten nach links oben. Gegen aussen wird dieser Rahmen mit schräg angeordneter $\dot{G} u b \bar{a} r$-Schrift von einem weiteren schmalen goldenen Band eingefasst. Die Breite dieses Rahmens mit Text in $\dot{G} u b \bar{a} r$ beträgt ca. $1.0 \mathrm{~cm}$.

Die weiteren Ausführungen gehen auf die Gestaltung dieses Mittelstreifens ein, wo durch Auslassungen von Leerstellen auf dem Hintergrund in $\dot{G} u b \bar{a} r$-Schrift zusätzliche Figuren entstehen. Die folgende Beschreibung verweist bei der Situierung der einzelnen Figuren jeweils auf ihre Anordnung in Bezug auf die 35 Textfelder:

Im Hintergrund von Textfeld I (АВB. 128) ${ }^{79}$ wurde der Text in $\dot{G} u b \bar{a} r$-Schrift auf horizontalen Zeilen angeordnet. Dieses Textfeld wird oben und unten durch eine mehrfach abgestufte, spitz zulaufende Linie bzw. Klammer eingefasst; sie ent-

79 Abb. Is 1622.2.1. steht durch Auslassungen auf dem Hintergrund in $\dot{G} u b \bar{a} r$. Vor und nach diesem Textfeld lässt sich eine vierteilige, achsialsymmetrisch ausgerichtete rautenförmige Figur erkennen, die auf dieselbe Art entsteht. Sie setzt sich ihrerseits aus vier kleineren Rauten zusammen. Die beiden Rauten in der Mitte enthalten Text in $\dot{G} u b \bar{a} r$ auf horizontalen Zeilen. In der Raute rechts ist der Text von rechts oben nach links unten geneigt. In der linken Raute verläuft der Text von rechts unten nach links oben.

Textfeld II ${ }^{80}$ (Muhammad ra[sūl]) greift die aus dem Anfangszierfeld bekannte Figur der Feder auf, deren Spitze nach rechts unten geneigt ist. Ausser in der Spitze wurde der Text in $\dot{G} u b \bar{a} r$ hier auf horizontalen Zeilen notiert. In der Spitze der Feder beginnt der Text rechts unten. Nach Textfeld II folgt eine weitere vierteilige Raute, deren Aufbau bereits zuvor beschrieben worden ist. ${ }^{81}$

Textfeld III ([ra]sūl Allāh $)^{82}$ hat die Gestalt einer auf der Spitze stehenden Raute, deren Seitenlinien mehrfach abgerundet worden sind.

Zwischen Textfeld III und IV $^{83}$ folgt ein neues Gestaltungselement, das durch Auslassungen von Leerstellen auf dem Hintergrund in $\dot{G} u b \bar{a} r$ entsteht. Unmittelbar vor bzw. nach diesem Element lässt sich je eine weitere vierteilige Raute erkennen, wie sie bereits am Anfang dieses Mittelstreifens angebracht worden ist. Das neue Gestaltungselement selbst setzt sich aus zwei je etwa gleich hohen Teilen zusammen: Im unteren Teil befindet sich ein Quadrat, dessen beide oberen Ecken nach aussen verlängert worden sind und spitz zulaufen. Dieses Quadrat ruht auf einem kleinen dreiteiligen Grundelement. Über diesem Quadrat befindet sich ein Aufsatz, der oben spitz zuläuft. Er weist ausserdem zu beiden Seiten spitz zulaufende Elemente auf. Diese Figur könnte eine Doppelaxt darstellen. ${ }^{84}$

\footnotetext{
8o Abb. Is 1622.2.2.

81 Vgl. die Hinweise zum Aufbau der beiden vierteiligen Rauten vor und nach Textfeld I hier unmittelbar zuvor.

82 Abb. Is 1622.2.2.

83 Abb. Is 1622.2.6.

84 Vgl. zu dieser Doppelaxt die Interpretation am Schluss dieses Abschnitts, bei Anm. 220-222.
} 
Textfeld IV ${ }^{85}$ (șallā Allāh 'alay-hi wa-āli-hī amā$m \bar{\iota})$ wurde wie Textfeld I gestaltet. Auf Textfeld IV folgt erneut eine vierteilige Raute.

Textfeld $\mathrm{V}^{86}$ (wa-Fāṭima) wurde wie Textfeld II gestaltet. Unmittelbar vor bzw. nach Textfeld v befindet sich eine vierteilige Raute.

Textfeld $\mathrm{VI}^{87}$ (bint rasūl) entspricht in der Gestaltung Textfeld III. Die Seitenlinien weisen hier allerdings tiefere Einbuchtungen auf.

Zwischen Textfeld VI und VII ${ }^{88}$ schliesst sich eine weitere Abfolge von vierteiliger Raute-Doppelaxt-vierteiliger Raute an.

Textfeld VII ${ }^{89}$ (Allāh șalawāt Allāh 'alay-hā) ist aufgebaut wie Textfeld I. Danach vierteilige Raute.

Textfeld VIII ${ }^{90}$ ( fawqa ra'sī) ist aufgebaut wie Textfeld II (Feder; Авв. 131).

Zwischen Textfeld VIII und $\mathrm{IX}^{91}$ folgt ein neues Gestaltungselement (АВ В. 134). Unmittelbar vor bzw. nach ihm lässt sich je eine vierteilige Raute erkennen. Beim neuen Gestaltungselement handelt es sich um einen achtstrahligen Stern. Seine einzelnen Strahlen wurden mit Text in $\dot{G} u b \bar{a} r$ Schrift ausgefüllt und werden durch textfreie Linien voneinander getrennt. Diese Trennlinien wurden über den eigentlichen Stern hinaus verlängert; auch an den Spitzen der einzelnen Strahlen lässt sich ein kurzer derartiger Fortsatz erkennen. Die einzelnen Strahlen wurden abwechselnd mit Text in rotem bzw. schwarzem $\dot{G} u b \bar{a} r$ ausgefüllt. Die Zeilen nehmen hier die Ausrichtung der einzelnen Strahlen auf. In der unteren Hälfte des Sterns steht der Text auf dem Kopf.

Textfeld $\mathrm{IX}^{92}$ (wa-amīr al-mu'minin) ist aufgebaut wie Textfeld I.

85 Abb. Is 1622.2.6.

86 Abb. Is 1622.2.6.

87 Abb. Is 1622.3.2.

88 Abb. Is 1622.3.2.

89 Abb. Is 1622.3.4.

90 Abb. Is 1622.3.6.

91 Abb. Is 1622.3.6.

92 Abb. Is 1622.4.1.
Zwischen Textfeld IX und $\mathrm{x}^{93}$ schliesst sich eine weitere Abfolge von vierteiliger Raute-Doppelaxtvierteiliger Raute an.

Textfeld $\mathrm{X}^{94}$ ('Alī Ibn) ist aufgebaut wie Textfeld vi. Unmittelbar auf Textfeld $x$ folgt eine vierteilige Raute.

Textfeld $\mathrm{XI}^{95}$ (AbīṬālib sic) ist aufgebaut wie Textfeld II (Feder).

Zwischen Textfeld XI und XII ${ }^{96}$ lassen sich hintereinander die folgenden Figuren erkennen, die alle bereits bekannt sind: a. vierteilige Raute; $b$. achtstrahliger Stern; c. vierteilige Raute; d. Doppelaxt; e. vierteilige Raute (АВв. 135).

Textfeld XII ${ }^{97}$ (șalawāt Allāh wa-salāmu-hū) ist aufgebaut wie Textfeld I. Danach vierteilige Raute.

Textfeld XIII ${ }^{98}$ ('alay-hi 'an) ist aufgebaut wie Textfeld II. Danach vierteilige Raute.

Textfeld XIV ${ }^{99}$ (yamin̄iwa): wie Textfeld III.

Zwischen Textfeld XIV und $\mathrm{XV}^{100}$ schliesst sich eine weitere Abfolge von vierteiliger Raute-Doppelaxt-vierteiliger Raute an.

Textfeld $\mathrm{Xv}^{101}$ (al-Hasan wa-l-Husayn) ist aufgebaut wie Textfeld I. Danach vierteilige Raute.

Textfeld XVI ${ }^{102}$ (wa-Muhammad) ist aufgebaut wie Textfeld II. Danach vierteilige Raute.

Textfeld XVII ${ }^{103}$ (wa-Ğafar) entspricht in der Gestaltung Textfeld III. Die Seitenlinien weisen hier allerdings tiefere Einbuchtungen auf.

Zwischen Textfeld XVII und XVIII ${ }^{104}$ schliesst sich eine weitere Abfolge von vierteiliger RauteDoppelaxt-vierteiliger Raute an. 
Textfeld XVIII ${ }^{105}$ (wa-Muhammad wa-Mūsā waAlīwa) ist aufgebaut wie Textfeld I. Danach vierteilige Raute.

Textfeld XIX ${ }^{106}$ ('Alī wa-l-Hasan) ist aufgebaut wie Textfeld II. Danach vierteilige Raute.

Textfeld $\mathrm{xx}^{107}$ (wa-l-ḥuğğat) hat die Gestalt einer auf der Spitze stehenden Raute (vgl. Textfeld III), deren Seitenlinien hier drei Stufen aufweisen.

Zwischen Textfeld $\mathrm{xx}$ und $\mathrm{XxI}^{108}$ schliesst sich eine weitere Abfolge von vierteiliger Raute-Doppelaxt-vierteiliger Raute an.

Textfeld Xxi ${ }^{109}$ (al-muntazir a'immatī) ist aufgebaut wie Textfeld I. Danach vierteilige Raute.

Textfeld XXII ${ }^{110}$ (șalawāt) ist aufgebaut wie Textfeld II. Danach vierteilige Raute.

Textfeld XXIII ${ }^{111}$ (Allāh wa-salāmu-hū) ist ähnlich aufgebaut wie Textfeld III; die Seitenlinien sind hier allerdings abgestuft und die Figur ist etwas mehr in die Länge gezogen. Danach vierteilige Raute.

Textfeld Xxiv 112 ('alay-him 'ağma'in 'an) ist aufgebaut wie Textfeld I. Danach vierteilige Raute.

Zwischen Textfeld XxIV und Xxv'113 schliesst sich eine weitere Abfolge von vierteiliger Raute ${ }^{114}$ Doppelaxt-vierteiliger Raute an.

Textfeld $\operatorname{xxv}^{115}$ (šimālī) ist ähnlich aufgebaut wie Textfeld III. Danach vierteilige Raute.

Textfeld XXvi ${ }^{116}$ (wa-Abū Darrwa) ist aufgebaut wie Textfeld II.

Zwischen Textfeld XXVI und XXVII ${ }^{117}$ schliesst sich eine weitere Abfolge von vierteiliger RauteDoppelaxt-vierteiliger Raute an.

$\begin{array}{ll}105 & \text { Abb. Is 1622.5.4. } \\ 106 & \text { Abb. Is 1622.5.5. } \\ 107 & \text { Abb. Is 1622.5.5. } \\ 108 & \text { Abb. Is 1622.6.2. } \\ 109 & \text { Abb. Is 1622.6.3. } \\ 110 & \text { Abb. Is 1622.6.5 f. } \\ 111 & \text { Abb. Is 1622.6.7. } \\ 112 & \text { Abb. Is 1622.6.9. } \\ 113 & \text { Abb. Is 1622.6.1O. } \\ 114 & \text { Die erste Raute entspricht jener, die soeben auch nach } \\ & \text { Textfeld xxIV erwähnt worden ist. } \\ 115 & \text { Abb. Is 1622.6.1O. } \\ 116 & \text { Abb. Is 1622.7.1. } \\ 117 & \text { Abb. Is 1622.7.3. }\end{array}$

Textfeld XXVII ${ }^{118}$ (Salmān wa-Miqdād wa-Hudayfa) ist aufgebaut wie Textfeld I. Danach vierteilige Raute.

Textfeld XXVIII ${ }^{119}$ (wa-'Ammāra) ist aufgebaut wie Textfeld III. Danach vierteilige Raute.

Textfeld XXIX ${ }^{120}$ (wa-așhāb) ist aufgebaut wie Textfeld II. Danach vierteilige Raute.

Textfeld $\mathrm{xxx}^{121}$ (rasūl Allāh ta'ālā radiya Allāh) ist aufgebaut wie Textfeld I.

Zwischen Textfeld $\mathrm{xxx}$ und $\mathrm{xxxI}^{122}$ schliesst sich eine weitere Abfolge von vierteiliger RauteDoppelaxt-vierteiliger Raute an.

Textfeld $\mathrm{xxxI}^{123}$ ('an-hum) ist aufgebaut wie Textfeld III. Danach vierteilige Raute.

Textfeld XXXII ${ }^{124}$ (ğamīan) ist aufgebaut wie Textfeld II. Danach vierteilige Raute.

Textfeld XXXIII ${ }^{125}$ (min warāı̀ wa-l-malāika) ist aufgebaut wie Textfeld I.

Zwischen Textfeld XXXIII und XXXIv ${ }^{126}$ schliesst sich eine weitere Abfolge von vierteiliger Raute-Doppelaxt-vierteiliger Raute an.

Textfeld XxxIv ${ }^{127}$ ('alay-him) ist aufgebaut wie Textfeld III. Danach vierteilige Raute.

Textfeld XXXV (Авв. 133) ${ }^{128}$ (as-sal $[\bar{a}] m$ haw wa-Allāhu ta'ālā rabbī) ist aufgebaut wie Textfeld I. Die Rolle endet sogleich nach Textfeld xxxv.

Es fällt auch auf, dass die linke Aussenspalte von Textfeld xxxIV an keinen Text mehr enthält. Der Inhalt der Stellen in $\dot{G} u b \bar{a} r$-Schrift wird in einem nächsten Durchgang erfasst:

Der Inhalt der Stellen in $\dot{G} u b \bar{a} r$-Schrift selbst: Wie bereits aufgezeigt lassen sich zuunterst im Anfangszierfeld auf der rechten und linken Seite zwei kleine Textfelder von knapp $1 \mathrm{~cm}$ Höhe erken-

\footnotetext{
118 Abb. Is $1622.7 \cdot 5$.

119 Abb. Is 1622.7.5.

120 Abb. Is 1622.7.7.

121 Abb. Is 1622.7.12.

122 Abb. Is 1622.7.13.

123 Abb. Is 1622.7.15

124 Abb. Is 1622.7.15.

125 Abb. Is 1622.7.18.

126 Abb. Is 1622.8.2.

127 Abb. Is 1622.8.2.

128 Abb. Is 1622.9.1-4.
} 
nen (АВ В. 128). ${ }^{129}$ Die Kartusche auf der rechten Seite enthält die Fātiḥa (Q 1:1-7). In der linken Kartusche steht Q 2:1-4 (Sūrat al-Baqara). Der Schreiber setzt die Abschrift von Q 2 danach in der oberen rechten Ecke der breiten Mittelspalte in $\dot{G} u b \bar{a} r-$ Schrift fort. Die Schrift ist klein (Höhe ca. 1mm). Es fällt auf, dass die Höhe gegenüber der Breite der Buchstaben deutlich stärker betont ist. Die Schrift ist auffallend steil.

Der Schreiber füllt zuerst das Dreieck in der oberen rechten Ecke der Mittelspalte aus (Q 2:5-9).130 Dann springt er ins Dreieck in der oberen linken Ecke der Mittelspalte und kopiert dort Q 2:9-14. Er setzt die Abschrift danach in der obersten vierteiligen Raute in der Mittelspalte fort. Hier lässt sich zuoberst die Fortsetzung von Q 2:14 erkennen. Zuunterst in dieser ersten vierteiligen Raute steht Q 2:26. Die letzten Wörter von Q 2.26 folgen dann allerdings am rechten Rand der Mittelspalte, wo sich auch der Anfang von Q 2:27 erkennen lässt. Hier stösst die rechte Spitze der ersten vierteiligen Raute an den rechten Rand des Mittelstreifens. ${ }^{131}$

Der Schreiber erreicht zuunterst in dieser Figur am rechten Rand Q 2:34 und setzt die Abschrift dieses Verses auf der gegenüberliegenden Seite der Mittelspalte zuoberst in der entsprechenden Figur fort. ${ }^{132}$ Am Ende dieser Figur auf der lin-

129 Vgl. oben bei Anm. 10.

130 Abb. Is 1622.1.5.

131 Die Übergangsstelle lautet:

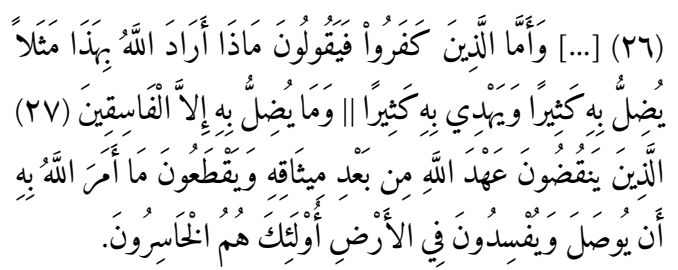

Die Markierung || kennzeichnet den Übergang von der untersten Zeile der vierteiligen Raute an den rechten Rand der Mittelspalte.

Die Übergangsstelle (Q 2:34) lautet:

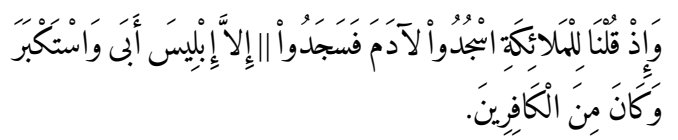

Die Markierung || kennzeichnet die Stelle, an der der Schreiber vom unteren Ende der Figur auf der rechten ken Seite steht Q 2:49 und mutmasslich das erste Wort von Q 2:50 (wa-i $\underline{i}$ ). Jetzt überspringt der Schreiber Textfeld I mit der Basmala und setzt die Abschrift unmittelbar unterhalb von Textfeld I in der angeschnittenen Raute am rechten Rand fort (A B B. 128). ${ }^{133}$ In dieser angeschnittenen Raute rechts folgen Q 2:50-58. Der Schreiber springt darauf an den Anfang der angeschnittenen Raute auf der gegenüberliegenden Seite und notiert dort den nächsten Vers (Q 2:59). Am Ende dieser Raute steht Q 2:62. Die beiden letzten Wörter dieses Verses (hum yahzzanūna) stehen allerdings bereits an der Spitze der vierteiligen Raute unmittelbar nach Textfeld I. ${ }^{134}$ Zuunterst in dieser vierteiligen Raute lässt sich Q 2:74 erkennen. In diesem Vers erreicht der Schreiber die untere Spitze dieser vierteiligen Raute. Er setzt die Abschrift etwas weiter oben am rechten Rand der Mittelspalte fort, wo die rechte Spitze der soeben erwähnten vierteiligen Raute den rechten Rand der Mittelspalte erreicht. Hier stehen die letzten Wörter von Q 2:74. Es folgt ein Eintrag in roter Tinte, der golden hinterlegt ist. Es handelt sich um einen $H i z b$-Vermerk. Unmittelbar danach beginnt Q 2:75. ${ }^{135}$

Seite des Mittelstreifens an den Anfang der Figur auf der linken Seite springt.

Abb. Is 1622.2.1. Q 2:5o lautet:

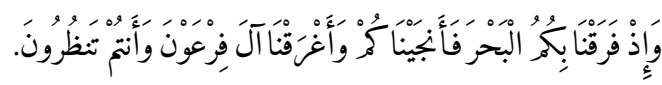

134 Abb. Is 1622.2.1. Die Übergangsstelle lautet:

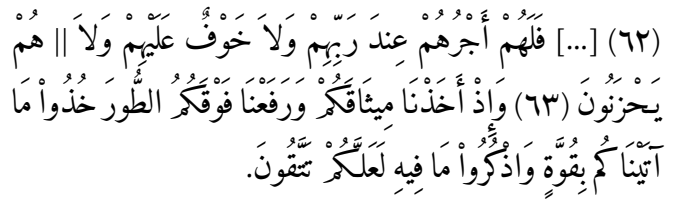

Die Markierung || kennzeichnet die Stelle, an der der Schreiber an die Spitze der vierteiligen Raute springt. Auch in der Kairiner Ausgabe befindet sich vor Q 2:75 ein $H i z b$-Vermerk. An der Stelle mit dem rot hervorgehobenen Hizb-Vermerk lässt sich folgender Text erkennen:

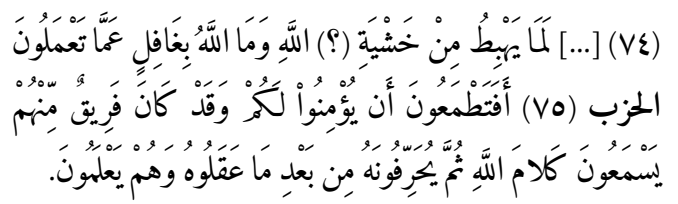


Der Schreiber setzt die Abschrift danach auf der rechten Seite entlang von Textfeld II (Muhammad $\mathrm{ra}[\mathrm{su} l])$ auf horizontal ausgerichteten Zeilen fort. ${ }^{136}$ Er erreicht am Schluss unterhalb von Textfeld I Q 2:93; hier stösst die rechte Spitze der nächsten vierteiligen Raute an den rechten Rand der Mittelspalte. ${ }^{137}$ Jetzt springt er zurück nach oben und setzt die Abschrift auf der Gegenseite links aussen oberhalb von Textfeld II fort. Hier steht Q 2:94. ${ }^{138}$ Unterhalb von Textfeld II erreicht der Schreiber im Schriftfeld mit $\dot{G} u b \overline{a r}$ Q 2:114a. Als nächste Stelle lässt sich an der Spitze der vierteiligen Raute auf dieser Höhe Q 2:11gb erkennen. Q 2:114b-2.119a liessen sich bis jetzt auf dieser Rolle nicht identifizieren. ${ }^{139}$ Diese Passage dürfte aber wohl doch irgendwo vorhanden sein. ${ }^{140}$

Am Schluss der vierteiligen Raute unterhalb von Textfeld II steht Q 2:127-128. Der Schreiber springt dann ins Schriftfeld am rechten Rand der Mittelspalte und setzt dort die Abschrift von Q 2:128 fort. ${ }^{141}$

136 Abb. Is 1622.2.3.

137 Einzelne Wörter lassen sich nur schlecht erkennen.

138 Q 2:94 lautet:

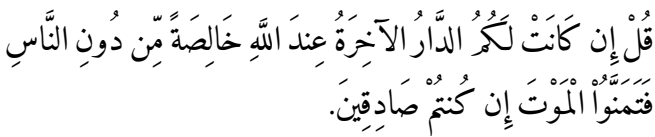

Bereits in Q 2:114a sind einige Wörter nicht deutlich notiert worden.

Die letzte identifizierte Stelle am linken Rand lautet (Q 2:114a):

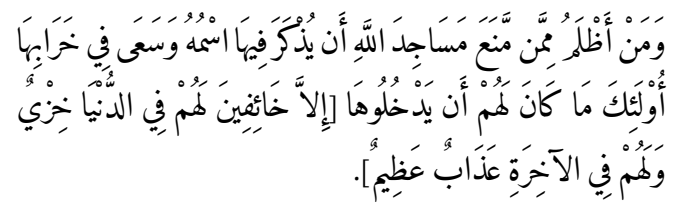

Die nächste identifizierte Stelle steht an der Spitze der vierteiligen Raute; es handelt sich um Q 2:119b:

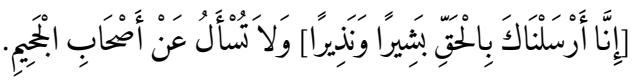

Q 2:128 lautet:

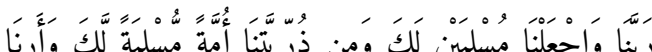

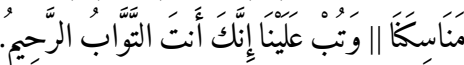

Die bis anhin festgestellten Beobachtungen legen die Annahme nahe, dass der Schreiber in einem ersten Durchgang in der Mittelspalte sämtliche Bereiche ausserhalb der 35 Textfelder ausfüllt. Er ergänzt den Text in diesen 35 Textfeldern erst in einem nächsten Durchgang. ${ }^{142}$ Diese Annahme wird auch durch einen $\breve{G} u z^{\prime}$-Vermerk bestätigt, der sich unmittelbar oberhalb von Textfeld III am linken Rand der Mittelspalte feststellen lässt. Hier

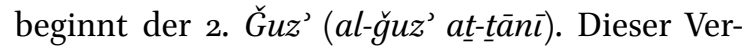
merk ist in roter Tinte notiert worden und golden hinterlegt. Unmittelbar danach beginnt Q 2:142.

Der weitere Aufbau der Rolle kann an dieser Stelle nicht lückenlos nachgezeichnet werden. Es soll aber an ausgewählten Stellen überprüft werden, ob der Kopist das vermutete Vorgehen weiterhin einhält. Es geht also darum, aufzuzeigen, dass der Schreiber in diesem ersten Durchgang auch weiterhin die 35 Textfelder überspringt und den Text vorerst ausserhalb davon notiert:

Auf der Höhe von Textfeld vi ([Fäțima] bint rasūl $[\text { Allāh] })^{143}$ fällt am linken Rand der Mittelspalte ein Eintrag in roter Tinte auf goldenem Hintergrund auf. Dieser Eintrag lautet: Sūrat Āl Imrān $\bar{a} y \bar{a} t u-h \bar{a} .{ }^{144}$ Es handelt sich um die Überschrift von Q 3, die direkt danach mit der Basmala beginnt. Unmittelbar vor dieser Überschrift steht Q 2:286 (Schlussvers von Q 2). An der Stelle, wo Textfeld vi auf den linken Rand der Mittelspalte trifft, steht Q 3:5. Die Fortsetzung folgt auf der gegenüberliegenden Seite unmittelbar unter Textfeld VI. ${ }^{145}$ Auch in der doppelaxt-förmigen Verzierung zwi-

Die Markierung || kennzeichnet die Übergangsstelle von der vierteiligen Raute ins Schriftfeld am rechten Rand der Mittelspalte.

Siehe dazu unten bei und nach Anm. 168.

Abb. Is 1622.3.3.

$\bar{A} y \bar{a} t u-h \bar{a}$ : Entzifferung unsicher.

Q 3:5-6 lautet:

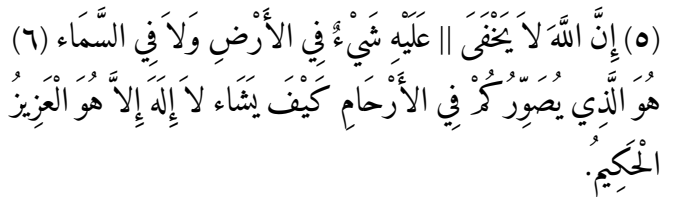

Die Markierung || kennzeichnet die Übergangsstelle. 
schen Textfeld vi und vi I stehen Verse aus Q 3; ganz zuunterst in diesem Zierelement lässt sich Q 3:75 erkennen. ${ }^{146}$

Q 4 (Sürat an-Nisà) beginnt unterhalb von Textfeld VII (fawqa ra'sī) am linken Rand der Mittelspalte (АВв. 134). Der Titel wurde in roter Tinte notiert und ist golden hinterlegt. ${ }^{147}$ Direkt vor dem Titel von Q 4 steht Q 3:200 (Schlussvers). Unmittelbar danach folgt ein erster achtstrahliger Stern, dessen einzelne Strahlen durch Leerstellen voneinander getrennt werden. Die vorangehenden Verse am Ende von Q 3 stehen übrigens auf der rechten Seite der Mittelspalte zur Rechten der vierteiligen Raute. Der Schreiber notierte Text aus Q 3 auch noch in den knappen Leerräumen der drei Strahlen am rechten Rand und erreicht dort zuletzt Q 3:199 (Anfang). In diesem Vers springt der Kopist dann nach oben auf die linke Seite der Mittelspalte und setzt dort Vers 199 fort.

Danach beginnt etwas oberhalb des achtstrahligen Sterns Q 4. In einem ersten Schritt füllt der Schreiber hier die Leerstellen entlang des linken Rands der Mittelspalte aus. Er erreicht auf der linken Seite der Mittelspalte zuletzt Q 4:5. Hier springt er nach oben in den Stern. Im schwarz ausgefüllten Strahl unmittelbar links von der Mittelachse des Sterns lässt sich zuoberst Q 4:6 erkennen. Die weitere Abschrift dieser Sure verläuft im Uhrzeigersinn. Die Strahlen des Sterns sind abwechselnd in schwarzer und roter Schrift ausgefüllt worden. Als letzte Stelle lässt sich in diesem Stern der Anfang von Q 4:14 erkennen. Der zweite Teil von Q 4:15 steht danach am rechten Rand der Mittelspalte unterhalb des Sterns. Q 4:14b-15a liess sich auf der Rolle nicht identifizieren. Es lässt sich aber

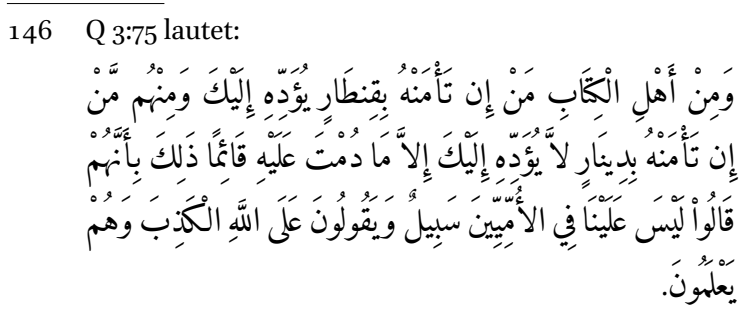

Auf Авв. 134 erkenntlich. nicht ausschliessen, dass der Text doch vorhanden ist, erfolgt diese Auslassung doch sehr willkürlich. Es könnte aber auch sein, dass der Schreiber einfach Text ausliess, um das übergeordnete Layout der Rolle einhalten zu können. Allenfalls handelt es sich um einen Kopistenfehler. Für eine Visualisierung dieser Stelle wird verwiesen auf АB B. 134.

Q 5 (Sürat al-Mā'ida) folgt nach Textfeld X ('Alī Ibn) und kurz vor Textfeld XI (Abițālib sic) auf der linken Seite der Mittelspalte. ${ }^{148}$ Hier steht in roter Tinte die Überschrift von Q 5, die mit der Basmala beginnt. Dieser Titel ist nicht golden hinterlegt. Direkt vor dem nächsten achtstrahligen Stern steht auf der linken Seite ein roter Eintrag (wohl: nișf alğuz'). Danach beginnt Q 5:28.149

Q 6 (Sūrat al-An'ām) beginnt unmittelbar nach Textfeld XII (Ṣalawāt Allāh wa-salāmu-hū) auf der rechten Seite der Mittelspalte. Der Titel ist rot hervorgehoben und golden hinterlegt. ${ }^{150}$ Rechts von Textfeld XIII steht in roter Tinte der Eintrag nisf alğuzw (bzw. nisf al-ǧuz'); er ist golden hinterlegt. Es handelt sich um den Übergang Q 6:35-36.

Q 7 (Sürat al-A'rā $f$ ) beginnt in der vierteiligen Raute vor Textfeld Xv (al-Hasan wa-l-Husayn waAlī $).{ }^{151}$ Der Titel wurde in roter Tinte notiert und ist golden hinterlegt. Links von Textfeld XVI steht in roter Tinte der Eintrag al-ğuzw (al-ğuz')at-tāsic (9. ğuz'); er ist golden hinterlegt. Hier befindet sich der Übergang Q 7:87-88. ${ }^{152}$

Q 8 (Sürat al-Anfāl) beginnt im untersten Feld der vierteiligen Raute direkt vor Textfeld XVIII ( waMuhammad wa-Mūsāwa-'Alīwa). ${ }^{153}$ Hier lässt sich ein Leerraum erkennen. Unmittelbar danach steht eine Basmala und die beiden ersten Wörter von Q 8:1. Der Titel selbst fehlt hier, aber der Raum dafür wurde ausgespart. Die Fortsetzung von Q 8:1 folgt auf der rechten Seite der Mittelspalte unmit-

\footnotetext{
148 Abb. Is 1622.4.3-4.

149 In der Kairiner Druckausgabe steht ein Hizb-Vermerk vor Q 5:27.

Abb. Is 1622.4.6-7.

Abb. Is 1622.5.1.

Abb. Is 1622.5.2.

153 Abb. Is 1622.5.4.
} 
telbar unterhalb der Stelle, wo die rechte Spitze der vierteiligen Raute ihren rechten Rand berührt. ${ }^{154}$

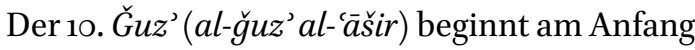
von Textfeld XIX ('Alīwa-l-Hasan) direkt unterhalb der nach unten geneigten Spitze der Feder. Dieser $\breve{G} u z^{\prime}$-Vermerk ist rot hervorgehoben, aber nicht golden hinterlegt. Hier befindet sich der Übergang Q 8:40-41.

Q 9 ist die einzige Sure im Koran, die ohne Basmala beginnt. Ihr erster Vers steht ganz zuunterst in der vierteiligen Raute direkt vor Textfeld xx (wa-l-ḥuğğa). ${ }^{155}$ Ein Titel fehlt auch hier. Allerdings lässt sich unmittelbar vor Q 9:1 ein Leerraum feststellen. Direkt davor endet Q 8:75 (Schlussvers). ${ }^{156}$ Der Schreiber setzt die Abschrift von Q 9 am rechten Rand der Mittelspalte fort; die rechte Spitze der vierteiligen Raute stösst hier auf den rechten Rand.

Q 10 (Sūrat Yünus) beginnt am Ende von Textfeld XXII (șalawāt). ${ }^{157}$ Ihr Titel ist rot hervorgehoben und im ersten Teil golden hinterlegt. Die Sure beginnt mit der Basmala. Q 11 (Sūrat Hūd) beginnt zwischen den beiden Textfeldern XxIV und XXv (XxIV: 'alay-him 'ağmaīn 'an; xxv: šimālī). Die Überschrift steht hier links neben der Doppelaxt. Sie ist rot hervorgehoben und golden hinterlegt. ${ }^{158}$ Direkt nach Textfeld xxv lässt sich auf der rechten Seite der Mittelspalte ein Bism illāh erkennen, das durch eine goldene Überstreichung hervorge-

154 Q 8:1 lautet:

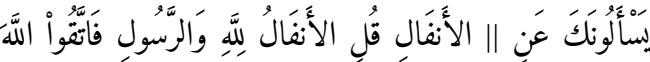

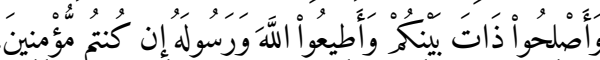

Die Markierung || kennzeichnet die Übergangsstelle.

Abb. Is 1622.6.6.

158 Abb. Is 1622.6.10. hoben wird. Hier steht Q 11:41, in der ein bism illāh enthalten ist. ${ }^{159}$

Q 12 (Sūrat Yūsuf) beginnt zwischen den beiden Textfeldern xxvi und xxviI (xxvi: $W a-A b \bar{u}$ Darr wa; XXVII: Salmān wa-Miqdād wa-Hudayfa) auf der Höhe der Doppelaxt am rechten Rand der Mittelspalte. Der Titel wurde in roter Tinte notiert und golden hinterlegt. Q 12 endet in der vierteiligen Raute vor Textfeld XxIx (wa-așhāa). ${ }^{160}$ Hier beginnt auch Q 13 (Sürat ar-Ra'd). Ihr Titel ist rot hervorgehoben und golden hinterlegt.

Q 14 (Sürat Ibrāhìm) steht zuunterst in der vierteiligen Raute direkt vor Textfeld xxx (rasūl [Allāh] ta'ālā radiya Allāh). Der Titel ist rot hervorgehoben und golden hinterlegt. Q 15 (Sūrat al-Hiğr, hier allenfalls ein alternativer Titel, der schlecht erkenntlich ist) beginnt am linken Rand der Mittelspalte zwischen den beiden Textfeldern xxx und XXXI (XXX: rasūl [Allāh] ta'ālā radiya Allāh; XXXI: 'an-hum). ${ }^{161} \mathrm{Er}$ ist rot hervorgehoben und golden hinterlegt. Hier beginnt auch der 14. Ğuz' des Korans. Dieser $\breve{G} u z^{\prime}$-Vermerk wurde ebenso rot hervorgehoben und golden hinterlegt. Q 16 (Sūrat an-Naḥl) beginnt am linken Rand der Mittelspalte direkt unterhalb der vierteiligen Raute. Hier lässt sich in roter Schrift der golden hinterlegte Eintrag Süra erkennen. Darunter befindet sich Textfeld Xxxi ('an-hum).

Q 16 endet in der vierteiligen Kartusche nach Textfeld XXXııI (min warā̄̄ wa-l-malā’ika). ${ }^{162} \mathrm{Hier}$ beginnt auch Q 17 (Sūrat al-Isrā'). Die Basmala zu dieser Sure steht im Teil der Raute links aussen. Im untersten Teil der vierteiligen Raute steht Q 17:1. Rot hervorgehoben und golden hinterlegt steht hier überdies der Eintrag für den 15. Ğuz'.

Am Schluss des vorliegenden Dokuments kommt es in der Mittelspalte zu Unregelmässigkeiten, die sich auch anhand des durch Aussparun-

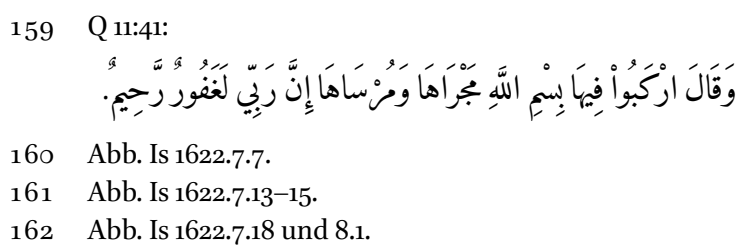

162 Abb. Is 1622.7.18 und 8.1. 
gen gebildeten Verzierungsmuster aufzeigen lassen. Diese Unregelmässigkeiten lassen sich unmittelbar vor Textfeld XXXIV ('alay-him) feststellen. ${ }^{163}$ Oberhalb dieses Textfelds befindet sich eine vierteilige Raute. Sie öffnet sich gegen unten, wo sich die Spitze eines weiteren Zierfelds erkennen lässt. Dieses Zierfeld wird allerdings nicht abgeschlossen, sondern es schliesst sich unvermittelt die Spitze von Textfeld xxxIv an. Hier befindet sich eine Bruchstelle, die sich auch im kopierten Text in $\dot{G} u b \bar{a} r$-Schrift feststellen lässt. ${ }^{164}$ Direkt oberhalb der Bruchstelle steht auf der rechten Seite Q 17:70 und auf der linken Seite Q 17:9293. Der Text bricht mitten in Q 17:93 ab. ${ }^{165}$ Unterhalb der auch optisch erkennbaren Bruchstelle steht auf der rechten Seite Q 33:12-13. ${ }^{166}$ Auf der linken Seite steht unterhalb der Bruchstelle Q 33:19b.

Soweit ersichtlich ist der Text im rechten und linken Seitenband aber nicht von dieser Unregelmässigkeiten betroffen, die sich nicht hinreichend erklären liess.

Q 33:73 endet unmittelbar vor Textfeld Xxxv (as-salām haw lì wa-Allāh ta'ālà rabbī) auf der linken Seite (Авв. 133). ${ }^{167}$ Hier beginnt auch Q 34 (Sūrat Saba). Dieser Titel ist rot hervorgehoben

163 Für die weiteren Ausführungen vgl. Abb. Is 1622.8.3 und $9 \cdot 5$.

164 Abb. Is 1622.8 .3

165 Q 17:93 lautet:

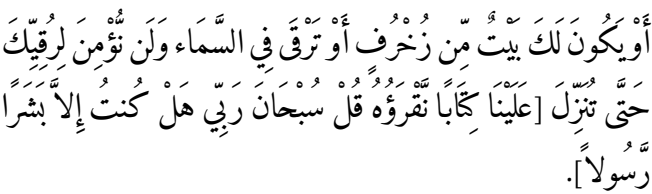

Der Text in eckigen Klammern fehlt auf der Rolle.

Q 33:12-13 lautet:

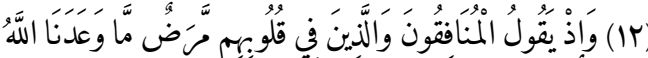

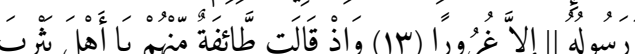

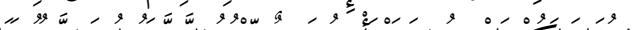

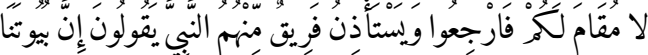

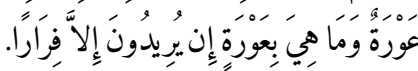

Von Vers 12 stehen hier nur die beiden letzten Wörter; der Rest dieses Verses fehlt. und golden hinterlegt. Die Fortsetzung von Q 34:1 folgt nach Textfeld XxxV auf der rechten Seite. Die Abschrift von Q 34 endet mit Vers 13a auf der linken Seite der Mittelspalte unterhalb dieses letzten Zierfelds.

Die Fortsetzung der Abschrift des Korans folgt in den Textfeldern I-XXXIV: Jetzt springt der Schreiber zurück an den Anfang der Mittelspalte und füllt nach und nach die einzelnen Textfelder IXXXIV aus, wobei er die für den übergeordneten grossen Text vorgesehenen Stellen ausspart.

Am Anfang von Textfeld I (Basmala) steht Q 17:97 (ganzer Vers, Beginn an der Spitze). ${ }^{168}$ Q 17 endet in diesem Textfeld auf der Höhe der beiden Wörter Bism Allāh. Zwischen diesen beiden Wörtern steht in roter Tinte auch der Titel von Q 18 (Sürat al-Kahf; ohne goldene Hinterlegung). Der Schreiber setzt die Abschrift von Q 18 im Textfeld II (Muhammad ra[sūl]) fort. Die zweite Hälfte von Q 18:40 steht senkrecht aufsteigend in der nach unten geneigten Spitze der Feder von Textfeld II. ${ }^{169}$ Auf der obersten horizontalen Zeile der Feder beginnt Q 18:41. ${ }^{170}$

In Textfeld IV (șallā Allāh 'alay-hi wa-āli-hì $a m \bar{a} m \bar{\imath})^{171}$ folgt der Übergang von Q $18 \mathrm{zu}$ Q 19.

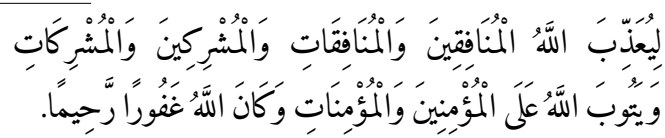
168

Abb. Is 1622.1.5; Q 17:97 lautet:

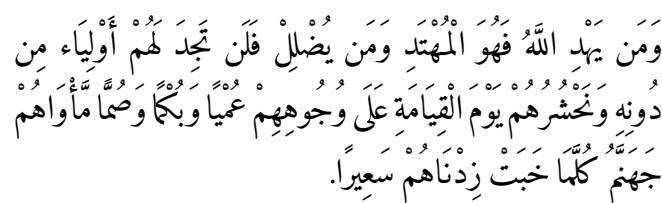

169

Q 18:40 lautet:

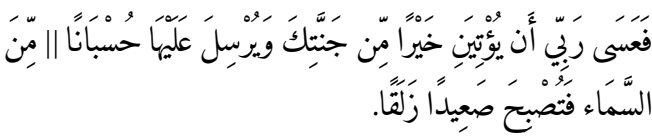

Die Markierung || kennzeichnet die Stelle, wo der Schreiber von Textfeld I zur Spitze der Feder in Textfeld II wechselt.

Q 18:41 lautet:

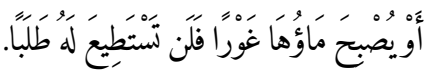


Die Überschrift Sūra ist rot hervorgehoben. Auch ist eine längere Stelle oberhalb der Basmala hier golden überstrichen. Es bestehen Hinweise darauf, dass in dieser Überschrift gewisse Ausdrücke getilgt worden sind. Q 19:1 beginnt danach ganz rechts aussen am Rand der Mittelspalte. Der Schreiber hat hier offensichtlich die rechte Hälfte des Textfelds IV ausgefüllt und springt dann an dessen Spitze, um die Abschrift von Q 19 fortzusetzen.

Q 20 (Sūrat Țā-hā) beginnt ganz am Ende von Textfeld vi (bint rasūl). Der Titel ist rot hervorgehoben und golden hinterlegt. Unmittelbar darauf folgt der rote Vermerk nisfal-ğuz’. Am Anfang von Q 20 beginnt in der Tat ein neuer hizb (ein ǧuz' umfasst zwei hizb). ${ }^{172}$

In Textfeld XXI (wa-amìr al-mu'minin) beginnt Q 21 (Sūrat al-Anbiy $\left.\bar{a}^{\prime}\right)$; hier beginnt zugleich der 17. $\breve{G} u z^{\prime}$. Titel und $\breve{G} u z^{\prime}$-Vermerk sind rot hervorgehoben und golden hinterlegt. In Textfeld XII (șalawāt Allāhwa-salämu-hū) folgt der Anfang von Q 22, der rot hervorgehoben und golden hinterlegt ist. ${ }^{173}$ In Textfeld XV (al-Hasan wa-l-Husayn wa-'Alī) steht der Titel von Q 23 (Sūrat al-Mu'minūn) und ein $\breve{G} u z^{\prime}$-Vermerk (hier beginnt der 18. Ğuz'). Surentitel und $\breve{G} u z^{\prime}$-Vermerk sind rot hervorgehoben und golden hinterlegt. ${ }^{174}$

Auf der linken Seite von Textfeld XviI (waĞafar) beginnt Q 24 (Sürat an-Nūr). Der Titel ist rot hervorgehoben und golden hinterlegt. ${ }^{175} \mathrm{Q} 24$ wurde offensichtlich auf der linken Seite dieses Textfelds kopiert. Auf der rechten Seite von Textfeld xx steht Q 25 (Sürat al-Furqān). Dieser Titel ist rot hervorgehoben und golden hinterlegt. ${ }^{176} \mathrm{Am}$ Anfang von Textfeld XXII (salawāt) steht der Titel von Q 26 (Sürat aš-Šu'arä'); er ist rot geschrieben und golden hervorgehoben. ${ }^{177}$

In Textfeld Xxv steht der Titel von Q 27 (Sürat an-Naml); er ist rot hervorgehoben und golden

\footnotetext{
172 Abb. Is 1622.3.2-3.

173 Abb. Is 1622.4.6-7.

174 Abb. Is 1622.5.1.

175 Abb. Is 1622.5.2.

176 Abb. Is 1622.5.5.

177 Abb. Is 1622.6.6.
}

hinterlegt. ${ }^{178}$ In der Mitte von Textfeld xxvi (Salmān wa-Miqdād wa-Hudayfa) folgt der Titel von Q 28 (Sūrat al-Qașaș); er ist rot geschrieben und golden hinterlegt. Die Stelle ist verderbt. ${ }^{179}$ Am Schluss der oberen Hälfte von Textfeld XxIx (nach dem alif von aṣhāb) endet Q 28:88 (Schlussvers). Darunter beginnt Q 29 mit der Basmala. Hier steht kein Titel; aber über der Basmala befindet sich ein Leerraum. ${ }^{180}$ In Textfeld XxxI ('an-hum) folgt die Überschrift von Q 30; sie ist rot hervorgehoben und golden hinterlegt (Sūra; es handelt sich um Sūrat ar-Rūm). ${ }^{181}$

In Textfeld XxxiI (ğamīan) endet Q 30:60 (Schlussvers). Unmittelbar danach beginnt Q $3^{1}$ (Sūrat Luqmān). Ihr Titel ist rot hervorgehoben und golden hinterlegt. ${ }^{182}$ In Textfeld XxxIII ( $\min$ warầ l-malāika) beginnen zwei Suren; beide Titel sind rot hervorgehoben und golden hinterlegt. ${ }^{183}$ Davor lässt sich in diesem Textfeld ausserdem ein rot hervorgehobener und golden hinterlegter Hinweis auf einen Halb-Ğuz' erkennen (nisf al-ğuzw). ${ }^{184}$ Danach folgt die Überschrift zu Q 32 (Sūrat as-Saǧda). Im unteren Teil dieses Schriftfelds folgt überdies die Überschrift zu Q 33 (Sūrat al-Ah̆zāb). Zuunterst in Textfeld XxxIII steht Q 33:12. ${ }^{185}$

Hier ändert der Schreiber sein Vorgehen. Die Fortsetzung von Q 33:12 steht bei Textfeld XxxIv ('alay-him) am rechten Rand der Mittelspalte ausserhalb des Textfelds. ${ }^{186}$ Unmittelbar unterhalb dieser Stelle endet in der linken Seitenspalte die Abschrift des Korans mit Q 114. Danach ist diese linke Seitenspalte nicht mehr beschrieben. Wir befinden uns hier erneut an der bereits zuvor festgestellten Bruchstelle. ${ }^{187}$ Unmittelbar unter-

\footnotetext{
178 Abb. Is 1622.6.10.

179 Abb. Is 1622.7.5.

180 Abb. Is 1622.7.8.

181 Abb. Is 1622.7.14

182 Abb. Is 1622.7.15.

183 Abb. Is 1622.7.18.

184 Hier endet Q 30:21. Die Kairiner Ausgabe vermerkt hier einen Hizb-Eintrag $\left(H i z b=\right.$ Halb- $\left.\breve{G} u z^{\prime}\right)$.

185 Abb. Is 1622.8.4.

186 Vgl. Is 1622.8 .3 .

187 Vgl. oben bei Anm. 164-167.
} 
halb der Bruchstelle lassen sich auf der rechten Seite der Mittelspalte die beiden letzten Wörter aus Q 33:12 erkennen (illā gurūran); darauf folgt Q 33:13. ${ }^{188}$

Die weitere Abschrift von Q 33 erfolgt jetzt ausserhalb der Textfelder. Sie endet mit Vers 73 (Schlussvers) auf der linken Seite der Mittelspalte unmittelbar vor dem letzten Textfeld (Textfeld Xxxv, Авв. 133: as-salām hawlì wa-Allāh ta'ālà rabbī $).{ }^{189}$ Hier folgt dann auch der Titel von Q 34 (Sürat Saba'). Der Kopist setzt die Abschrift dieser Sure unterhalb des letzten Textfelds am rechten Rand der Mittelspalte fort. Am Schluss der Mittelspalte steht auf der linken Seite Q 34:13a. ${ }^{190}$

Die nächste Stelle aus Q 34 (34:21) steht an der Spitze von Textfeld XXXIV ('alay-him). ${ }^{191} \mathrm{Q} 34: 13 \mathrm{~b}$ 20 liess sich auf der Rolle nicht identifizieren. Dies dürfte mit der bereits erwähnten Bruchstelle zusammenhängen. Allenfalls kam es hier zu einem späteren Zeitpunkt zu einem Eingriff, der sich allerdings nicht weiter präzisieren lässt. ${ }^{192}$

Gewiss ist jedoch, dass Q 34:54 (Schlussvers) am Anfang von Textfeld Xxxv endet (letztes Text-

188 Q 33:12 lautet:

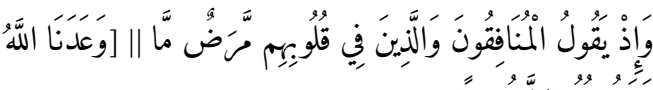

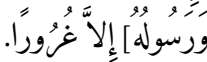

Die Markierung || kennzeichnet das Ende von Textfeld XXXIII. Der Text in eckigen Klammern liess sich auf der Rolle nicht feststellen.

189 Abb. Is 1622.9.5.

190 Q 34:13 lautet:

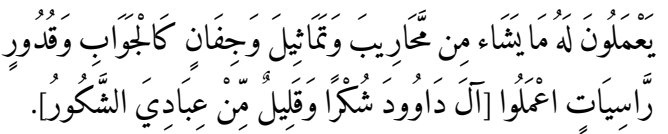

Der Text in eckigen Klammern fehlt an dieser Stelle.

4:21 lautet:

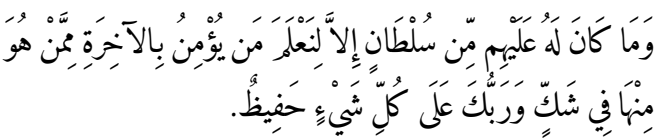

Bei einer Überprüfung der Stelle mit einem light sheet (2. November 2017) liessen sich allerdings keine Hinweise darauf feststellen, dass hier ein Abschnitt der Rolle entfernt worden wäre. Etwa $1.3 \mathrm{~cm}$ nach dieser Stelle beginnt der letzte Papierstreifen des Dokuments. feld, Ав в. 133). Am Anfang dieses letzten Textfelds beginnt darauf auch Q 35 (Sürat al-Malāika, auch als Sūrat Fāṭir bekannt). ${ }^{193}$ Dieser Titel ist rot hervorgehoben und golden hinterlegt.

Der Aufbau von Textfeld Xxxv liess sich nicht abschliessend klären. ${ }^{194}$ Gewiss ist, dass am Anfang dieses Textfelds - wie soeben erwähnt - die Überschrift von Q 35 steht. Auf der linken Seite der durch das Schluss-Yä̉ von hawlī gebildeten Mittelachse lässt sich Text feststellen, der von rechts unten nach links oben verläuft. Hier steht der Anfang von Q 36. Auch stehen zuunterst in diesem Textfeld nochmals zwei rot hervorgehobene Überschriften. Es müsste sich um die Überschriften zu Q 36 (Yā-sīn) und Q 37 (Sūrat aș-Ṣaffāt) handeln. Dies liess sich aber nicht abschliessend klären. Gewiss aber ist, dass der Schreiber die Abschrift von Q 37 in einem nächsten Durchgang fortsetzte.

Die Fortsetzung der Abschrift des Korans in den beiden schmalen Seitenspalten: Der Schreiber springt jedenfalls am Schluss des Dokuments innerhalb von Q 37 wieder ganz nach oben. Er füllt jetzt in einem nächsten Durchgang die beiden schmalen Seitenspalten auf der rechten und linken Seite des Dokuments aus. Hier lässt sich zuoberst in der Mitte des Dokuments unmittelbar unterhalb des Anfangszierfelds ein Dreieck erkennen, das von einem goldenen Blüten- und Rankenmuster ausgefüllt wird (АВ B. 127-128). ${ }^{195}$

Unmittelbar rechts davon steht Q 37:142 ff. ${ }^{196}$ Der Schreiber setzt die Abschrift von Q 37 danach in der schmalen Spalte auf der rechten Seite des Dokuments fort. Die Zeilen sind hier steil geneigt (Winkel von ca. $55^{\circ}$ ) und verlaufen von rechts unten nach links oben. Am Anfang von Textfeld I (Basmala) endet Q 37. Hier folgt auch der Titel

\footnotetext{
193 Abb. Is 1622.9.5.

194 Abb. Is 1622.9.5.

195 Abb. Is 1622.1.5.

196 Q 37:142 f. lautet:

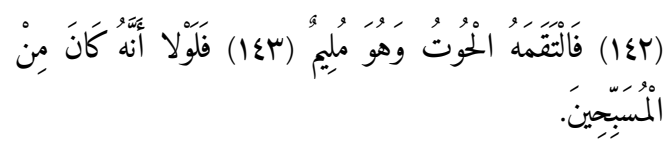


von Q 38 (Sürat Șād). Er ist rot hervorgehoben und golden hinterlegt. ${ }^{197}$

Nach Textfeld III ([ra- $]$ sūl Allāh) folgt die Überschrift von Q 39 (Sürat az-Zumar).198 Dieser Titel ist rot hervorgehoben und golden hinterlegt. Q 40 (Sürat $\dot{G}$ âfr) beginnt am Anfang von Textfeld viI (Allāh șalawāt Allāh 'alay-hā). ${ }^{199}$ Diese schmale rechte Seitenspalte soll hier nicht im einzelnen analysiert werden. Es sei einzig darauf hingewiesen, dass sich zwischen Textfeld XxxIV ('alay-him) und Xxxv (letztes Textfeld: as-salām hawlì waAllāh ta'ālā rabbì) die Überschrift von Q 54 (Sūrat al-Qamar) erkennen lässt. Sie ist rot hervorgehoben und golden hinterlegt. ${ }^{200}$ Dies lässt vermuten, dass davor auch die weiteren Suren lückenlos kopiert worden sind; dies wurde allerdings nicht durchgehend überprüft.

Soweit ersichtlich steht auf der Rolle zuunterst in der Mitte Q 54:47; danach ist der waagrechte Teil der Aussenspalte ganz am Schluss der Rolle leer. ${ }^{201}$ Der Kopist springt jetzt erneut nach oben und füllt die schmale Aussenspalte auf der linken Seite aus. Unterhalb des Anfangszierfelds lässt sich auf der linken Seite der goldenen Verzierung Q 54.:5o ff. erkennen. ${ }^{202}$ Die beiden Verse Q 54:48-49 fehlen auf der Rolle soweit ersichtlich. Eigentlich hätte dem Kopisten am Schluss des Dokuments genügend Platz zur Verfügung gestanden, um sie zu notieren. Auch hätte er die Abschrift am Anfang der linken Aussenspalte einfach mit Vers 48 fortsetzen können. Mit grosser Wahrscheinlichkeit hat

197 Abb. Is 1622.1.5 und 2.1.

198 Abb. Is 1622.2.4; Q 39:1 lautet:

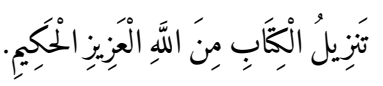

Abb. Is 1622.3.3.

Abb. Is 1622.9.1.

Abb. Is 1622.9.5; Q 54:47 lautet:

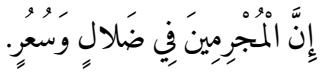

202

Abb. Is 1622.1.5; Q 54:5of. lautet:

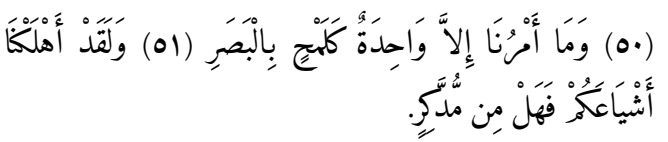

der Schreiber hier eine Pause gemacht. Als er die Abschrift am Anfang der Rolle fortsetzte, gingen die beiden Verse wohl aus Unaufmerksamkeit vergessen.

Am Anfang der Rolle lässt sich im horizontalen Band aussen darauf die Überschrift von Q 55 (Sürat ar-Raḥmān; Titel in roter Schrift und golden hinterlegt) erkennen. Nach der Basmala folgt ein Hizb-Vermerk bzw. der Eintrag nişf al-ǧuzw (al$\left.\check{g} u z^{\prime}\right)$. Auch in der Kairiner Ausgabe hat es hier einen $H i z b$-Vermerk.

Soweit ersichtlich hat der Schreiber in diesem letzten Durchgang den weiteren Korantext in dieser linken schmalen Aussenspalte kopiert. Auch hier sind die Zeilen von rechts unten nach links oben geneigt. Die Abschrift des Korans endet auf der Höhe von Textfeld XxxIv ('alay-him) kurz vor dem Schluss der Rolle. ${ }^{203}$ Hier lassen sich zuletzt die rot hervorgehobenen und golden hinterlegten Überschriften von Suren 111-114 erkennen. Nach dem Ende der Abschrift des Korans liess der Schreiber den Rest der linken Aussenspalte einfach leer (А B B. 133).

Schlussfolgerungen: Die beiden Dokumente Is 1622 und Is 1621 weisen grosse Ähnlichkeiten auf, sind aber miteinander nicht identisch. Die weiteren Ausführungen äussern sich im wesentlichen zu Is 1622. Es enthält eine ursprünglich wahrscheinlich vollständige Abschrift des Korans in $\dot{G} u b \bar{a} r-$ Schrift. Für die Einordnung dieses Belegstücks sind aber v. a. die Einträge in grosser Schrift von Bedeutung, die sich über die insgesamt 35 Textfelder verteilen. Sie enthalten eine Anrufung an die als Čahārdah Mașūm bekannte Gruppe von Personen. ${ }^{204}$ Daraus ergibt sich, dass dieses Belegstück aus einem zwölferschiitischen Umfeld stammt. Diese Anrufung präzisiert den Schutz durch diese vierzehn Personen dahingehend, dass Muhammad (1.) vor dem Betenden stehe. Fāțima (2.) wiederum befinde sich über seinem Haupt. 'Alī b. Abī Ṭālib (3.) soll den Träger des Dokuments zu seiner Rech-

203 Abb. Is 1622.9.1.

$204 \mathrm{Zu}$ den Čahārdah Maṣūm, den 14 Sündlosen, siehe Algar, Čahārdah Ma'ṣūm, in EIr. 
ten beschützen. Es schliesst sich (4.) eine Anrufung der weiteren Imame an (2.-12. Imam), die den Gläubigen zu seiner Linken beschützen. Diese auch von Arabe ${ }^{102}$ (Paris) ${ }^{205}$ bekannte Anrufung der Čahārdah Mașūm wird auf dem vorliegenden Belegstück durch die Bitte um Schutz durch verschiedene Prophetengenossen (aṣhāb rasūl Allāh) ergänzt (5.). Is 1622 zählt unter ihnen Abū Darr, Salmān, Miqdād, Ḥudayfa und 'Ammāra (sic) namentlich auf. ${ }^{206}$ Sie würden dem Betenden den Rücken

205 Vgl. dazu Kapitel 5.4.

206 Weitere Angaben zu diesen fünf Personen finden sich u. a. bei Mufĩd Ibn al-Mu'allim, Muhammad b. Muhammad al-Mufīd (947-1022), al-Ihtișāṣ. Țihrān, Maktabat aṣ-Ṣadūq, 1379/1959; darin die folgenden Indexeinträge: 1. Abū Darr al-Ġifārī, 418; 2. Salmān al-Fārisī, 43o; 3. alMiqdād b. al-Aswad, 443; 4. Ḥuḍayfa al-Yamān, 425; 5 . 'Ammār b. Yāsir, 436 (Exemplar der Universitätsbibliothek Basel, Signatur: Meier 2395). Zu diesen fünf auf den Rollen erwähnten Personen siehe ausserdem die folgenden Angaben:

1. Abū Darr al-Ġifārī (gest. 32/652): Er soll zu den frühesten Personen gehört haben, die sich zum Islam bekehrten. Er war angeblich der vierte oder fünfte Anhänger Muhammads. Die Sunniten und Schiiten verehrten ihn wegen seiner Frömmigkeit und Enthaltsamkeit. Unter den Schiiten gehört er neben Salmān alFārisī und Miqdād b. al-Aswad zu den drei loyalsten Anhängern 'Alīs. Viele pro-'alidische Überlieferungen gehen auf ihn zurück. Vgl. zu ihm Afsaruddin, Abū Darr al-Ghifārī, in $E I^{3}$; Gozashteh, Abū Dharr al-Ghifārī, in Encyclopaedia Islamica, Online-Ausgabe; Robson, Abū Dharr, in $E I^{2}$; Tayob, Abū Dharr al-Ghifārī, in The Oxford Encyclopedia of the Islamic World I, 23-24.

2. Salmān al-Fārisī (gest. angeblich 35/655 oder 36/656): vgl. zu ihm auch die weiteren Angaben in dieser Darstellung. Salmān spielt eine bedeutende Rolle in der Entwicklung der Futuwwa und in den Handwerksgilden. Er wird als Schutzherr der Barbiere verehrt. Salmān soll ausserordentlich alt geworden sein (200, 300, 35 o oder sogar 553 Jahre). Vgl. zu ihm Levi Della Vida, Salmān al-Fārisī, in $E I^{2}$.

3. al-Miqdād b. al-Aswad: er wird erwähnt bei Ahmed, The religious elite 40; al-Wāqidī, Muhammad b. 'Umar al-Wāqidī, The life of Muhammad: al-Wāqidì's Kitāb al-Maghāzī; herausgegeben von R. Faizer. Hier Index s. v. „Miqdād b. al-Aswad“ (56o).

4. Hudayfa: Mit ihm ist Ḥudayfa b. al-Yamān (gest 36/656) gemeint; er zählte zu den Ahl aș-Șuffa.

5. 'Ammār b. Yāsir (gest. 37/657) zählt zu den Prophetengenossen und war später Parteigänger 'Alīs. Er stärken und stünden hinter ihm. Der Träger der Rolle kann (6.) ausserdem auf den Schutz durch die Engel zählen, die sich um ihn herum versammelt hätten.

Die Aufzählung der soeben erwähnten fünf Genossen des Propheten dürfte für die ideologische Einordnung des vorliegenden Belegstücks relevant sein. Ihre Tragweite lässt sich im einzelnen einstweilen aber nicht abschliessend beurteilen. Die folgenden Ausführungen machen auf allenfalls zu beachtende Aspekte aufmerksam:

a. Gewiss ist, dass die fünf soeben aufgeführten Männer zu Muhammads engsten Vertrauten zählten. Sie waren ganz besonders als Fürsprecher und Verteidiger von 'Alīs Rechten auf das Kalifat bekannt.

b. Unter den soeben aufgeführten fünf Männern spielt Salmān al-Fārisī eine besondere Rolle. Er nimmt einerseits unter den Nuṣayriern (bzw. Alawiten) eine zentrale Stellung ein und wird von ihnen mit den soeben genannten Prophetengenossen in Verbindung gebracht.

c. Salmān al-Fārisī nimmt anderseits auch in den Handwerksgilden einen zentralen Platz ein, wie F. Taeschner aufzeigen konnte.

Diese Aspekte könnten für die Kontextualisierung der beiden vorliegenden Belegstücke relevant sein und sollen im folgenden verdeutlicht werden.

Zu a. und b.: Unter den Nuṣayriern zählt Salmān al-Fārisī neben Muhammad und 'Alī zu jener Trinität, die besonders verehrt wird. ${ }^{207}$ Er nimmt in

soll gemäss Ṭabarī an allen Schlachten Muhammads teilgenommen haben. Vgl. zu ihm Hasson, 'Ammār b. Yāsir, in $E I^{3}$; auch Reckendorf, 'Ammār b. Yāsir, in $E I^{2}$.

Zusätzliche Angaben zu diesen fünf Personen finden sich in Werken über das Leben Muhammads und seine Eroberungen, z. B. in The Life of Muhammad. AlWāqidì’s Kitāb al-Maghāzī, edited by R. Faizer; beachte darin die - alphabetisch ausserordentlich gelungen angeordneten - Indices s.v. 1. Jundub. b. Janāda, Abū Dharr al-Ghifārī (558); 2. Salmān al-Fārisī (567); 3 . Miqdād b. al-Aswad (56o); 4 . Huduayfa b. al-Yaman (556); 5. 'Ammār b. Yāsir (577).

207 Für die folgenden Ausführungen vgl. Moosa, Extremist Shiites $342-351$, v. a. 344-346 („29. The Nusayri 'Trinity'. Ali, Muhammad, and Salman al-Farisi“). 
der Abfolge der göttlichen Emanationen den zweiten Platz direkt hinter 'Alī ein. Bei den Nuṣayriern gilt er als drittes Glied jener Trinität, die durch die Buchstabenfolge 'ayn-mim-sin dargestellt wird ('ayn für 'Alī; mìm für Muḥammad; sìn für Salmān). Sie umfasst das mana ('Alī), den ism (Muhammad) und den $b \bar{a} b$ (Salmān). Es ist im einzelnen nicht geklärt, weshalb Salmān aus Persien (al-Fārisī) in der islamischen Überlieferung einen derart zentralen Platz einnimmt. Jedenfalls sind sein Leben und seine Person von Geheimnissen umhüllt und Gegenstand von oft heftig geführten Auseinandersetzungen. $\mathrm{Cl}$. Huart ${ }^{208}$ stellte Salmān al-Fārisīs historische Existenz in Frage, gestand aber ein, dass ein Mann dieses Namens im Jahre 627 an der Grabenschlacht ( $\dot{G}$ azwat al-Handaq) teilgenommen habe. Er setzte sich dabei auf Seiten des Propheten gegen die vereinigten Stämme aus Mekka ein. J. Horovitz (1922) wiederum sieht im angeblichen Ratschlag Salmāns an den Propheten, er solle gegen die angreifenden Mekkaner einen Graben (handaq) ausheben, bloss eine Fabel. Sie diene der Ausschmückung der damaligen Ereignisse. Jedenfalls seien zu wenig gesicherte Fakten vorhanden, die es gestatten würden, in Salmān einen persischen Ingenieur zu sehen, der sich vom Mazdaismus zum Islam bekehrt habe und zum privaten Berater Muhammads geworden sei.

L. Massignon allerdings übernimmt diese kritische Haltung nicht und erkennt in Salmān eine Person, die wirklich gelebt hatte. Gemäss den von L. Massignon konsultierten Quellen stammte Salmān al-Fārisī aus einer vornehmen persischen Familie und war Anhänger des Mazdaismus, einer Abspaltung des Zoroastrismus. Als er auf der Jagd an einem christlichen Kloster vorbeigekommen sei, habe er sich zum Christentum bekehrt. Er sei danach als Asket (zāhid) von Stadt zu Stadt weitergereist. In Alexandria habe er gehört, dass in Arabien ein Prophet namens Muhammad auftreten werde. Unterwegs nach Arabien geriet Salmān

208 Huart, I. Selmân du Fârs 297-310, in Mélanges Derenbourg, 19o9, und II, 1-16, in Annuaire de l'Ecole des Hautes Etudes, 1913. allerdings in Sklaverei. Er erreichte Mekka schliesslich dennoch und stiess dort auf Muhammad, an dem er die Merkmale der wahren Prophetschaft erkannte. Salmān bekehrte sich darauf zum Islam.

M. Moosa äussert sich zwar kritisch zum Realitätsgehalt dieser Berichte. Er hält aber fest, dass Salmān in der frühen Geschichte des Islams eine bedeutende Stellung einnehme. Muhammad und seine wenigen Gefolgsleute hätten sein Wissen, seine Frömmigkeit und seine Kenntnis von Mazdaismus und Christentum zweifellos zu schätzen gewusst. Salmān habe sein Wissen nützlich machen können, als er dem Propheten riet, vor der Schlacht eben jenen Graben zu errichten. Muhammad habe Salmān in Anerkennung seiner Dienste als eine Person bezeichnet, die zu den Ahl albayt gehöre („Salmān min Ahl al-bayt“). Gewisse Ungläubige hätten Salmān sogar bezichtigt, dem Propheten den Koran zu lehren.

Salmān war also nicht nur ein frommer Asket (zāhid), der sich durch seinen frühen Übertritt zum Islam auszeichnete. Er galt vielmehr auch als bevorzugter Gefährte und Berater des Propheten. Er zählte zu den Pionieren unter den Muslimen (Ahl aṣ-Șuffa), unter denen sich die Anhänger bzw. Parteigänger 'Alīs zumeist rekrutierten, deren wichtigste Vertreter bereits aufgezählt worden sind: 'Ammār b. Yāsir, Abū D̄ārr al-Ġifārī, alMiqdād b. al-Aswad und weitere Personen. Sie erkannten in 'Alī jene Person, die am würdigsten war, die Nachfolge des Propheten anzutreten. Sie waren für ihre Frömmigkeit, Demut, Selbstlosigkeit und Aufopferung für die Sache des Islams bekannt. Sie unterstützten 'Alī, den Helfer der Schwachen, Armen und Hilflosen. In diesem Sinn begann die Geschichte der Schia bereits zur Zeit des Propheten. Ihre Helden waren 'Alī und jene Gefährten des Propheten, die ihn unterstützten.209

Für die Schiiten ist Salmān vielleicht die bedeutendste Person nach 'Alī. Er war der Erste, der 'Alīs Recht auf die Nachfolge des Propheten verteidigte. Dieses Recht 'Alīs auf die Nachfolge des Propheten stellt für die Schiiten die Grundlage des Imamats

209 Vgl. so bei Moosa, Extremist Shiites 346. 
dar. Sie sehen in Salmān keinen gewöhnlichen Menschen, sondern eine Person, die über göttliche Weisheit und Wissen von den früheren Religionen verfügte. Nach der islamischen Legende war er ausgesprochen langlebig. Er soll ein Zeitgenosse Jesu und seiner Apostel gewesen sein. Salmān wird als Bindeglied zwischen dem Christentum und dem Islam betrachtet. Als sich Salmān in Kūfa im Iraq aufhielt, das als bedeutendes Zentrum der Schia figurierte, bemühte er sich darum, mit den Banū 'Abd al-Qays und ihren Verbündeten, den al-Ḥamrā', eine Allianz zugunsten 'Alīs zu bilden. Salmāns Beziehung zu 'Alī war derart stark, dass er als einer der bedeutendsten Zeugen von 'Alīs Überlegenheit gilt. ${ }^{210}$ Salmān soll den frühen Muslimen auch anvertraut haben, sie würden 'Alī als wahnsinnig betrachten, würden er ihnen alles über dessen überlegenen Charakter erzählen. Gemäss Salmāns Aussage manifestiert sich 'Alīs Überlegenheit in seiner ausserordentlichen Spiritualität und seinem göttlichen Wissen, das er vom Propheten erhalten hatte.

Die von M. Moosa ${ }^{211}$ angeführten Quellen zielen auch darauf ab, in Salmān das fehlende Bindeglied göttlicher Autorität zwischen 'Alī und Muhammad zu sehen. Dies erklärt wiederum, dass die Schiiten der Beziehung Salmāns mit Muḥammad und 'Alī grosses Gewicht zuweisen. Salmān trägt aus dieser Perspektive gesehen wesentlich dazu bei, dass die Schiiten 'Alīs Anspruch auf das Kalifat legitimieren können. Muhammad soll Salmān einmal sogar als Modell des wahren Muslims bezeichnet haben („Ibn al-Islām“).

Von der Zeit des Propheten an wurde Salmān ausserdem mit weiteren Prophetengenossen in Verbindung gebracht, die unter den Nuṣayriern eine bedeutende Rolle spielen. Diese Personen werden als aytām (die Unvergleichlichen, Pl. von yatim) bezeichnet und gelten als die ersten Schiiten bzw. Anhänger 'Alīs. M. Moosa verweist auf ein Prophetenwort, gemäss dem das Paradies gesagt habe, es sehne sich nach dem Treffen mit 'Alī,

210 Vgl. weiterhin bei Moossa, op. cit. $346 \mathrm{f}$.

211 Moosa, op. cit. 348.
'Ammār, Salmān und al-Miqdād. ${ }^{212}$ Diese und weitere Parteigänger 'Alīs waren derart wichtig, dass die Schiiten vier von ihnen auswählten und sie als nuqabā' (Pl. von naqīb) bzw. später als arkān (Pl. von rukn) bezeichneten. Es handelt sich bei ihnen um Salmān, Abū Darr, al-Miqdād b. al-Aswad und Hudayfa b. al-Yaman. Gemäss 'Alī b. Ibrāhīm alQummī soll Q 8:2 auf diese vier Männer hinweisen. ${ }^{213}$ Die Nuṣayrier gehen davon aus, dass Salmān diese aytām erschaffen habe.

Grundsätzlich schreiben die Schiiten den Imamen göttliche Autorität zu. Und Salmān gilt ihnen als der göttliche Berater, den Muhammad für 'Alī zurückgelassen hatte. Dies sollte auch dazu beitragen, dass alle Muslime gestützt auf Salmāns Zeugnis in 'Alī den wahren Imam und Erben des Propheten erkennen sollen. Das Amt des Imamats bzw. des Kalifats war ausschliesslich für 'Alī bestimmt. Aus dieser Perspektive betrachtet sind Abū Bakr, 'Umar und 'Uțmān Usurpatoren. Auch diese Auffassung stützt sich erneut auf das Zeugnis Salmāns.

Ibn al-'Arabī betrachtet Salmān in den alFutūhāt al-makkiyya (I, 255-256) überdies als unfehlbar und Mitglied der Ahl al-bayt. Er galt ihm als heilig und sündlos. Während Salmān den Schiiten im allgemeinen als Zeuge für 'Alīs Anspruch auf das Imamat und Kalifat gilt, gingen gewisse extremistisch ausgerichtete Schiiten ( $\dot{G} u l \bar{a} t)$ einen Schritt weiter. Sie vergöttlichten die Imame im allgemeinen. Es sind ebenso Belege dafür bekannt, dass auch Salmān selbst göttliche Natur zugeschrieben wurde. Bei Abu l-Ḥasan al-Ašcarī (gest. 324/935) finden sich jedenfalls Hinweise darauf, dass Salmān al-Fārisī zu jener Zeit als Gott verehrt wurde. ${ }^{214}$ Gewisse $\dot{G} u \bar{a} t$-Gruppierungen schrie-

\footnotetext{
212 So bei Moosa, op. cit. 347 (mit Anm. 28).

213 Q 8:2-3 lautet (Übersetzung H. Bobzin): „(2) Die Gläubigen, das sind jene, deren Herzen sich ängstigen, wenn Gott genannt wird, und deren Glaube zunimmt, wenn ihnen seine Verse vorgetragen werden, und die auf ihren Herrn vertrauen, (3) die das Gebet verrichten und von dem, womit wir sie bedachten, spenden." Vgl. dazu auch Moosa, Extremist Shiites 347.

214 Vgl. Moosa, op. cit. 348 (mit Anm. 36).
} 
ben 'Alī, Muḥammad und Salmān zusammen göttliche Natur zu. Sie erkannten in ihren Namen auch eine spirituelle Dimension und verehrten sie unter ihren Initialen 'A-M-S.

Es kann nicht a priori ausgeschlossen werden, dass die soeben angesprochenen Auffassungen aus dem Umfeld der Gulät-Schia auch bei der Kontextualisierung des vorliegenden Belegstücks zumindest implizit eine Rolle spielen. Allerdings dürfte bei der Erwähnung von Abū Darr, Salmān, Miqdād, Hudayfa und 'Ammār doch in erster Linie ihre Stellung als Gefährten Muhammads ganz allgemein im Vordergrund stehen. Ihre Erwähnung dürfte für eine Einordnung dieses Dokuments in einen schiitischen Kontext sprechen.

Zu c.: Auch der zusätzliche Bezug einer Einordnung in das weitere Umfeld der Futuwwa-Tradition könnte bei der Kontextualisierung von Is 1621 und 1622 eine zentrale Rolle spielen. Bei dieser Interpretation kommt Salmān erneut eine Schlüsselstellung zu. Denn Salmān nimmt in der FutuwwaTradition einen wichtigen Platz ein. Diese Feststellung trifft gerade auch auf die später daraus hervorgegangenen Handwerksgilden (șinf, Pl. așnāf) $\mathrm{zu}^{215}$ Die relevanten Auffassungen halten fest, dass 'Alī b. Abī Ṭālib Salmān in Gadīr Humm gegürtet habe. Auch soll 'Alī ihn bei dieser Gelegenheit dazu aufgefordert haben, weitere 17 Gefährten zu gürten. ${ }^{216}$ Salmān soll in der Zunft der Barbiere eine bedeutende Rolle gespielt haben. Dies erklärt sich wahrscheinlich mit seinem Namen, besteht doch eine enge Beziehung zwischen Salmān und salmānī, persisch für die Tätigkeit des Barbiers. In der Barbier-Zunft waren deshalb auch spezielle Mythen zu Salmān im Umlauf.

F. Taeschner macht anhand von Seyyid Mehemmed b. es-Seyyid 'Alā' ud-Dīn el-Huseynī erRadawīs Grossem Fütüvvet-nāme auf die besondere Bedeutung der Gürtung Salmāns durch 'Alī auf-

215 Siehe für die weiteren Ausführungen Ridgeon, Morals and mysticism 137.

216 Beachte die abweichende Darstellung bei F. Taeschner sogleich anschliessend; die Ausführungen bei Ridgeon dürften nicht gänzlich korrekt sein. merksam. ${ }^{217}$ Das Grosse Fütüvvet-nāme weist auch ausführlich auf die vier Patriarchen Adam, Seth, Abraham und Muhammad hin. ${ }^{218}$ Es hält dann fest, wie Muhammad bei der Abschiedswallfahrt (hiğğat al-wadā') in Gadīr Humm 'Alī als seinen Nachfolger eingesetzt habe. Er habe ihm bei dieser Gelegenheit auch die Lenden gegürtet (šadd). Diese Gürtung hat gemäss F. Taeschner in den türkischen Zünften das entscheidende Moment bei den Initiationszeremonien von neuen Bundesmitgliedern dargestellt. Muhammad habe 'Alī danach aufgefordert, seinerseits 17 Prophetengenossen zu gürten und sie derart zu den Vorstehern einer bestimmten Handwerkszunft zu machen. ${ }^{219}$

'Alī habe darauf als ersten Salmān al-Fārisī gegürtet, der als Schutzherr der Zunft der Barbiere gilt. 'Alī habe Salmān ausserdem dazu aufgefordert, seinerseits 55 Prophetengenossen zu gürten und sie derart als Zunftpatrone einzusetzen. Durch diese Gürtung erhält jede Zunft eine Traditionskette (silsila) in der Futuwwa. Diese Kette geht über 'Alī auf Muhammad zurück, der auf Geheiss Allāhs durch den Erzengel Gabriel gegürtet worden war. Diese prophetische Abstammung verlieh den einzelnen Zünften eine sakrale Weihe. Die Initiation des Novizen stellt eine Reinszenierung dieses ursprünglichen Geschehens dar. Es ist zu betonen, dass das Grosse Fütüvvet-nāme eindeutig in einer schiitischen Tradition steht.

Wenn auch F. Taeschner anhand eines Texts aus dem Osmanischen Reichs auf Salmāns Rolle im Umfeld der Handwerksgilden aufmerksam macht, ist doch davon auszugehen, dass die Situation in einem iranischen Kontext, in dem Is 1621 und 1622 mit grosser Wahrscheinlichkeit entstanden sind, nicht gänzlich anders aussah.

Diese allfälligen Bezüge von Is 1622 zum islamischen Zunftwesen könnten auch in zwei zusätzlichen, auf Is 1622 angebrachten Zierelementen zum Ausdruck kommen. Es ist bekannt, dass

\footnotetext{
217 Vgl. Taeschner, Zünfte und Bruderschaften 409, 424 und v.a. $439-445$.

218 Vgl. Taeschner, Zünfte und Bruderschaften 409.

219 Vgl. zu Salmān al-Fārisī auch die Hinweise bei Thorning, Vereinswesen 89.2.
} 
Handwerksgilden und damit verwandte Männerbünde in Iran bis heute eine wichtige Rolle bei der Organisation der 'Āšūrā-Zeremonien spielen, die alljährlich in Erinnerung an Ḥusayns Martyrium in Karbalä' im Jahr 61/68o abgehalten werden. Zum Gedenken an dieses Desaster finden auch Prozessionen statt, bei denen Standarten mitgetragen werden. Sie sind häufig mit hoch aufragenden Federn versehen. Es könnte sein, dass die im Anfangszierfeld von Is 1621 und Is 1622 abgebildete Feder einen Bezug zu ihrem Pendant auf den Standarten aufweist. Allerdings liess sich dies nicht mit Sicherheit klären. ${ }^{220}$

Auch das hier als Doppelaxt beschriebene Zierelement auf dem $\dot{g} u b \bar{a} r$-farbenen Hintergrund von Is 1622 könnte einen Bezug zu diesen unterschiedlichen Männerbünden und ihrem Brauchtum aufweisen (АBB. 135). In diesem Zusammenhang könnten auch Bezüge zu Abū Muslim eine Rolle spielen. Abū Muslim wurde von I. Mélikoff bereits im Titel zu ihrer Untersuchung zu ihm als der „Axtträger (tarab-dār) aus Khorasan“ bezeichnet. ${ }^{221}$ Aber auch diese allfälligen Bezüge werden hier erst als Hypothese formuliert und wären im Rahmen weiterer Abklärungen zu verifizieren. Es kann überdies daran erinnert werden, dass eine Axt zur Grundausrüstung von Derwischen gehört. ${ }^{222}$ Es ist jedenfalls bekannt, dass der bereits mehrfach erwähnte Salmān eine wichtige Gewährsperson in den silsilas mehrere Sufi-Orden darstellt.

Im Vordergrund der soeben angestellten Überlegungen steht jedenfalls die Vermutung, dass bei

220 Zu diesen Bezügen vgl. Ayoub, 'Āšūrā', in EIr. Siehe auch von Grunebaum, Muhammadan festivals 85-94; Ayoub, Redemptive suffering in Islam.

221 Mélikoff, Abū Muslim, beachte darin v.a. 98-101, Kapitel vi: „Comment Ahī Hurdek forgea la hache d'Abū Muslim“.

222 Es sind auch Doppeläxte bekannt; vgl. dazu Frembgen, Kleidung und Ausrüstung; Doppeläxte (țabarzin bzw. tabarzīn): 139-143 (Nr. 43-45); einfache Äxte: $136 \mathrm{f}$. (Nr. 42) und 144-149 (Nr. 46-48); beachte ebenso die Derwischabzeichen, 228-231 (Nr. 75-78; Iran, 20. Jh.) und den Gebetsteppich mit der Abbildung von zwei Doppeläxten (236f.; Nr. 79; Iran, 19. Jh.). der Einordnung von Is 1621 und 1622 neben Bezügen zur Zwölfer-Schia im allgemeinen auch solche zu bestimmten Handwerksgilden und zum Derwischtum in Betracht zu ziehen sind. 

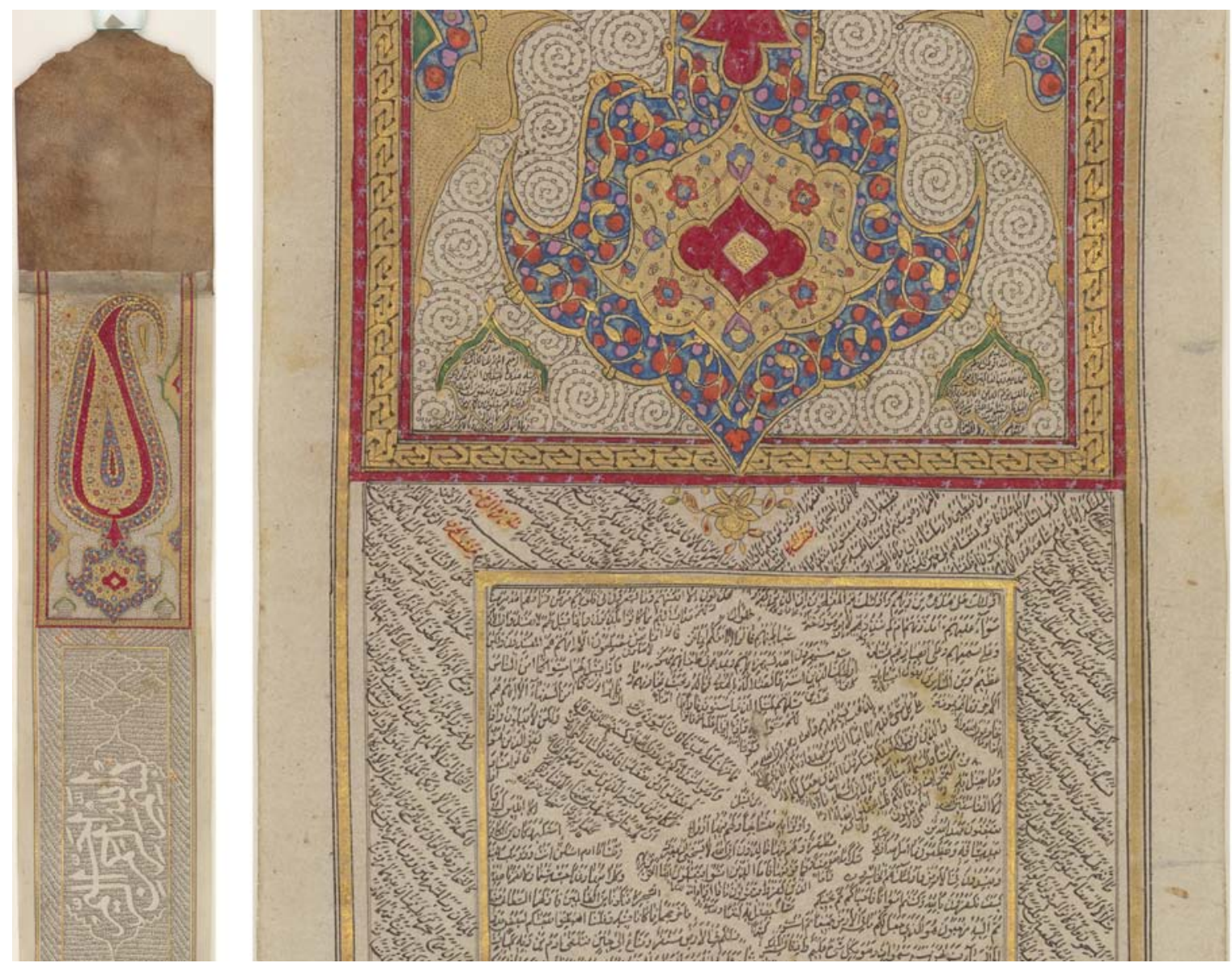

ABB. 127

Dublin, Chester Beatty Library, Is 1622; mit ergänzenden Hinweisen zu Is 1621 (vgl. bei Anm. 610, 195f., 202, 220): Die Rolle Is 1622 beginnt mit einem aufwendig gestalteten Zierfeld von ca. $16.9 \mathrm{~cm}$ Höhe. Davor schützt ein Stück braunes Leder das Dokument gegen aussen. Auf dem Anfangszierfeld dominiert eine grosse Feder, deren Spitze nach rechts geneigt ist. Am unteren Ende dieses Anfangszierfelds lassen sich zwei Kartuschen mit Text erkennen. In der rechten Kartusche steht Q 1 (Sürat al-Fätiha); in der linken Kartusche steht Q 2:1-4. Q 2:5 folgt im Mittelstreifen (innerhalb des goldenen Rahmens) rechts oben.

(C) THE TRUSTEES OF THE CHESTER BEATTY LIBRARY, DUBLIN (CHESTER BEATTY, DUBLIN. CC BY-NC 4.0) 


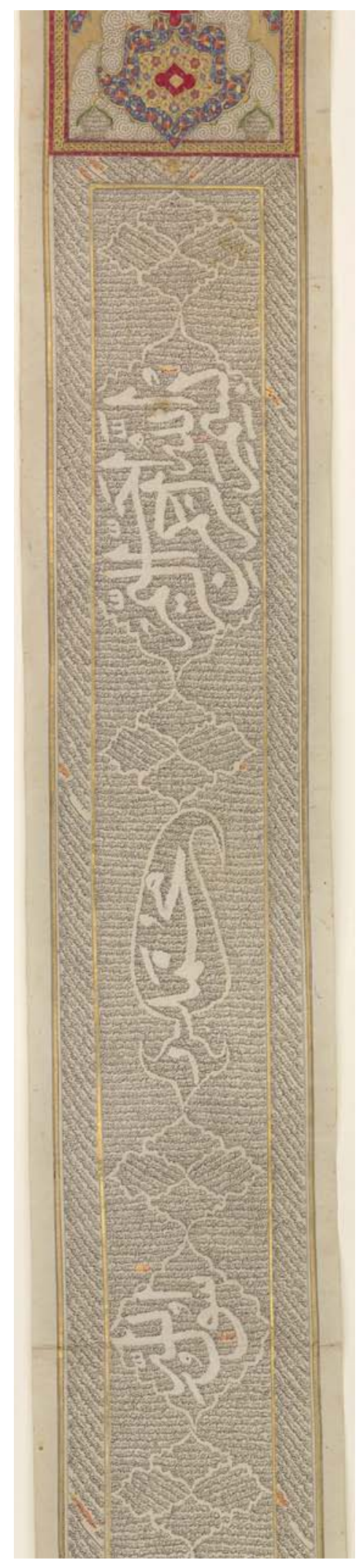

ABB. 128

Dublin, Chester Beatty Library, Is 1622; mit ergänzenden Hinweisen zu Is 1621 (vgl. nach Anm. 10, nach Anm. 79, bei Anm. 129-135, bei Anm. 168-170, 197): Diese Abbildung zeigt den Anfang des Hauptteils der Rolle, der eine Abschrift des Korans in Gubār enthält. Der Schreiber ordnete den Text in mehreren Durchgängen in geometrischen Figuren, Textfeldern und in Seitenstreifen an. Die Beschreibungen der Rolle halten das Vorgehen des Kopisten im Detail fest. In roter Schrift auf goldenem Hintergrund lassen sich Einträge mit den Surennamen und zur Texteinteilung erkennen ( $\breve{G} u z^{\prime}$-Vermerke). Der Inhalt der hier gezeigten Textfelder lautet: Textfeld I: Basmala: Bismi Allāhi r-raḥmāni r-raḥim; Textfeld II: Muhammadun ra-; Textfeld III: [ra-] sūl Allāh.

(C) THE TRUSTEES OF THE CHESTER BEATTY LIBRARY, DUBLIN (CHESTER BEATTY, DUBLIN. CC BY-NC 4.0) 

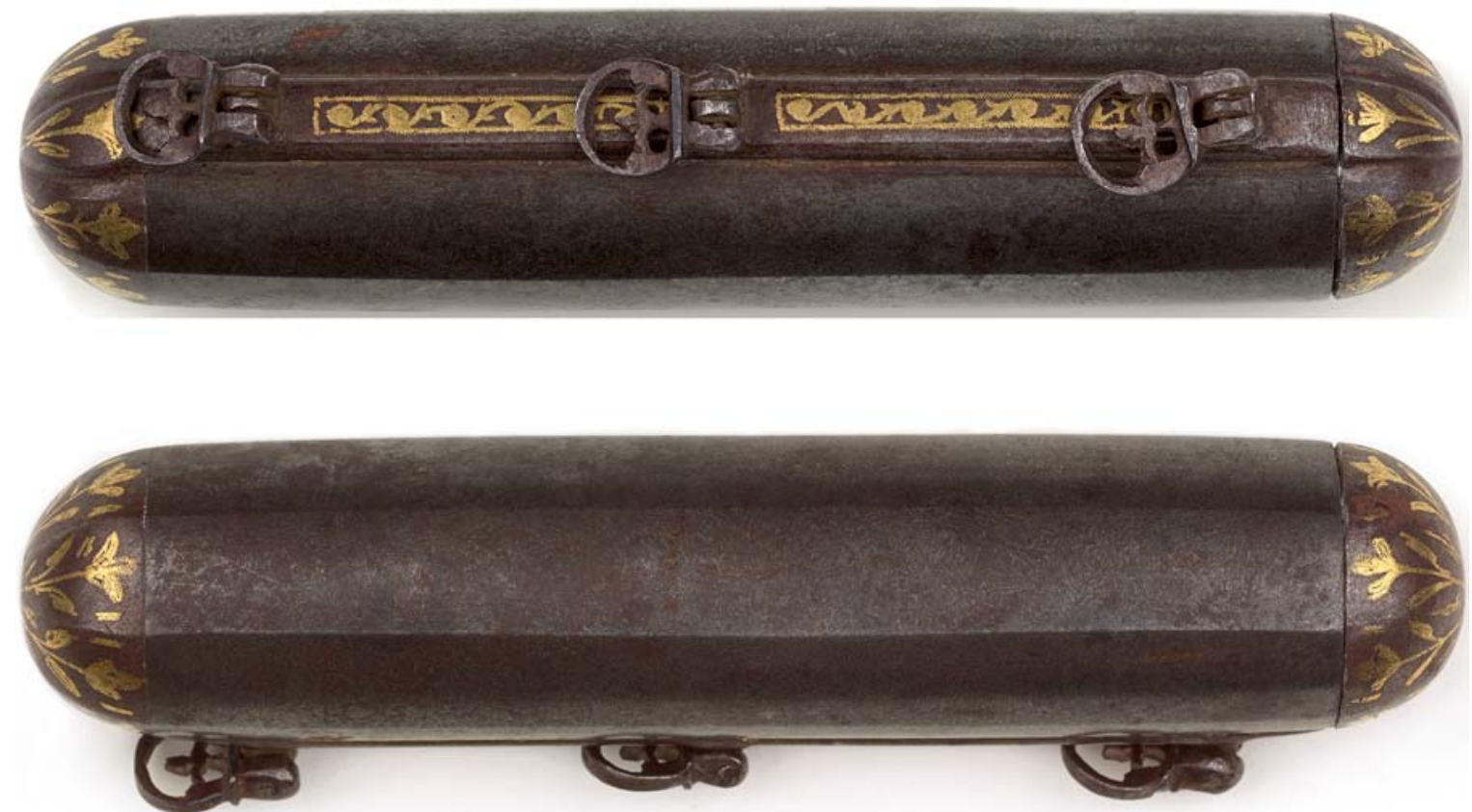

AвB. 129 Dublin, Chester Beatty Library, Is 1622; mit ergänzenden Hinweisen zu Is 1621 (vgl. Abschnitt mit Anm. 6; Signatur: CBL Is X33): Die Chester Beatty Library besitzt ein metallenes Behältnis, das zusammen mit den beiden Dokumenten Is 1621 und 1622 aufbewahrt wird; es lässt sich nicht abschliessend beurteilen, ob es ursprünglich zu einer der beiden Rollen gehörte. Das Behältnis ist achteckig und mit drei Ösen versehen, durch die sich eine Schnur ziehen lässt. Derartige Rollen wurden in solchen Behältnissen auf dem Körper getragen. Die Länge des Behältnisses beträgt $11.0 \mathrm{~cm}$, sein Durchmesser ca. $2.2 \mathrm{~cm}$. Die Rollen passten nur in diese Behältnisse, wenn sie äusserst satt aufgewickelt wurden.

(C) THE TRUSTEES OF THE CHESTER BEATTY LIBRARY, DUBLIN (CHESTER BEATTY, DUBLIN. CC BY-NC 4.0) 

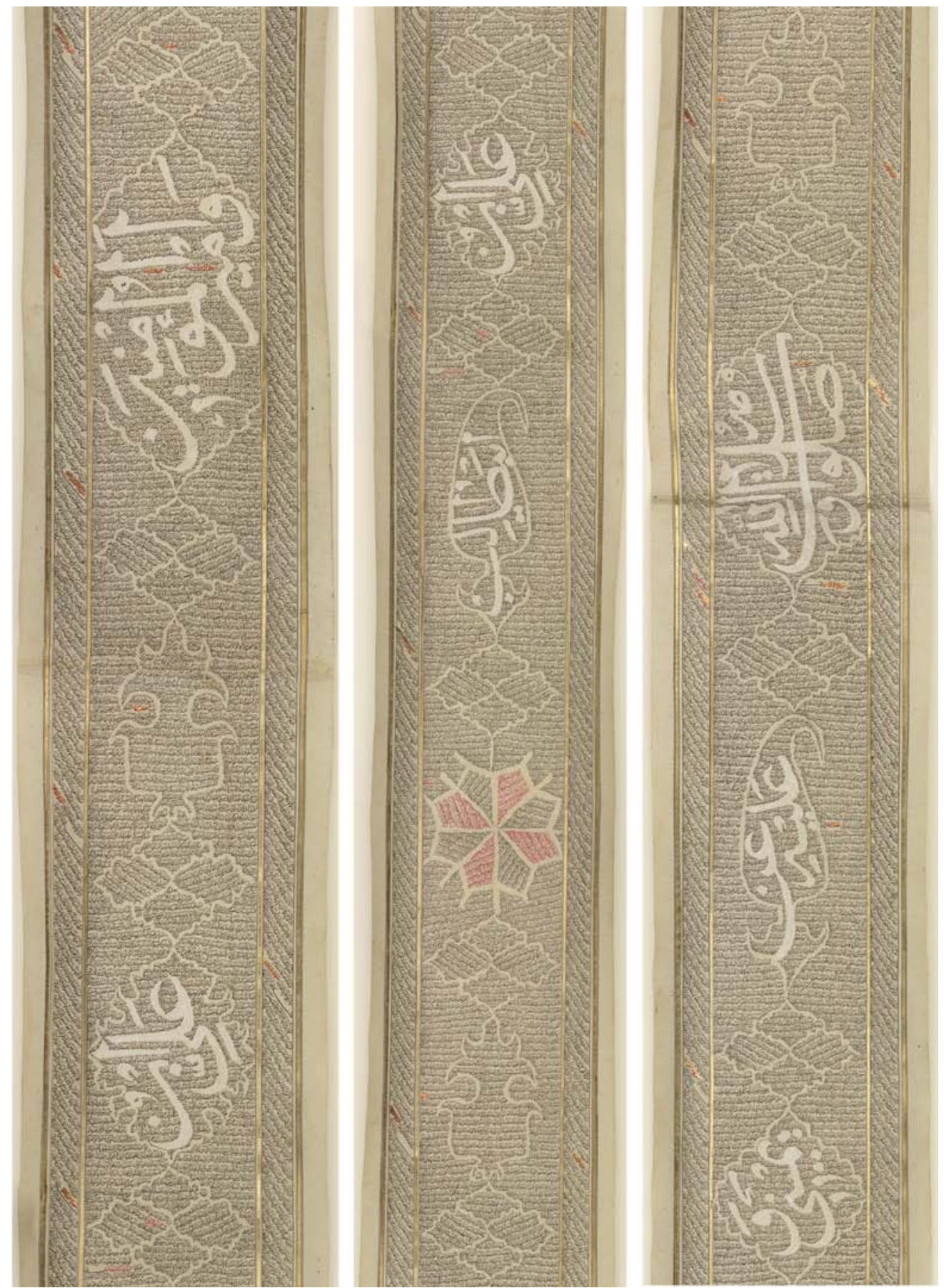

ABB. 130

Dublin, Chester Beatty Library, Is 1622; mit ergänzenden Hinweisen zu Is 1621 (vgl. zwischen Anm. 20-25, 92-99, 148-150): Der Kunsthandwerker hat über die gesamte Länge der Rolle 35 Textfelder von unterschiedlicher Länge verteilt. Ausgesparte Stellen auf dem $\dot{g} u b \bar{a} r$-farbenen Hintergrund bilden darin einen übergeordneten Text. Hier werden die Textfelder IX-XIV mit der Anrufung 'Alī b. Abī Ṭālibs gezeigt. Beim Text im Hintergrund handelt es sich um Stellen aus dem Koran.

(C) THE TRUSTEES OF THE CHESTER BEATTY LIBRARY, DUBLIN (CHESTER BEATTY, DUBLIN. CC BY-NC 4.0) 


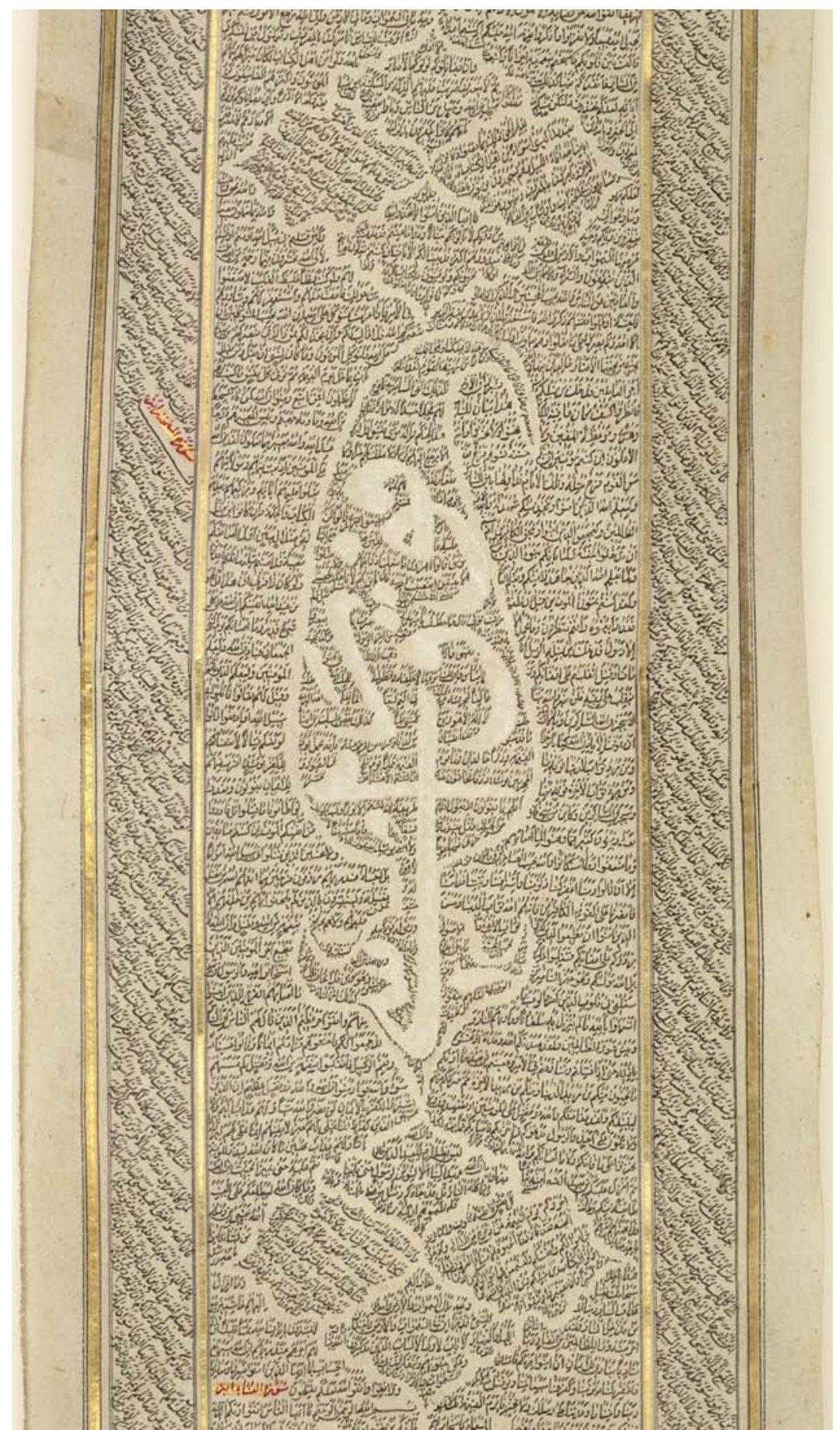

ABв. 131 Dublin, Chester Beatty Library, Is 1622; mit ergänzenden Hinweisen zu Is 1621 (vgl. bei Anm. 19, 9o): Der Kunsthandwerker fügte den grossen Text wiederholt in Figuren ein. Hier die Wendung fawqa ra'sı̄ in einer Feder, mit nach rechts geneigter Spitze. Diese Figur greift die Feder im Anfangszierfeld auf.

(C) THE TRUSTEES OF THE CHESTER BEATTY LIBRARY, DUBLIN

(CHESTER BEATTY, DUBLIN. CC BY-NC 4.0) 


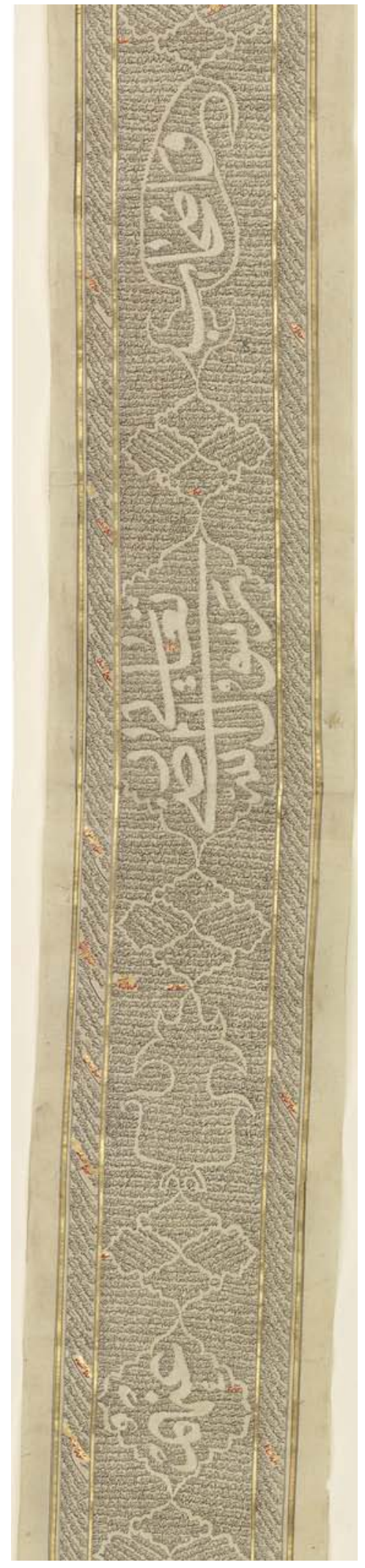

ABB. 132

Dublin, Chester Beatty Library, Is 1622; mit ergänzenden Hinweisen zu Is 1621 (vgl. bei Anm. 42, 121, 161): Textfelder IXXX-XXXI schliessen die Aufzählung von Prophetengenossen in den vorangehenden Textfeldern mit einer Eulogie ab: Textfeld Ixxx: wa-aṣhāab; Textfeld xxx: rasūl Allāh ta'ālā radiya Allāh; Textfeld xxxI: 'anhum. Der Ausdruck Allāh ist hier einmal geschrieben, aber zwei Mal zu lesen. (C) THE TRUSTEes of THE CHESTER BEATTy LIBRARY, DUblin (CHESTER BEATTY, DUBLIN. CC BY-NC 4.0) 


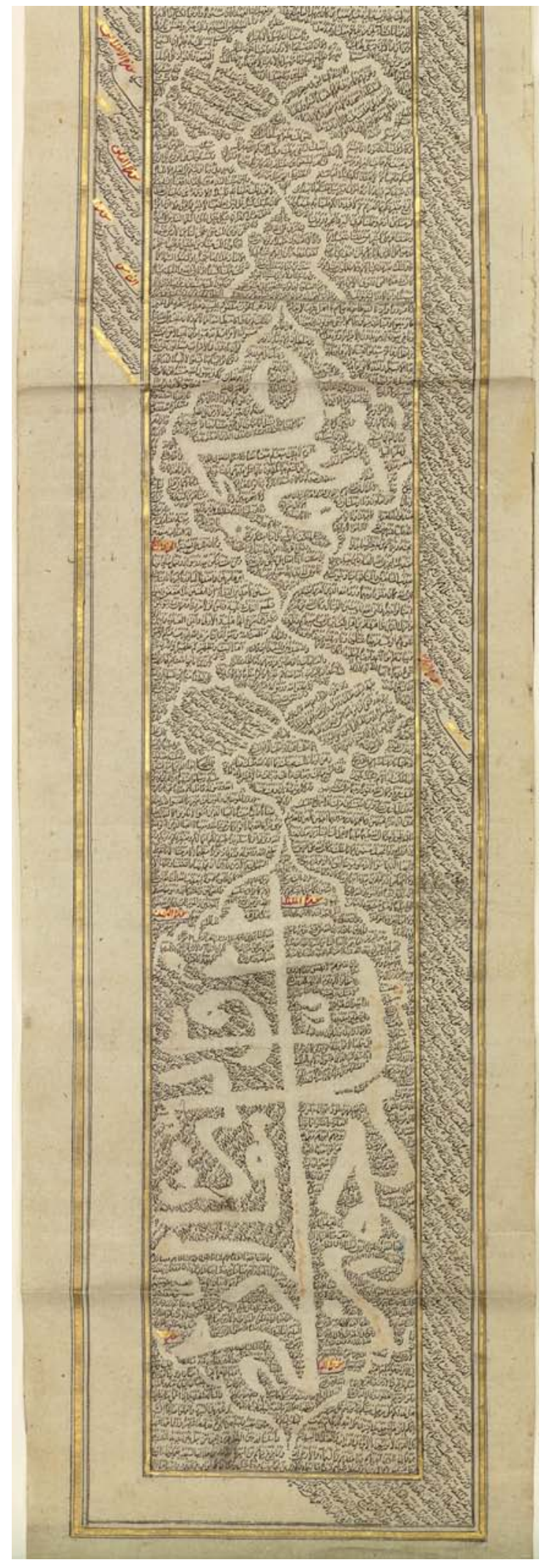

ABB. 133

Dublin, Chester Beatty Library, Is 1622; mit ergänzenden Hinweisen zu Is 1621 (vgl. bei Anm. 47-48, 127-128, 163167, 189-194 und 203): Textfeld xxxv schliesst die Rolle ab. Man beachte, dass der Schreiber den Platz in der linken Aussenspalte nicht vollständig ausfüllte. Im Textfeld XXXIV steht: 'alay-him; im Textfeld Xxxv folgt as-salam (sic) havali wa-Allāh ta'àlà rabbì.

(C) THE TRUSTEES OF THE CHESTER BEATTY LIBRARY, DUBLIN (CHESTER BEATTY, DUBLIN. CC BY-NC 4.0) 




ABB. 134

Dublin, Chester Beatty Library, Is 1622; mit ergänzenden Hinweisen zu Is 1621 (vgl. bei Anm. 91, 147-148): Der Kunsthandwerker fügte mehrfach auch Sterne ein; hier ein achtstrahliger Stern. Der Schreiber kopierte den Text darin abwechselnd in roter und schwarzer Tinte. Wenig oberhalb des Sterns lässt sich links aussen in roter Schrift auf goldenem Hintergrund der Titel von Q 4 (Sūrat an-Nisā') erkennen. Unmittelbar darüber steht Q 3:200 (Schlussvers). Im Stern selbst lassen sich die Verse am Anfang von Q 4 feststellen.

(C) THE TRUSTEes of THE CHESTER BEATTY LIBRARY, DUBLIN (CHESTER BEATTY, DUBLIN. CC BY-NC 4.0) 


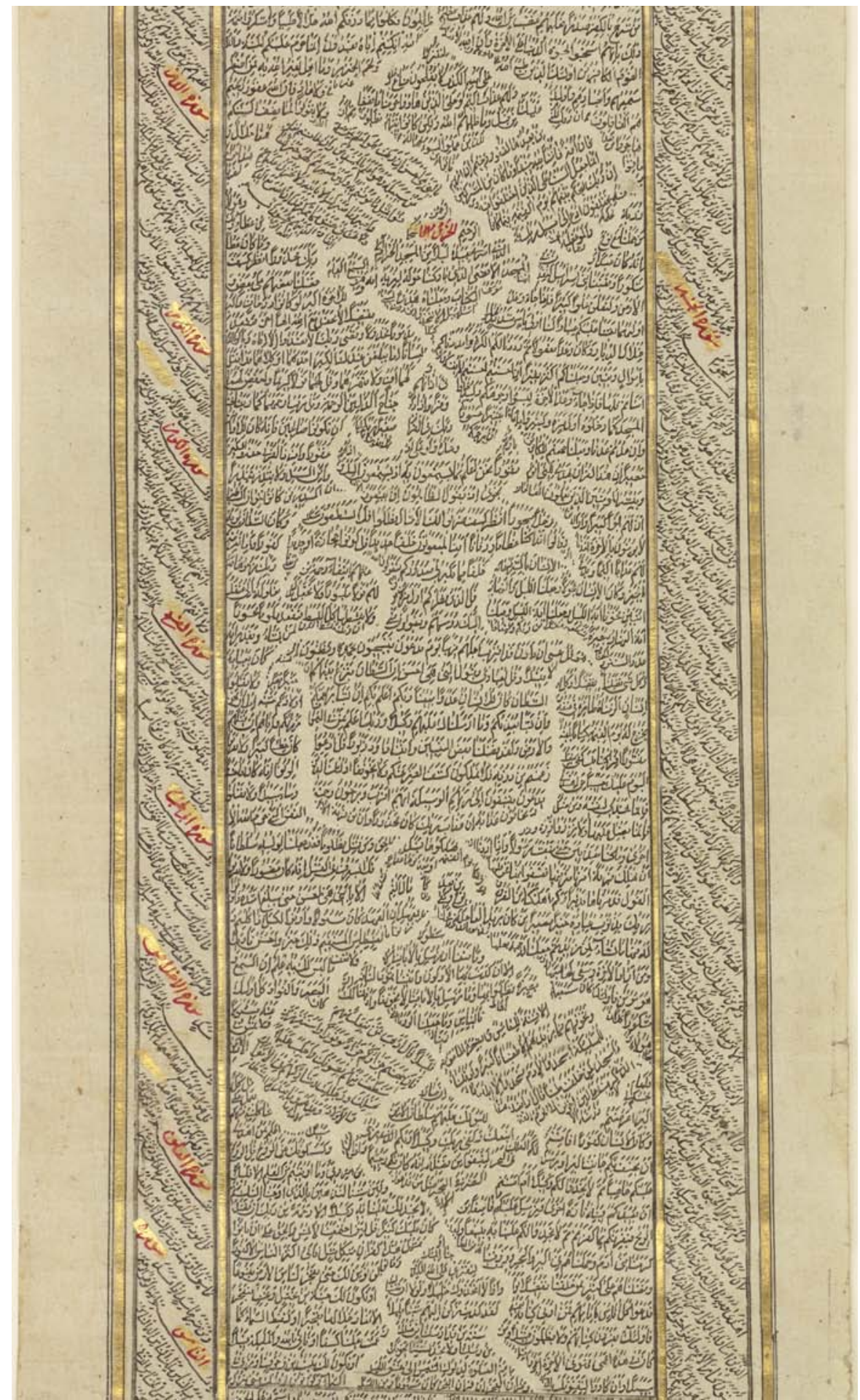

Авв. 135 Dublin, Chester Beatty Library, Is 1622; mit ergänzenden Hinweisen zu Is 1621 (vgl. bei Anm. 96 und 22O-222): Unter den auf Is 1622 enthaltenen Figuren fällt ausserdem ein Element auf, das hier als Doppelaxt beschrieben wird.

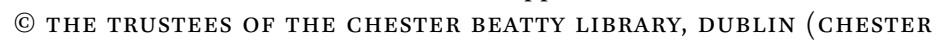
BEATTY, DUBLIN. CC BY-NC 4.0) 